\title{
Narratives of human trafficking: Defining policy, practice and positioning in a contested field
}

\author{
By \\ Bryony Cornforth-Camden
}

A thesis submitted to the Victoria University of Wellington

in fulfilment of the requirements

for the degree of Doctor of Philosophy

in Criminology

Victoria University of Wellington

2021 


\section{Abstract}

This research uses narrative criminology to investigate the way the problem of human trafficking is narrated in New Zealand and international settings. It draws on accounts from professionals who are responsible for defining and responding to human trafficking, and reports, policy, and other guiding documents. The main issue driving this research is the contested nature of human trafficking. Human trafficking is a crime type that has been highly politicised resulting in shifts and changes to the way the problem of trafficking has been approached over the past 20 years, with differing trends coming to the fore and dominating trafficking practices at different times. The internationally dominant approaches which emphasise prostitution, harsh criminal responses, and border security have come under criticism for having harmful impacts for migrant workers. This research aims to understand how human trafficking is defined, what discourses are drawn on, and how international narratives may be influencing local responses with the overall aim of identifying new and less problematic ways of conceptualising human trafficking and responding to migrant exploitation.

This thesis finds that different ways of narrating human trafficking are constitutive of different trafficking realities. Narratives determine the shape the problem takes, who is involved, what the causes and solutions are, who responds, and who are classed as victims and perpetrators. This research concludes that as narratives structure reality and action, in order to change how we deal with certain problems, the way the problem is narrated must also change.

The findings of this thesis reflect current challenges in the wider international anti-trafficking field of how to avoid positioning western states and systems as outside of the problem of trafficking, issues with broadening definitions of victimhood, and questions of the role of international versus local bodies in defining problems involving migration and crime. As well as reflecting these current challenges, the findings from this research provide insights for moving forwards by proposing an alternative narrative. This counter narrative is created through drawing together components of narratives identified in this research. It avoids the issues of western exceptionalism, narrow forms of victimhood, and a focus on sex trafficking, and provides a different method for conceptualising migration, exploitation, and harm. 


\section{Acknowledgments}

I would like to sincerely thank the professionals who took part in this research. They generously shared their time, knowledge, and experiences. Their willingness to share reflects their passion for the work they do and commitment to helping those affected by exploitation. Thank you to Victoria University of Wellington for providing funding which allowed me to carry out this research.

My sincere thanks also go to my two supervisors, Professor Simon Mackenzie and Dr Lynzi Armstrong, for their invaluable support and guidance. They have continuously challenged my thinking, provided inspiration, shared their insights, showed kindness especially when needed, and have been most generous with their time. They have been fantastically supportive in strange circumstances including a global pandemic! Their generosity with their time and expertise speaks to their commitment to the criminological field and their dedication to creating a more socially just world. It is greatly appreciated.

I would not have been able to write this thesis without the help of my close family. Thank you to Megan, Sue, Mike and Cisco for the ongoing support, encouragement, and particularly to Mike for his editing. Thank you to Cecilia, Sue and Mike for all the childcare, cooking dinners and hanging out of washing. Thank you to Cisco for his ongoing support and encouragement. We are a team and our achievements over the past few years are shared between us. Thank you to little Emilia and Álvaro for all the laughter and distractions, they have truly taught me to work efficiently.

Lastly and most of all I would like to thank my mother, Sue. I would not have started or finished this thesis without her ongoing support, encouragement, and wisdom as well as the care she provided to my family. Her original and thoughtful perspective of the world, which has been a part of my upbringing, has no doubt contributed to the thinking in this thesis. 


\section{Table of Content}

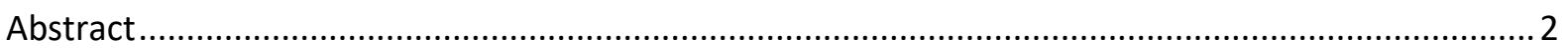

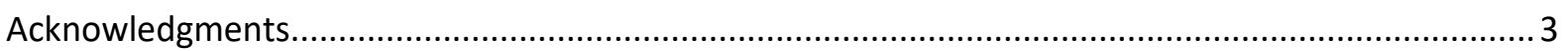

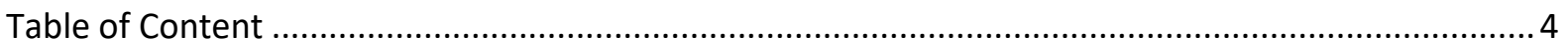

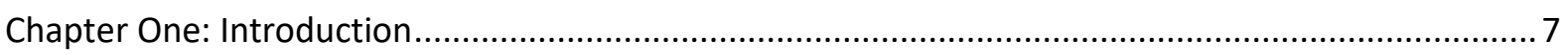

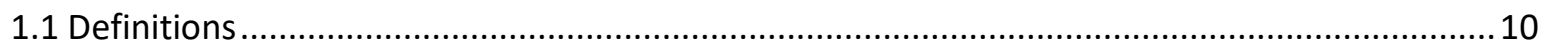

1.2 The New Zealand context ................................................................................ 12

1.2.1 New Zealand's participation ......................................................................... 13

1.2.2 The Prostitution Reform Act 2003 ....................................................................... 14

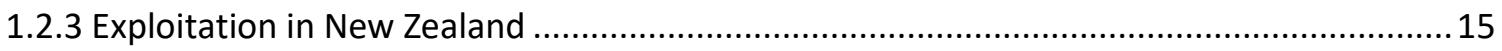

1.2.4 Human Trafficking legal cases in New Zealand ...................................................... 19

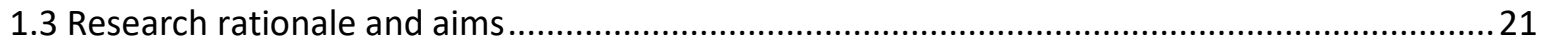

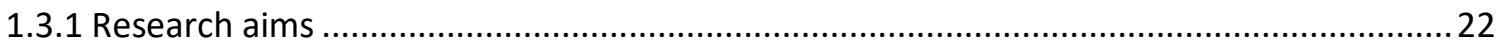

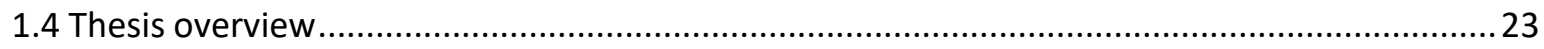

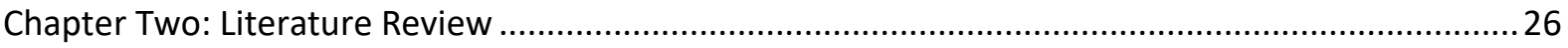

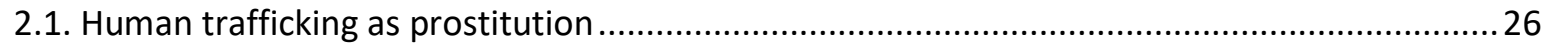

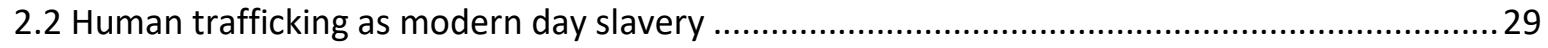

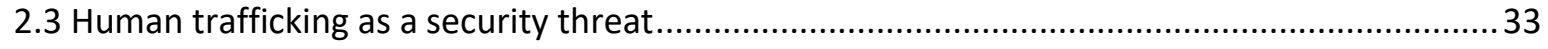

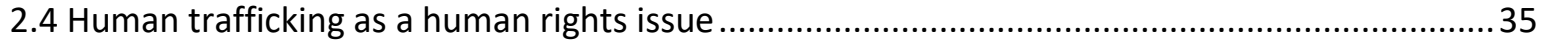

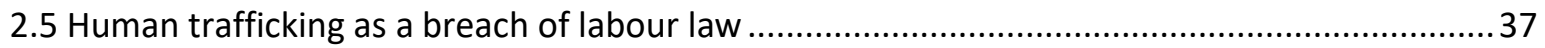

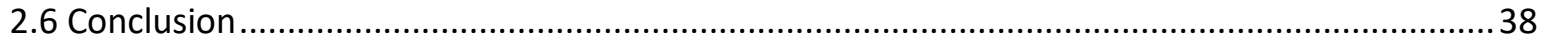

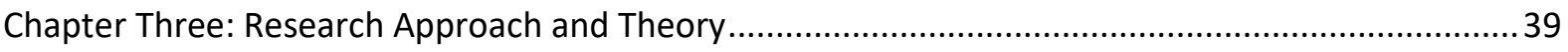

3.1 How human trafficking has been researched, and deciding on a research approach ............. 40

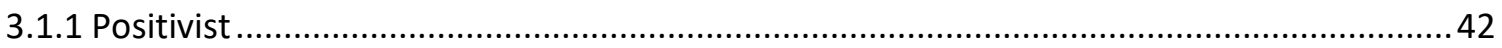

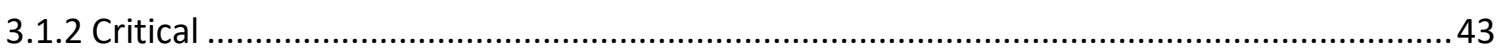

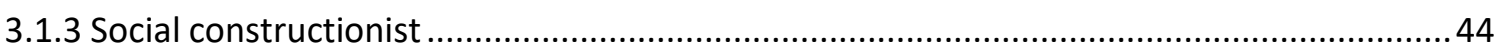

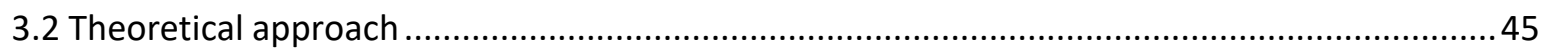

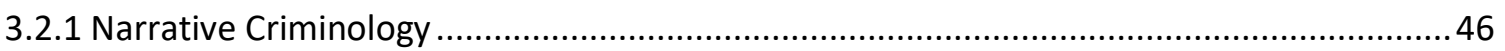

3.2.2 Using narrative criminology to analyse human trafficking as a contested crime type........49

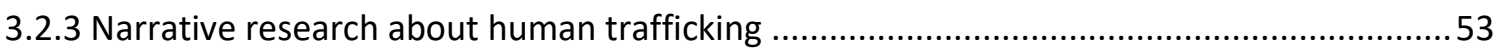

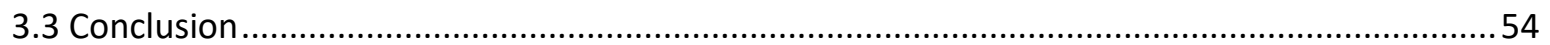

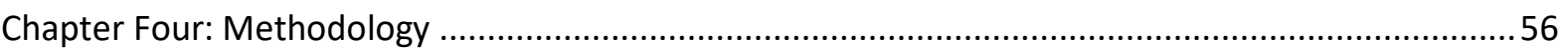

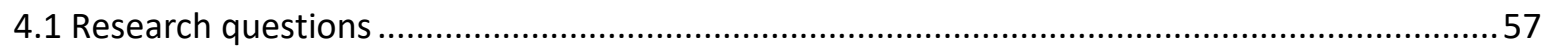

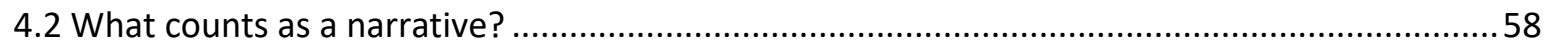




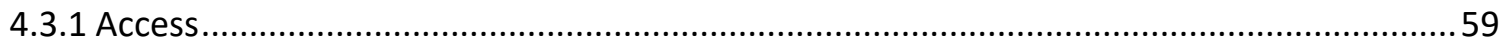

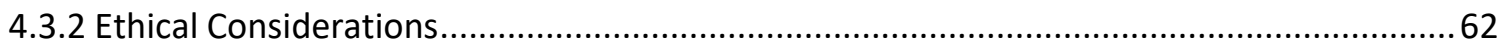

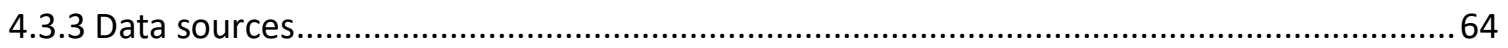

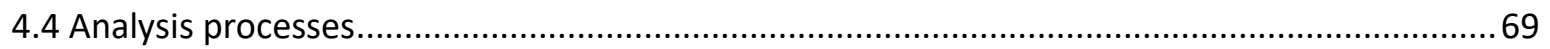

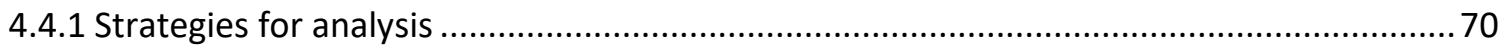

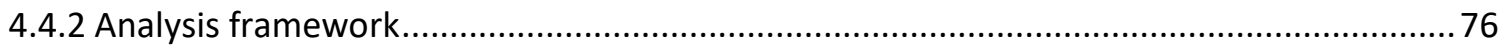

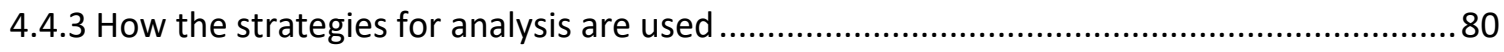

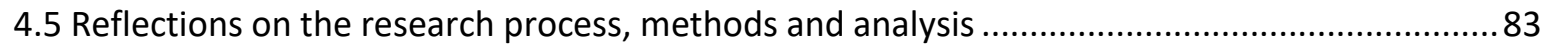

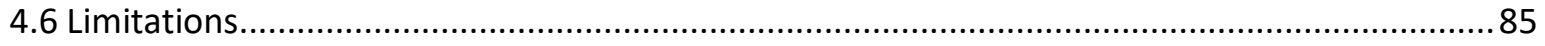

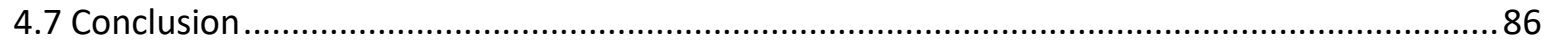

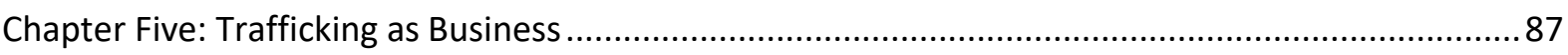

5.1 Narrative 1. Trafficking as a profitable organised criminal enterprise ...................................... 87

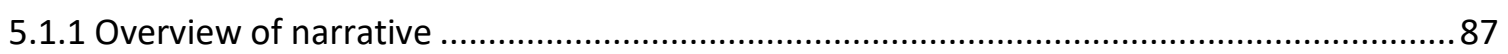

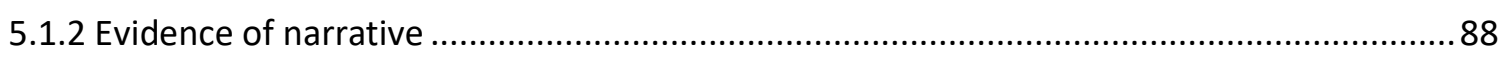

5.1.3 Outcomes of the trafficking as profitable organised criminal enterprise narrative .............93

5.2 Narrative 2. Commercial businesses and systems as saviours ................................................96

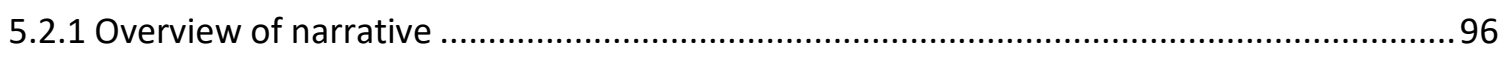

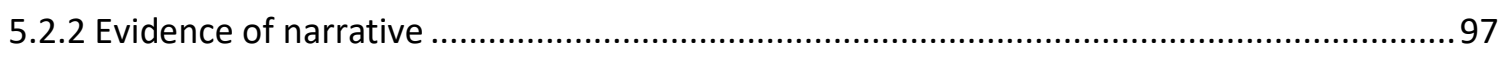

5.2.3 Outcomes of the commercial businesses and systems as saviours narrative ....................105

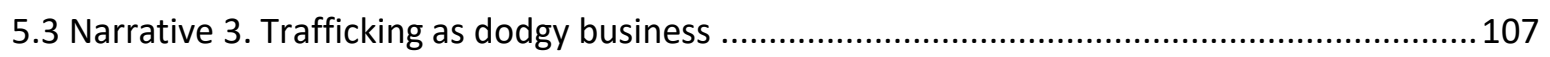

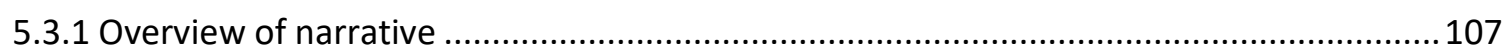

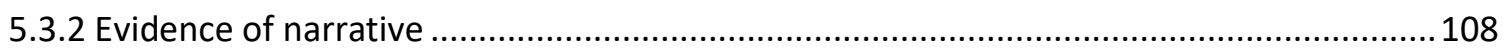

5.3.3 Outcomes of the trafficking as dodgy business narrative ................................................114

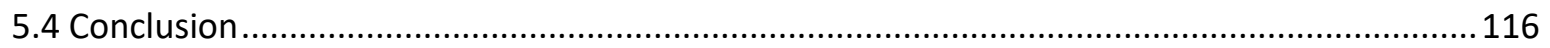

Chapter Six: Western exceptionalism and individualising trafficking..............................................119

6.1 Narrative 1: Trafficking as a foreign other problem .........................................................120

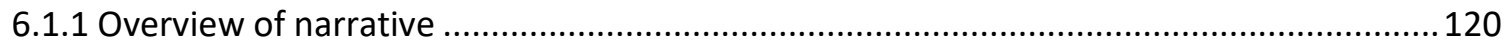

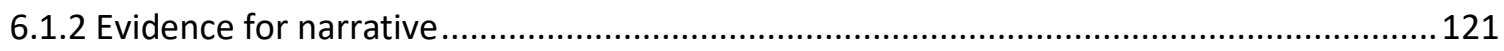

6.1.3 Outcomes of the trafficking as a foreign other problem narrative .................................130

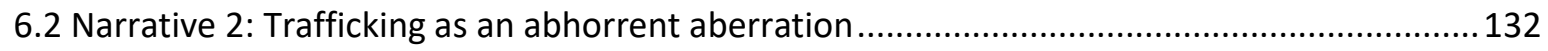

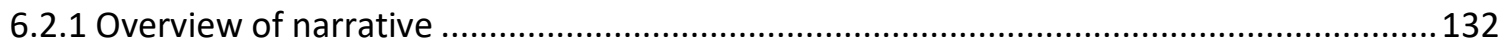

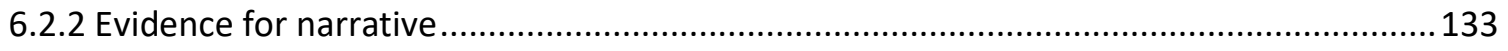

6.2.3 Outcomes of trafficking as an abhorrent aberration narrative ....................................... 137

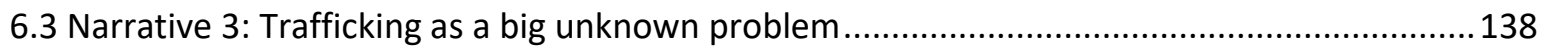

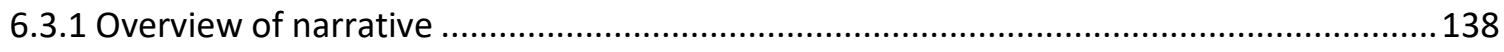


6.3.3 Outcomes of the trafficking as a big unknown problem narrative. 146

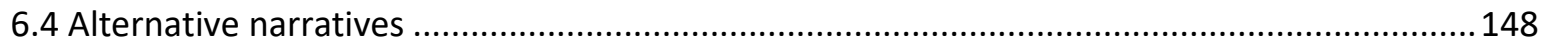

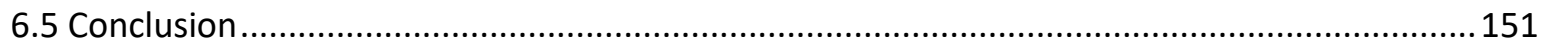

Chapter Seven: Victimhood, vulnerability, agency, and consent .............................................. 154

7.1 Narrative 1. The innocent victim of sex trafficking .................................................... 155

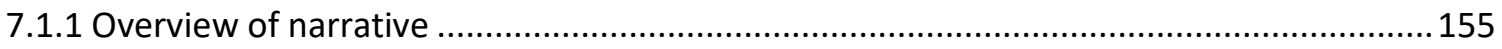

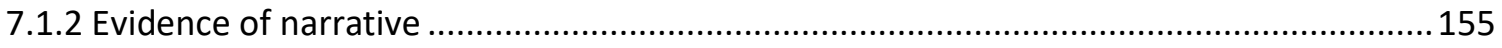

7.1.3 Outcomes of the innocent victim of sex trafficking narrative ................................... 166

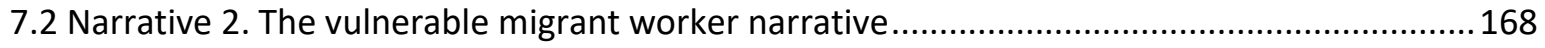

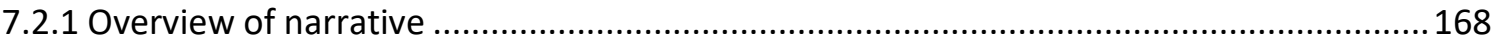

7.2.2 Evidence of narrative ................................................................................. 168

7.2.3 Outcomes of the vulnerable migrant worker narrative............................................ 177

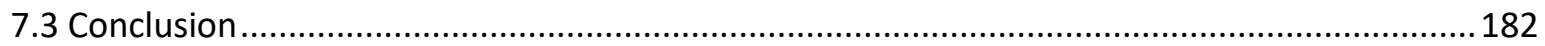

Chapter Eight: Towards an alternative narrative................................................................ 185

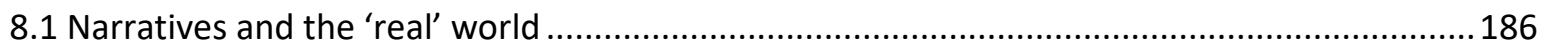

8.2 Entrenched narratives and the New Zealand perspective.............................................. 190

8.2.1 Western exceptionalism from the problem of trafficking ........................................... 191

8.2.2 Differing narratives at international and New Zealand level....................................... 197

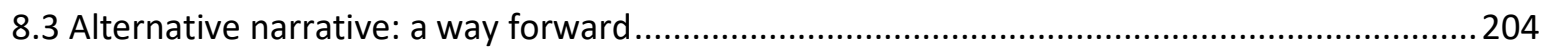

Alternative narrative: Structured vulnerability and hidden capital....................................205

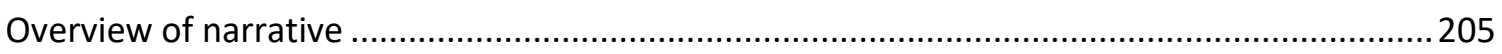

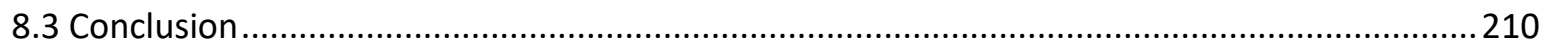

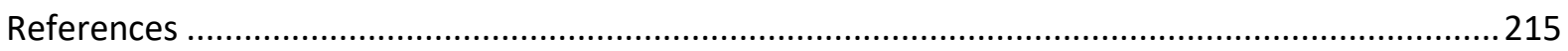

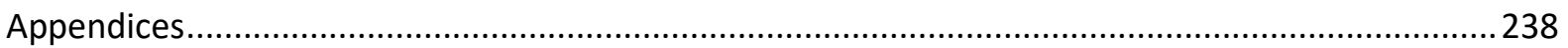

Appendix A: Ontology of human trafficking research ......................................................238

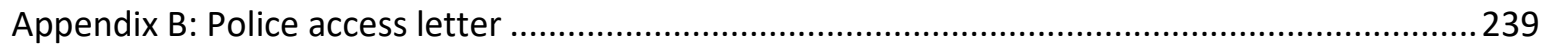

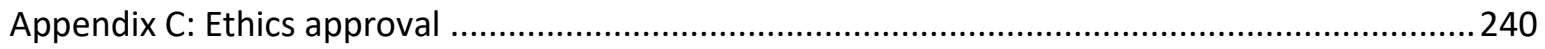

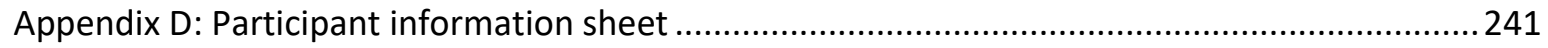

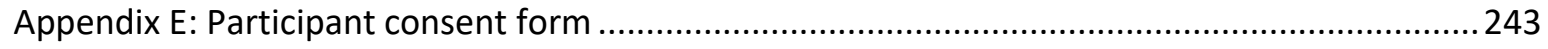

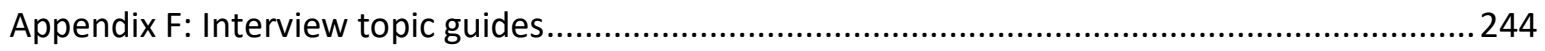




\section{Chapter One: Introduction}

Human trafficking is a crime type that has received rapidly growing attention in the past 20 years around the world. While the idea of human trafficking has a long history, in its more modern form it was initially a concern raised and pushed by advocacy and religious groups, later picked up by the United Nations Office of Drugs and Crime, written into international law, and distributed around the world into state governments' legislation and practice. Alongside human trafficking's establishment into law and practice, it has received much media attention as well as being used as means for promoting various political agendas.

Human trafficking is a highly politicised concept that has been used as a way of defining migrant exploitation internationally and applied around the world to complex issues of migration, work, and related harm (Segrave et al., 2018; Lloyd and Simmons, 2015; Anderson and O'Connell Davidson, 2002). The idea of human trafficking rose to prominence in its modern form as an issue of sexual exploitation, tied to moral campaigns about women in the sex industry (Kempadoo, 2005). Responses deemed appropriate have largely been harsh criminal justice sanctions (Chew, 2006). Since its initial rise, there have been ongoing attempts to shift the focus from women and sex trafficking to encompass broader labour exploitation and a shift from a sole focus on criminal justice responses to a human rights and victim focus (GAATW, 2007). Alongside these shifts and struggles, anxieties about security threats and immigration concerns have become compounded with the debate. Approaches where trafficking is presented as 'modern day slavery', drawing on discourses of slavery abolitionism, are seeing a re-emergence and are currently adding to discussions about what counts as trafficking (Kempadoo, 2015; Chuang, 2014).

Each of these approaches is loaded with different discourses about migration control, gender, western exceptionalism, and current anxieties around 'global threats' and 'international security challenges'. Each approach leads to different treatments of those involved. The internationally dominant approaches which emphasise trafficking into the sex industry, harsh criminal responses, and border security have come under particular criticism for having harmful impacts for migrant workers (Andrijasevic and Mai, 2016; Dottridge, 2007; Kempadoo, 2005; Sanghera, 2005).

The politicised nature of human trafficking has resulted in shifts and changes to the way the problem of trafficking has been approached over the past 20 years, with differing trends coming to the fore and dominating trafficking discourse and practices at different times (Kempadoo, 2015). Such shifts in the way the problem is defined and conceptualised determine how it is dealt with and have had significant and often harmful effects for those affected by trafficking. The approach to the problem can determine who is deemed worthy of receiving support, who is criminalised, who is repatriated, 
and who receives residency rights. There has been much advocacy and scholarship work critiquing the different approaches with the aim of pushing certain ideologies, reducing harm for those affected, or creating definitions and responses that better reflect the 'realities' of those in trafficking situations (see for example GAATW, 2018; Wylie, 2016; Kempadoo, 2015; Doezema, 2010).

The grounding premise for this research is that human trafficking is a contested concept and studying the way the problem of human trafficking is constructed as a crime type is important as a way of unpacking the discourses that are drawn on, the positions available to groups involved, and the resulting responses. The philosophical approach to this research is that social problems are constructed, constructions are multiple and, while there is no right answer, they are important to study because they have different effects for the populations they are about.

This research uses the theoretical approach of narrative criminology where narratives are used to study the construction of a problem and its outcomes for those involved. The version of narrative criminology I use is post-structural and treats policy texts and language about human trafficking as the key sources where the problem is narrated. Policy texts and language used and developed by official actors are important sources to use in studying human trafficking. These policy narratives tell a story about who is considered to be the deserving victims, which groups should be subject to crime control policies, and what types of harm are considered acceptable and unacceptable. These narratives have real world consequences for those involved. They determine who receives state protection and benefits such as citizenship rights, and who is criminalised, imprisoned, or deported. As well as determining how groups will be treated, narratives have the power to produce positive social change (Fleetwood, 2016). This has been recorded in many fields, including narratives about rape and coming out (Jackson, 1998; Plummer, 1995). The aim of this approach is to identify harmful narratives and to identify other narratives, which are likely to produce more useful and less harmful results to those involved.

From the post-structural grounding of this research, the main questions of this study are what are the narratives present and what effects do they have for those involved. This line of inquiry creates a basis for assessing whether some narratives have more harmful impacts than others, and whether there are new or existing narratives which could be taken up in order to provide better outcomes for the groups involved. In terms of narrative's relationship with fact, this thesis does not assess the accuracy of narratives or their alignment with truths or realities. Rather it takes the post-structural perspective that discursive and material processes are not divisible from one another (Mumby, 2011; Dale, 2005). Discourses constitute the material world, individuals make sense of the material world through discourse and the material world is shaped by discursive understandings (Hardy and 
Philips, 1999). From this perspective, it is important to examine narratives as a means of examining discourses and their effects, rather than to seek the accuracy of narratives or their alignment with facts. The outcomes are seen as lived experiences which are constituted through different discursive lenses rather than as truths or facts which exist on their own, outside of human perception. The problems with trafficking 'facts' and 'realities', which are discussed in the literature review, alongside the politically contested nature of trafficking definitions, makes a post-structural analysis approach appropriate for research into trafficking narratives.

This research is about human trafficking in New Zealand. In New Zealand there is a problem of exploitation of migrant workers which is receiving increasing attention through media and research (Stringer, 2016; Searle, McLeod and Ellen-Eliza, 2015; Searle, McLeod and Stichbury, 2015; Yuan et al., 2014; Anderson et al., 2012; Tipples et al., 2012). New Zealand is a signatory to the United Nations (UN) Trafficking Protocol and at the time of this research the New Zealand Government was developing its anti-trafficking work as a way of responding to migrant exploitation. The narratives about the types of harm that are unacceptable, who deserving victims are, and what actions are legitimised, were under construction. Given the mix of agendas, positions and constructions of human trafficking as a crime type internationally, and their potential harmful impacts, it is important to understand how trafficking is being defined in New Zealand and the associated outcomes for migrant workers. While this research does not include the lived experiences of people who have been in situations of exploitation, it focuses on the evolving definitions and official responses as a way of understanding the impacts for those who are affected by exploitation.

New Zealand also provides a unique setting for studying how trafficking is conceptualised and to what effect. New Zealand is the only country in the world to have decriminalised prostitution and at the time of this research, moral and religious debates about abolishing prostitution (which have been prominent in anti-trafficking responses) are less apparent. As a geographically remote country, discourses about security threats and immigration concerns are also less prominent in New Zealand compared to the UK, EU and US. In this way, by carrying out New Zealand based research I hope to contribute to the ongoing conversations in which legislators, policy makers, and academics around the world are trying to re-think 'trafficking' within the broader framework of labour exploitation as opposed to approaches which focus on trafficking into the sex industry and border security.

In this chapter I introduce the issues this research speaks to and provide the context for the research aims. I start by outlining the dominant international definition of human trafficking and the key groups involved in defining trafficking, and then present the New Zealand context as the setting for this research. This includes New Zealand's uptake of human trafficking into law and policy, the 
influence of the Prostitution Reform Act, a very brief overview of what we know about the types of exploitation taking place in New Zealand, and information about cases prosecuted using trafficking law. At the end of this chapter I show the rationale and aims for this research and the contribution it seeks to make. This is followed by an overview of the structure of the thesis and what each chapter covers.

\subsection{Definitions}

While human trafficking is a contested concept, there is a high level definition which can be taken as widely internationally agreed. This definition was set out in the United Nations Convention against Transnational Organized Crime (UNTOC, also called the Palermo Convention) in 2000, in the Protocol to Prevent, Supress and Punish Trafficking in Human Beings, Especially Women and Children (also called the Trafficking Protocol) (UNODC, 2000).

In its more modern form, trafficking is an issue that sits in the United Nations Office of Drugs and Crime (UNODC) portfolio and the UN is seen as a point of authority providing guidance for states and governance about what should be done to address trafficking and monitoring and reporting on states' actions. The definition in the Trafficking Protocol can be taken as widely internationally agreed as when state governments signed the Palermo Protocol they were required to accept the definition and translate it into law and practice. The Protocol has had wide uptake and, at the time of this research, there were 189 States who were parties to the Convention.

Another key group in shaping the form trafficking takes is the United States Department of State (US DoS). The US DoS carries out annual monitoring of state governments around the world and reports on their anti-trafficking efforts. Countries are ranked based on the extent that their efforts meet the minimum standards for the elimination of human trafficking as set out in the United States Victims of Trafficking and Violence Protection Act (2000) (TVPA). Receiving a low ranking can have impacts for a country as this can result in funding restrictions to services or supports provided by the US Government (United States Department of State, 2018a, p. 41). The TVPA's minimum standards are said to be 'generally consistent with the Palermo Protocol' (United States Department of State, 2018a, p. 39) and so can be taken as another way the international definition of trafficking is enforced.

The following definition is set out in the Trafficking Protocol:

(a) "Trafficking in persons" shall mean the recruitment, transportation, transfer, harbouring or receipt of persons, by means of the threat or use of force 
or other forms of coercion, of abduction, of fraud, of deception, of the abuse of power or of a position of vulnerability or of the giving or receiving of payments or benefits to achieve the consent of a person having control over another person, for the purpose of exploitation. Exploitation shall include, at a minimum, the exploitation of the prostitution of others or other forms of sexual exploitation, forced labour or services, slavery or practices similar to slavery, servitude or the removal of organs;

43

(b) The consent of a victim of trafficking in persons to the intended exploitation set forth in subparagraph (a) of this article shall be irrelevant where any of the means set forth in subparagraph (a) have been used;

(c) The recruitment, transportation, transfer, harbouring or receipt of a child for the purpose of exploitation shall be considered "trafficking in persons" even if this does not involve any of the means set forth in subparagraph (a) of this article;

(d) "Child" shall mean any person under eighteen years of age.

In attempts to simplify this definition, human trafficking is often considered in terms of three component parts: the act, means, and purpose. Firstly an act of recruitment, movement, harbouring, or receiving people, carried out by a means of coercion, deception, abuse of power, for the purpose of exploiting those people (UNODC, 2019a).

Despite having this internationally agreed definition as well as a general sense that trafficking is a large, serious, global problem, trafficking is a contested concept and there are issues with defining what trafficking is as well as a lack of robust information about the size and nature of the problem (Doezema, 2010). The topic itself is complex as definitions attempt to capture the experiences of people moving around the world in many different situations, with different reasons, varying levels of agency, and facing a wide range of exploitative conditions. In operationalising definitions of trafficking, governments must consider what types of exploitation are considered acceptable or unacceptable and classify forms of migration into categories such as refugee, illegal immigrant, trafficking victims, or criminals. On top of this, definitions are politically and morally charged. They were built on debates about harm and agency in sex work, as well as political agendas promoting border security or anti-immigration populist rhetoric.

The lack of reliable statistics about human trafficking has been well documented (Weitzer, 2005, 2007, 2014; Kelly, 2005; Laczko and Gozdziak, 2005; Tyldum and Brunovskis, 2005). This is partly 
because of the 'hidden' nature of trafficking as cases of trafficking are only recorded when they come into contact with official channels or advocacy groups. The lack of a sound evidence base is also due to the difficulties in defining human trafficking (Dempsey, 2017; Weitzer, 2014; Kangaspunta, 2007). If trafficking is not defined as a crime then there is often no data collected about it. There are also varying applications of trafficking law meaning that different situations are recorded as trafficking. Despite the clear lack of robust evidence, statistics are quoted freely in much official, media, and advocacy reporting. The international estimates of the number of trafficking victims worldwide such as the Global Slavery Index (Walk Free Foundation, 2018) are often used by media and advocacy groups to enforce the magnitude and global nature of the problem (Wylie, 2016; Doezema, 2010). Furthermore, there is a general assumption that the problem is much bigger than we know, with the term the 'dark figure' often used to suggest the large number of victims who remain unrecorded (United States Department of State, 2018a).

Throughout this research I refer to human trafficking as a 'global crime type' or 'international crime type'. Human trafficking is viewed in this research as a concept which is used to understand harm that occurs where there is migration, work and exploitation. The focus of this thesis is on how human trafficking, as a constructed concept, is narrated and what the impacts of such constructions are for the people who are the recipients of migration and work related harms. Therefore it is essential to discuss trafficking not as a universally acknowledged truth but as a concept which is agreed on and applied to certain situations by states, law enforcement, and in public discourse. I call it a 'crime type' because it has been conceptualised as a category of crime applied to certain situations. It could be called an international 'law' but human trafficking law is only one part of trafficking as states often have a whole raft of activities associated with trafficking of which trafficking legislation is only one factor. I call it an 'international' or 'global crime type' as it is a concept which has been defined largely by international bodies and distributed around the world through nations signing the Trafficking Protocol.

\subsection{The New Zealand context}

This section describes the New Zealand context as the setting for this research. This includes New Zealand's participation in the Trafficking Protocol and anti-trafficking efforts, the Prostitution Reform Act which provides a different start point for New Zealand's anti-trafficking work compared with other states, a brief summary about what is known from research about the types of exploitation that occur in New Zealand, and a summary of cases which have used trafficking law. 


\subsubsection{New Zealand's participation}

The New Zealand Government signed the Trafficking Protocol on 14 December 2000 and ratified it on 19 July 2002. The Protocol entered into force on 25 December 2003 (Glazebrook, 2010). Since the ratifying, New Zealand has participated in some reporting to the UN on anti-trafficking work and has undergone regular annual assessments carried out by the US Embassy on behalf of the US Department of State. New Zealand is also a member to the Bali Process - an international forum designed for sharing information about human trafficking and people smuggling which started in 2002. New Zealand currently holds a leadership role in this forum.

A key requirement of the Protocol is that signatory states criminalise trafficking in state law and investigate and prosecute instances of trafficking. In implementing the Protocol, Human trafficking was classified as a crime in New Zealand legislation in section 98D of the Crimes Act 1961 in 2002. As a part of New Zealand's commitments under the Trafficking Protocol, New Zealand also created a plan of action to address people trafficking in 2009 (Department of Labour, 2009). At the time there had been no prosecutions using trafficking legislation and the plan was designed to lay out how government agencies would respond to instances of human trafficking if they were detected.

Since the trafficking in persons legislation was introduced in to the Crimes Act in 2002, at the time of this research, it had only been used in four prosecutions (Immigration NZ Assistant Manager Peter Devoy quoted in Radio New Zealand, 2018). Of these prosecutions, two were successful in bringing about a conviction for human trafficking charges and two failed to bring about charges under trafficking law and the defendants were convicted on exploitation or immigration charges. These cases are described in more detail later in this subsection.

In 2014 the definition of human trafficking was changed to include domestic movement rather than solely cross border movement (this was done through the Organised Crime and Anti-Corruption Legislation Bill Clause 5). This change was made to better align New Zealand law with international definitions of trafficking and allowed for the trafficking in persons legislation to be used in a broader range of situations.

At the time of this research, the New Zealand government was revising and developing its response to trafficking cases. The 2015 change in legislation to remove the requirement to cross a state border meant that cases would no longer be exclusively led by Immigration New Zealand (Immigration NZ) as cases that did not involve border movement would be managed by New Zealand Police. The New Zealand plan of action for responding to trafficking and the trafficking legislation was also being reviewed. 


\subsubsection{The Prostitution Reform Act 2003}

Although human trafficking definitions and legislation have been applied in New Zealand in a topdown way as the definition of trafficking is set through the UN Trafficking Protocol, New Zealand has always differed in its approach as it is the only country to have decriminalised prostitution. In 2003 the New Zealand Government passed the Prostitution Reform Act (PRA) which decriminalised the sale and purchase of sexual services involving consenting adults over the age of 18 . While sex work has gone through a process of legalisation or partial decriminalisation in a handful of countries, New Zealand remains the only country to have decriminalised prostitution. This was done by removing it from the context of the Crimes Act and law enforcement and repositioning it within the jurisdictions of labour standards and immigration monitoring and regulation.

Although sex work is decriminalised in New Zealand for permanent residents and citizens, temporary visa holders are prohibited from engaging in sex work and/or investing or operating a business of prostitution (under Section 19 of the PRA which refers to the Immigration Act 2009). In this way they are excluded from legally working in the sex industry. Section 19 was included as a measure against human trafficking, with the intention of preventing people being brought into New Zealand and forced to work in the sex industry (Martin, 2016). Temporary visa holders who are found to be working in the sex industry are treated as breaching their visa conditions and can be deported. In 2019 Immigration NZ visited 57 brothels across Auckland, Hamilton, Tauranga, Wellington, Christchurch, Queenstown, and Dunedin and identified 36 people working on visitors visas and two on student visas (Immigration NZ, 2019a). While Immigration NZ do not report whether the 38 people identified were served deportation liability notices or deportation orders, other sources report that temporary visa holders found to be working in the sex industry have been deported (Block, 2019; Gee, 2019).

Internationally, viewing sex work as fundamentally exploitative has been a key trend in the development of human trafficking as a crime type in the last 20 years. Political, advocacy, and academic groups have promoted a version of trafficking where trafficking is essentially a problem of prostitution and an example of the harms prostitution can cause (Kempadoo, 2005). In this presentation trafficking and sex work are conflated and anti-trafficking campaigns are used to further abolitionist agendas with the aim of preventing prostitution through criminalising sex work (Tomkinson, 2012; Doezema, 2010; Desyllas, 2007; Weitzer, 2007). As well as mixing abolitionist views about sex work with anti-trafficking efforts, these approaches have equated trafficking with sex trafficking and the associated response is to focus anti-trafficking efforts on sex trafficking as opposed to trafficking involving forced labour or other types of exploitation. 
The PRA positions sex work as labour rather than as an inherently harmful criminal activity. By treating sex work as labour, prostitution is not positioned as a problem to be addressed through human trafficking criminal legislation, criminal investigations, and prosecutions, and has meant that convictions brought under trafficking legislation have tended to take a broader focus on labour exploitation. Exploitation that takes place in the sex industry falls within the labour exploitation remit rather than being singled out as 'sex trafficking' - as a particular criminal harm which sits in a category of its own. The New Zealand Government has come under pressure over the years from the US Department of State to re-criminalise sex work (Showden, 2017; United States Department of State, 2007) and to adopt a definition of trafficking which aligns with the US Trafficking Victims Protection Act, where minors who engage in prostitution are considered as victims of sex trafficking (United States Department of State, 2018a). However, abolitionist approaches to prostitution, where prostitution is seen as inherently harmful to women and which involves campaigning for the total abolition of prostitution, have not had a strong hold in New Zealand anti-trafficking policy.

There is an international trend in the anti-trafficking initiatives where attempts are being made to broaden the scope of trafficking definitions and enforcement to involve a greater focus on labour trafficking as opposed to sex trafficking (Wylie, 2016). The aim of broadening the scope of antitrafficking work is so that other forms of trafficking are recognised and so that people experiencing exploitation in a range of different situations and work-types can seek assistance. New Zealand is in a unique position in being largely focused on labour trafficking. Through studying the approach taken in New Zealand through narrative research, this research contributes to discussions of how to move forward with a broadened version of human trafficking.

\subsubsection{Exploitation in New Zealand}

While there has only been a small number of cases that have been investigated or prosecuted as human trafficking in New Zealand, there is a general perception that these cases are the 'tip of the iceberg' and that there are many more instances of trafficking or other serious exploitation that go undiscovered (Frazer, 2014, 2017; Caritas, 2016; Stringer, 2016; Glazebrook, 2010). There is very little research on human trafficking or similar serious exploitation in New Zealand. There is a small body of qualitative research investigating exploitation of migrant workers in certain industries including the types of exploitation that are occurring and in which industry sectors. At the time of this research there was no quantitative information about the extent to which exploitative practices take place. 
Research has found migrant workers experience exploitation and exploitative labour conditions in certain industry sectors in New Zealand. These are agriculture (Caritas, 2016; Stringer, 2016; Promsaka Na Sakolnakorn et al., 2013; Tipples et al., 2012), horticulture and viticulture (Caritas, 2016; Stringer, 2016; Prochazkova, 2013; Anderson et al., 2012; Anderson and Naidu, 2010; Beer and Lewis, 2006), fisheries (Macfarlane, 2017; Stringer, 2016; Stringer et al., 2016; Simmons and Stringer, 2014), construction (Stringer, 2016; Searle, McLeod and Ellen-Eliza, 2015), hospitality (Caritas, 2016; Stringer, 2016; Searle, McLeod and Stichbury, 2015), and health care services (Lovelock and Martin, 2016; Peligman-Toclo, 2011; Walker, 2008; Manchester, 2005; O’Connor, 2005).

This small body of research about migrant exploitation in certain New Zealand industry sectors consistently showed the same types of exploitation or poor labour conditions were occurring across sectors. These include inaccurate or irregular payments where migrant workers were being underpaid or paid inaccurately for the work they had done (Caritas, 2016; Stringer, 2016; Searle, McLeod and Ellen-Eliza, 2015; Searle, McLeod and Stichbury, 2015; Anderson et al., 2012; Anderson and Naidu, 2010), not being paid for overtime or all of the work done, or being paid irregularly (Caritas, 2016; Searle, McLeod and Stichbury, 2015; Anderson et al., 2012), not being paid for 'training' periods (Caritas, 2016; Searle, McLeod and Ellen-Eliza, 2015; Searle, McLeod and Stichbury, 2015), and not being given holiday pay or paid sick leave (Caritas, 2016; Stringer, 2016; Searle, McLeod and Ellen-Eliza, 2015; Searle, McLeod and Stichbury, 2015).

Having no employment agreement was frequently reported, which meant variability in types of work and payments received and meant that the employee could not argue against poor working conditions as there was no proof of employment (Caritas, 2016; Stringer, 2016; Searle, McLeod and Ellen-Eliza, 2015; Searle, McLeod and Stichbury, 2015). There were also reports of contract substitution where workers would sign a contract in their home country and when they began work in New Zealand there would be changes to salary, hours, or nature of work (Caritas, 2016; Searle, McLeod and Ellen-Eliza, 2015). A common finding across studies was migrants working long hours, often where workers were not paid overtime or paid below minimum wage, and in some cases were not allowed breaks (Caritas, 2016; Lovelock and Martin, 2016; Stringer, 2016; Searle, McLeod and Ellen-Eliza, 2015; Searle, McLeod and Stichbury, 2015; Anderson and Tipples, 2014; Beer and Lewis, 2006).

Existing research found cases of employers or recruitment companies controlling workers through holding their passports and other documents, withholding their pay or controlling their bank accounts, or threatening to report the workers to Immigration New Zealand for breaching their visa terms if they complained (Caritas, 2016; Stringer, 2016; Searle, McLeod and Stichbury, 2015; 
Anderson et al., 2012; Tipples et al., 2012). There were also cases where the employer put restrictions on the employees' free time such as not allowing them to drink alcohol or to leave their accommodation or worksite (Stringer, 2016; Prochazkova, 2013; Beer and Lewis, 2006).

The research also found reports of abusive and discriminatory behaviour from employers or coworkers. This included bullying, threats, and verbal abuse such as swearing at the worker and in a couple of reports, physical abuse (Stringer, 2016; Searle, McLeod and Stichbury, 2015; Walker and Clendon, 2012 in Yuan et al., 2014; Peligman-Toclo, 2011; Manchester, 2005; O'Connor, 2005). It also included discrimination through allocating more physically demanding or demeaning tasks or difficult shifts to migrant workers from certain ethnic groups (Caritas, 2016; Stringer, 2016; Searle, McLeod and Ellen-Eliza, 2015; Searle, McLeod and Stichbury, 2015; Peligman-Toclo, 2011).

There were some reports of debt bondage where the employee was required to provide part of their salary to repay debts to their employer. This included fees for accommodation, which could be excessive, costs of work equipment, and recruitment fees which had been paid to recruiters or immigration agents in other countries (Caritas, 2016; Stringer, 2016; Searle, McLeod and Ellen-Eliza, 2015, 2015; Searle, McLeod and Stichbury, 2015; Anderson et al., 2012; Tipples et al., 2012; Peligman-Toclo, 2011). Some cases were documented where the employee would give some of their pay to the employer and in return the employer would sponsor their residency applications (Searle, McLeod and Ellen-Eliza, 2015; Searle, McLeod and Stichbury, 2015). There is some indication that some Private Training Establishments are being presented to students, especially from India, as being a pathway to residency (Stringer, 2016). These schemes neglect the undesirable aspects of such a pathway such as placing students in precarious work situations with potentially illegal visa status. After incurring large debts to take part in these schemes, students are required to work outside of the conditions of their student visa in order to repay them, often in the horticulture industry, and research has shown this precarious legal status allows for dangerous and illegal working conditions to go unchecked (Anderson et al., 2012).

In research into horticulture, dairy farming, construction, and hospitality industries, there were reports of employers providing dirty, overcrowded, inadequate accommodation with little room, inadequate bathrooms, and heating (Caritas, 2016; Stringer, 2016; Searle, McLeod and Ellen-Eliza, 2015; Searle, McLeod and Stichbury, 2015).

This research indicates that the types of work where migrant workers are more at risk tend to be in primary production, with low paid and low skilled jobs, which involve physically demanding labour (Stringer, 2016; Yuan et al., 2014; Lamm et al., 2010). These findings reflect a wider international pattern of the types of industries where exploitative practices take place and where migrant workers 
are most at risk. Migrant labour is often described as 3D jobs - work which is Dirty, Dangerous, and Demeaning (Martin et al., 2010). This is work which is legally precarious, physically demanding, with low pay and long hours, and carrying a greater risk of injury, illness and fatalities (Salminen, 2011; Hao, 2008; Vartia-Vaananen et al., 2007; McKay et al., 2006; Bohle et al., 2004; Loh and Richardson, 2004).

The research summarised above does not give a comprehensive picture of all industries where migrants are at risk. Most of these studies have focused on certain industries with the assumption that exploitation is likely to be occurring within them. Questions about human trafficking and exploitation in the New Zealand sex industry have been raised by the US Department of State and in media reporting (Showden, 2017; United States Department of State, 2007). A small number of studies have included questions about the exploitation of migrants in the New Zealand sex industry. While there is not a sufficient amount of research to draw any conclusion about whether trafficking is taking place, there has been no direct evidence found showing that migrants are being forced to work in the New Zealand sex industry.

Two small qualitative studies found no indication of people being forced to come into New Zealand to engage in sex work or any individuals being forced into sex work against their will (Abel and Roguski, 2018; Armstrong, 2018). These studies found reports of migrant sex workers being subjected to poor work conditions such as long working hours and having to pay unreasonable living costs, and concluded that the current law excluding migrants from working legally in the sex industry creates conditions that may be conducive to exploitation. An earlier survey of migrant workers in the sex industry found most were satisfied with their work conditions (Roguski, 2013). Despite this finding, this study also found that migrant workers may be unlikely to report poor practices for fear of deportation as under the Immigration Act 2009 temporary migrant workers are not permitted to work in the sex-industry and so would be working illegally.

A review of migrant worker exploitation in New Zealand compiled a small number of media articles reporting instances of either people coming into the country and being coerced into working in the sex industry or of migrant workers being exploited in the New Zealand sex industry (Stringer, 2016). The qualitative component of this study found one participant who had come to New Zealand to work as a massage therapist but then had been asked to provide commercial sexual services. When they refused their employer threatened to report them to Immigration NZ which may have led to deportation.

While these four studies do not demonstrate trafficking occurring in the New Zealand sex industry, they all conclude that the exclusion of temporary visa holders from the benefits of a decriminalised 
sex industry creates a precarious situation for migrant workers as it does not allow them to access the same rights and protections afforded through decriminalisation (Abel and Roguski, 2018; Armstrong, 2017; Stringer, 2016; Roguski, 2013).

This summary of research gives an indication of the types of exploitative practices which are likely to be occurring in New Zealand industries. However, it focuses exclusively on migrant workers and largely those on temporary working visas. The change to trafficking in persons legislation through the Organised Crime and Anti-Corruption Legislation Bill 2014 removes the need for a person to cross a border and means that trafficking law could apply to New Zealand residents or migrants who have settled in New Zealand. It is difficult to discuss how this newly determined form of trafficking or serious exploitation may be occurring in New Zealand as it is yet to be seen what the law change will mean for definitions of trafficking which do not include border movement. For example, research by Thornburn (2018) reports evidence of sex trafficking in New Zealand where victims have been forced or coerced into prostitution, often as minors who are coerced by family members or partners, without any relation to migration. However, it is not known whether human trafficking legislation would be considered relevant to these types of abusive relationships.

This ambiguity of what situations count as trafficking is not unique to New Zealand and has been an ongoing question for anti-trafficking work around the world (Dempsey, 2017; Weitzer, 2014; Kangaspunta, 2007). The ambiguity and changing nature of definitions of trafficking makes studying the policy narratives about what counts as trafficking important. As the concept is redefined and narrated in different ways, different responses become relevant and lead to different outcomes for affected groups. Narratives can have a powerful impact for the groups and issues they are about and this is why this research looks at existing narrative strands and studies how they evolve.

\subsubsection{Human Trafficking legal cases in New Zealand}

As noted above, to date there have been four cases which have been prosecuted using human trafficking law in New Zealand (Immigration NZ Assistant Manager Peter Devoy quoted in Radio New Zealand, 2018). Of these four, two have been successful in bringing about trafficking convictions. The other two were unsuccessful in bringing about trafficking convictions and have resulted in exploitation, immigration fraud and other immigration related convictions.

In this subsection, I describe these four cases as a way of providing a picture of the types of situations trafficking law has been applied to, to give an idea of what the problem looks like in the New Zealand context. However, this description will be nowhere near complete as there is no way of identifying all of the cases which have at some stage been considered as trafficking for official 
purposes. This description captures only cases where there has been a human trafficking charge as opposed to cases which have been investigated with at some stage a view to use trafficking law.

All of the cases discussed here are about labour trafficking. They involve people coming from Samoa, Fiji, India or Bangladesh in search of work and ending up working under exploitative conditions in the horticulture, hospitality and construction industries in Auckland, Bay of Plenty, MarlboroughTasman region, and Hawkes Bay.

New Zealand's first successful trafficking prosecution was completed in 2016. The case involved 16 Fijian nationals who came to New Zealand to seek work (Miller et al., 2017). Their entry into the country was arranged by a travel agent - a woman and her sister based in Fiji, and their employment was arranged by Faroz Ali, who was based in New Zealand. They had paid large amounts of money to the agent which they had borrowed or sold property to gain and were expecting to be brought to New Zealand, issued valid working visas, and provided with food and accommodation, and to receive around $\$ 16$ an hour, with the aim of sending money back to their villages. When they arrived in New Zealand they were either sent to work for Faroz Ali in his Gibraltar Board hanging business in Auckland or to work for a third party, Jafar Kurisi in the Bay of Plenty picking fruit. The victims were housed in poor conditions, with little food, had their movement and activities restricted, and received little or no pay.

Faroz Ali was convicted of charges relating to trafficking in persons and Jafar Kurisi was convicted on exploitation charges (Miller et al., 2017). In 2018 the Barrister Mohammed Idris Hanif, who provided legal services to Faroz Ali was found guilty of fraud for providing fraudulent information to Immigration NZ in visa applications submitted on behalf of the victims (Immigration NZ, 2018a). At the time of this research, further arrests and charges were being carried out for the travel agents involved in this case (Bateman, 2018; Immigration NZ, 2018b).

The second successful trafficking prosecution was carried out during the period this research was conducted from 2018 to 2020. In this case, Joseph Auga Matamata, a Hawkes Bay horticulture worker, was found guilty of human trafficking and slavery charges (Immigration NZ, 2020). Matamata is a New Zealand and Samoan resident and the offending prosecuted in this case involved him arranging to bring 13 Samoan nationals to New Zealand between 1994 and April 2019 to work for him in the Hawkes Bay horticulture industry without working visas (Immigration NZ, 2018c, 2020). In this prosecution the Court heard that those brought to New Zealand were actively recruited with the promise of well-paid work. On arriving in New Zealand, the workers were not paid, had their passports confiscated, were subject to threats an assaults, and had their movements and activities restricted (Immigration NZ, 2018c). 
Before the first successful trafficking prosecution there had been one other trial where the defendants had been charged with human trafficking charges in 2014. Jaswinder Singh Sangha, his brother Satnam Singh, and Kulwant Singh were found not guilty of human trafficking charges. Jaswinder Singh Sangha and Kulwant Singh were convicted on immigration fraud charges for supplying false statements to a refugee officer as a part of organising false refugee claims (Immigration NZ, 2016). Jaswinder Singh Sangha and his brother Satnam Singh arranged for 18 men from Northern India to pay around \$33,000NZD each to come to New Zealand with the promise of receiving a two year work visa and jobs in the horticulture industry in the Marlborough-Tasman region (Carson, 2015). When they arrived in New Zealand Kulwant Singh, an interpreter who worked for an immigration lawyer, submitted refugee applications containing false information about the men's backgrounds, such as having being subjected to violence in India, in order to improve their chances of gaining refugee status (Pullar, 2016).

Instead or receiving two year work visas and jobs, they received a seven month visa and no ongoing work (Bonnett, 2019). Some returned to India and some overstayed their visa conditions. The men and their families who remained in New Zealand are currently disputing their right to stay in the country (Radio New Zealand, 2017). After being initially granted a category of work visa for people who have been trafficked, they have had their residency applications declined based on their unconfirmed status as victims of trafficking (Bonnett, 2019).

A recent case brought human trafficking charges against a couple who ran a Bangladeshi sweet shop in Auckland. In March 2019 the couple, Mohammed Atiqul Islam and Nafisa Ahmed, were found not guilty of human trafficking charges but were convicted of charges of exploitation and other immigration related offences (Immigration NZ, 2019b). They were found to have exploited five victims while they worked in their sweet shop over a two year period (Immigration NZ, 2019c). The couple had advertised for a chef in Bangladesh to work in their sweet shop and to be paid \$17 an hour and work six days a week (Shaw, 2019; Williams, 2019). The chefs who came to New Zealand worked seven days a week, for long periods which breached their visa conditions, had few breaks and were paid $\$ 7-8$ per hour. Their passports were confiscated and they had paid around $\$ 12,000$ in recruitment costs (Shaw, 2019).

\subsection{Research rationale and aims}

The underlying premise of this research is that it is important to study how social problems are constructed and presented, as their construction determines how the problem will be responded to and how the groups involved will be affected. This is an important line of inquiry in anti-trafficking 
research as human trafficking is a contested term whose construction has gone through many shifts in the past 20 years. This is described in a review of literature in Chapter Two. As shown in Chapter Two, different constructions of trafficking have had harmful outcomes to the groups involved. As human trafficking is applied around the world through state government's actions and law, it is necessary to consider how the problem is constructed, what the likely outcomes may be, and which versions may be more useful and avoid harm for those involved.

From a philosophical basis, seeing social problems as socially constructed, the theoretical and methodological approach taken in this research is a post-structural version of narrative criminology. In this approach, narratives are important to study as they are constitutive - all experience is storied, it makes up how we see the world and leads to future action (Presser, 2009). From this perspective trafficking is seen as a crime type that is constructed and based on power. We can see in the antitrafficking field, there are multiple constructions of trafficking, with differing perspectives held by different groups. The aim of this approach is to identify problematic processes, inequalities and exclusions (who is left out), and new ways of thinking about the problem (Kohler Riessman, 2008, p. 105; Czarniawska, 2006, p. 88; Silverman and Torode, 1980).

\subsubsection{Research aims}

This research seeks to identify and unpack narratives of human trafficking in New Zealand. It involves the analysis of policy documents about the problem of human trafficking and how it should be responded to, and interviews with and observations of, government officials who are responsible for implementing trafficking law, designing the New Zealand Government anti-trafficking response, and responding to suspected cases of human trafficking.

The research seeks to understand how human trafficking is defined, what discourses are drawn on, and how international narratives may be influencing local responses. This research also seeks to identify new and less problematic ways of conceptualising human trafficking and responding to migrant exploitation.

The aims of this research are:

- To identify what are the narratives about the problem of human trafficking in New Zealand and how they fit, contrast, conflict, merge, or replace one another

- To understand how these narratives relate to the dominant international narratives of human trafficking 
- To identify how narratives are taken up or heard in policy language and by those responsible for responding to migrant exploitation and enforcing trafficking law

- To identify the apparent or potential consequences these narratives have for how the problem of human trafficking is defined and responded to, for the affected groups.

This research will contribute to the growing body of international literature about the framing of human trafficking. New Zealand data will provide a new perspective through presenting data from a unique context which has not yet been heard by international audiences.

This thesis also sets out to contribute to discussions about how to respond to trafficking and migrant exploitation in New Zealand. At the time of this research the New Zealand Government was developing its response to migrant exploitation. Officials were developing their anti-trafficking work as a fairly new area of work and having discussions about how the problem should be considered, whether it is an issue for immigration officials or a serious crime to be dealt with by police, and whether new legislation is needed to frame the issue as a problem of 'modern day slavery' as opposed to 'human trafficking'. By drawing together the voices of professionals involved in dealing with trafficking law and migrant exploitation, I hope to provide insights into the different ways of thinking about migrant exploitation and potential avenues for political change.

\subsection{Thesis overview}

The first chapters of this thesis focus on why and how this research was carried out. They include an introduction to the issue the research seeks to address, the relevant literature, the research approach and theory used, and the methodology and analysis techniques. Once the aims and methods of this thesis are established, there are three chapters which present the findings of this research followed by a discussion and conclusion.

Following from this introductory first chapter, Chapter Two presents the international literature which presents and critiques human trafficking's modern form and how it has risen to be a popular and much attended global crime type in the last 20 years. This body of literature is drawn together to show the different ways the trafficking problem has been approached during its rise to prominence. Alongside the different approaches, I present literature which critiques each of these ways trafficking has been approached and responded to including where there have been harmful outcomes for the groups involved.

Chapter Three is about the theoretical approach taken in this research - a post-structural interpretation of narrative criminology. This chapter shows the process I followed in deciding on a 
research approach and theory. It starts with a summary of the different philosophical and epistemological approaches which anti-trafficking research is based on. Drawing on this summary, I demonstrate my decision to ground this research in a social constructionist approach. Following from this, I present narrative criminology as an appropriate theoretical and methodological starting point, and explain how I draw on post-structural concepts in order to create a framework for analysing policy narratives of an international crime type.

Chapter Four outlines the methodology used and describes the research and analysis processes. In this chapter I present the research methodology and then show the research process I followed from seeking ethics, gaining access to certain groups and spaces and the data sources I collected. The second half of this chapter is about the strategies I used analysing the data and describes the analysis process, using one specific data source as an example. This chapter ends with a reflection of the research process, methods and analysis I carried out.

Chapters Five, Six and Seven present the findings from this study. Each chapter explains the narratives that were identified in the data. These findings chapters follow a structure of presenting each narrative, showing the evidence for the narrative in the data including quotes and document texts as illustrative examples. This is followed by a description of the outcomes that each narrative lends itself to.

Chapter Five examines three narratives where trafficking is linked to business and discussed in terms of commercial enterprise. These are trafficking as organised criminal enterprise, commercial businesses as saviours, and trafficking as 'dodgy' business. These three narratives are largely discrete and lend themselves to three different sets of outcomes - individualised criminal responses, promoting consumerism and capitalism, and addressing exploitative industry and employment practices. These are discussed and compared with the conclusion that their joint focus on profits and wider systems of commerce can be beneficial to anti-trafficking work.

Chapter Six presents three overlapping narratives about trafficking as a foreign 'other' problem, trafficking as an abhorrent aberration to normal systems, and trafficking as a large unknown and threatening problem. These narratives hang together and result in western countries being presented as exempt from the trafficking problem and result in an individualised, often criminal response to trafficking.

Chapter Seven presents two narratives that are about people who have been trafficked. One is the more traditional narrative of an innocent victim of sex trafficking while the other is a newer emerging narrative about the vulnerable migrant worker. Both narratives have different outcomes 
for the groups they are applied to, and within the emerging migrant worker narrative, the outcomes are likely to differ based on how the idea of vulnerability is presented, as either inherent or structured.

Chapter Eight is a discussion and conclusion which draws together the findings from the three prior chapters and uses them to propose an alternative narrative. The discussion covers how the findings reflect current challenges identified in the body of literature and anti-trafficking work internationally, and show where they offer ways forward to current debates. This proposed counter narrative provides a way forward in challenging the long-standing issue of western exceptionalism, addresses the need to redefine victimhood to be more accessible for those affected, and addresses the question of whether trafficking definitions and responses should be defined by international versus local bodies. 


\section{Chapter Two: Literature Review}

This chapter presents a review of international literature which documents how human trafficking has become a prominent and much attended issue in the last 20 or so years. This body of literature shows how human trafficking has been defined and responded to by international bodies and state governments, as well as how it has been conceptualised and presented in advocacy campaigns, media portrayals, and political rhetoric.

The section summarises this body of literature by grouping the way that trafficking has been approached into five themes. These are: approaches where human trafficking is conflated with prostitution; where human trafficking is defined as modern day slavery; where human trafficking is approached as a security threat; where human trafficking is approached as a human rights issue; and where human trafficking is seen as a breach of labour law. Each of these approaches has received much discussion and critique in the international literature. I describe each of these five ways of approaching trafficking, how and when they became a part of anti-trafficking efforts, and present how they have been discussed and critiqued in international literature. For the purposes of this chapter, I have grouped the approaches into these five categories. These categories are not discrete and will be grouped in different ways in other literature. However, the five themes are not a new creation and each has been the subject of much academic and political debate.

The purpose of presenting this body of literature is to show how human trafficking as a contested concept has been defined, approached, and responded to in different ways and how the different approaches have come under criticism for creating harmful outcomes for those involved. The purpose is also to show how legal, policy, advocacy, and academic actors are still struggling to find a less harmful way of responding to complex issues that go along with migration. This chapter aims to show the importance of analysing how trafficking is conceptualised, studying the likely outcomes, challenging those which are harmful, and identifying new or less harmful approaches and the need to find new ways of thinking about migration and labour exploitation issues.

\subsection{Human trafficking as prostitution}

While the idea of human trafficking has been around since the $19^{\text {th }}$ century, in its modern form, it rose in popularity as a problem of prostitution (Kempadoo, 2005). Positions that conflate human trafficking with prostitution are still prominent in discourses, campaigns, and legal responses, often under the guise of a victim-centred human rights approach. This position was set out in international law through the 1949 UN Convention for the Suppression of the Traffic in Persons and the Exploitation of Prostitution of Others which focuses on prostitution. However, its current dominance 
can be tied to the feminist prostitution abolitionism movement, US anti-prostitution political agendas, and its uptake in popular campaigns.

In the 1980's the feminist abolitionist movement began to focus on human trafficking, as viewed as an embodiment of global sexual violence seen as being committed to women by men (Barry, 1995, pp. 10-11). While there are range of varying perspectives of feminist abolitionism, in the context of trafficking advocacy, there has been one dominant branch (Sullivan, 2003). This branch of feminist abolitionism has since inception viewed prostitution as inherently harmful, defining it as sexual violence against women, caused by women's subordination in a patriarchal society (Barry, 1984). This movement has presented trafficking as a key example of the harms of prostitution and has often conflated sex work with trafficking. In this approach concerns about trafficking cannot be separated from concerns for women working in the sex industry. This perspective is prominent in anti-trafficking campaigns and ranges on a continuum from focusing on trafficking for prostitution as the main form of trafficking, to the more extreme view of equating all prostitution with sexual slavery (Raymond and Hughes, 2001). The trafficking as prostitution position was further entrenched around the world through the US Government trafficking policy under the George W. Bush administration which, from 2003, cut funding locally and internationally to anti-trafficking organisations who did not adopt an abolitionist policy towards prostitution (Ditmore and Allman, 2013).

This approach has been adopted and spread through popular awareness campaigns and is a key part of anti-trafficking movements which use 'celebrity humanitarianism' (Haynes, 2014; Kapoor, 2013) and sexual humanitarianism (Mai, 2016). In campaigns of celebrity humanitarianism, celebrities team up with non-government organisations (NGOs) in anti-trafficking programmes where trafficking is conflated with prostitution (see for example Majic, 2021). While celebrity humanitarianism has not exclusively been directed towards campaigns which conflate sex work with sex trafficking, it has been an influential channel through which the trafficking as sex trafficking approach has been promoted. These campaigns draw on simplistic narrative tropes about victims and offenders, positioning themselves as saviours, 'rescuing' ideal victims. The product is an 'antitrafficking industrial complex' - as named by Carol Leigh (2015), where anti-trafficking efforts create a profitable industry which must then be sustained. This includes increased publicity for celebrities, profits for supporting businesses, and funding for NGOs ${ }^{1}$. 'Sexual humanitarianism' is often a feature

\footnotetext{
${ }^{1}$ Criminal justice enforcement bodies can also be included in the anti-trafficking industry - see Cojocaru (2016) for a description of how anti-trafficking criminal justice system funding prompted the anti-trafficking industry in US.
} 
of celebrity campaigns and refers to moralistic campaigns that aim to control sexual behaviour, which are delivered through the guise of humanitarianism (Mai, 2016). These campaigns present trafficking as exclusively a problem of prostitution, and they draw on the same simplistic pictures of innocent female victims and sinister male traffickers. Prostitution is presented as morally wrong and the desired result is to suppress prostitution through criminalising the sex industry.

The trafficking as prostitution approach produces a simplistic narrative of innocent female victims being abused by 'bad' male traffickers. Such campaigns position the trafficked women as being in need of rescue $(2007,2012)$. This approach takes away women's agency and has put restrictions on women migrants - it has resulted in 'victims' being deported although it may not be safe, or they may not willing, to return to their home country, and are often 're-trafficked' (GAATW, 2007). In some countries, trafficking victims are nominally 'rescued' and 'protected' by being forcibly detained in shelters which resemble detention centres where they have their freedoms limited (Abdul-Hamid, 2019; Lee, 2014; Gallagher and Pearson, 2010). For example, Abdul-Hamid (2019) found in her research on victim shelters in Malaysia that women were detained in shelters with armed guards, were forced to wear uniforms and to take part in interviews or interrogations with officials and had their contact with the outside world, including access to services, restricted. Shelters have also been reported to place victims in labour schemes where the form of labour is deemed morally acceptable (e.g. sewing; Hoefinger, 2016, p. 75). In some countries, women's ability to migrate is restricted as a protective measure against future exploitation. These responses tend to be misaligned with the situations and motivations of migrants as, in most cases, 'victims' are actively trying to improve their work conditions by migrating, using the networks available to them (GAATW, 2007).

Representations of ideal, innocent victims excludes many migrants from claiming victim status, making them ineligible for support services. This occurs in particular for male victims and women who seek to continue working in the sex industry (Cojocaru, 2016; Hoefinger, 2016; Andrijasevic, 2007). Alongside innocent 'victims' are the traffickers who are positioned as serious offenders who are heavily policed and dealt with using harsh criminal justice measures. Criminalising the traffickers implies that the problem of human trafficking is something individualist and a horrific exception to 'normal' migration. Consequently the problem is oversimplified, the breadth of complex situations that do not fit into an idealised worst case scenario are discounted, and the global structural factors that drive migration and exploitative working conditions are neglected (Segrave et al., 2018; Andrijasevic and Mai, 2016; Hoefinger, 2016).

The human trafficking as prostitution position has been heavily critiqued by liberal feminists, NGOs and academics and there is a body of research that demonstrates how the situations of trafficking 
'victims' and the motivations of migrant women are at odds with the way they are positioned in this approach (Guha, 2019; GAATW, 2007, 2018; Ham, 2017; Andrijasevic and Mai, 2016; Shah, 2014; Tomkinson, 2012; Mahdavi and Sargent, 2011; Segrave et al., 2009; Kapur, 2005; Doezema, 2001). Feminist debates about women's agency in working in the sex industry and the distinction between free and forced prostitution were influential in the definition of the 2000 UN Trafficking Protocol. The Protocol includes a rather ambiguous definition of human trafficking where 'exploitation' is largely open to interpretation. This ambiguity allows states to take a different approaches to trafficking. It allows for the long-standing stance where trafficking is approached as an embodiment of the harms of prostitution, and for approaches where trafficking is a problem of forced labour which can take place in many industries and includes forced labour in the sex industry (Sullivan, 2003). Despite the broad remit of allowed by the Trafficking Protocol, the fusing of trafficking with prostitution is still a major theme throughout anti-trafficking campaigns, NGOs, policies, popular representations, and research.

Although the UN and many state governments have made conscious attempts to move away from the trafficking as prostitution approach, its persistence in much discourse, campaigns, media, and political rhetoric raises difficulties in how to conceptualise migrant agency in trafficking situations (Segrave et al., 2018; Wylie, 2016; Doezema, 2010). In this version of trafficking there is no room for people who actively migrate for better work opportunities and choose to work in the sex industry (Tomkinson, 2012; Mahdavi and Sargent, 2011; Lebov, 2010; Doezema, 2001). Victims are presented as deceived, abducted, or tricked as opposed to seeking such opportunities without anticipating the exploitation they would experience. The trafficking as prostitution approach does not accept victim agency and the result is that there are no safe or legal avenues for people migrating and working in the sex industry, or actively seeking work in other industries, and no channels to seek legal protection when they are exploited (Guha, 2018, 2019; Shah, 2009, 2014). This problem with consent and agency has embedded itself in anti-trafficking responses and currently is presenting a problem in expanding anti-trafficking practices to have a greater focus on labour trafficking (Wylie, 2016). The same picture of non-consenting female victims does not fit when applied to men and women who chose to engage in certain work and are exploited.

\subsection{Human trafficking as modern day slavery}

Approaches which align human trafficking as modern day slavery are another popular way of conceptualising trafficking. This approach to trafficking has been present in anti-trafficking campaigns for the past 20 or more years, especially in the UK and the US (Kempadoo, 2015). While it 
has not perhaps been as dominant as the trafficking as prostitution theme, it has in recent years seen an increasing presence and has worked its way into law and policy in the UK, France, and Australia (Australian Government Department of Home Affairs, 2018; Assemblee Nationale, 2017; Legislation UK, 2015).

The trafficking as modern day slavery approach has been promoted largely by US slavery abolition groups including NGOs (such as Free the Slaves and Walk Free Foundation), journalists, authors, academics (see for example: Bales and Soodalter, 2009; Kara, 2009; Bales, 1999), and businesses over the past couple of decades (Kempadoo, 2015). In this approach, all forms of trafficking are called slavery (Chuang, 2014). Slavery is largely undefined in this approach but can be taken to mean removals of a range of freedoms for workers and can cover a diverse set of issues such as forced labour, debt-bondage or forced prostitution. The anti-slavery movement draws on discourses of trafficking, as conflation of prostitution with sexual slavery tends to be emphasised. As with the trafficking as prostitution approach, these campaigns use the same moralistic, emotive language, and often feature celebrity involvement (Brace and O'Connell Davidson, 2018; O'Connell Davidson, 2010, 2016; Kempadoo, 2015).

At the time of this research approaches which equate trafficking with modern slavery were undergoing a reinvigoration. The UK Government passed the 2015 Modern Slavery Act which compiled trafficking and slavery offences, increased criminal sanctions for offenders, and established an Anti-Slavery Commissioner. A later provision was also added to the Act to increase transparency in supply chains which holds businesses responsible for investigating potential slave labour (Legislation UK, 2015). This model of trafficking response where harsh criminal penalties for traffickers and involvement of businesses in ethical sourcing work, both under the name of anti'slavery' efforts, is being promoted globally as best practice (Segrave et al., 2018; O'Brien, 2018a). Similar legislation was taken up in France in 2017 through the addition of Article L.225-102-4 to the Trade and Industry Code (Assemblee Nationale, 2017) and in Australia through the 2018 Modern Slavery Act (Australian Government Department of Home Affairs, 2018). Australia's Modern Slavery Act is of relevance to trafficking prevention work in New Zealand as it will affect New Zealand businesses which are registered in Australia and New Zealand based businesses that are a part of the supply chain used by large Australian businesses (Pointon, 2020). At the time of this research the Act had not come into force and so its impact was not yet visible. The Act requires large businesses to take a role in anti-trafficking work through ethical sourcing and creating supply chain transparency by disclosing work practices within their organisation and supply chain (Australian Government, 2018). Under the Act it is estimated that around 500 New Zealand businesses will be required to publicly disclose a set of labour practices which relate to modern slavery (Swan and Wheeler, 2020). 
The modern slavery approach compounds many different forms of exploitative labour under the heading of 'slavery', so it is difficult to determine what slavery is and how it differs from poor working conditions which may occur in legal forms of labour (Segrave et al., 2018; O'Connell Davidson, 2006). Anti-slavery advocates use a lack of 'freedom' as the basis of their definition. For example, the UK Anti-Slavery Commissioner in defining slavery states stated that "Whilst they are exploited and abused in many different ways, all victims share one defining experience - a loss of freedom" (Independent Anti-Slavery Commissioner, 2015, p. 1). The use of 'freedom' is problematic as it is a nebulous term and different groups will have different interpretations of the extent of freedom that can be expected in employment. By calling a range of exploitative practices slavery, it evokes harsh criminal punishments based on the precedence set by slavery in international law (Chuang, 2014) as well as the historical and moral associations (Segrave et al., 2018; O'Connell Davidson, 2017).

Other criticisms of the slavery approach are that it focuses on individual victims and offenders - the first in need of rescue, and then second, punishment - as opposed to addressing the overall neoliberal capitalist system that facilitates exploitative labour (Kempadoo, 2015; Chuang, 2014). The rise of neoliberal policies in state governments around the world as well as increasingly globalised labour markets are drivers of both exploitative work practices and of migration. Demand for cheap labour causes migration as it displaces people through limiting opportunities in some countries and increasing them in others (Chang and Kim, 2007). Where this increased movement takes place, so do illegal and unprotected forms of migration such as trafficking (Mahdavi and Sargent, 2011). Increased migration for work tends to be misaligned with states' immigration policies. This creates a gap between demand for cheap goods and services and the legal channels for incomers to provide them which, in turn, encourages non-legal and unsafe migration (Sanghera, 2005).

By presenting exploitation as slavery it is shown as abhorrent and abnormal, and as something that stands apart from systems which provide cheap goods and services such as global supply chains and labour markets, and local industry sectors and employment structures. This individual focus takes trafficking out of the context in which it occurs and means that a range of structural factors causing or facilitating trafficking are not addressed (Kempadoo, 2017; Okyere, 2017). For example, programmes that focus on eliminating slavery in corporate supply chains position corporations as either doing good or as having the potential to do good (O'Brien, 2018a). They overlook a range of questions about the ethics of outsourcing production to countries where wages and overheads are lower in order to make greater profits for business owners. 
Kempadoo (2015) discusses how an individual-focused criminal response that results from a trafficking as slavery approach maintains the systems that hold up global capitalism by focusing on criminalising of individuals. The individuals who violate the state's methods of governing a capitalist society (e.g. labour laws) are positioned as offenders, and the state institutions that respond are positioned as the protectors. The greater system remains untouched as the methods of governing a capitalist and neoliberal state are separated from the 'offenders' and preserved. This can be seen in the focus and blame given to offenders under the UK Modern Slavery Act. In introducing the Act to Parliament, MP James Brokenshire states its aim to "send the strongest possible message to criminals that if you are involved in this disgusting trade in human beings, you will be arrested, you will be prosecuted and you will be locked up." (UK Home Office, 2013).

The trafficking as slavery approach has also been criticised as it draws on moral discourses of good and evil where Western countries are positioned as civilised, and must rescue the non-Western victims from uncivilised or evil slavers (Kempadoo, 2015; Chuang, 2014; Agustin, 2012). Kamala Kempadoo (2015) applies these critiques to both the trafficking as slavery and trafficking as prostitution positions, and argues that these approaches are damaging as they distract from structural factors and preserve and perpetuate the underlying drivers of trafficking. She discusses how the both approaches rely on white supremacy (defined as an ideology that is a combination of racism and neoliberalism which protects the developed world at expense of rest), where the global north has the right and ability to intervene and rescue victims. They embed the distinction between the civilised and uncivilised, upholding the Western interveners as saviours and as morally superior rather than looking at the causes and exploiters of global inequality (Andrijasevic and Mai, 2016; Cojocaru, 2016; Kempadoo, 2015; Agustin, 2012). This idea is tied to white supremacy and postcolonialism where the post-colonial identity of the western saviour is used to separate the 'us' from the 'them' (Kapur, 2005, 2010; Sharp, 2009, p. 106).

Scholars and advocates have also criticised the use of language about slavery for misappropriating imagery of the transatlantic slave trade and using it to further certain political agendas. The use is seen as a misappropriation as human trafficking and the transatlantic slave trade are very different as trafficking involves choice and voluntary movement whereas the slave trade did not (Kempadoo, 2017; Maher, 2017; O'Connell Davidson, 2017). Slavery based campaigns evoke dramatic images of an extreme form of slavery where choice is not present. This is criticised for discounting migrants' agency and the normality of migrating in countries that have a long history of people moving away for work, including through non-legal channels (Maher, 2017). 
The use of the transatlantic slave trade imagery has also been criticised by academics for not engaging with slavery history in a meaningful way and using it superficially to attract attention to another cause (Kempadoo, 2017; O'Connell Davidson, 2017). Anti-slavery campaigns use slavery imagery to portray trafficking as an extreme and horrific form of crime, from which systems of capitalism and neoliberalism are separate, and where Anglo-countries take a protector role. Critics have argued that a more appropriate way of drawing on transatlantic-slavery would be to address inequality and prejudice within western Anglo-countries (O'Connell Davidson, 2017). For example, Beutin (2017) discusses how attracting attention to campaigns such as Black Lives Matter in the US, which is about race relations and inequality, would be a more relevant, appropriate and historically accurate use of transatlantic slave trade imagery.

Janie Chuang (2014) notes that there is some promise in using slavery discourse. In the US it has resulted in bringing a greater labour perspective to anti-trafficking work, where previously the focus had been on sexual exploitation and criminal sanctions. The slavery approach broadens the focus of trafficking to include labour violations outside of prostitution and to include responses that focus on regulating labour and migration conditions in the receiving country which allow exploitation to occur. However, she notes that the modern day slavery approach is at a cross roads and has the potential to go down the more harmful individualising, criminalising and moral path, or the less harmful path of strengthening local labour conditions and migration frameworks.

\subsection{Human trafficking as a security threat}

Alongside the two positions already discussed, human trafficking has also been approached and responded to as a security threat caused by irregular migration, often linked to transnational organised crime. This is shown, or perhaps led, through the 2000 UN Protocol to Prevent, Supress and Punish Trafficking in Persons, Especially Women and Children (Trafficking Protocol) which sits under the UN Convention Against Transnational Organised Crime (UNTOC). The Trafficking Protocol was designed to define human trafficking as a crime type (Chew, 2006, p. 74). It sits alongside the protocols on smuggling migrants and arms trafficking and is implemented through the UNODC, situating trafficking alongside issues of organised crime and irregular migration. This positioning has encouraged the trafficking as a security threat approach with signatory governments (Dottridge, 2007; Kempadoo, 2005). The policies stemming from this approach are measures to prevent migration in source countries, tighten border security, and repatriate victims, and heavy surveillance and harsh criminal sentences for those carrying out the trafficking in receiving countries. This 
approach tends to emphasise trafficking as being carried out by organised criminal networks as sophisticated and profit driven groups (Maher, 2017).

Positions that do not distinguish between trafficking and migration present trafficking as a threat to state security and have the resulting actions of tightening border control and attempting to limit migration (Sanghera, 2005). This response is more likely to increase human trafficking than to prevent it (Anderson and O'Connell Davidson, 2002). Attempts to prevent or control migration mean that there are fewer legal options available to people seeking to migrate. The factors driving migration remain the same, such as limited opportunities in the home country and demand for work in destination country, and so unregulated forms of migration emerge (Meyer and Boll, 2018). These illegal or 'irregular' forms are more open to exploitation as migrants do not have legal rights (Ahmed, 2005). Lack of legal rights to move across borders creates a precarious situation for groups who already have limited work opportunities available to them (Pickering and Weber, 2006; Sanghera, 2005, p. 8). Those who are already in limited or vulnerable situations have their movements constricted and are policed and punished through anti-trafficking interventions (including repatriation or institutionalisation) (Anderson and O'Connell Davidson, 2003; Ahmed, 2005). In this way 'human trafficking' can be seen as the outcome of an international legal system that has not caught up with globalised labour flows (Sanghera, 2005).

Equating trafficking to a migration security threat is built on an understanding of trafficking as a 'foreign' problem. In this approach, the causes of trafficking are situated outside of the receiving country. These causes can be 'push' factors driving trafficking such as war, conflict and extreme poverty in sending countries which creates vulnerable populations (O'Brien, 2016). In this version of trafficking the source of the problem is also externalised through defining trafficking as being carried out by transnational criminal groups. In this way trafficking is presented as a foreign threat to national security. These portrayals have been directly used in populist political and media rhetoric, harnessing and inflaming public anti-migration sentiment and xenophobia (Vicol and William, 2014; Fox et al., 2012; Kapur, 2005).

Human trafficking as a foreign organised crime threat is a convenient political position as it individualises the problem, highlighting it as a form of 'bad' migration carried out by criminal groups, rather than addressing the local and global driving factors or focusing on strengthening local labour frameworks (George et al., 2017; Dottridge, 2007). Trafficking is presented as an exception to rather than as a consequence of a globalised neoliberal market. Treating human trafficking as a crime carried out by foreign criminal groups maintains both the systems of governing a capitalist state (governance and enforcement institutions) and ignores the role of legitimate, legal bodies that 
benefit from the supply of cheap labour (Szörényi, 2016; Kempadoo, 2015). It also allows governments and policing bodies to carry out migration control agendas whilst positioning themselves as rescuers and protectors of vulnerable groups against serious criminals (Hill, 2016; Segrave et al., 2009; O'Connell Davidson, 2006). The ideology behind this approach is one of blaming developing countries for poverty and crime, tied to white supremacy and colonialism, with the desired result of "keeping the 'Rest' away from the 'West'" (Kapur, 2005, p. 25).

\subsection{Human trafficking as a human rights issue}

A human rights based approach focuses on promoting and protecting individual human rights of people during trafficking and ensuring states' responses comply with international human rights law (Haddadin and Klímová-Alexander, 2013). This means putting the trafficked person's rights at the centre of the response and tailoring responses to individual victim's needs (GAATW, 2007, p. 7). This approach partly grew out of attempts to prevent the harmful practices carried out in response to human trafficking such as institutionalising and repatriating victims. These harmful policies are tied to the earlier conceptions of trafficking as prostitution and trafficking as a security threat and so this approach to trafficking can be seen as a reaction to these earlier approaches.

Human rights based interventions are designed to protect or minimise harm to the trafficked person. This approach is partially included in the Trafficking Protocol as it stipulates victim protection measures. However, unlike law enforcement measures they are not obligatory for signatories (Gallagher and Karlebach, 2011; GAATW, 2007, p. 5). UN agencies and other international groups and NGOs have developed guidelines for applying a human rights based approach to make up for the lack of emphasis in the Protocol (see for example The Bali Process, 2016; OHCHR, 2002).

A human rights based or victim centred approach is nominally used by many governments. However these forms of 'human rights' approaches have been criticised in many jurisdictions for being ostensibly used as a guise for criminal policies (Andrijasevic and Mai, 2016; GAATW, 2007; Kempadoo, 2005). For example, in many states temporary visas are granted to support victims of trafficking by allowing them to stay in the country. Although intended in part to support victims, these visas serve criminal justice responses by allowing victims to remain in the country long enough to act as witnesses in trafficking prosecutions. In these cases, 'victims' are dependent on police classifying them as trafficking victims and so visas and other services are granted with conditions that they cooperate with police and, in some cases, victim status is only granted when a prosecution is successful (Dottridge, 2007; Pearson, 2007). 
There is a movement that advocates for a human rights based approach that includes GAATW, NGOs, academics, and international bodies such as IOM, WHO, OHCHR, and most recently, is laid out in the intergovernmentally negotiated and agreed 2018 Global Compact for Migration (Kaye et al., 2019; IOM, 2018; GAATW, 2007, 2014; Gallagher and Karlebach, 2011). This approach focuses on the rights of migrants to move and work safely and emphasises the need to recognise and challenge global factors driving exploitation. This approach is not widely put into practice to the same extent as the trafficking as prostitution and trafficking as a security threat approaches. For states that have made a commitment to such an approach through statements such as signing the 2018 Global Compact for Migration, a human rights approach is often is at odds with states' immigration policies (Milivojevic et al., 2017).

This movement pushes for legitimising migration and monitoring and regulating labour conditions. This includes allowing for safe migration through a controlled and monitored liberal migration regime and focusing on receiving country labour conditions rather than movement across borders. This means building protections for migrant workers into local labour laws about work conditions, ensuring monitoring and enforcement bodies are in place, and encouraging more of an advocacy role from trade unions (Dottridge, 2007; Chew, 2005, p. 77; Marshall and Thantun, 2005; Sanghera, 2005).

A criticism of the human rights based approach is that it draws on the ideas of a "supposedly unified 'humanity' and individual victims to be cared for" (Andrijasevic and Mai, 2016, p. 2), and in this way is paternalistic and authorises the "West" to rescue the "Rest" (Kapur, 2005, p. 25). Positioning Western states as rescuers then exacerbates migrants' dependence and consequent vulnerability (Anderson et al., 2009). It also portrays trafficking and exploitation as an aberration to migrant working conditions rather than as a consequence of free-market and neoliberal policies (Andrijasevic and Mai, 2016). Scholars, activists and international governance actors who are aware of these criticisms respond by stressing the need to consider and address wider global structural factors driving exploitation in migration. These include factors driving the demand for cheap labour and the supply of migrants looking to better their position on the labour scale, factors in countries of origin that drive people to migrate, and receiving country factors that make is possible for exploitive work situations to occur (Milivojevic et al., 2017; Hoefinger, 2016; Kempadoo, 2015; Sanders, 2008; Anderson and O'Connell Davidson, 2003; Kelly and Regan, 2000).

A more radical solution proposed is to disestablish all borders and work on a basis of 'commons rights', including the right to movement (Anderson et al., 2009). Anderson and colleagues (2009) criticise the human rights based approach for not challenging the right of sovereign states to control, 
criminalise, and grant rights for migrants. In this argument, restricting movement serves global capitalism and the system of sovereign states as it provides cheap labour through creating a controllable workforce through criminalising migrant workers or granting them subordinate working status (e.g. temporary visas or visas that tie the employee to one employer). States thus benefit from the cheap labour that is created through neoliberalism, globalisation, and sovereign state control (Mahdavi and Sargent, 2011).

Sharma (2017) challenges the 'logic of constraint' where states regulate human mobility through immigration controls. She analyses $19^{\text {th }}$ century colonial migration law and shows how regulating migration was used as a method to create a cheap and controllable labour force, but a labour force that was essentially considered as 'free'. This 'free' labour force filled a gap left by the abolition of the transatlantic slave trade. These forms of 'free' yet controlled migrant labour included the 'coolies' indenture system and other migration schemes to the British Colonies. Sharma identifies this as the route of current migration policy and argues that states have a role and agenda in generating cheap labour. By approaching human trafficking as a human rights issue, state governments are positioned as the protectors and their role in creating such labour situations is neglected. She argues that a more appropriate response is to lessen controls on movement.

\subsection{Human trafficking as a breach of labour law}

This approach focuses on labour conditions in receiving countries rather than movement across borders. This means building protections for migrant workers into local labour laws about work conditions, ensuring monitoring and enforcement bodies are in place, and encouraging more of an advocacy role from trade unions (Segrave et al., 2015; Dottridge, 2007; Chew, 2005, p. 77; Marshall and Thantun, 2005; Sanghera, 2005). This approach uses other tools alongside trafficking law, such as labour laws and regulations.

This approach is rarely put into practice but is proposed as a solution to the issues raised with the trafficking as prostitution, trafficking as modern day slavery, and trafficking as a security threat approaches discussed above. It avoids a sole focus on prostitution, moral campaigns about sex work and the foreign other, and Western exceptionalism from the trafficking problem. Using a forced labour framework has the potential to lift labour standards for all workers as opposed to the established trafficking responses, which have a focus on extreme forms of victimisation occurring for migrant workers (Segrave et al., 2015). This approach promotes unionisation, employer responsibility, and improved working conditions and wages. As Chuang notes in her analysis (2014), there is potential for a labour approach to sit alongside anti-slavery language. As anti-slavery 
language becomes popular, there may be an increasing focus on labour regulations as when trafficking is conceptualised as modern day slavery it includes forced labour. However, this depends on the modern slavery movement relinquishing its focus on individuals and its use of moral language which drives a focus on criminal punishment for individual traffickers.

An issue with conceptualising trafficking as labour exploitation is the difficulty of defining what counts as exploitation in the workplace as opposed to difficult or unfair labour conditions which may be legal or socially accepted (Wylie, 2016, p. 135; van den Anker and van Liempt, 2012; Coghlan and Wylie, 2011). This is an issue for both agencies who are responsible for policing labour exploitation and workers who may have different ideas of what are acceptable and unacceptable labour standards. These difficulties have lead researchers to question the use of trafficking law as a way of responding to labour exploitation and its ability to capture complex problems about migration and labour (Wylie, 2016, p. 135). International definitions about human trafficking and law have grown out of an idea of trafficking as a severe crime which is morally abhorrent. Sophisticated organised criminal groups are often cast as the perpetrators and innocent, non-consenting victims are cast as those who are effected. The results are harsh criminal penalties. Fitting such definitions and law to the range of complex range of situations that can happen when people, often migrants, are exploited for labour proves difficult.

\subsection{Conclusion}

This summary of literature shows the different ways a social issue, as defined by international bodies such as the UN, can be defined and applied, and the political, economic, and moral agendas that come into play. This literature review demonstrates the problems with different approaches used and shows some harmful outcomes that have been delivered through anti-trafficking work. In summarising these critiques, I aim to highlight the importance of studying the way the problem of human trafficking is constructed and show how legal, policy, advocacy, and academic actors are still struggling to find a less harmful way of responding to complex issues that go along with migration. Through this literature review I have shown my commitment to investigating how trafficking is conceptualised, with the aim of challenging constructions and their outcomes and identifying new or less harmful approaches. In the next chapter, I summarise the different types of research that have been carried out about human trafficking. In doing this I show the different ontological perspectives that have been taken in research in this field and use them to find the most appropriate perspective in which to situate my study. Once I have situated my approach in a certain ontological field, I go on to discuss the theory I used in this research. 


\section{Chapter Three: Research Approach and Theory}

The literature discussed in the previous chapter shows the different ways in which trafficking has been defined, approached, and responded to, and what this had meant for how migrants are treated and how states and systems are positioned. The shifts in approaches over the past 20 years shows how those carrying out anti-trafficking work are searching for ways of responding to complex situations which involve migration, work, and exploitation.

This research studies narratives about human trafficking found in official policy text and interviews with official actors. These narratives are important in making sense of how social problems are constructed. They tell a story about who the deserving victims are, which groups should be subject to crime control policies, and what types of harm are considered acceptable and unacceptable. Narratives can result in different outcomes for the groups they are about such as who receives state support, protection, or citizenship rights, and who is criminalised, imprisoned, or deported (Meyer and Boll, 2018).

The theoretical approach I use in this study is a post-structural version of narrative criminology. In this research I take Lois Presser and Sveinung Sandberg's narrative criminology theory (2015a), and draw on post-structural concepts and narrative policy analysis. In doing this, I create an appropriate framework for a narrative criminology analysis of human trafficking as an internationally constructed crime type.

This approach is based on narrative criminology's premises that narratives are important to study as they are constitutive - all experience is storied; it makes up how we see the world and leads to future action (Presser, 2009). In narrative criminology, narratives can be studied to show what is considered harmful and what is not, what society tolerates, and the 'cultural processes that legitimise or undermine responses against harmful behaviour' (Tognato, 2015, p. 279; Presser and Sandberg, 2014; Presser, 2009). The ultimate aim of narrative criminology is to understand and challenge social narratives that legitimise or facilitate harm, and identify new less problematic narratives (Maruna, 2015).

The post-structural version of narrative criminology used in this thesis treats the narrative itself as the unit of analysis rather than the individual speaker, as narratives are seen as being spoken through individuals rather than by them (Sandberg, 2010; Foucault, 1970a). This also involves using multiple data sources such as interviews and document analysis, as narratives can be seen as being conveyed through multiple sources, rather than being tied to individuals, organisations or certain reports. This means treating narratives as multiple which can be repeated, conjoined, and 
conflicting. The subject positions that are available in narratives and how these constrain and enable action become important (Davies and Harré, 1990). Also important is attention to exclusions, what is it possible to say, and what is left out of a narrative. This post-structural version also requires paying attention to how meaning is constructed and how topics are narrated rather than what is narrated or the content of the stories (Juntrasook et al., 2013; Smith and Sparkes, 2006). The aim of this approach is to not to determine facts about trafficking or to measure the accuracy of narratives but rather to understand how narratives work and what their consequences can be for those involved and the ongoing shaping of anti-trafficking policy.

I also draw on narrative policy analysis literature to define what is counted as a narrative. The main idea I draw from this body of literature is that the definition of policy problems can be treated as a narrative and these narratives are important in making sense of how social problems are constructed (Fischer, 2003; Stone, 2002; Hajer, 1995; Roe, 1994). Treating policy texts as narratives aligns with a post-structural approach to narrative criminology as the stories themselves are the focus rather than the speaker, thus making policy documents, language, and work stories important sources of narrative.

This chapter shows the process followed in determining which research approach and theory to use in the study. It starts with a summary of the different philosophical and epistemological approaches which anti-trafficking research is based on. From this summary, I show my decision to ground this research in a social constructionist approach. Following from this, narrative criminology is presented as an appropriate theoretical starting point, with the use of post-structural concepts and policy analysis theory to create an appropriate framework for a narrative criminology analysis which is suited to the study of international crime types. This chapter ends with a discussion of a small but growing body of literature which examines narratives of human trafficking. From this discussion I demonstrate how this thesis builds on this tradition.

\subsection{How human trafficking has been researched, and deciding on a research approach}

After having defined the problem this project seeks to address, the next step was to review the types of research that had been carried out about human trafficking in order to gain a picture of the major different philosophical approaches taken in this field. This review formed the basis for deciding which ontological approach I would take and the most appropriate theoretical and methodological frameworks to use. 
The literature presented in the literature review showed how the different ways the trafficking problem has been approached has led to different ways of responding to the issue. Through this review I had already defined my ontological position to some extent as the review shows the trafficking problem as something whose definition has changed over time and as something that needs critical reflection, rather than being an absolute or positivist phenomenon to be studied and understood. The next step for me was to review how trafficking has been researched by others and what ontological position would be useful in progressing the debates about how trafficking is approached and responded to.

Being clear on the position of this research was also important as trafficking research, as with trafficking advocacy and politics, is a messy field. As put by Jyoti Sanghera, advisor on trafficking to the UN OHCHR:

"It is no secret that the anti-trafficking arena is a beleaguered one. It has been made murkier by the melding together of complicated categories, constructs, and players. Issues of migration, trafficking, and sex work are peppered with constructs of sexuality, gender, and vulnerability, threaded through with categories of victim and agent, consent and coercion, and stirred together in a cauldron by cooks, who are far too many in number, much too disparate in their culinary skills, and have at their disposal a budget which is far too lavish for a mere broth. These 'too many cooks' have not only managed to spoil the broth, but some of them have also ended up bonking each other with their spatulas." (Sanghera, 2005, p. 3)

As well as helping me to navigate a murky field, being clear on an ontological approach is a way of acknowledging the type of knowledge that is being produced in this research.

Through this review I grouped human trafficking research into three main streams which I have named 'positivist', 'critical' and 'social constructionist'. These three streams are described below and in Table 4 in Appendix A.

Positivist research on human trafficking treats trafficking as an objective phenomenon that is occurring and seeks to understand the size and the nature of the problem. The critical research aims to critique the way trafficking is approached and responded to in government programmes, advocacy campaigns, and media representations. These critiques tend to focus on assessing how closely responses or representations of trafficking align with victims' experiences. The social constructionist stream of research treats trafficking as a crime type that is constructed based on power, with multiple constructions, and differing perspectives held by different groups. The aim of this approach is to identify problematic processes, inequalities, exclusions, and new ways of thinking 
about the problem. This social constructionist philosophy is the starting point that I chose to adopt in this thesis.

The following subsections summarise the three ontological approaches I identified trafficking research being based on.

\subsubsection{Positivist}

Positivist research on human trafficking treats trafficking as an objective phenomenon that is occurring, and seeks to understand the size and the nature of the problem. It uses largely quantitative methods to scope the size of the problem through using data on the detection and prosecution of trafficking cases. This type of research is often carried out by advocacy groups or journalists as well as academics. For example, the advocacy organisation the Walk Free Foundation carries out the Global Slavery Index (The Global Slavery Index, 2018) which estimates the number of people worldwide in slavery. Qualitative research has also been carried out in this line to show victims' experiences of trafficking. For example, the qualitative investigations of Siddarth Kara are used to show the horrific experiences of victims of sex trafficking (Kara, 2009).

Results from positivist studies largely infer that human trafficking is a huge global issue which is constantly growing in scale with horrific social harm (see for example Walk Free Foundation, 2018; Kara, 2009). These claims have been criticised for having little evidentiary basis and the positivist stream of research has been criticised for methodological failings and in some cases bias (Weitzer, 2005, 2007, 2014, 2014; Kelly, 2005; Laczko and Gozdziak, 2005; Tyldum and Brunovskis, 2005). It is difficult to quantify trafficking as situations which could be considered as trafficking tend to be hidden and it is likely that only a small proportion of these are recorded through official channels. The changing definitions of trafficking both over time and between countries means that data collected from different areas or over time may not be comparable (Kangaspunta, 2007). Even when the same legal definitions are used, different results can be gained through differing applications of the definition (Dempsey, 2017; Weitzer, 2014).

In terms of bias, critics of the positivist approach have argued that studies which seek to raise awareness of the harms of trafficking have a self-fulfilling aspect as research methods involve seeking out certain situations or forms of harm such as women in forced prostitution (Weitzer, 2014). Much of the trafficking research which takes a positivist approach has the abolitionist perspective on prostitution as its ideological underpinning. A key characteristic of abolitionist antiprostitution discourse more broadly is the positivist notions of 'hard facts' and 'truths' which are 
used to demonstrate the size and severity of the harms of the sex industry (Khan, 2015, p. 193). The anti-prostitution basis of many positivist studies has meant that they focus on the sex industry and treat people working in the sex industry as forced and trafficked, while neglecting conflicting experiences (see for example Roguski, 2013; Lebov, 2010).

Despite problems with the evidence, these positivist findings are frequently used by state governments, official institutions addressing trafficking, NGOs and political actors (Russell, 2018; Wylie, 2016; Weitzer, 2014; Doezema, 2010). For example Doezema attempted to track the source of a figure that was being repeated in anti-trafficking reports from IOM and media reporting that the number of women and girls trafficking into the Western European sex industry was ' 500,000 annually' (Doezema, 2010, p. 5). However, the source of the figure remained evasive and Doezema was not able to find the source of the figure through the IOM as the organisation which was quoting it.

Owing to these critiques which highlight significant problems associated with a positivist approach to studying trafficking, I chose not to adopt it. The quantitative macro level claims as well as some of the positivist qualitative investigations tend to propagate a certain picture of trafficking, without reflecting on the methodological issues or moral or political assumptions underlying the common propositions of trafficking - that it is a large and threatening global issue, carried out on certain groups by immoral actors. These political and moral propositions or agendas are important to consider as they have been a part of how the trafficking problem has evolved over the last 20 years and determine how it is addressed.

\subsubsection{Critical}

Sitting alongside positivist research, there is a growing body of research that critiques human trafficking portrayals, law, and policing, emphasising victims' voices to do so. The critical voice from this stream has been central in identifying and addressing some of the harmful impacts of antitrafficking initiatives (the most significant example being the GAATW Collateral Damage project, which led to a greater push for a human rights approach by the UN; GAATW, 2007). This approach includes much of the literature discussed in the literature review and has been critical of approaches where trafficking is treated as a problem of prostitution, a threat to be dealt with through tighter border security, and most recently, a growing body of literature critiquing the modern day slavery approach. 
I call this approach 'critical' rather than 'social constructionist' as it views trafficking as a socially constructed crime type but often falls in to what Woolgar and Pawluch name 'ontological gerrymandering' $(1985$, p. 217) where certain versions of the socially constructed phenomenon are treated as more 'real' than others. While part of the phenomenon studied is seen as socially constructed - the official or dominant framing of trafficking, there is part that tends to be treated as essentially 'real' - the NGO or victim experience.

One part of this body of research is designed for practical application and comes up with recommendations for policy makers and operational actors, such as, research by GAATW and Anne Gallagher (for example GAATW, 2016 and Gallagher, 2016). The more critical pieces tend to conclude that wide social change is needed. Examples are the idea of a world without borders (King, 2016; Anderson et al., 2009) or the need to remove white imperialism and western exceptionalism from trafficking approaches (Kempadoo, 2015). While these critical analyses are valuable and have brought about change, there is sometimes a gap between the aims of the critiques and how they can be practically applied. The last stream of research - social constructionist, offers a more tangible means of bringing about change.

\subsubsection{Social constructionist}

There is a very small number of studies about human trafficking which take a dedicated social constructionist approach. These few studies are based on the idea that there are multiple conceptualisations or 'truths' about human trafficking. The aim of this stream of research is to identify and challenge these constructions, and their underlying discourses and power relations and to identify problematic processes, inequalities and exclusions. By looking at multiple constructions, the aim is to identify new and less problematic ways of thinking about trafficking and to identify the processes through which systems of meaning are propagated, transferred, and translated into practice.

Jo Doezema (2010) provides the most detailed example of this approach. She uses the idea of myths and ideology to show how the myth of white slavery was translated into trafficking law throughout the 2000 Trafficking Protocol deliberations. In her study the concept of trafficking is constructed based on ideas of consent and deserving victims as 'defiled innocents'. These ideas are a repetition of the myth of white slavery which is about women in prostitution. Other examples include Edward Snajdr (2013) who shows how an international master narrative of trafficking is retold and reproduced through media and the US DoS Trafficking in Persons (TIP) reporting. This is achieved by using certain techniques including the use of maps and figures to convey authority and reason and 
the selective exclusion of victim stories which do not align with the master narrative. Carol Vance's analysis (2011a, p. 936) shows how melodrama as a narrative form and the repetition of an unsubstantiated trafficking statistic work to show trafficking as a serious threat and as an individual issue, from which the role of the state and other structural factors are obscured.

Although it may sound counterintuitive to associate social constructionist approaches with practical solutions, I found this small grouping of studies to provide more guidance for how to move forward in the contested field of trafficking, as they draw attention to important processes for conveying meaning and identifying new ways of thinking about migration harms. This approach allows for a focus on how trafficking is constructed and how constructions are propagated, as well as identifying alternative constructions. For example, the methods of construction in Doezema's (2010) work were the interactions at meetings during the Trafficking Protocol deliberations, including presences and absences (namely the overt absence of sex workers) and the inclusions and exclusions in documentary text. For Snjar (2013) they included the use of maps and figures, and for Vance (2011a) they were the use of melodrama and unsubstantiated statistics.

I chose to situate my research in this ontological perspective as it allows for the multiple framings of trafficking to be studied, along with the processes that are used to construct each system of meaning, and to identify alternative constructions.

\subsection{Theoretical approach}

Literature about the construction of social problems offers many different theories that could be used to examine the construction of human trafficking. During the early stages of this project, within the field of criminology, narrative analysis was undergoing a 'reinvention'. Using narrative theory and methods seemed well suited to the construction of trafficking. Previous research has highlighted the use of narrative tropes in trafficking representations such as naïve victims and cruel villains, and heroic protectors, as well as dramatic imagery around modern slavery, sex slaves, kidnapping, and the importance of morality as actors are cast as good and evil (Stiles, 2018; Cojocaru, 2016; Hoefinger, 2016; Mai, 2016; O’Brien, 2016; Haynes, 2014; Warren, 2012; O'Connell Davidson, 2010; Andrijasevic, 2007).

Further to this, I considered narrative theory to be appropriate as media reports and political speech internationally about migration show much variation in narratives used and seem liable to undergoing vast swings. These narratives range from presenting migration as a threat to presenting 
migration as economic growth, and migrants are presented as characters ranging from vulnerable victims, to economic entrepreneurs, to terrorists or criminals (Scuzzarello, 2015; Skilling, 2012).

A further reason for choosing this theoretical approach is that although narrative analysis is a wellestablished form of analysis in many fields, it has not been used in criminology as extensively. I saw this as an opportunity to investigate this 'reinvented' theory and set of methods for analysis and in trialling this approach, to contribute to the development of narrative criminology and its range of applications.

\subsubsection{Narrative Criminology}

In this research I use narrative criminology as a theoretical and methodological approach, and draw on post-structural concepts in the narrative methodology and analysis. Narrative criminology is a 'reinvention' of narrative theory and analysis specifically for criminology (Presser, 2009). The main proposition of this reinvention is that narratives are important to study in criminology as they are constitutive - all experience is storied, it makes up how we see the world, and leads to future action (Presser, 2009).

Narrative analysis and the idea that stories shape action has been around for a long time in the social sciences and used across disciplines (Presser and Sandberg, 2014). Although narratives have been studied in criminology previously (see Sandberg and Ugelvik, 2016 for a list of studies, p. 130; and Presser, 2009, pp. 180-184), Lois Presser and Sveinung Sandberg, who are the main proponents of this approach, argue that the way they have been used is limited (2014, p. 7).

Lois Presser (2009) argues that in criminology, narrative has been treated as a record of an individual's behaviour and experience and used to provide additional information about crime (e.g. to show what events in people's lives influence their behaviour, leading to crime), or as interpretive in which narratives are used to explain criminogenic perceptions of the world which lead to crime. Presser (2009) argues that in criminology there has been little use of narrative as constitutive. The main difference from the previous uses is that, in this form, narrative cannot be divided from reality or experience - narratives make up our reality and determine action. The reinvention of narrative theory and analysis for criminology makes this explicit.

Narrative criminology involves studying harm rather than crime. It involves the study of how narratives are used to legitimise certain types of harm and criminalise others (Tognato, 2015; Presser and Sandberg, 2014; Presser, 2009). Narratives can show what is considered harmful and what is not, what society tolerates, and the 'cultural processes that legitimise or undermine 
responses against harmful behaviour' (Tognato, 2015, p. 279). This is important for understanding the treatment of people who move across borders, as currently they are positioned within conflicting narratives of illegal immigrants, victims of trafficking and exploitation, and a necessary labour force. The ultimate aim of this approach is to understand and challenge social narratives that legitimise or facilitate harm and identify new less problematic narratives (Maruna, 2015).

Narrative criminology also provides a way of understanding both the role of social, cultural, political influences, and individuals' agency as producers of crime, without over-reliance on either (Aspden and Hayward, 2015, p. 430). Existing narratives enable certain actions and constrain others, but are not all controlling as narratives can be altered, merged, and drawn on in new ways to understand or construct a problem. This addresses criticisms that criminology has gone too far in either direction with too much use of rational-choice theories or too much emphasis on socialisation theories - as Maruna and Matravers comment "Gone are the complexities, the conflicts, the contradictions, the insecurities and confusions that all of us struggle with as vulnerable sensitive, emotional beings, replaced by a sort of 'stick figure' of the over-socialised individual or the rational actor" (2007, as cited in Aspden and Hayward, 2015, p. 430).

Reflexivity is an important part of narrative criminology - stories are co-constructed through the research process so it is important to reflect on the research approach used, the role of the researchers, and the physical settings for the research. This reflexivity is a useful part of this approach as it helps researchers to reflect on what kind of knowledge is being produced through the research project (for example, is the research reproducing knowledge privileged by the global north). Reflexivity also attends to the role of institutions creating, reproducing, and making available certain narratives, an important factor for criminology as it often involves studying the institutions that are involved in managing deviant behaviour.

Although narrative criminology can be considered as a theory to guide research practice, there are a range of philosophical stances which can be taken while using this theory (Aspden and Hayward, 2015, p. 239). It is important to state what stance is taken as it will affect what is considered a narrative and the type of findings produced (Sandberg, 2013; Kohler Riessman, 2008).

Sandburg (2013) shows theoretical approaches on a continuum based on the importance given to agency or structure and the type of narratives favoured under each approach. Perspectives that emphasise individuals' agency focus on a unified narrative of self. This means seeking out stories about the self, constructed by individuals as a way of understanding their life. Individuals are motivated to produce a coherent and consistent story, and this story is the focus of the narrative analysis as it tells you how individuals understand their experiences and how they are likely to act in 
the future. This approach is based on narrative psychology with narrative criminologists tending to rely on the work of Dan McAdams (for example McAdams, 1999). On the other end of the continuum, theoretical perspectives that emphasise structure focus on multiple, diverse, conflicting, and fragmented narratives which are present in society and can be drawn on and expressed by individuals (Sandberg, 2013). The focus is on the stories that are present in society as opposed to the individual speaker and their role in constructing a narrative about their life. In this structural approach, while individuals exercise agency in drawing on existing narratives, they are limited to the range of narratives that are available within certain settings (Brookman, 2015; Sandberg, 2009).

The problem with the unified narrative/agency theoretical position is that it lends itself to individual cognitive interventions that focus on changing individuals' narratives rather than addressing harmful social narratives more widely (Fleetwood, 2016). Fleetwood (2016) points out the potential harms of this approach - being that existing narratives people hold and abide by may be replaced with an equally harmful narrative which comes along with its own set of power dimensions. She uses the example of interventions which try to re-socialise women by encouraging them to adopt narratives of what it is to be a woman which are based on commonly held ideas of gender appropriate roles. A post-structural approach avoids these issues by treating the narrative itself as the unit of analysis rather than the individual (Sandberg, 2010, p. 458). Rather than aiming to change individuals' thoughts and behaviours, it aims to challenge societal narratives which can facilitate harmful practices, and to identify those which are less harmful (Tognato, 2015; Jackson, 1998; Plummer, 1995).

In this post-structural version of narrative criminology a Foucauldian perspective on discourse is important as narratives are seen as embedded in, and working to, sustain and enact discourses (Sandberg, 2010, p. 454). Discourses are seen as being a set of power relationships which construct subjects' positions and objects, constitute meaning, and allow certain things to be known (Foucault, 1980). Discourses construct 'truths' (Foucault, 1980, p. 137) which are multiple. Discourses are unavoidable as they constitute the meanings or 'truths' that are available and govern systems of meaning. They are however, not all controlling. They can be selectively 'taken up' and enacted by individuals through taking different subject positions as ascribed by the discourse. Discourses can also be disrupted. In his 1970 inaugural lecture at the College du France Foucault (1970b) emphasises the need to pay attention to what is left out of a discourse and by doing this, seek ways of disrupting the discursive processes. By paying attention to exclusions, other 'truths' become visible or come to the fore. In considering discourses the focus is on the processes and systems through which meaning is conveyed. This is an attention to how meaning is constructed and conveyed rather than what the meaning is. 
This theoretical perspective translates into a post-structural version of narrative criminology through treating the narrative itself as the unit of analysis rather than the individual speaker, as narratives are seen as being spoken through individuals rather by them (Sandberg, 2010; Foucault, 1970a). This also involves using multiple data sources such as interviews and official documents as narratives can be seen as being conveyed through multiple sources, rather than being tied to individuals, organisations or certain reports. This means treating narratives as multiple which can be repeated, conjoined, and conflicting. It also means studying the subject positions that are available in narratives and how these constrain and enable action (Davies and Harré, 1990). A post-structural version of narrative criminology also requires an attention to exclusions, what is it possible to say and what is left out of a narrative, and through doing this, highlights other ways of thinking about trafficking. Lastly the post-structural concepts are used in this application of narrative criminology through paying attention to how meaning is constructed and how topics are narrated rather than what is narrated or the content of the stories (Juntrasook et al., 2013; Smith and Sparkes, 2006).

\subsubsection{Using narrative criminology to analyse human trafficking as a contested crime type}

While narrative criminology has quite a broad remit, at the time of this research it had been most often used to study stories from individual offenders, namely their life stories or stories of committing a crime. These stories are then used to understand societal influences and encourage desistance.

The review of literature covered in Chapters Two and Three highlighted the problem with both the 'facts' and 'realities' of human trafficking. The 'facts' about trafficking, namely the size, scale and nature of the problem, have been shown to be unreliable, as discussed earlier in this chapter in regard to positivist research (for example see Weitzer, 2005, 2007, 2014, 2014; Kelly, 2005; Laczko and Gozdziak, 2005; Tyldum and Brunovskis, 2005). Critical anti-trafficking literature has also shown the 'realities' of trafficking to be problematic. Studies have shown that being ascribed trafficking victim status often does not align with the experience of those having lived through trafficking and exploitation and that the victim label can in fact have harmful impacts (for example see Guha, 2019; Anderson and Li, 2018; Mahdavi and Sargent, 2011; Segrave et al., 2009; GAATW, 2007). Alongside the problems with trafficking 'facts' and 'realities', defining human trafficking as a global crime type has been a contested process where different political and moral agendas are played out (for example, the Palermo Protocol deliberations discussed in Doezema, 2010).

Given the contested and evolving nature of trafficking definitions, the disputed 'facts', and questionable 'realities', I decided that an important story worth investigating was being told through 
policy language as states and international bodies struggle to define trafficking and how it should be responded to. These policy narratives tell a story about who the deserving victims are, which groups should be the subject of crime control policies, and what types of harm are deemed acceptable or unacceptable. As with offenders' life stories, these policy narratives have temporal and moral aspects, and lead to action, in the form of the state's policies and practices. Furthermore, using narrative criminology to focus on policy narratives as stories is a useful exercise as it provides a means for studying wider discourses of migration control, western exceptionalism, and current anxieties around 'global threats' and 'international security challenges' that are drawn on in constructing human trafficking as a global crime type.

A focus on policy narratives was particularly important in the New Zealand context. As described in Chapter One, at the time of this research the New Zealand Government was designing their antitrafficking policy and responses, and there had only been one case which had been successfully prosecuted using human trafficking legislation. The narratives about the types of harm that are unacceptable, who deserving victims are, and what actions are legitimised, were under construction. These were an important form of narrative to study as such policy stories have significant impacts for those experiencing exploitation.

It is worth noting that while this research treats policy as an important source of stories about the trafficking problem, the experiences of people who have lived through exploitation are another important source of narratives which ideally would be used to compare, contrast, and problematize policy narratives. In particular, personal stories of exploitation are crucial in understanding the effects of being ascribed trafficking victim status. This research sought specifically to understand the narratives of trafficking which are created in defining the problem and which are constituted through the anti-trafficking work, as opposed to the stories of those experiencing exploitation. There were also ethical and practical reasons as to why seeking personal experience type narratives from those experiencing exploitation was not possible in this study. These are discussed in the limitations section of Chapter Four.

While using narrative criminology theory as a basis for this research, I draw on narrative policy analysis literature to define what is counted as a narrative. While there are differing theories about narrative policy analysis (Jones and McBeth, 2010), the field is based on the idea that the definition of policy problems can be treated as a narrative and these narratives are important in making sense of how social problems are constructed (for example see Fischer, 2003; Stone, 2002; Hajer, 1995; Roe, 1994). 
Policy narratives are similar to the definition of narratives employed by narrative criminology. They are seen as being temporal, with a beginning, middle, and end (McBeth et al., 2005; Stone, 2002; Roe, 1994), they involve different characters (McBeth et al., 2005, 2007; Stone, 2002), and usually come to some form of resolution or moral typically in the form of a policy recommendation (Stone, 2002). As with narrative criminology they also have a setting and an audience (McBeth et al., 2005, 2007). In a similar line to narrative criminology, the aim of narrative policy analysis it to find new, different, or revised narratives which provide solutions to complex policy problems (Jones and McBeth, 2010; Bridgman and Barry, 2002; Roe, 1994). Treating policy texts as narratives aligns with a post-structural approach to narrative criminology as the stories themselves are the focus rather than the speaker, thus making policy documents, language, and work stories important sources of narrative, rather than individual offenders' stories.

Narrative criminology's premise that narratives are important because they lead to action, stands true with policy narratives. The way that policy problems are narrated determines how a problem is understood as it shapes the evidence drawn on in understanding the problem, and the proposed solutions - it shapes 'the truth' (Breuil et al., 2011, p. 31), invokes 'knowledge claims' (Boswell et al., 2011), or makes problems 'thinkable and thus governable' (Edwards and Gill, 2002a). It also shapes how a policy problem is responded to. Claims made about a social problem become institutionalised and take effect in policy, practice, and institutions formed (Weitzer, 2007; Spector and Kitsuse, 1973). The way that the populations who are the subject of the policy are constructed in policy language affects the opportunities available for these populations, how they are perceived and treated, their identity, how institutions are formed to regulate them, and the development of further policies (Ingram et al., 2007; Ingram and Schneider, 1991).

Treating policy texts as narratives becomes particularly important for issues involving migration, as policies convey the categories that are used to label and describe different groups. These labels are presented as distinct and have hugely varying outcomes for the groups they are about (Meyer and Boll, 2018). Categories include refugees, economic migrants, smugglers, illegal immigrants, human trafficking victims, and offenders. These categories divide groups into deserving and underserving, they influence how groups are treated by authorities, and they define the hierarchy of support or resources made available to those fitting into the different categories (Elliott, 2018; Erdal and Oeppen, 2018). They can result in a wide range of outcomes from state support, protection, and citizenship rights, to imprisonment or deportation (Meyer and Boll, 2018).

Migration policy texts present these groups as distinct and are underlined by binaries about innocence/complicity and agency/force, yet often fail to capture the complexities of migration and 
the range of situations people find themselves in. Research has shown that for the populations who are the subject of migration policy, their experience does not always fall into such discrete and mutually exclusive categories. For example, studies have shown that terms presented as mutually exclusive can be used to describe the same groups and have shown boundaries are blurred between the categories of 'smuggled migrants' and 'asylum seekers' or 'trafficked persons' and 'irregular migrants' (Blouin and Button, 2018), and 'refugees' and 'trafficking victims' (Anderson and Li, 2018), and 'victims of trafficking', 'smuggled migrant', 'illegal alien', and 'refugee' (Soltis and Walters, 2018). The unreliable nature of these categories is concerning as the way a person is categorised determines their legal status and the services available to them. Studies have also shown that classifying migratory categories along lines of victims and offenders does not capture the situation many people find themselves in (Juliawan, 2018; Sanchez, 2018) or can work to exclude certain groups who do not fit the victim definition (Mahdavi and Sargent, 2011).

Using narrative criminology in a way that treats policy problems as narrative allows for the study of how such populations are constructed and what this means for official responses, how groups are treated, who is criminalised and who is supported, and what types of harm are deemed acceptable or unacceptable. In applying narrative criminology to a narrative of trafficking as a policy problem, I hope to show what narratives are at play, what their outcomes are, and which are less likely to be harmful and should be used going forward to respond to trafficking both in New Zealand and internationally. This will feed into national discussions on how to conceptualise and respond to trafficking, and international debates on how to best respond to complex issues of migration and exploitation.

From the post-structural grounding of this research, this study seeks to identify the narratives which are used in human trafficking policy language and to assess what effects they have for the groups involved. The research includes considering whether some narratives have more harmful impacts than others, and whether there are new or existing narratives which could be taken up in order to provide better outcomes for the groups involved. In terms of narrative's relationship with fact, this thesis does not assess the accuracy of narratives or their alignment with 'truths' or realities. Rather it takes the post-structural perspective that discursive and material processes are not divisible from one another (Mumby, 2011; Dale, 2005). Discourses constitute the material world as we make sense of the world through discourse, and the material world is in turn shaped by discursive understandings (Hardy and Philips, 1999). From this perspective it is important to examine narratives as a means of analysing discourses and their effects rather than evaluating the accuracy of narratives in terms of their alignment with facts. The outcomes are seen as lived experience which are 
constituted through different discursive lenses rather than as essential 'truths' or facts which exist on their own, outside of human perception.

\subsubsection{Narrative research about human trafficking}

There is a growing body of work which analyses narratives about human trafficking. These studies analyse narratives in different contexts including advocacy, popular culture and media, as well as policy settings. In terms of ontological approaches, they range from critical to social constructionist perspectives, as discussed earlier in section 3.1. This research also employs varying theoretical and methodological approaches to narrative analysis.

This thesis contributes to this emerging field of study by providing a narrative analysis of the New Zealand anti-trafficking policy and official practice settings. This research offers a unique angle to this body of work as, at the time of this research, there were no other narrative studies of New Zealand anti-trafficking work. A study of the New Zealand context is also likely to be of particular interest within this field as New Zealand differs in its legal approach to the sex industry. Under the Prostitution Reform Act, sex work is legally framed as labour rather than as a crime. This legal framing clashes with the long-standing narratives, identified in the body of research discussed in this section, where sex work is presented as dangerous, harmful and intrinsically linked with trafficking. Key pieces of work in this emerging field include research by Erin O'Brien (2018b) which examines narratives about human trafficking in government reports, entertainment and news media, and awareness campaigns. In this work O'Brien deconstructs the dominant narrative of human trafficking in public discourse through a close examination of the featuring characters, namely the victims, villains and heroes ( $O^{\prime} B$ rien, 2018b, p. 3). This study provides insights into the underlying assumptions, exclusions and the impacts of the dominant narrative construction. Work by Sabrina Balgamwalla (2016) studies narratives within public discourse about trafficking over time, in headlines, public perceptions, advocacy and political settings. She challenges the role construction for 'victims', 'offenders' and 'rescuers' (Balgamwalla, 2016, p. 1) and the implications such roles have for maintaining frameworks of punishment and protection in the anti-trafficking field.

Analyses by Kinney (2015), Sharapov and Mendel (2018), and Albright and D'Adamo (2017) apply a narrative lens to trafficking representations in popular media. Research by Edith Kinney (2015) investigates the construction of 'victims, villains, and valiant rescuers' ( $p .87)$ as narrative subjects. She demonstrates how these popular characters become legal subjects and enable certain criminal responses. Kiril Sharapov and Jonathan Mendel (2018) assess media narratives' significant role in 
generating knowledge about human trafficking. They show how oversimplified interpretations of trafficking inforce individualist representations of trafficking and avoid structural issues. Erin Albright and Kate D'Adamo (2017) asses dominant media narratives about human trafficking and demonstrate how such narratives have impacts for how trafficking is conceptualised in both public opinion and government responses to the problem. In their study they identify a problematic narrative which represents trafficking as overly simplified and sensationalised.

When taken together, this body of work advocates for the importance of analysing narratives in the anti-trafficking field. It shows the potential for narratives to have serious impacts for those involved in migration and exploitation as well as shaping the approaches to trafficking which are taken up in legislation and government responses. This thesis builds on this tradition by analysing trafficking narratives with the aim of steering anti-trafficking work away from some of its more harmful conceptualisations.

\subsection{Conclusion}

The ethos of this research is that narratives are important to study as they impact the groups they are about. This chapter has shown how this ethos came to be decided on through the review and analysis of the existing philosophical approaches to trafficking research and the selection of narrative criminology as a key informing theory. It also demonstrated how post-structural concepts are used in order to study the construction of human trafficking as an international crime type and the impacts of such constructions on the groups involved.

The following chapter demonstrates how this theory is applied through the methodological design and the processes used in carrying out this research. Building on the literature discussed in this chapter, I define what counts as a narrative by drawing on both narrative criminology and narrative policy analysis. This is described further in the following chapter where a narrative is defined as an event type story which is temporally ordered and involves a set of events experienced by the narrator. It can also be a description of a policy problem, its causes, and remedies. Both forms of narrative feature characters, have an order such as a beginning, middle and end, with conclusions, morals, or recommendations.

The post-structural view of narratives described in this chapter is applied in the methodology chapter through the use of multiple data sources. By using a mix of data sources, narratives are treated as the unit of analysis rather than focusing on the individual speaker or report. By using multiple sources I try to capture multiple narratives and show how they may be reproduced, replaced, or come into conflict with one another (Angeli, 2017; Brouwer et al., 2017). 
The post-structural perspective outlined in this chapter is also carried forward in the next chapter in the analysis process used. The Methodology Chapter describes a two-step approach to the analysis where I first focus on 'what' is being said and secondly 'how' it is said, to whom, and for what purpose (Juntrasook et al., 2013; Kohler Riessman, 2008; Smith and Sparkes, 2006). This method is recommended for post-structural narrative analyses. The following chapter also describes six strategies for analysis which are taken from narrative criminology literature and which are specifically suited for a post-structural analysis (Presser and Sandberg, 2015a). They are metaphor analysis, positioning, symbolic boundary drawing, analysis of the moral of the story, and setting. These techniques help to show how a narrative acts, how meaning is conveyed and through which mechanisms, and how actions are constrained or enabled by the narrative. 


\section{Chapter Four: Methodology}

This chapter outlines the methodology used in this study and describes the research and analysis processes. It begins by setting out the research questions and then defines what is counted as a narrative in this research. The remainder of the chapter is split into research processes and analysis processes. Under research processes I show the processes followed in carrying out this research, starting with gaining access to certain organisations and data sources, ethical considerations, and details about what the data sources were. In terms of the analysis processes followed, I describe how I analysed the data and the six specific strategies for analysis used. Using one specific data source as an example, I demonstrate how these strategies are applied in the analysis. This chapter concludes with a reflection of the research process, methods, and analysis carried out and a discussion of the limitations of this research approach.

This thesis uses narrative criminology theory and methods to study how human trafficking is constructed as a social problem in the New Zealand context. As discussed in the previous chapter, the version of narrative criminology employed draws on post-structural concepts and narrative policy analysis. In this version, narrative is treated as the policy definition of what human trafficking is, which groups are involved, and what the given responses to the problem are. These policy narratives are important to study as they lead to action and have material consequences for the groups they are about. They tell a story about the groups involved, how they are positioned to act, and what can and should be done. They determine who is treated as a victim and who is criminalised, who receives support and assistance, who is deported or faces criminal sanctions, and what types of harm are considered as acceptable or unacceptable to society.

A post-structural approach to narrative research, as has been described in the previous chapter, treats narratives as multiple which can be repeated, conjoined, and conflicting. There are multiple 'truths' and constructions about human trafficking, and it is important to look for interdiscursivity and plurality (Lippert and Stenson, 2010). This post-structural perspective also means the narrative itself is treated as the unit of analysis rather than the individual speaker or text, as narratives are seen as being spoken through individuals rather by them (Sandberg, 2010).

In considering that there are multiple narratives about a social problem and that they are spoken or written through different people or sources, it is important to use multiple data sources (Breuil et al., 2011). The data sources used in this thesis are interviews with key officials who carry out antitrafficking work, policy documents about human trafficking and anti-trafficking work, and observations of meetings where key officials come together to discuss anti-trafficking work. Mixing policy document analysis with interviews and observations provides a window in to the dynamism of 
narratives about crime and migration and how they are reproduced, replaced, merged, and how they come apart and conflict with one another (Angeli, 2017; Brouwer et al., 2017).

This data is then used in a narrative analysis to identify what narratives are present about the problem of human trafficking in New Zealand, how they fit, contrast, conflict, merge or replace each other, and how they relate to the dominant international narratives of human trafficking. The purpose of this analysis is to identify the responses that each narrative privileges, to challenge responses that may cause harm, and to identify alternative, new or emerging narratives which have the potential to deliver less harmful outcomes for those involved, and to identify how these narratives are conveyed and can be used.

\subsection{Research questions}

This research seeks to identify narratives about human trafficking. The ultimate purpose of narrative criminology is to identify and challenge societal narratives which legitimise or facilitate harm, and to identify new or different narratives which are less problematic (Maruna, 2015; Tognato, 2015; Presser and Sandberg, 2014). In line with this aim, this research looks for narratives about the problem of human trafficking in New Zealand, how they fit, contrast, or conflict with one another, and how they relate to the dominant international framing of human trafficking.

As well as identifying narratives, this research examines how the narratives operate, and to what effect. This is where a post-structural approach to narrative is key. A post-structural approach asks how the narrative works and what it does, and centres the research on not only identifying narratives but looking at their effects (Kohler Riessman, 2008, p. 105; Czarniawska, 2006, p. 88; Silverman and Torode, 1980). This research asks how narratives are taken up or heard in policy language and what the implications are of such narratives for the groups involved.

The key research questions underpinning this study are:

1. What are the narratives about the problem of human trafficking in New Zealand and how do they fit, contrast, or conflict with one another?

2. How do these narratives relate to the dominant international framing of human trafficking?

3. How are narratives taken up or heard in policy language and by those responsible for responding to migrant exploitation and enforcing trafficking law?

4. What are the consequences of these narratives for how the problem of human trafficking is defined and responded to, for the affected groups? 


\subsection{What counts as a narrative?}

A key consideration that needs to be addressed at the very early stages of a narrative research project is to come up with a working definition of what counts as a narrative. There are many different versions of 'narratives' in social science literature (Kohler Riessman, 2008; Czarniawska, 2006). In this research I draw on the following definitions.

The first is taken from Labov and Waletzky (1967) and interpreted by Lois Presser for use in narrative criminology. In this definition narratives have a temporal component and involve a set of events experienced by the narrator. Presser describes a narrative as "a temporally ordered statement concerning events experienced by and/or actions of one or more protagonists" (Presser, 2009, p. 178). The second definition is taken from narrative policy analysis literature, where the description of the policy problem, its causes, and remedies are treated as a narrative (Fischer, 2003; Stone, 2002; Hajer, 1995; Roe, 1994). Stone describes narratives in policy texts in the following way: "definitions of policy problems usually have a narrative structure; that is, they are stories with a beginning, middle and an end, involving some change or transformation. They have heroes and villains and innocent victims, and they pit forces of evil against forces of good." (Stone, 2002, p. 138). Although this version focuses on problem definition as the unit of analysis, rather than an individual's life or event story, it is similar to the version used in narrative criminology as narratives are seen as temporal, moral, and involving different characters, usually coming to some form of resolution or moral typically in the form of a recommendation for the governing of the problem.

The third definition sees narratives as repeated and reinforced through conversations and actions which the researcher witnesses and from these constructs the narrative (Kohler Riessman, 2008, p. 26; Czarniawska, 2006). This form of narrative is used across fields of practice. Barbara Czarniawska provides a useful example of this in her work in management studies where she carried out interviews and observations with Council management officials in three European capitals (2006). This form of narrative does not require the formal narrative structure to occur (a discrete story which follows a typical story plot). Narratives can be hinted at, incomplete, repeated in part, and started and then contradicted. This is a more flexible form of narrative and avoids one of the key criticisms of narrative analysis - that narrative research can be Western-centric and excludes other forms of knowledge (Labov, 1972). A 'Western' narrative is a story about one character, used to form and present a unified self, which follows a plot-line that involves a setting, challenge, and resolution, and ends with a 'point' or moral (Kohler Riessman, 2008, p. 80). By seeking a 'Western' plot, researchers risk reproduces knowledge privileged by the Global North. 


\subsection{Research processes}

This section describes the research processes followed in this study, starting with the processes of gaining access to certain organisations, officials, documents, and spaces. This is followed by the ethical considerations that were taken into account before starting data collection. The data sources, which are comprised of interviews with key professionals responsible for anti-trafficking work, guiding documents about human trafficking and anti-trafficking work both nationally and internationally, and observations of meetings where professionals came together to discuss antitrafficking work, are then described.

\subsubsection{Access}

The first part of collecting data for this research was to identify which government agencies were responsible for carrying out anti-trafficking work and within these agencies, who were the key groups or individuals responsible for anti-trafficking work. Alongside this, I also needed to identify the guiding policy documents for New Zealand anti-trafficking work, both nationally and internationally, and the key forums where anti-trafficking work were discussed.

Through internet searches and speaking to contacts in the New Zealand government public sector I identified the Ministry of Business and Innovation (MBIE) as the government agency leading New Zealand's anti-trafficking work both from operational enforcement and policy and decision making perspectives. There are several other government agencies also involved in planning and delivering anti-trafficking work. These agencies are a part of the Government Inter-Agency Working Group on People Trafficking. This inter-agency working group designs and delivers anti-trafficking work and is led by MBIE. At the time of this research, the government agencies represented in this group included the Department of the Prime Minister and Cabinet, the Ministry of Foreign Affairs and Trade, the Ministry of Justice, the Ministry of Social Development, the Ministry for Women, the Ministry of Health, the New Zealand Police, the New Zealand Customs Service, the Accident Compensation Corporation and the Department of Internal Affairs (Immigration NZ, 2019d).

In order to undertake this research, I needed to access government officials and official documentation which could be of a sensitive nature. Support and cooperation was needed from the agencies involved. To gain access, I met with key officials from the Ministry of Business and Innovation (MBIE) as the government agency leading New Zealand's anti-trafficking work both from operational enforcement and policy and decision making perspectives. I also met with representatives from the New Zealand Police (NZ Police) as a government agency involved in the enforcement of human trafficking laws. Although I quickly ascertained that the MBIE led the anti- 
trafficking work, with their Immigration New Zealand (Immigration NZ) branch carrying out trafficking prosecutions, I initially focused on Police. The reason for this was that in many countries police lead anti-trafficking work and act as the key enforcement agency responsible. However, I soon learned that New Zealand is unique in that MBIE, through Immigration NZ, leads this work.

These key officials were willing to meet with me and were generous in the time they gave in discussing their work, putting me in contact with other key staff and providing relevant materials. I took this generosity to be a sign of their interest in and commitment to the work they carried out on anti-trafficking initiatives. MBIE has no formal process for gaining access to staff and documents for research. Instead I met with key staff involved and discussed my research. The MBIE Manager People Smuggling, Human Trafficking and Regional Cooperation acted as my key contact at MBIE and put me in touch with other professionals across government agencies, mostly those who sat on the Government Inter-Agency Working Group on People Trafficking. During interviews participants also referred to other people I could interview and put me in contact with them.

To access NZ Police resources, permission had to be granted by their Research Review and Access Committee (RRAC) (NZ Police, 2016). The RRAC approval is attached as Appendix B. While I had already made contacts at NZ Police, this process gave me formal approval to approach staff and to be at the Police Headquarters and view confidential documentation. My main contact at NZ Police put me in contact with others at NZ Police who had anti-trafficking work as a part of their role or detectives who had worked on trafficking or potential trafficking cases.

This snowballing recruitment method was appropriate in this research as there was a relatively small group of professionals working in this area, most of whom knew one another. Snowballing has been shown as an effective way to recruit groups who are 'hidden' due to social stigma or being asked about potentially sensitive topics such as sexuality (Browne, 2005) or groups based on certain characteristics who are not readily accessible (Naderifar et al., 2017). In this case, the people I wanted to contact were 'hidden' in the sense that they were not easily identifiable. They worked in a range of organisations across a range of topics. There was no list of those working in the area or set team dedicated to anti-trafficking work exclusively.

To identify potential participants, I also had access to the NZ Police's National Intelligence Application (NIA) database to identify staff who had worked on cases that had been investigated with the potential to be prosecuted under human trafficking law. Cases are recorded in NIA when they first come to police attention and as they progress. Helped by a police researcher, I searched the database using offence codes for human trafficking and related offences such as 'slave dealing' and 'exploitation of person not legally entitled to work', as well as searching for key words such as 
'human trafficking', 'people trafficking', 'slavery', and 'labour exploitation'. The search resulted in hundreds of cases most of which were not about trafficking or situations which involved exploitation. These cases were then narrowed down to eight and through follow-up discussions with management, I identified which staff to contact and invite to participate.

Through these contacts I was invited to attend presentations at MBIE and NZ Police, as well as a conference for anti-trafficking practitioners. I also had various coffee catch-ups with professionals working in the area during the research process. Having worked as a researcher at various government agencies before starting my PhD helped facilitate my access as initially I was able to use my professional networks to find key contacts.

Participants gave their time generously and most of those I approached were willing to take part, except for those I approached from the Labour Inspectorate (which is part of MBIE). I was not able to include officials from this group and I consider this to be a limitation of the research as Labour Inspectors are responsible for enforcing employment standards and carry out work on cases that involve migrant exploitation. During the time of this research the Labour Inspectorate was underresourced and had publicly come under pressure for its inability to investigate many cases due to an extremely high case load (Morrah, 2018; Tan, 2018). It is likely that they would not have had the time to take part.

A relatively large proportion of the participants were from NZ Police. This is in part because they had all worked on trafficking cases or had carried out anti-trafficking work from a policy or management position. It is also in part due to the Police research access process. Part of NZ Police staff time is allocated for research purposes and so when access is approved through the RRAC process, staff are supported in taking part.

While I interviewed representatives from a range of agencies, there were other government agencies who are involved in anti-trafficking work that I did not include in the research such as the Ministry of Justice, the Department of the Prime Minister and Cabinet, Customs NZ, and Ministry of Foreign Affairs. After carrying out interviews with the 25 participants, along with the observations and documents, I considered that I had reached data saturation as I was no longer gaining new insights or different narrative categories through the data (Charmaz, 2006, p. 113). Repetition of the same narratives across the data was visible, and when taken together there was enough data to consider how the narratives interacted or related to one another (Czarniawska, 1998). The participants were also referring to the same people as key professionals they worked with and to the same guiding documents as being important. Based on this I did not believe I was missing anything within the parameters I had set for the data sources. 
In terms of non-governmental groups, several participants also suggested I speak with NGO groups but I decided to set a parameter for the study at the government officials who were involved in defining and responding to trafficking. The exception to this was the participants from commercial companies. During the fieldwork it became evident that commercial companies were taking up a role in responding to human trafficking and worker exploitation through supply chain transparency or ethical sourcing work. In the UK and Australia and to some extent New Zealand, they were partnering with government and taking responsibility for responding to trafficking. In this way, I believed they were taking on an increasing role in governing the problem of trafficking and so it would be important to consider how trafficking is constructed through their work. The participants included are in no way representative of all businesses carrying out this type of work, but they are key stakeholders who manage large programmes on ethical sourcing which are considered best practice in New Zealand. The data gathered from the company representatives and reports is not being generalised as indicative of other corporations in New Zealand.

The documents used in this analysis are all publicly available and so negotiating access was not required. They were identified both through the research scoping and literature review stage of the research and also through the interviews. During the interviews, I asked if there were any other policy documents which describe the trafficking problem, policies, and practices to address it. Some participants provided further policy and operational documents. During the research process, I was allowed to read short summaries of potential trafficking cases which had been identified by police officers and recorded in their database. I was not permitted to take these records off-site for confidentiality reasons and so could not include them in the analysis other than as background.

\subsubsection{Ethical Considerations}

Prior to starting the fieldwork I sought ethical approval from Victoria University of Wellington Human Ethics Committee. The Committee granted ethical approval and this is attached as Appendix C. As well as following the VuW Human Ethics Policy, I also followed the Australia New Zealand Society of Criminology code of ethics: http://www.anzsoc.org/cmsthesociety/.

The main ethical considerations for this study were ensuring voluntary participation and confidentiality for the participants and ensuring that any sensitive details about cases of trafficking that were discussed were also kept confidential. Procedures to ensure voluntary participation, confidentiality, and secure data storage are set out, as they were conveyed to participants, in the participant information sheet (Appendix D) and consent form (Appendix E). Before conducting the interviews I explained by phone or email that the interviews were confidential and participants 
would not be named in reporting, and that sensitive details of cases of trafficking or exploitation would not be used in any reporting. Participants were then emailed a copy of the consent form and information sheet to read before the interview. At the start of the interview I went over the procedures again as written in the information sheet and consent form.

When carrying out interviews I quickly realised that what I had guaranteed in terms of keeping participants' identities confidential was not sufficient. The original method for achieving confidentiality was to use agency-level reporting of the findings, for example - 'officials from Immigration NZ' or 'NZ Police'. However, because there was such a small number of professionals working in this field and a small number of set key roles, naming the organisation would likely have made the participant identifiable to others who worked in the area. As a result of this, I altered the wording and said that findings would be attributed to officials from two categories - officials in policy roles and officials in front-line roles.

There was also an ethical question about the use of information about trafficking cases or situations that involved people being exploited. In interviews I started off by saying that interviews involve asking about participants' work and any sensitive information about cases they have worked on will be kept confidential. This included aggregating findings about specific cases in reporting and checking with the participant if there was a chance that a specific finding may make the case or any individuals involved identifiable. In such cases, these references would be removed if we agreed this should be done. I also noted that I did not need actual details and was more interested in a description of the types of cases they were dealing with, and asked them to use a made-up example if they preferred. Interviewees were very open to talking to me about cases they had worked on, and in detail, but were quite clear on which could be used publicly and which could not. This was tied to their stage of investigation and progress through the Courts.

This meant that certain cases and large chunks of narrative could not be used in my write-up. Even for the cases that I was given permission to discuss publicly and which were already being discussed in the public domain, I was resistant to do so in some cases. Some cases involved personal and unfortunate situations the victims had experienced. I did not have consent from the people involved to reproduce their stories, and even though they had been covered in media articles, it did not feel right to reproduce them in detail for the purposes of this thesis as the aim is to study how events are narrated rather than to raise awareness of a type of social harm. 


\subsubsection{Data sources}

In this section, each of the data sources is described. The data sources used in this research are:

- Interviews with professionals who are responsible for designing and delivering the New Zealand Government's anti-trafficking work

- Documents which are designed to guide New Zealand's anti-trafficking work

- Observations of meetings where the key professionals come together to discuss antitrafficking work

- Observations of the research process

As discussed in the introduction to this chapter, using different data sources was important in this research. The theoretic underpinning of this study is that there are multiple narratives about any social problem and that they are spoken or written through different people or sources (Breuil et al., 2011). By mixing policy document analysis with interviews with officials and observations, this research sought how narratives are reproduced, replaced, merged, come apart, and conflict with one another (Angeli, 2017; Brouwer et al., 2017).

Another reason for using different data sources is that research which studies the construction and governance of social problems tends to take a 'top-down' approach by studying accounts given in official documents and by high level decision makers (Breuil et al., 2011; Lippert and Stenson, 2007, 2010; Stenson, 2005). There is little attention to accounts 'from below' (Lippert and Stenson, 2010, p. 476) or from 'front-line bureaucrats' (Breuil et al., 2011), or to how claims about a social problem are taken up by these official actors (Snider, 2003). The observations and interviews will show the 'bottom-up' narratives from those at the interface of implementing trafficking law, which may problematise official narratives, or show how official 'top-down' narratives, shown in high level guiding documents, are heard and taken up.

\subsubsection{Interviews with officials}

Interviews were conducted with 25 officials from government departments and organisations who were responsible for responding to trafficking through either front-line operational, policy, or management roles.

These interviews provided narrations of the problem of human trafficking, causes, groups involved, and conclusions or morals of the story in the form of recommendations. Some interviews produced event-type narratives which were stories of specific cases of human trafficking that the participants had come across in their work. These discussions provided descriptions of what the problem of 
trafficking looked like in New Zealand, the nature of the problem, causes, the different groups who were involved and what the responses were, and what was needed. These accounts can be taken as 'bottom-up' narratives from those at the interface of implementing trafficking law (Breuil et al., 2011; Lippert and Stenson, 2010, p. 476; Snider, 2003).

The interviews were largely face-to-face interviews as this format is considered the most appropriate method for eliciting narratives (Kohler Riessman, 2008; Gabriel, 2000). In line with narrative methods, the interview structure was very open and while I had an interview guide (attached as Appendix F), I encouraged the participants to take the lead as much as possible (Presser and Sandberg, 2015b). In this way they could include what they thought was important and worth talking about in their work.

In three of the interviews, colleagues who I was intending to interview separately had come together to do their interview as a group. While literature on narrative analysis largely recommends one-onone interviews, I found the group interviews to be a good way of producing a narrative of cases the participants had worked on. Participants worked together to narrate what had happened with little prompting from me. Three of the interviews were group interviews with two or three participants in each. This meant that I carried out a total of 21 interviews with 25 participants.

The interviews were carried out in three cities in New Zealand. As a part of ensuring participant' confidentiality, I have not included the areas where the participants worked. Interviews were carried out at participants' workplace in a private meeting room. Five of the interviews were carried out over the phone at their workplace. While this was not ideal for narrative research, it was necessary as I could not always travel due to pregnancy and then being at home caring for a young baby.

Of the participants, 22 were from government agencies and three were from private companies. The majority of the 22 participants who worked for government agencies were either from MBIE or NZ Police. While participants from other agencies also took part, I have not named these agencies as doing so would make the participants' identity apparent to others who worked in this field.

Eleven of the participants were in front-line operational enforcement roles, 11 were in either policy roles or operational management roles (the two tended to overlap), and three were in policy roles at private companies. In designing this study, I had anticipated that I would find different types of narratives for those in front-line enforcement roles and those in policy or management roles, and accordingly compiled two separate interview guides (both attached as Appendix F). The front-line officials were responsible for investigating cases of suspected trafficking, compiling evidence, and carrying out prosecutions. Professionals in policy or management roles were responsible for 
designing policy about trafficking, determining how the New Zealand Government responds to cases of trafficking, and representing their agency in terms of determining what role they would play in carrying out anti-trafficking work.

For front-line professionals I imagined I would hear event-stories as they talked through a case they had worked on, while policy and management may narrate trafficking as a policy problem as they were responsible for designing policy and making decisions about what counted as trafficking and what appropriate responses were. In practice, interviews tended to produce both types of narrative as policy and management staff talked about both trafficking as a policy problem and cases they had heard of or their team had worked on, and front-line staff discussed particular cases but also their wider views on what trafficking looked like and how it should be responded to.

\subsubsection{Document review}

Alongside the interviews, I carried out a review of key policy documents which set out what human trafficking was as a policy problem, its causes, and what needed to be done to address the problem. These text are public facing and set out a picture of what trafficking is and what should be done to address it both internationally and in New Zealand. While the focus of this research is on narratives in the New Zealand context, the document review also included a small number of documents produced by either an international organisation (the UN) or other countries (United States and Australia), intended for international consumption. I included these documents as they have a direct influence on guiding New Zealand policy and practice as trafficking is an internationally defined policy problem, and its definition and response is driven by international groups. Together these documents provide a picture of the 'top-down' narratives of human trafficking which are static, and guiding documents setting out what trafficking is and how to respond to it (Breuil et al., 2011; Lippert and Stenson, 2007, 2010; Stenson, 2005). The following table shows the documents used in the review.

\section{Table 1}

Documents Included in the Document Review

\begin{tabular}{|l|l|}
\hline Document name & Description \\
\hline $\begin{array}{l}\text { UNODC Global } \\
\text { Report in Trafficking }\end{array}$ & $\begin{array}{l}\text { This is a report published by the UNODC every two years based on data } \\
\text { gathered from } 155 \text { countries. It is designed to provide a "global }\end{array}$ \\
\hline
\end{tabular}




\begin{tabular}{|c|c|}
\hline $\begin{array}{l}\text { in Persons } 2018 \\
\text { (UNODC, 2018a) } \\
\text { and } \\
\text { UNODC Global } \\
\text { Report in Trafficking } \\
\text { in Persons } 2016 \\
\text { (UNODC, 2016) }\end{array}$ & $\begin{array}{l}\text { assessment of the scope of human trafficking and what is being done to } \\
\text { fight it." (UNODC, 2017). It includes country specific information and an } \\
\text { overview on trafficking as a problem and what is being done to address } \\
\text { trafficking. This report stands alongside the US State Department report } \\
\text { on Trafficking in Persons as the only sources of data on human trafficking } \\
\text { as a global phenomenon. This is a guiding document for signatory states to } \\
\text { the Trafficking Protocol. I used reports from } 2016 \text { and } 2018 \text { as these were } \\
\text { the most up to date reports during the research process. }\end{array}$ \\
\hline $\begin{array}{l}\text { United Nations } 2010 \\
\text { Global Plan for } \\
\text { Action to Combat } \\
\text { People Trafficking } \\
\text { (UNODC, 2010) }\end{array}$ & $\begin{array}{l}\text { This plan of action is designed to promote a coordinated and consistent } \\
\text { approach to addressing human trafficking among governments } \\
\text { worldwide. It is a guiding document for states like New Zealand who are } \\
\text { signatories to the Trafficking Protocol. }\end{array}$ \\
\hline $\begin{array}{l}\text { United States } \\
\text { Trafficking in Persons } \\
\text { Report } 2018 \text { (United } \\
\text { States Department } \\
\text { of State, 2018a) } \\
\text { and } \\
\text { United States } \\
\text { Trafficking in Persons } \\
\text { Report } 2017 \text { (United } \\
\text { States Department } \\
\text { of State, 2017) }\end{array}$ & $\begin{array}{l}\text { The Trafficking in Persons report (TIP report) is an annual report produced } \\
\text { by the US State Department which provides a "global look at the nature } \\
\text { and scope of trafficking in persons and broad range of government actions } \\
\text { to confront and eliminate it." (United States Department of State, 2018b). } \\
\text { It includes a global overview of trafficking and 'country narratives' which } \\
\text { are reports of what trafficking looks like in different countries and what } \\
\text { governments are doing to respond. Countries are given a rating based on } \\
\text { their anti-trafficking work, New Zealand included. The TIP report is an } \\
\text { influential document in New Zealand and worldwide. It is a key } \\
\text { information source on human trafficking and, some have argued, a } \\
\text { diplomatic tool to drive actions and legislation in foreign governments } \\
\text { (Kelley and Simmons, 2015; Mahdavi and Sargent, 2011). It shapes policies } \\
\text { as well as discourses about what trafficking is and how governments and } \\
\text { NGOs should respond (Taylor and Isgro, 2018). These articles provide a } \\
\text { critical discussion on the purpose of the US Department of State TIP } \\
\text { reporting: Taylor and Isgro, 2018; Kelley and Simmons, 2015; Snajdr, 2013; } \\
\text { Gallagher, } 2011 \text {. }\end{array}$ \\
\hline $\begin{array}{l}\text { New Zealand Plan of } \\
\text { Action to Prevent }\end{array}$ & $\begin{array}{l}\text { This plan is the New Zealand Government's planned response to human } \\
\text { trafficking. At the time of analysis it was the guiding document for }\end{array}$ \\
\hline
\end{tabular}




\begin{tabular}{|c|c|}
\hline $\begin{array}{l}\text { People Trafficking } \\
2009 \text { (Department of } \\
\text { Labour, 2009) }\end{array}$ & $\begin{array}{l}\text { definition and responses for trafficking for officials in New Zealand. A new } \\
\text { plan is being developed but was not available at the time of analysis. }\end{array}$ \\
\hline $\begin{array}{l}\text { Text from } \\
\text { Immigration NZ } \\
\text { website } \\
\text { (Immigration NZ, } \\
\text { 2019d) }\end{array}$ & $\begin{array}{l}\text { This is a small amount of text from the Immigration NZ website that goes } \\
\text { along with the New Zealand Plan of Action to Prevent People Trafficking. }\end{array}$ \\
\hline Company reports & $\begin{array}{l}\text { Three company reports were included in the document analysis. These } \\
\text { were reports which were recommended to me through interviews with } \\
\text { company representatives and during a conference of anti-trafficking } \\
\text { practitioners. These reports were recommended as good-practice } \\
\text { examples of companies' responses to trafficking and forced labour in } \\
\text { supply chains. While I did not set out to include commercial companies' } \\
\text { documentation in this analysis, during the conference it became apparent } \\
\text { that commercial companies were increasingly taking a role in responding } \\
\text { to trafficking. While this data cannot be used as an indication of other } \\
\text { corporations in New Zealand, I decided it would be important to capture } \\
\text { this in my analysis as I thought that if companies are being given } \\
\text { responsibility for responding to trafficking alongside governments, then } \\
\text { they will also be taking a role in defining and governing the problem. } \\
\text { These three reports are publicly available, however, I have not named } \\
\text { them here as the companies the reports come from are the same } \\
\text { companies that employ the company representatives interviewed in this } \\
\text { study. Naming the reports may make these interviewees identifiable. }\end{array}$ \\
\hline
\end{tabular}

\subsubsection{Observations}

This research also involved observations of meetings, presentations, and a conference where antitrafficking practitioners gathered to discuss New Zealand's response to trafficking. The observation work follows the broader form of narrative where workplace conversations and interactions are a place for repetitions and contradictions of narratives (Czarniawska, 2006). While fully formed and more traditionally structured narratives are unlikely to be produced in this setting, these brief 
repetitions and contradictions, taken together, form narratives and show how conflicting narratives are disputed, with some emerging as more strongly than others.

I originally hoped to observe the biannual workshops of the Government Inter-Agency Working Group on People Trafficking. These workshops are a forum for discussing and planning the ongoing delivery of the New Zealand Governments' Plan of Action to Prevent People Trafficking (Department of Labour, 2009). While I was unable to gain permission to sit in on this group, I was invited to a number of meetings, presentations, and a conference where anti-trafficking practitioners from government agencies, NGOs, religious groups, and commercial companies came together to discuss the problem of human trafficking. After these events I made notes on what I had observed and used these notes as a part of my data. Narratives can be considered as being built over ongoing conversations between the researcher and participants, and between the different groups constructing a narrative (Kohler Riessman, 2008; Czarniawska, 1998, 2006). In keeping with this definition of narrative, I treated my observation notes a form of data to study the construction of such narratives.

\subsubsection{Observations of the research process}

Throughout the research process, I kept a reflexive journal of my observations and decisions. Reflecting on the research process is an integral part of narrative research. Narratives are coconstructed throughout the research process between the participant, the researcher, the theoretical and methodological frameworks used, and the physical and contextual setting. For narrative criminology, Sandberg (2010) recommends at the minimum acknowledging the physical setting and the audience of the narrative (both the apparent, such as the interviewer, or the imagined, such as the public). Kohler Riessman (2008) recommends keeping a journal throughout the research process - which includes the researcher's observations especially after interviews, and more generally alongside the research process as different decisions about theoretical and methodological approaches are made.

\subsection{Analysis processes}

This section describes the analysis process used in this study. After showing how the interviews were transcribed and how the data was coded, I describe the six strategies for narrative analysis used. Following from this, the analysis framework which served as a guide for the analysis is outlined. This section ends with a description of how the strategies for analysis were applied to the data by using 
one data source, the UNODC Global Report on Trafficking in Persons 2018 (UNODC, 2018a) as an example.

The first step in narrative analysis is to construct the narrative. In the words of two experts, "Stories don't fall from the sky or emerge from the inner most 'self'" (Kohler Riessman, 2008, p. 105) nor are they like "mushrooms waiting to be picked" (Czarniawska, 2006, p. 37). They are not there to be discovered by an objective outsider, rather, they are constructed between participants, researchers, setting, transcription, and analysis, and report writing. An important part of constructing the narrative is during transcription of interviews as the way the transcripts are presented will affect the type of conclusions reached (Kohler Riessman, 2008). With this in mind, I attempted to capture the interview in a comprehensive way by transcribing the audio files verbatim and including details such as pauses and silences.

The analysis was carried out using printed copies of the documents, transcripts and using my written notes of observations and coding them using pen and highlighters. This approach was preferable to using NVivo or a similar programme for sorting data into coding categories, as I wanted to keep the texts as a whole. Narrative analysis guides warn against 'disembodied text' where text is taken out of the context of the report or interview and placed in a separate discrete category created by the researcher during coding (Kim, 2015, p. 195; Cohen et al., 2011, p. 553). Dividing the texts in this way would mean that the aspects of narrative analysis used, as described in the following section, would not be visible. For example, conceptual metaphors which are repeated through the text or the setting of the document or interview would only stand out when analysing the text as a whole. As I analysed each text I also typed notes for each data source in a table using the six categories of analysis (shown below) and followed this with notes on my reaction to the data.

\subsubsection{Strategies for analysis}

Six strategies of analysis were used to analyse the data. These are thematic analysis, metaphor analysis, positioning, symbolic boundary drawing, analysis of the moral of the story, and setting. Each of these techniques are described in the following sections.

Narrative guides recommend using a mix of strategies to analyse data and a two-step approach and analyse firstly 'what' is being said in a narrative and then 'how' is it said, to whom, and for what purpose (Juntrasook et al., 2013; Kohler Riessman, 2008; Smith and Sparkes, 2006). The thematic analysis focuses on the 'what', while the metaphor analysis, positioning, symbolic boundary drawing, analysis of the moral of the story, and setting focus on the 'how'. The 'how' strategies are 
recommended for narrative criminological research by Presser and Sandberg (2015b) and reflect the post-structural approach taken in the analysis.

\subsubsection{Thematic Analysis}

The first step was to carry out a narrative thematic analysis of the transcripts and policy documents. It is common practice for narrative studies to start with the thematic analysis. This focuses on the content of what is said, as opposed to how it is said (Juntrasook et al., 2013; Smith and Sparkes, 2006, 2009; Kohler Riessman, 2008, pp. 53-4). Common questions to ask in this type of 'what' analysis are 'what does the story tell us about $x$ ?', 'what does $x$ mean to a certain individual or group?', 'what is happening in the story?', 'what type of narrative is being told?'(Smith and Sparkes, 2006, p. 184).

I used the thematic analysis to identify key themes that were reoccurring across sources (see Cain, 1991) or that stood out in any way (Tamboukou, 2003, 2011). Key themes can be common propositions made about the problem being narrated. For example, in Skilling's (2012) narrative policy analysis he studies reoccurring themes in New Zealand immigration policy. His themes are common propositions about how a problem is defined, including 'Immigration is needed as a part of the economic race to the future', and 'the nation is threatened by a flood of migrants'. Cain (1991) looked at common propositions about alcohol as narrative themes including 'alcohol as a disease' and 'alcohol as a helper'.

In a similar vein, themes can be the way a group is presented. For example Scuzzarello (2015) found narrative themes in policy texts and interviews with officials to be the way migrants were presented with thematic categories including 'the cosmopolitan entrepreneurial migrant narrative', 'the employed migrant narrative', 'the migrants as economic resources narrative', 'the participating migrant narrative', and 'the migrants as security threats narrative'.

Themes can also be a particular plot type or type of story. For example Juntrasook et al (2013) considered plot types as themes of the narrative, identifying heroic plots and victim plots in their data. Gabrielle (2000) identified themes which were story types, for example, stories about breaking the rules or stories about meeting the organisation's leader.

Once the key themes were identified, the following post-structural narrative techniques were used to investigate how a story is told and for what purpose and effect. The following strategies for analysis are used around the key themes. For example, I considered what metaphoric language is used in relation to certain themes, how are groups positioned, how are boundaries drawn, what the 
moral or proposed solution was presented as in relation to the key themes, and whether certain themes were present in certain settings.

\subsubsection{Metaphor}

Metaphors are used to foster shared understanding between the narrator and audience by drawing on shared cultural scripts (Presser and Sandberg, 2015b). Analysing metaphors provides a way of studying the wider discourses drawn on. An important part of metaphor analysis is not just trying to identify metaphor but looking at what they do, the imagery they present, and what the implications are of such imagery (Czarniawska, 2006).

Metaphors can be linguistic or conceptual. The linguistic metaphors are the more obvious figures of speech which are used for an action or object, which cannot be used literally (Deignan, 2016). These types of metaphors are analysed by "'asking the data' whether the speaker literally means what he or she says" (Presser and Sandberg, 2015b; Lakoff and Johnson, 1980).

Conceptual metaphors are where a certain type of language is used to portray the object of the speech in a certain way (Lakoff and Johnson, 1980). Conceptual metaphor theory studies conceptual metaphors by treating the repetitive use of certain terms or concepts and grammatical structures as creating metaphoric language (Deignan, 2005, 2016). Concepts from certain domains can be used repeatedly in a different context to convey meaning or create an image. Repetitive use of certain grammatical structures such as active voice, can also be used repeatedly to convey a certain picture. In this way metaphors are seen as a pervasive and subtle way of communicating a certain ideology that 'stands behind the text' (Deignan, 2016).

For example Armstrong (2009) shows that conceptual metaphors are common in criminal justice policy documents. She shows how certain terms or concepts which are associated with certain domains are used systematically to convey meaning and construct imagery of an issue. For example, she shows how metaphoric language about systems and machines, for example 'monitor and supervise' and 'systems incompatibility', conveys the concept of risk management and show the criminal justice system as scientifically precise and in control. She also shows how the consistent use of active voice as a grammatical structure conveys imagery of the government as an active 'doer'.

Other studies have found that language borrowed from the managerial domain that focuses on organisational processes and tasks is used in migration policy documents as a way of conveying an image of a methodological and in-control actor, when dealing with issues which are full of moral ambiguities and uncertainty (Boswell, 2011; Bosworth and Guild, 2008). 


\subsubsection{Positioning}

Positioning involves studying the characters or roles ascribed to the narrator and different groups. This tells you about the different positions that are available to the narrator and other groups. The importance of this is that the positions available constrain or enable what the narrator and other actors can do (Davies and Harré, 1990). Positioning also has the effect of assigning rights such as citizenship or illegal status, and positioning groups against each other - for example which groups are 'to be saved', or 'to be wiped out' (Moghaddam and Harré, 2010, p. 2).

Davies and Harré (1990) describe positioning as a discursive practice where speakers or authors are constituted in certain ways, can take up certain positions, and these can be multiple or changing. Different subject positions can be created through story lines as the speaker or author presents themselves as belonging to one category and not others (Davies and Harré, 1990). This can be done through use of pronouns such as 'me', 'our', and 'them'.

Story types and characters can also be used to evoke preordained positions available in certain story lines or cultural scripts, plotlines, or narrative genres. Along with studying pronoun use, studying characters and story lines is also a way of investigating positionality. For example, Juntrasook et al (2013) identify a hero plot where the speaker takes the position of a heroic protagonist who takes a stand against the authorities, and a victim plot where the speaker is positioned as a passive subject, acted on by authority.

\subsubsection{Symbolic boundary drawing}

Symbolic boundaries are described by Lamont and Molnár as being "conceptual distinctions made by social actors to categorise objects, people, practices, and even time and space. They are tools by which individuals and groups struggle over and come to agree on definitions of reality.... They are an essential medium through which people acquire status and monopolize resource". (2002, p. 168).

Studying symbolic boundaries is an important tool to use in researching global crime issues that involve migration, as borders are a significant form of symbolic boundaries (Alvarez, 1995). Studying boundaries can show how members of the state versus outsiders are constructed as well as other groups such as illegal immigrants versus trafficking victims, or migrant workers versus local workers. They determine status in terms of the type of citizenship and rights given to certain groups and resources in terms of the support for those deemed as deserving. Symbolic boundaries play an important role in creating inequalities and enacting power (Lamont et al., 2015). Studying 
boundaries can also show the process through which boundaries are produced or dissolved (Lamont and Molnár, 2002).

Symbolic boundaries can be studied by looking at use of pronouns like 'us', 'we' and 'them' and who is included and excluded from these categories (Czarniawska, 2006, p. 88). From a policy narrative analysis perspective, the language used to position some groups at the heart of a problem, some as causing it, and others as left out, through assumptions made about actors shows symbolic boundaries (Scuzzarello, 2015; Stone, 2002). For example, Scuzzarello (2015) looked at how two categories of migrants are constructed in policy text and interviews with officials. She found migrants were split into 'integrated' and 'non-integrated' and the boundaries for each community were narrated by the policy actors and in policy documents as they set out assumptions about each group.

Symbolic boundaries are also seen as an enactment of moral discourses as moral assumptions or views can manifest in the boundaries that are drawn in terms of what is considered acceptable and unacceptable, and who are considered the 'good guys' versus the 'bad guys' (Espiritu, 2000). For example, Copes (2016) shows how drug users use symbolic boundaries to construct themselves as either 'functional users' who are in control of their life or 'dysfunctional users' who have lost control, drawing boundaries dividing normality with deviance. These boundaries then guide behaviour of those identified. For example, those who identify as functional may only take drugs in the weekend as weekday use is associate with dysfunctional users.

\subsubsection{The moral of the story}

The moral of the story for life or event stories is the conclusion or reflection made by the narrator. In policy documents it is the recommendations or next steps. Studying the moral of the story shows the likely effects of the narrative, as the moral constrains or enables certain actions (Presser and Sandberg, 2015b). The moral also provides a strategy for studying the tools used to position different actors as moral and the discourses of morality drawn on (Ugelvik, 2012). This can be an unspoken acknowledgment of what is considered to be right and wrong in certain circumstance.

This is a useful technique to use in studying policy narratives as policy making is full of moral assumptions even though through its presentation may claim to be objective or moral free (Wagenaar, 1995). By writing morals into policy documents, it is likely that they are then enacted by practitioners. It is therefore important to examine recommendations or conclusions as a way of understanding the moral underpinnings present in policy documents and related practices. 


\subsubsection{Setting}

Studying the setting involves acknowledging the physical setting, the people present, and the audience of the story, including those who may not be physically present (Sandberg, 2010, p. 20). Setting is important because it is where a narrative is produced and exists (Tamboukou, 2011) and certain narratives will be available in certain settings (Ugelvik, 2012). Narratives are composed for certain audiences and draw on through discourses circulating in certain cultures (Kohler Riessman, 2008). Therefore it is important to note who is present during interviews, who is the audience or intended audience and where the interview or report writing took place.

For example, Ugelvik (2012) found that the prison setting encouraged a certain type of narrative from prisoners. Aspects of the physical setting contributed to positioning prisoners as 'immoral others' who need to account for their actions. In doing so prisoners used narrative strategies to construct themselves as moral by telling their story in a way where there was no victim, and so no person who had been wronged was present.

For policy documents considering the anticipated audience is important. Although policy documents present themselves as objects without authors and audiences, they are not without either (Shore and Wright, 1997, p. 10). The audience for a policy document could be a Minister, colleagues, or wider society. The anticipated audience plays a role in the creation of the narratives as they draw on what is considered socially acceptable within certain groups (Wagenaar, 1995).

Including the setting in analysis is an important part of reflecting on the role of the researcher and research process in the co-construction of the narrative. In considering the setting it is also important to consider whether an interview or observation is a part of an ongoing dialogue across meetings, interviews, and other contact like email as all of these steps contribute to building the narrative (Kohler Riessman, 2008).

\subsubsection{Reflexivity}

As well as using these strategies for analysis, I will also consider and record my reaction to the text and what struck me as the reader with some sort of impact. This could be a particular metaphor I found striking, an emotional story that I reacted to, a contradiction that stood out to me, or a sudden change in direction in the narrative. This is a part of acknowledging the researcher's role in narrative analysis and presenting the findings of a narrative study in the context of the research process from which they came (Sandberg, 2010; Kohler Riessman, 2008). 
4.4.2 Analysis framework

To guide the analysis I developed the following framework. It includes the six strategies used for the narrative analysis. The upper section of the table shows what I looked for and coded in the texts. The lower section of the table shows what I 'asked' the data while coding. In analysing each transcript, document or my journal notes, I referred to this framework and wrote notes in a blank table with the same headings. After analysing each text, I would make notes at the bottom of the table of my reaction to the text.

\section{Table 2}

Analysis Framework Developed for this Thesis

\begin{tabular}{|c|c|c|c|c|c|c|}
\hline & $\begin{array}{l}\text { Thematic narrative } \\
\text { analysis }\end{array}$ & Metaphor analysis & Positionality & $\begin{array}{l}\text { Symbolic boundary } \\
\text { drawing }\end{array}$ & The moral of the story & Setting \\
\hline $\begin{array}{l}\text { What to } \\
\text { look for } \\
\text { and code } \\
\text { in the } \\
\text { texts }\end{array}$ & $\begin{array}{l}\text { Highlight key, } \\
\text { reoccurring themes } \\
\text { in the way human } \\
\text { trafficking is } \\
\text { narrated } \\
\text { This can be: } \\
\text { - things that stand } \\
\text { out in any way } \\
\text { - type of story that } \\
\text { is being told (e.g., } \\
\text { Victim plot, hero } \\
\text { plot, crime story) } \\
\text { - what imagery is } \\
\text { being portrayed } \\
\text { - any characters } \\
\text { that seem to } \\
\text { dominate the story } \\
\text { or be at the } \\
\text { forefront }\end{array}$ & $\begin{array}{l}\text { Highlight obvious } \\
\text { linguistic } \\
\text { metaphors - } \\
\text { language where the } \\
\text { author/speaker } \\
\text { does not literally } \\
\text { mean what they say } \\
\text { Highlight well } \\
\text { known metaphoric } \\
\text { sayings } \\
\text { In looking for } \\
\text { conceptual } \\
\text { metaphors: } \\
\text { Highlight } \\
\text { reoccurring words } \\
\text { or phrases } \\
\text { borrowed from a } \\
\text { different field, used }\end{array}$ & $\begin{array}{l}\text { Identify who the } \\
\text { characters are in the } \\
\text { narrative (e.g., the } \\
\text { Government, } \\
\text { companies, New } \\
\text { Zealanders, } \\
\text { migrants, vulnerable } \\
\text { people, victims, } \\
\text { offenders, } \\
\text { employers, travel } \\
\text { agents) } \\
\text { What terms are used } \\
\text { to describe the } \\
\text { characters? } \\
\text { (e.g., offenders, } \\
\text { criminals, } \\
\text { employers, travel } \\
\text { agents, victims, } \\
\text { migrants, vulnerable } \\
\text { people) }\end{array}$ & $\begin{array}{l}\text { Highlight key words that } \\
\text { show potential symbolic } \\
\text { boundaries (e.g., New } \\
\text { Zealanders, migrants, } \\
\text { New Zealand workers, } \\
\text { migrant workers, } \\
\text { victims, offenders, } \\
\text { overstayers, vulnerable } \\
\text { migrants) } \\
\text { Look at pronouns used } \\
\text { to include and exclude } \\
\text { people, groups, } \\
\text { agencies, and to draw } \\
\text { boundaries (e.g., us, } \\
\text { them, we) } \\
\text { Look at the type of } \\
\text { pronouns used around } \\
\text { the key themes }\end{array}$ & $\begin{array}{l}\text { In documents highlight: } \\
\text { - recommendations } \\
\text { - next steps } \\
\text { - concluding points } \\
\text { - areas for improvement } \\
\text { In interviews highlight: } \\
\text { - concluding remarks } \\
\text { - the ending of a story } \\
\text { - what was learned } \\
\text { - what needs to be done } \\
\text { Look for who is active in } \\
\text { what needs to be done, } \\
\text { who is responsible, who } \\
\text { is the action being done } \\
\text { to and who is left out } \\
\text { (e.g., is the government } \\
\text { the doer, are the } \\
\text { vulnerable migrants } \\
\text { being acted on, are the }\end{array}$ & $\begin{array}{l}\text { For documents } \\
\text { note: } \\
\text { - Where is the } \\
\text { document } \\
\text { located? (e.g., on } \\
\text { an organisation's } \\
\text { website) } \\
\text { - who is the } \\
\text { author? } \\
\text { - who is the } \\
\text { intended } \\
\text { audience, present } \\
\text { or anticipated? } \\
\text { - is the document } \\
\text { publicly available? } \\
\text { - what language(s) } \\
\text { is the document } \\
\text { presented in? } \\
\text { For interviews } \\
\text { note: }\end{array}$ \\
\hline
\end{tabular}




\begin{tabular}{|c|c|c|c|c|c|c|}
\hline & $\begin{array}{l}\text { - common } \\
\text { propositions about } \\
\text { trafficking as a } \\
\text { problem that stand } \\
\text { out (e.g., trafficking } \\
\text { is an abhorrent } \\
\text { crime, or trafficking } \\
\text { is a normal part of } \\
\text { migration) }\end{array}$ & $\begin{array}{l}\text { around key themes } \\
\text { (e.g., bureaucratic } \\
\text { language, medical } \\
\text { language, military } \\
\text { language, consumer } \\
\text { language) } \\
\text { Highlight } \\
\text { reoccurring } \\
\text { language structures } \\
\text { used around a } \\
\text { theme (e.g., active } \\
\text { voice) } \\
\text { Highlight where } \\
\text { comparisons are } \\
\text { drawn between } \\
\text { trafficking and } \\
\text { other types of } \\
\text { crime (e.g., } \\
\text { terrorism, domestic } \\
\text { violence) }\end{array}$ & $\begin{array}{l}\text { Are there characters } \\
\text { who are left out or } \\
\text { alluded to but not } \\
\text { directly mentioned? } \\
\text { What type of story } \\
\text { line do the } \\
\text { characters evoke? } \\
\text { (e.g., crime story, } \\
\text { heroic quest, good } \\
\text { news story) } \\
\text { How are the } \\
\text { characters } \\
\text { positioned in active } \\
\text { or passive voice? } \\
\text { (e.g., who is the } \\
\text { narrator, who is } \\
\text { active, who is being } \\
\text { acted on, what } \\
\text { person is the story } \\
\text { narrated in?) }\end{array}$ & & $\begin{array}{l}\text { offenders being acted } \\
\text { on?) }\end{array}$ & $\begin{array}{l}\text { - where did the } \\
\text { interview take } \\
\text { place? } \\
\text { - who was } \\
\text { present? } \\
\text { - who was the } \\
\text { audience, actual } \\
\text { and imaginary? } \\
\text {-was this the first } \\
\text { meeting or part of } \\
\text { an ongoing } \\
\text { conversation? }\end{array}$ \\
\hline $\begin{array}{l}\text { What to } \\
\text { 'ask' the } \\
\text { data } \\
\text { while } \\
\text { coding }\end{array}$ & $\begin{array}{l}\text { When identifying } \\
\text { key themes, think } \\
\text { about which } \\
\text { narrative analysis } \\
\text { strategies will be } \\
\text { useful in the next } \\
\text { stages of } \\
\text { interrogating the }\end{array}$ & $\begin{array}{l}\text { What cultural } \\
\text { scripts are drawn } \\
\text { on in the use of } \\
\text { metaphors? } \\
\text { What image is } \\
\text { conveyed by } \\
\text { metaphors or by }\end{array}$ & $\begin{array}{l}\text { What types of } \\
\text { storylines are drawn } \\
\text { on through the use } \\
\text { of characters? } \\
\text { How do the } \\
\text { storylines constrain } \\
\text { and enable actions? }\end{array}$ & $\begin{array}{l}\text { Who is excluded from } \\
\text { the pronouns 'us', 'we' } \\
\text { and 'them'? } \\
\text { What group is the } \\
\text { speaker speaking from } \\
\text { and who are they } \\
\text { speaking about? (e.g., }\end{array}$ & $\begin{array}{l}\text { What actions are } \\
\text { enabled or constrained } \\
\text { by the moral or } \\
\text { recommendation/conclu } \\
\text { sion? } \\
\text { (e.g., the state as the } \\
\text { actor, as responsible, } \\
\text { victims as passive, }\end{array}$ & $\begin{array}{l}\text { What is the role of } \\
\text { the interviewer, } \\
\text { the setting and } \\
\text { the intended } \\
\text { audience in } \\
\text { constructing the } \\
\text { narrative? }\end{array}$ \\
\hline
\end{tabular}




\begin{tabular}{|c|c|c|c|c|c|}
\hline $\begin{array}{l}\text { data around each } \\
\text { theme } \\
\text { Keep in mind, and } \\
\text { to some extent } \\
\text { look for, the ways } \\
\text { trafficking has been } \\
\text { historically framed, } \\
\text { as covered in the } \\
\text { literature review. } \\
\text { These are } \\
\text { trafficking as: } \\
\text {-sex trafficking } \\
\text {-modern day } \\
\text { slavery } \\
\text {-a security threat } \\
\text {-a human rights } \\
\text { issue } \\
\text {-a breach of labour } \\
\text { law }\end{array}$ & $\begin{array}{l}\text { the reoccurring use } \\
\text { of concepts from } \\
\text { another domain? } \\
\text { How is cross } \\
\text { domain mapping } \\
\text { used? What other } \\
\text { domains are } \\
\text { concepts taken } \\
\text { from and used (e.g., } \\
\text { medical concepts } \\
\text { used to describe } \\
\text { responses to } \\
\text { exploitation) and to } \\
\text { what effect? } \\
\text { What is inferred } \\
\text { about trafficking by } \\
\text { drawing examples } \\
\text { with other types of } \\
\text { crime? }\end{array}$ & $\begin{array}{l}\text { What actions or } \\
\text { outcomes are } \\
\text { available to the } \\
\text { characters? } \\
\text { How much agency } \\
\text { do different groups } \\
\text { have? } \\
\text { What are the } \\
\text { implications for how } \\
\text { exploitation is } \\
\text { responded to and } \\
\text { what will happen to } \\
\text { the groups affected? }\end{array}$ & $\begin{array}{l}\text { government officials, } \\
\text { vulnerable victims) } \\
\text { Are the groups alluded } \\
\text { to through pronoun use } \\
\text { consistent or do the } \\
\text { boundaries shift or } \\
\text { dissolve in some parts? } \\
\text { Are some groups } \\
\text { positioned at the heart } \\
\text { of the problem of } \\
\text { human trafficking? Are } \\
\text { some the causes of the } \\
\text { problem? Are some } \\
\text { outside of the problem? } \\
\text { (e.g., are Western } \\
\text { countries, consumers, } \\
\text { governments, or } \\
\text { offenders excluded?) } \\
\text { What are the } \\
\text { implications of the } \\
\text { symbolic boundaries for } \\
\text { who has access to } \\
\text { resources, support or } \\
\text { citizenship? } \\
\text { What exclusions are } \\
\text { made and what does this } \\
\text { mean for who is } \\
\text { responsible for } \\
\text { responding to trafficking }\end{array}$ & $\begin{array}{l}\text { inactive, unable, or the } \\
\text { state as helpless) } \\
\text { What are the moral } \\
\text { assumptions that the } \\
\text { conclusions or } \\
\text { recommendations are } \\
\text { based on? } \\
\text { Are certain groups } \\
\text { positioned as moral and } \\
\text { others as immoral? (e.g., } \\
\text { companies are doing the } \\
\text { 'right thing', the state as } \\
\text { a rescuer) } \\
\text { Are there particular } \\
\text { discourses of morality } \\
\text { that are drawn on? }\end{array}$ & $\begin{array}{l}\text { Is it likely that the } \\
\text { setting has caused } \\
\text { certain narratives } \\
\text { to be drawn on? } \\
\text { Are there certain } \\
\text { narratives which } \\
\text { are likely to be } \\
\text { available in that } \\
\text { setting? } \\
\text { What are the } \\
\text { implications or } \\
\text { limitations of } \\
\text { these available } \\
\text { narratives for how } \\
\text { trafficking is } \\
\text { responded to? }\end{array}$ \\
\hline
\end{tabular}




\begin{tabular}{|l|l|l|l|}
\hline & & $\begin{array}{l}\text { and causing the problem } \\
\text { (e.g., are Western } \\
\text { countries or consumers } \\
\text { excluded and their role } \\
\text { in facilitating or driving } \\
\text { exploitation neglected?) } \\
\text { What does the stability } \\
\text { or flexibility of } \\
\text { boundaries say about } \\
\text { trafficking and the } \\
\text { groups involved? }\end{array}$ \\
\hline
\end{tabular}

My reaction: note any of the content, narrative style or structure that stood out to me or provoked a strong reaction. 


\subsubsection{How the strategies for analysis are used}

To better illustrate how the analysis was conducted, in this section I give an example of how I used each strategy, demonstrating the analysis work I carried out on the UNODC Global Report on Trafficking in Persons 2018. This report is accessible at: https://www.unodc.org/unodc/en/humantrafficking/global-report-on-trafficking-in-persons.html

I started with a thematic analysis and found that there was a reoccurring proposition that trafficking is a battle to be fought and the language used created an image of military responses. From this I identified one key narrative theme to be the trafficking as warfare narrative. This theme stood out in both content and language. The content of the report focused on trafficking in armed conflict situations rather than other situations where trafficking happens. Armed conflict is also emphasised as a cause of trafficking as opposed to other causes such as global labour markets and demand for cheap goods and labour. Language about combatting or tackling trafficking is used and traffickers are presented as criminals, armed groups, militia groups, terrorists, and extremists. The warfare narrative was also expressed through the use of illustrations which have a military aspect as some feature figures standing by images of victims and holding machine guns.

Through the initial thematic review, I identified conceptual metaphors as creating warfare imagery. Language from the military domain was borrowed to explain trafficking. For example: "Enhanced national capacity to detect victims could be achieved through strengthened institutional efforts to combat trafficking." (p7), "This growth can reflect positive and negative developments in the fight against trafficking in persons..." (p13), "...it is important to ensure that UN and other agencies peacekeeping personnel deployed in field missions have the capacity to identify and report on cases on trafficking in persons..." (p13). Language includes combat trafficking, the fight against trafficking, and personnel being deployed in field missions. There are many maps of the world used in the report and these contribute to the metaphoric military image. Maps can be seen as taken from the military domain and represent knowledge and authority in Western culture (Harley, 1988). Some maps feature arrows showing the flow of trafficked people internationally and this contributes to imagery of a threat, attack or invasion (Snajdr, 2013). 


\section{Figure 1}

\section{UNODC Global Report Map Showing Transregional Trafficking Flows}

| MAP 6 Main detected transregional trafficking flows, 2014-2017

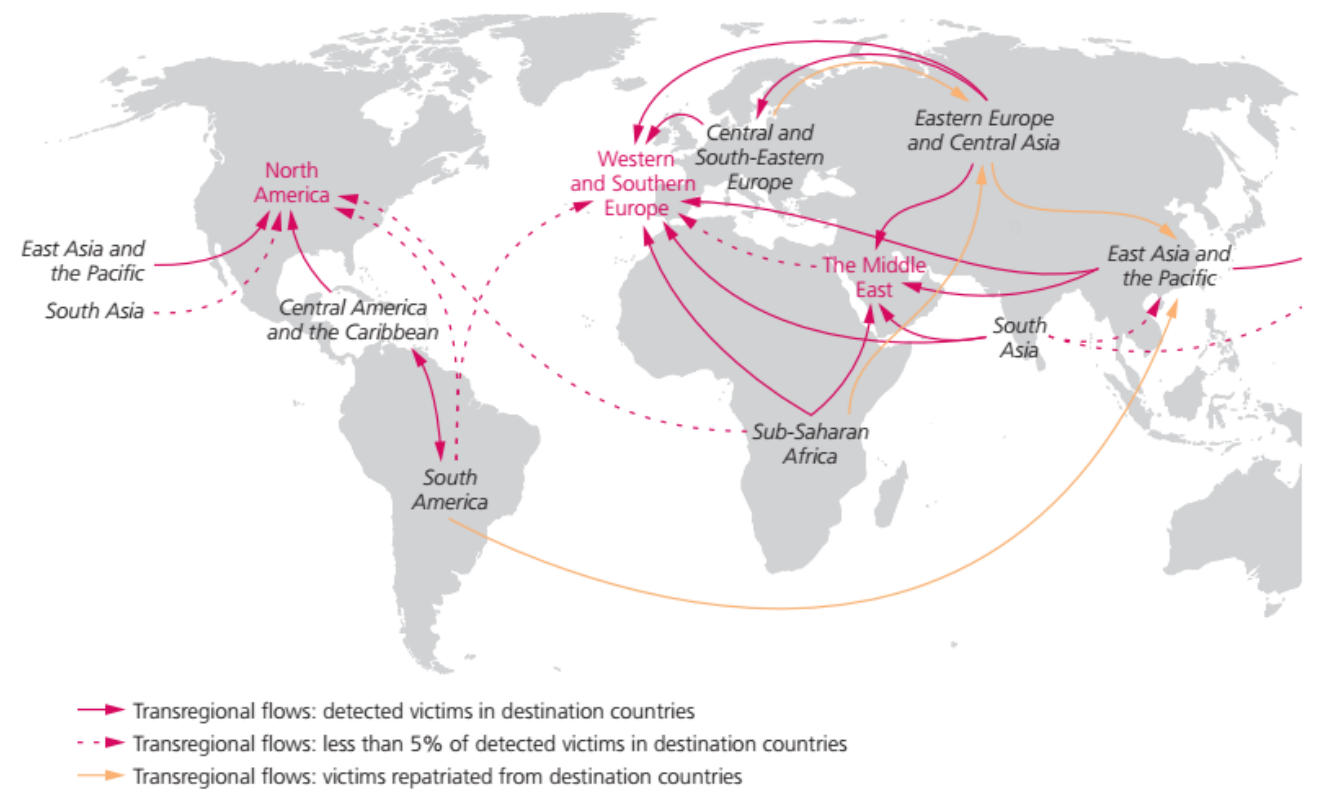

Source: UNODC Global Report on Trafficking in Persons 2018, page 44

I further investigated the trafficking as warfare theme using positioning. The main characters of this warfare story were the traffickers, the victims and the responders. The traffickers were equated with "armed groups", "criminals", "militia", "terrorists" and "extremists" as well as opportunistic businesses. The offenders are positioned in text as active. The victims are presented as passive, vulnerable, and children and women. For example "Some armed groups involved in conflict may exploit civilians. Armed groups and other criminals may take the opportunity to traffic victims including children - for sexual exploitation, sexual slavery, forced marriage, armed combat and various forms of forced labour." (p11), "It has been documented how militia and criminals are coercing detained migrants and refugees for different exploitative purposes." (p12), and "Children recruited and exploited by terrorists and violent extremist groups are not only the victims of human trafficking but victims of violence at multiple levels as children may be used for violent purposes by the groups that recruited them." (p13-14).

The responders are the governments from UN signatory states or the UN. The responder is largely not directly referred to but sits behind proposed actions, as well as systems and processes.

Processes and systems are used in place of directly naming states or groups as actors. In this way the responders are removed and positioned as objective. For example "Detections of domestic victims have increased over the last 15 years" (p9), "Most of the victims detected are females; mainly adult 
women, but also increasingly girls.", and "Where the number of detected victims has increased after legislative or programmatic action, however, these actions - including amendments to legislation, enforcement of well-designed action plans, victim protection schemes and national referral mechanisms - have clearly contributed to improving the identification of victims and the effectiveness of criminal justice responses." Systems such as detection, programmatic action, victim protection schemes and referral mechanisms appear to operate of their own volition.

In an analysis of symbolic boundaries, the clear-cut boundaries between these characters stood out. Traffickers are separate from the responders, even when trafficking is occurring in situations of armed conflict involving militia groups in disputed states. Traffickers and victims are presented as separate, with only one brief mention that some people may be vulnerable to becoming traffickers as well as trafficked. These boundaries produce an oversimplified picture of trafficking with villains, victims and protectors which fits with the trafficking as warfare theme. There is also a more obscure boundary which divides the countries where trafficking happens and the countries who are the protectors. This is done through tying trafficking to warzones and references to 'trafficking flows' which exist as people move from country to country and can be 'confined' by the actions of the protector states.

In studying the moral of the story, the Policy Implications section of the executive summary concludes that international collaboration is needed to fight trafficking and recommends a number of systems and processes that states should use in doing so. In this moral, the actors are state governments and the UN, and they are given the ability to uncover and address trafficking through using processes of precision and control such as 'mechanisms', 'schemes', 'action plans' and 'strategies'.

The analysis of setting helps to understand the theme of trafficking as warfare. The report is located on the UNODC webpage, with the UNODC given as the author. The UN Trafficking Protocol has historically been designed and implemented through the UNODC and sits alongside other UNODC portfolios of organised crime and irregular migration. Critics have argued that this positioning encourages trafficking to be viewed and responded to as a serious crime and threat to state security (Dottridge, 2007; Chew, 2006; Kempadoo, 2005). The trafficking as warfare narrative may be a narrative available in the UNODC setting. In terms of audience, the report is presented as being for international consumption and of particular interest for governments around the world in planning anti-trafficking work. However, the full report and country profiles are only available in English. The executive summary is available in English, French, Spanish, Russian, Chinese and Arabic. This seems 
to align with the symbolic boundary created which separates the responders from the countries where trafficking occurs and implies the responders or protectors are Anglo-countries.

In terms of my response in reading the report, the apparent contradiction between the data presented and the warfare narrative stood out to me. The data shows that most trafficking occurs within countries or regions, where detected victims are citizens or residents of the country or subregion they are detected in. This seems at odds with the warfare narrative and the symbolic boundaries drawn between countries that produce victims and those that protect them.

\subsection{Reflections on the research process, methods and analysis}

As a part of a narrative approach, I am including my reflections on the research process. This section includes my reflections on the research approach, theory, methods and strategies for analysis, whether the process evolved as I anticipated, anything that was surprising, and things that were difficult or worked well. Including information on the research process and the decisions and experience of the researcher is recommended for narrative analysis and fits with the philosophy of a narrative approach where narratives are seen as constructed between the researchers, the research process and the participants and any other sources used (Kohler Riessman, 2008; Czarniawska, 2006). It is also worth reflecting on how useful and effective the post-structural narrative criminology framework that I use has been in studying policy narratives about human trafficking as a global crime type.

In regards to the philosophical grounding of this thesis, I found the social constructionist and poststructural approach to studying trafficking useful during the research process. From this perspective there are multiple constructions of trafficking, with differing perspectives held by different groups, found in multiple sources. The aim of this approach is to identify problematic processes, inequalities and exclusions (who is left out), and new ways of thinking about the problem. The multiple constructions of trafficking were evident across the data sources I used. The way groups were constructed, in particular, people who have been trafficked and traffickers, stood out to me.

In New Zealand, as with many countries, anti-trafficking legislation, policy and enforcement is recent and there is little precedent in terms of labels for groups. It was evident that these groups were being characterised, sculpted and represented in ways which were often different from the dominant international mold. While analysing the data, the Global Alliance against Trafficking in Women published a special issue of the Anti-Trafficking Review (GAATW, 2018) about migratory categories and how they are used among authorities and other professionals. These articles 
promoted the importance of looking at how migratory categories are constructed and the impact they have on migrants' access to citizenship or support. This special issue included research where migratory categories had been applied to people in a way that did not reflect their experience or where arbitrary seeming categories were applied to complex realities often with harmful impacts to those involved. For me, this highlighted the importance of studying how these migratory categories are constructed and demonstrated the usefulness of such an ontological approach.

Using narrative criminology theory to following these constructions proved useful and helped me to understand the various constructions of trafficking that I experienced as I collected and studied the data. Viewing narrative in a post-structural sense was also useful as it showed narratives as multiple and dynamic in their ability to shift, merge, and conflict with one another. Such shifts and swings were evident in some of the observations I carried out at various meetings and presentations. I saw at a two-day conference, a shift in language from 'human trafficking' to 'modern day slavery', as a new narrative was presented, taken up and tested. In other situations, dominant narrations from the Global North clashed with local narrations especially where sex work was discussed. In these settings the uptake of narratives, exclusions, disruptions, repetitions and contradictions became obvious. In this way I also found the use of observation work as a means of studying narratives to be very insightful.

A difficulty I found with using narrative methods with this topic was that I was not able to reproduce large segments of data for readers to see stories in their entirety and types of language used. In the interviews, sensitive and confidential instances of exploitation or trafficking were discussed and often could not be reproduced. This was as some of the cases discussed had not yet reached the courts or if they were being dealt with in court, parts of the case were not available for public discussion. There were also a small number of professionals working in this area, each with different and specialised roles, and including large chunks of interview material would have made them identifiable.

During the analysis, I found the six strategies I had chosen worked well with the data and helped in identifying narratives and thinking about how they operate and to what likely effect. The strategies worked together and it was often possible to study aspects of a theme using each method. Coming up with clear items to look for in the text or simple questions to 'ask' the text (as shown in the analysis framework table) made these strategies accessible.

For the interviews, I kept the format very open so that the interviewee could follow their own narration of events or policy problems and the strategies for analysis worked well with the data produced. At the end of the interviews, I asked directly for a metaphor - participants were asked if 
they could think of a metaphor that represented their work in this area as a way of reflecting on their experience. Although this question did not always elicit a metaphor, in every case it led to a broader summing-up or reflection of the interviewee's experience on a case or piece of work. This was useful to take as a conclusion or moral of the story to use in this analysis.

In writing up this research I faced the question of how to write, in what language and voice. After studying narratives in the data, I then had to consider how to write about them which would be a narrative in itself. During the writing, I felt aware every time I used obvious metaphoric language and what I could be implying. The urge was then to write in a more cut and dried official pattern, but by doing that I was sure I would be drawing on language from anther domain somewhat unconsciously and creating certain imagery. Perhaps I would be even portraying my research as precise and scientific, which is not in line with the social constructionist ontological approach. I decided to write in my normal style and hoped that readers would see enough of the researcher role in constructing this text through my reflecting throughout.

Despite challenges around reproducing pieces of data and questions about language use in conveying narrative findings, I found taking a narrative approach to studying human trafficking a useful and interesting exercise. The social constructionist and post-structural approach fit as a useful way of understanding the multiple ways of presenting trafficking which came through in the data. The analysis techniques showed how meaning was conveyed through the narratives identified and what the likely effects would be for both definitions of the types of harm that are considered as acceptable and unacceptable and the outcomes for the groups involved. However, this approach was not without limitations. These are discussed in the following section.

\subsection{Limitations}

This research does not include the lived experiences of migrant workers who have been identified as victims of trafficking or who are working in exploitative situations and who could potentially be classed as having been trafficked. In this way, this project does not capture the voices of those affected by trafficking and the State's response. While collecting narratives of affected groups would have added another valuable line of narrative and 'trafficked' people have largely been left out of the construction of narratives they feature in (Mahdavi and Sargent, 2011), I decided that the focus of this thesis would be how the problem of trafficking is narrated in decision making documents, by those in decision making roles, and by those responsible for enforcing international law on trafficking. At the time of the research, these sources and actors were actively determining the definition and response to trafficking. Furthermore, at the time of this study there were only a small 
handful of people who had received trafficking victim status and who had since left the country. As the number of trafficking prosecutions grows and more people receive trafficking victim status, research with those labelled as trafficking victims will become a viable and important line of inquiry.

Another limitation of this project is that the interviews do not capture all, or a representative sample, of official actors and commercial businesses carrying out anti-trafficking work. There are several professionals from government agencies in policy or management positions who have antitrafficking work as a small part of their role. I did not have the capacity to interview all of these professionals. For front-line enforcement officials, I was not able to include labour inspectors and there may have been police officers who had worked on cases that were at some stage considered for trafficking charges but were not recorded through official channels and so could not be identified. For the professionals from commercial companies, I interviewed only a very small number.

While there were more professionals I could have included, I had included those in key roles and considered, at the point of ending the interviews, I had reached data saturation and had a sufficient amount of data to carry out a narrative analysis. Furthermore, as a qualitative narrative study, the research aimed to understand how trafficking as a concept is being translated and taken up by key actors involved rather that gathering quantitative, representative data on officials' responses to trafficking.

\subsection{Conclusion}

This chapter has outlined the methodological approach taken in this study, the processes used in gaining access to certain groups and spaces, the data collection, and sources used. It describes the analysis process that was applied to the data, and specifically, which techniques were employed in identifying and understanding narratives in the interviews, observations, and texts. By showing both the methods and analysis I hope to contextualise the findings from this research which are presented in the following three chapters. 


\section{Chapter Five: Trafficking as Business}

Through analysis of the data I identified three separate narratives which link trafficking to business, where trafficking is discussed in terms of commercial enterprise. The three narratives are discrete with little overlap, but all show that trafficking is considered to be something that happens in the world of business, within commercial enterprise, often driven by profit. The narratives are firstly trafficking as a profitable organised criminal enterprise; secondly commercial systems and companies as saviours; and thirdly trafficking as dodgy business. Although all three narratives are linked to business, they each lend themselves to very different outcomes, and have different implications for how the problem of trafficking is conceptualised and dealt with. In this way, through the three narratives, three different forms of trafficking are constituted.

This chapter concludes that by positioning trafficking narratives within a 'business' frame, the neoliberal and capitalist systems in which trafficking takes place are highlighted. The anti-trafficking interventions empowered by a 'business' type narrative would focus on redistribution of profits and targeting systems which drive exploitative labour. In this chapter, these three contrasting narratives are discussed together so that three versions of a 'business' type narrative can be considered, especially in terms of their impacts for the groups they are about. The first two narratives explained in this chapter are problematic. The first portrays trafficking narrowly, as being carried out by organised criminal groups and the second shows businesses as being exclusively good and protective of workers, positions which both ignore the impact of wider profit-making. The third narrative provides a more inclusive approach which covers a broader range of situations and where there is potential to include commercial systems as contributors to the trafficking problem.

The three narratives are each tied to different groups and institutions as they are produced by these bodies and guide their work. The embeddedness of these narratives within certain institutions has implications for change as their ongoing repetition limits the uptake of alternative stories.

\subsection{Narrative 1. Trafficking as a profitable organised criminal enterprise \\ 5.1.1 Overview of narrative}

In this narrative trafficking is presented as a large scale international business carried out by sophisticated and highly organised criminal groups. In this story trafficking is carried out in order to make profit and large profits are made. This type of business is presented as immoral and illegal. The traffickers are the main character of this story, although little detail or description is given about them. These hollow characters are active in the storyline and are equated with terrorists, militia 
groups, and organised criminals. There is a transnational aspect to these organised businesses and they are often narrated as a threat to national security of other countries. In terms of the form this narrative takes, it is a common proposition about the problem of trafficking (see for example Skilling, 2012; Cain, 1991) - that it is a highly organised, profitable business, carried out by immoral criminal groups.

\subsubsection{Evidence of narrative}

This narrative is largely conveyed through the US Department of State Trafficking in Persons (US DoS TIP report) and UN reporting, including the US DoS TIP reports, UN Trafficking in Persons reports (UNODC TIP reports), and UN Plan of Action to Combat People Trafficking. It can be seen also in the New Zealand Plan of Action to Prevent People Trafficking (DoL, 2010) and was evident in interviews at times where cases from other countries (largely the UK and Australia) are discussed. It was otherwise not present in interviews with New Zealand officials or commercial company representatives.

This is not a new narrative but one that has been presented by anti-trafficking agencies for the past 30 years as the concept of trafficking in its modern form has developed (Maher, 2017; Dottridge, 2007; Kempadoo, 2005). The same narrative can be traced to the conversations which lead to the design of the Palermo Protocol (Hobbs and Antonopoulos, 2013; Woodiwiss and Hobbs, 2009; Edwards and Gill, 2003, pp. 8-9). Woodiwiss and Hobbs (2009) show how characterisations of threatening and immoral organised criminal groups were key themes in speeches given first at a conference in Washington DC for high-level US law enforcement and intelligence officials in September 1994, and then a few months later at the UN World Ministerial Conference on Organised Transnational Crime in Naples. Descriptions of organised criminal groups recorded from speakers at the UN conference included "forces of darkness", "a new monster", and "armies of evil" (United Nations, 1994). The US approach to organised crime voiced at the Washington conference, was influential at the UN conference where it was held up unquestionably as a successful model (Woodiwiss and Hobbs, 2009; Edwards and Gill, 2003, pp. 8-9). The result of the UN conference was a call to action for UN member states to act on transnational organised crime which led to the creation of the United Nations Convention against Transnational Organized Crime (UNTOC), which includes the Trafficking Protocol.

From this start point, the Trafficking Protocol was developed alongside protocols on smuggling migrants and arms trafficking, situating trafficking alongside issues of organised crime which involves cross-border activity. The UN's anti-trafficking work is led by the UNODC, an organisation whose 
primary aims have been to address organised crime, corruption, and terrorism on a transnational level (UNODC, 2019b). Given the origins of the Trafficking Protocol and the UNODC as the author of the UN reports, it is not surprising that this same narrative is present in the UN reporting. It is also unsurprising that it is present in the US DoS TIP reports as the narrative itself comes, at least in part, from a long-established representation of an organised criminal threat which has been a part of the discourses drawn on in US crime control agencies (Hobbs and Antonopoulos, 2013; Woodiwiss and Hobbs, 2009).

The presence of this narrative in the New Zealand Plan of Action to Prevent People Trafficking is also not surprising as the plan drew heavily on information about trafficking presented by the UNODC and US DoS. The plan was written in 2009 and at the time the New Zealand Government had carried out little anti-trafficking work. During the interviews some officials noted that the Plan was the first step in the New Zealand Government's anti-trafficking efforts and at the time New Zealand was largely reliant on definitions of trafficking and its appropriate responses as given in UNODC guidance documents and US DoS TIP reporting. The presence of this narrative in some of the interviews with New Zealand officials where they are discussing examples they have heard of in international settings such as international training courses or international reporting, suggests that they are drawing on and reproducing an internationally prevalent presentation of trafficking as shown in international guidance documents.

In this section I present evidence of this narrative from the data using quotes as illustrative examples. I have grouped the evidence into two areas. The first is character positioning of immoral businesses and shows how traffickers are presented as carrying out organised and immoral business ventures and those responsible for fighting trafficking are positioned as moral. The second is the focus on big profits made by traffickers as sophisticated entrepreneurs.

\subsubsection{Character positioning of immoral businesses}

The evidence discussed in this subsection shows how through character positioning, traffickers are presented as sophisticated and highly organised business operators. These businesses are also positioned as being immoral as they are presented as criminal, military, and threatening. Their immoral positioning is enforced by the portrayal of a range of moral actors who operate in opposition to them. For the most part, these are bodies which have international influence such as the UN and US DoS, or are state governments or a collaboration of state governments. This character positioning shows traffickers as carrying out organised commercial enterprise which is by nature immoral and sinister. 
In the trafficking as profitable organised criminal enterprise narrative, the traffickers are the main character. However, there is little description given about them, who they are, how they operate, what they do, and where they are in the world. Rather than giving detailed descriptions, they are equated with certain groups. These groups are both illegal and threatening such as criminal groups, terrorists, and militia groups, as well as being high functioning, skilled, opportunistic, and operating as highly organised businesses.

This positioning is shown where traffickers are labelled as "organised criminal groups" ((UN Plan of Action, p10 and 11), "trafficking syndicates" (DoL, 2010), and as groups who carry out "transnational organized crime" (UNODC, 2016, p9). In the US DoS and UNODC reporting traffickers are also named as being terrorists, armed groups, militia groups, and violent extremists, some of which operate transnationally. For example, the text below is taken from the 2017 US DoS TIP report and shows traffickers being described as terrorists, armed groups and transnational organised crime networks.

“...wars and conflicts have become the prime driver of trafficking in persons. They provide an enabling environment for traffickers to operate, as persons fleeing persecutions and conflicts are particularly vulnerable to being trafficked. Conflicts have created conditions for terrorists, armed groups and transnational organized crime networks to thrive in exploiting individuals and populations reduced to extreme vulnerability by persecution and multiple forms of violence." (US DoS, 2017, p8)

Similarly, the example below taken from the 2018 UNODC report shows traffickers being positioned as armed groups, militias and criminals.

"Some armed groups involved in conflict may exploit civilians. Armed groups and other criminals may take the opportunity to traffic victims -... In Libya, for example, militias control some detention centres for migrants and refugees. It has been documented how militias and criminals are coercing detained migrants and refugees for different exploitative purposes..." (UNODC, 2018, p11-12)

As well as equating traffickers with threatening and immoral groups who operate transnationally, they are also shown as working in an organised fashion and actively seeking to exploit others. They are shown as operating in an organised, skilled and sophisticated manner and as running innovative businesses which thrive. This is shown in the excerpt below taken from the UNOCS 2016 report. It shows traffickers as working in an opportunistic fashion and running a thriving commercial operation. 
"At the same time, armed conflicts represent an opportunity for traffickers. The state of impunity originating from the erosion of the rule of law and the breakdown of order allows traffickers to operate more easily and their business to thrive" (UNODC, 2016, p64)

The quote below is taken from the 2018 US DoS report and is an example of how traffickers are presented as operating in a sophisticated and skilled manner. It also gives an example of how traffickers in this narrative are positioned as being active in their activities and actively seeking to exploit others.

"In this age of interconnected markets, mobile workforces, and digital communication, human traffickers are developing newer and more sophisticated ways to exploit their victims. Traffickers are particularly skilled at identifying and cultivating vulnerability in those they exploit, taking advantage of difficult circumstances and instability, and exploiting government policies and activities in unexpected ways." (US DoS, 2018, p476)

Similarly, the following excerpt from the UNODC 2018 report shows how trafficking groups are presented as skilled, organised in working across borders, sophisticated in their operations, opportunistic and active in that they take advantage of opportunities to run their business and actively exploit others.

"Evidence suggests that traffickers are skilful when working across borders, leveraging low economic development in some countries and available medical expertise in others. Traffickers operate in increasingly sophisticated ways, making use of corrupt environments and fraudulent measures, exploiting people caught in destitution, poverty and hardship." (UNODC, 2018, p30)

International bodies such as the UN, state governments, and sometimes a collaboration of both, are positioned in opposition to these groups and are shown as being moral and as being in a position to "fight" trafficking. They are presented as the unquestionable moral actors who are responsible for addressing trafficking and protecting victims from harm. Presenting states as indisputably moral has problematic outcomes (discussed further in the following section on this narrative's impact) as it produces a simplistic narrative of heroes versus villains (O'Brien, 2018b, p. 144; Vance, 2011a; Segrave, 2009). This obscures the role states have in creating situations where exploitation can occur such as through immigration laws that create an illegal and vulnerable working class.

The positioning of states as moral is visible in the UN and US DoS reporting. In this reporting the emphasis is on these groups to "fight" the traffickers as the immoral other. This positioning can be seen in the introductory sections of UN TIP reporting, the UN plan of action, and the US TIP reports. 
For example, the following text is taken from the UN Plan of Action and shows the UN signatory states being positioned as "combatting" trafficking. They are also positioned as being moral actors who "condemn" trafficking, whereas traffickers are presented as immoral and those who violate "human dignity" and commit a "heinous crime".

"We, the States Members of the United Nations, reaffirm our commitments to end the heinous crime of trafficking in persons, especially women and children, express our determination to prevent and combat trafficking in persons, protect and assist victims of trafficking in persons, prosecute crimes of trafficking in persons and promote partnerships to strengthen coordination and cooperation, and resolve to translate our political will into concrete actions by adopting an action plan to:

1. Consistently and strongly condemn trafficking in persons, which constitutes a criminal activity violating human dignity and has negative effects on development, peace and security and human rights..." (UN Plan of Action, 2010)

The text below taken from the US DoS 2018 report shows the US government as positioned as able to "combat" trafficking and as being able to "end the scourge" which is trafficking. Trafficking is also explicitly referred to as a moral issue.

"Combating human trafficking is not merely a moral issue or one that affects the interests of the American people; it is also an issue that threatens international peace and security. The United States remains a committed leader in combating this global threat. The findings in this report help inform policymakers, law enforcement, and civil society on gaps and areas of concern, as well as serve as a roadmap forward to end the scourge" (US DoS, 2018, introduction by the Secretary of State)

This positioning works to entrench the idea that these organised criminal businesses are immoral and need to be targeted by states and international groups. The positioning of state governments as being outside of the problem of trafficking and as separate from its causes and facilitators, is discussed in Chapter Six.

\subsubsection{Focus on big profits}

Evidence for the trafficking as profitable criminal enterprise narrative also came through in the emphasis given to the large financial profits made by people carrying out exploitation and the emphasis on trafficking as an international enterprise that generates huge profits worldwide. This 
emphasis portrays trafficking as a highly effective and sophisticated money making enterprise. For example in the 2017 US DoS TIP report trafficking is described as a multi-billion dollar industry:

"While this progress is encouraging, traffickers around the world continue to exploit millions of victims in forced labour and sex trafficking. This multi-billion dollar industry destroys families and communities, weakens the rule of law, strengthens criminal networks, and offends universal concepts of human decency." (US DoS, 2017, p1)

This focus on profits was seen in the reports by the UNODC 2018 report which included a section on 'gauging the criminal income in trafficking in persons cases' (p39). This section draws on a small number of cases where information was available and presents it in a chart titled "Criminal income earned from the exploitation of trafficking victims, by sub region and by type of exploitation, USD \$ or Euro € per victim per day or per act." (UNODC, 2018, p39).

Profits made by exploiting others and financial profit as a motivator for people to carry out exploitation was also discussed frequently in the interviews with New Zealand officials. However, the way profit was talked about worked to situate trafficking within everyday business practices within New Zealand rather than representing it as a large threatening international industry. This focus on profit is described in-depth under the third narrative - trafficking as dodgy business, discussed later in this chapter.

\subsubsection{Outcomes of the trafficking as profitable organised criminal enterprise narrative}

In their description of narrative criminology, Presser and Sandberg show narratives as being constitutive as they structure realities and shape actions (Presser and Sandberg, 2014). By narrating trafficking as profitable organised criminal enterprise, a certain form of trafficking is constituted. This narrative lends itself to a certain set of enforcement responses and policy implications. The treatment of trafficking as being carried out by immoral individuals lends itself to policing, prosecution, and legal responses involving harsh criminal sanctions for individual traffickers. The presentation of trafficking as carried out by international organised enterprises which are sinister or threatening lends itself to responses which focus on increased border security and the detection of traffickers. By prioritising these types of responses over others, traffickers are detected and criminalised, in particular those who fit the image of organised and immoral transnational groups, and these groups become the cause and target of the problem of trafficking.

This is a dominant and pervasive narrative which has been influential worldwide through its uptake and distribution through the UN and US DoS, both of which guide definitions and responses to 
trafficking internationally. These bodies have driven responses which focus on policing and prosecuting trafficking, harsh criminal sanctions under criminal law for individual traffickers, as well as increased border security, which have to date been a major focus of anti-trafficking work internationally (Maher, 2017; Dottridge, 2007; Kempadoo, 2005). The propagation of these types of responses can been seen through avenues such as the UN Trafficking Protocol requirement that state governments criminalise trafficking under criminal legislation and law enforcement measures are obligatory for signatory states whereas other measure such as victim protection are not. It can also be seen through the US DoS reporting where number of criminal prosecutions for trafficking are used as a positive indication that trafficking is being addresses and for which state governments can be rewarded.

A problem with the trafficking as profitable organised criminal enterprise narrative is that it constitutes a narrow version of trafficking which does not appear to fit with many situations which have been classified as trafficking which were described in the data. In the UN reporting there appears to be a mismatch between the description of traffickers in the main text and the descriptions of specific situation which have been classed as trafficking. The main text portrays traffickers as being well organised groups who work in a sophisticated manner to make large profits, whereas the cases reported often show individuals or small groups working together, often who have family ties, and who are often known to the victim. In the US DoS reporting, the narrative of trafficking as organised criminal enterprise is also present yet the individual victim stories (short vignettes showing forms of trafficking) tend to show trafficking as a small scale, less organised practice.

This is an example of a case discussed in the UN reporting:

"In Argentina, for example, a girl was brought to that country from the rural parts of the Plurinational State of Bolivia by her aunt. The aunt promised the victim's parents that she would give the girl a proper education in Argentina. However, the girl was exploited as a servant in the household." (UNODC, 2016, p27)

This is an example of part of a victim vignette shown in the US DoS reporting:

"When Raul was in high school in the Dominican Republic, he jumped at the opportunity to go to the United States to continue his education. A family friend offered to be his sponsor and hire Raul in his restaurant while Raul attended school. Shortly after Raul arrived in the United States and began attending the local high school, his sponsor pulled him out of 
classes and forced him to work in his restaurant full-time for less than $\$ 1$ an hour." (US DoS, 2018, p7)

Furthermore, the organised criminal enterprise narrative clashes with the types of situations viewed as trafficking in New Zealand. The four cases prosecuted using trafficking law to date have all involved either an individual or two or three people who were related to one another as opposed to organised criminal groups.

This mismatch between the narrative and the cases of trafficking described may be reflective of a shift in anti-trafficking work where there is a conscious effort to broaden trafficking definitions to allow for a wider range of situations to be considered as trafficking (UNODC, 2018a, 2016). This shift represents an effort to step away from a more rigid picture of trafficking which focuses on victims, often of sex trafficking, who have been subject to violence or kidnapping, do not consent to any part of the work scheme, and who are exploited by organised criminal groups (Wylie, 2016; Tomkinson, 2012; Doezema, 2010). However, the ongoing presence of this narrative in the international guidance reports indicates that it is still influential. It may be that the discourses available within the UNODC and the US DoS are constraining efforts to move away from these earlier representations of trafficking. For the UNODC, the organisation's history as a body that addresses transnational organised crime, terrorism and security may be limiting its ability to redefine trafficking situations. For the US DoS, there is a long history of political rhetoric where external groups which are seen as immoral and threatening are blamed for social problems (this is discussed further in Chapter Eight: Discussion).

The mismatch between the trafficking as profitable organised criminal enterprise narrative and the types of situations considered as trafficking creates a problem for anti-trafficking work, in particular for trafficking prosecutions. Trafficking prosecutions are low internationally and are well known as being very difficult and time intensive to bring about (Gallagher and Karlebach, 2011). This is often attributed to the complexity of trafficking situations. However, the difficulties of bringing about a prosecution may be in part due to the mismatch between the internationally dominant idea of trafficking, as shown here, as organised criminal enterprise, and the broad range of situations that are treated as trafficking. These often involve small scale operations, are unorganised, and involve family members, or victims and offenders who have a relationship with one another, and where the victims are active in seeking out work which later turns out to be exploitative. According to this dominant narration of trafficking, offenders are highly organised, immoral, and a threat to states through the ongoing harmful nature of their business. This must be demonstrated throughout legal proceedings in order to bring about a successful prosecution. 
Another problem with the trafficking as serious organised criminal enterprise narrative is that it is simplistic in its focus on individuals, largely offenders and to a lesser extent victims, and ignores the complex range of conditions that allow exploitation to occur. The problem of trafficking is seen as a problem of bad, immoral individuals who become the focus of an individualised criminal response where individuals are investigated, prosecuted, and convicted under criminal law. By individualising the problem, structural factors which allow trafficking to occur are obscured and left out of any response. These structural factors include those that create vulnerability and potential for exploitation to occur such as immigration and visa laws which place limits on migrant workers' rights to work legally, or employment structures and arrangements within certain industries which create precarious employment situations for workers. While the simplistic caricatures of bad traffickers in this narrative may have contributed to its popularity, a more nuanced narrative which acknowledges a more complex range of factors may enable more effective responses to trafficking. These structural factors are under states' control and altering them provides a more accessible way of stopping exploitation compared with seeking out immoral individuals, across borders, and investigating and prosecuting them (Sharapov et al., 2019; Vance, 2011a; Segrave et al., 2009).

\subsection{Narrative 2. Commercial businesses and systems as saviours}

\subsubsection{Overview of narrative}

The form this narrative takes is a story about a group involved in the issue of trafficking (see for example Scuzzarello, 2015). In this narrative commercial businesses are presented as moral characters who take responsibility for preventing trafficking in their supply chains, help improve the lives of workers, and help consumers by providing them with ethically sourced products that they want. The wider systems of commerce such as global supply chains, international labour markets, and consumerism are also presented as good systems which work to help pull people out of poverty in developing nations. Companies and commercial systems are presented as either doing good or having the potential to do good. Companies' role and motivation in making profits is not included in this narrative. Consumers are also positioned as doing good or having the potential to do good through consumer power and a desire to choose ethically sourced products. In this narrative, the moral of the story is that human trafficking and worker exploitation can be solved through consumerism and the international sourcing of products. 


\subsubsection{Evidence of narrative}

Evidence of this narrative comes from texts and discussions which are about companies monitoring labour conditions in their international supply chains as a method for preventing and responding to human trafficking and other forms of exploitation. Companies taking on this role is a relatively new method for addressing trafficking, which is gaining traction worldwide (Brace and O'Connell Davidson, 2018; Segrave et al., 2018; O'Connell Davidson, 2016). At the time the fieldwork was carried out for this thesis, this method had been formalised in UK law through the 2015 Modern Slavery Act which included a provision to increase transparency in supply chains which holds businesses responsible for investigating potential slave labour (Legislation UK, 2015).

Evidence for this narrative comes from the three interviews with commercial company representatives and the three company reports used in this study. This narrative was also present in the 2017 and 2018 US DoS TIP reporting where ethical sourcing and supply chain transparency was discussed. It was also present in a small number of interviews with New Zealand government officials, and in observations where officials and other professionals were discussing ethical sourcing and supply chain transparency as a way of responding to trafficking. The data from companies cannot be generalised as being representative of other companies in New Zealand as there were only three representatives included in this study along with documents attached to their work. The companies were selected for this research as their work on responsible sourcing was being held up an example of good practice in the New Zealand anti-trafficking field. In this way, the narratives present in the company data were analysed as contributing to the construction of the trafficking problem and the appropriate responses, in the New Zealand context.

It is not surprising that this was a dominant narrative in the data from companies and company representatives who were carrying out ethical sourcing work as a way of addressing exploitation in their supply chains. Given that businesses are embedded within commercial and neoliberal systems, it is not surprising that these same systems would be positioned as a solution to problems of exploitation, rather than taking up a narrative which is critical of wider commercial systems. This narrative is also beneficial to companies as it promotes their role as an ethical body, separate from problems of exploitation, and encourages consumerism as a way of tackling exploitation. In this way the narrative can be seen as a strategic tool used by companies as it plays a role in reaching their aims of selling products and promoting their brand to consumers. However, this narrative was also present in the US DoS reporting and in some of the interviews and observations with government officials where the role of commercial companies was discussed. This suggests that this narrative is becoming more widespread in anti-trafficking work and that it is not simply a narrative manufactured by commercial companies which supports their commercial position. As discussed in 
this section as well as in the following chapter on western exceptionalism and in the discussion chapter, the separation of commercial systems from the problem of trafficking is a wider theme in anti-trafficking work and one which may become more persistent as commercial companies are ascribed a larger role in addressing exploitation.

In this section I present evidence of this narrative from the data using quotes as illustrative examples. The evidence is grouped into three areas. The first of these is character positioning of commercial companies, systems, and consumers as doing good where companies and systems are shown as having the ability to pull workers out of poverty and provide consumers with the products they want. The second is symbolic boundaries between commercial systems and the problem of trafficking where commercial systems are shown as outside of problems of trafficking and exploitation as opposed to being a part of them. The third is consumerism and global sourcing as the moral of the story where consumerism and capitalist systems of trade and sourcing are presented as the solution to trafficking and exploitation.

\subsubsection{Character positioning of commercial companies, systems, and consumers as doing good}

The evidence discussed in this subsection demonstrates how through character positioning, commercial companies, systems, and consumers are presented as good and being in the position to do good through helping workers in developing countries and providing ethical products.

Commercial companies are presented as moral, doing good or as having the potential to do good through striving to help workers by improving their labour conditions, helping to build the productivity and success of factories or producers, and as helping consumers through providing ethically sourced goods. In this narrative, the role and motivation of companies to make a profit is not included. The following text taken from a company report gives an example of this. In this text, the company is positioned as having a duty to protect worker welfare, and their work has resulted in improvements to the working conditions for people in developing countries. As well as helping workers, the company is positioned as helping consumers by meeting their needs.

"We recognised then, as now, our duty to customers, team members, and shareholders to protect the welfare of workers in our supply chain.... The past decade has seen an unprecedented global effort by numerous brands to leverage the power of their trading relationships towards better outcomes for workers. There is no question that as a result, millions of workers have seen dramatic improvements in their working conditions....We are 
proud to see our efforts to meet customer needs here in New Zealand also contributing to the income and welfare of citizens in developing countries." (Company report 3 )

Similarly, the following quote from a company representative shows how a commercial company is positioned as helping workers in the company's production chain and helping consumers by providing an ethical choice of product. The company is also shown as generally ethical and as doing "the right thing".

"The outcome here is that actually over time everyone starts to put in that same effort to ensure good outcomes for workers in their supply chain, and it's a visible, and consumers can choose then if they want to make a difference in terms of where they shop because of it and it means that companies who want to do the right thing because that's the sort of company they are" (Company representative 2 )

While consumers are not the main character in this narrative, they are positioned as doing good or as being in a position to do good through buying ethically sourced products. For example, the following excerpt from a company report shows consumers as being "delighted" to be able to buy products from a company which is benefiting society.

“The [company's] plan helps us secure a high-quality, reliable supply of [the product] from communities in West Africa. Resilient, sustainable communities are better able to do this, and as such, support our business in reaching consumers with the [product] brands that they know and love. Tackling child labour in [product industry], and the other initiatives we invest in as part of the [company's] plan, are a core part of how we do business in a way that benefits society and delights our consumers" (Company report 1 )

An assumption behind the positioning of companies and consumers as doing good is that wider systems of commerce and capitalism such as consumerism and the international sourcing of products and labour, are also assumed to be doing good. This assumption underlies this narrative and is also explicitly noted in the following interview with a company representative and in a quote by the UN Secretary General used in the 2018 US TIP report:

"You know, as we know, hundreds of millions of people have been lifted out of poverty through trading relationships with developing economies" (Company representative 3 ) "Global supply chains have transformed many lives for the better-but not always without costs. Clothes, food, smartphones, jewellery and other consumer goods may bear, wittingly or unwittingly, the traces of exploitation. Gleaming new skyscrapers may owe some of their 
shine to the sweat of bonded laborers." - Antonio Guterres, United Nations Secretary General" (US DoS, 2018, p52)

\subsubsection{Symbolic boundaries between commercial systems and the problem of trafficking}

The commercial businesses and systems as saviours narrative is enforced through a symbolic boundary drawn between commercial systems and the problem of trafficking. This boundary is shown through the presentation of such systems as good and of trafficking or exploitation as being an aberration to good moral systems. It is also visible through exclusions as the role of commercial businesses in making a profit is left out of this narrative. Companies are also distanced from exploitation and trafficking in two ways - through presenting trafficking and exploitation as a foreign issue with foreign causes and through the use of conceptual metaphors which show companies' work as objective, scientific, and removed.

The following examples show how exploitation and trafficking are shown as abnormal instances and a 'taint' on commercial systems that otherwise do good. In this example, a company representative presents international trade and supply chains as a method of helping workers and developing economies, presenting instances of exploitation as "extreme and isolated examples".

"Most of these enterprises [factories and suppliers] are positive enterprises. They care about their workforce, they pay people well, they care about health and safety, they're good productive enterprises... So I still feel like there's too much focus on the negative. Not saying it doesn't exist and we need to guard against them. But uh, the story overall is overwhelmingly positive. Yeah definitely I think it's a really tainted thing. The problem from my perspective is its come from that NGO that's quite rightly got a mission around protecting the extremities of the supply chain where workers are bonded and exploited and trafficked. Not saying that doesn't happen. But suddenly, you know uh an enterprise has to report on its supply chain as if it was you know riddled with modern day slavery. And these are extreme and isolated examples. I mean in the sum it amounts to millions of people right. But there's a lot more workers in the supply chain which aren't in that place." (Company representative 3)

In the following example taken from the 2018 US TIP report, global industries and supply chains are presented as being separate from problems of exploitation and as being "tainted" by instances of trafficking. Financial institutions, brands, and suppliers are also positioned as separate from the 
problem and as being those which are in a position to address it rather than playing a more complex role in creating situations where exploitation occurs.

"Monitoring the daily activity of local and global industries for evidence of illicit activity is a monumental task and governments cannot do it alone. Private financial institutions also play an important role through internal mechanisms to monitor their customers' transactions for potential red flags. To mitigate risk, financial institutions, brands, and suppliers often turn to internal and third-party risk assessment, due diligence, and compliance firms for data on entities with which they are doing business and on potential perpetrators of financial crimes. [This is followed by a description of the work of these third party firms carry out in compiling databases about 'potential perpetrators of trafficking'.].... Expanding the amount of data within this existing and effective institutional framework promises to help disrupt significantly financial flows and supply chains tainted by human trafficking, making it an effective tool for the prevention of human trafficking and the prosecution of perpetrators of human trafficking." (US DoS, 2018, p29)

The exclusion of the role of businesses in profiting from internationally sourcing goods and labour was carried throughout the discussions of ethical sourcing. For example, in one report, poverty is given as one of the drivers for poor working practices amongst producers of a product. The report also notes that sometimes the producers' sale of the product cannot supply them with a sufficient income to survive on. As a result, the commercial company is working with communities of producers to develop new schemes, unrelated to the products they purchase, to provide an additional income. What is missing from this is the commercial company's role in purchasing the product from the suppliers and at what price. The commercial company provides the income for the producers, yet it is not enough to keep them out of poverty. It may be that the commercial company cannot pay the producer a greater amount because it will mean they do not make a profit or a significant profit. The exclusion of companies' roles as the buyer of the product and as a profitmaking enterprise implies that the labour conditions surrounding the production of the product are not related to them.

Another way the symbolic boundary between commercial systems and the problem of trafficking and exploitation is drawn is through the presentation of exploitation as a foreign issue which takes place in developing countries and is due to local factors. Presenting exploitation as a foreign issue works to distance the companies and systems which source goods from these countries from the problem. 
The focus of the discussions with company representatives and the content of the company reports was about production in industries in developing countries, as opposed to production in New Zealand or other Western countries. This is the nature of much supply chain transparency work worldwide and highlights the idea of western exceptionalism from the problem of trafficking (this is discussed further in Chapter Six). Alongside this focus on developing nations, the problem of exploitative labour is discussed as being caused by local factors in developing countries. These local factors include poverty, norms, culture, tradition, education, a lack of awareness about acceptable labour standards, local infrastructure problems, demographic trends such as an aging population, limited national immigration policies, a lack of enforcing local labour laws, and corrupt officials.

The following quote is taken from an interview with a company representative and shows an example of how problems of labour exploitation relate to other countries and are caused by local factors in the sourcing country as opposed to contextualising the problem within the wider commercial system. These external causes include corruption and a lack of enforcement on the part of the Malaysian government and local labour shortages.

“...and in Malaysia they have systemic migrant labour issues um a lot of Malaysian industries depend on migrants and the government has a quota system and they don't actually issue enough quota and a lot of businesses in Malaysia have to resort to the grey market or the illegal market to recruit and retain workers because they can't access the workers. And what we found in this particular factory was a lot of undocumented workers that uh had no visa, no legal entitlement to be in Malaysia and to work. Uh their passports were withheld by management. They had paid significant recruitment fees to access the jobs they had. They uh were working significant amounts of overtime and the dormitories they were being housed in were not up to standard from a health and safety point of view.... To some extent that's indirectly sanctioned in my view from the Malaysian government and a passive attitude to migrant labour abuses...and there's a lot of corruption involved in access to quota. So when you actually peel the onion back a little bit you have this isolated incident which looks like isolated abuse, it is actually a part of a bigger picture, a bigger problematic picture in the county." (Company representative 3)

Another company representative discusses the causes of exploitative labour, in this case child labour, as being due to the local norms and culture.

“...but we had found many many cases of um child labour, inappropriate child labour. Because it is normalised in their culture." (Company representative 1) 
The focus on local causes of exploitation as opposed to global causes such as global income inequality or international demand for cheap goods, are not included and this contributes to a picture of exploitation as happening separately from international commercial systems.

As well as presenting exploitation as a foreign issue, the repeated use of a conceptual metaphor, where companies' ethical sourcing work is discussed using scientific language about systems and processes, works to embed the symbolic boundary between commercial systems and the problem of trafficking. As a conceptual metaphor, the language used is borrowed from the field of computer science. The language is used is about systems, processes, and mechanisms. Its repeated use here creates an image of ethical sourcing work as objective, scientific, precise, and involving a set of systems and processes that operate of their own accord to produce an accurate solution. This is not an uncommon language pattern and is not unique to these particular texts. It is a common metaphor where scientific and technical language is used to show precision and authority on a topic without going into detail about what the processes or systems are. In this instance, the effect this has is to show these monitoring and remediation processes as operating independently on supply chains and on exploitation in an objective way. The use of such language further distances commercial systems and companies from exploitation.

Examples of the type of language used includes companies carrying out the "execution of any corrective action plans" and "a schedule of corrective action" as a way of addressing exploitation in the supply chains. Such plans and schedules are shown as being delivered through "audit processes" and "functioning grievance mechanisms".

"Beyond these thresholds suppliers will be given the opportunity to demonstrate continuous improvement over time through the execution of any corrective action plans arising from site audits." (Company report 2)

"Continuous improvement is achieved through a schedule of corrective actions agreed by the factory as an output of the audit process." (Company report 3 )

"Every factory audit includes an evidence based check on the presence of a functioning grievance mechanism for workers." (Company report 3)

\subsubsection{Consumerism and global sourcing as the moral of the story}

In this research I studied report recommendations and concluding points as the moral of a story. Studying the moral of the story shows the likely effects of the narrative, as the moral constrains or enables certain actions (Presser and Sandberg, 2015b). In discussions and texts about supply chain 
transparency, the moral of the story was that commercial systems of consumerism and global sourcing can address trafficking and exploitation. This moral enforces the commercial businesses and systems as saviours narrative as it places companies, consumers, and commercial systems both as moral actors and as being able to act to stop exploitation. The answer to the problem of trafficking and exploitation is more consuming and more sourcing of goods and labour internationally.

This moral is shown through discussions of commercial companies carrying out ethical sourcing work to address exploitation in supply chains. Consumers are also given a part in that they are seen as being in a position to address exploitation through 'consumer power' and choosing ethically sourced goods.

The following example, taken from one of the company reports, shows how companies carrying out supply chain monitoring is presented as the answer to problems of exploitative labour.

"As mentioned above the cumulative effort of multiple brands enforcing these policies across their supply chains coupled with the work of local government has generated significant improvements in working and living conditions for millions of workers - as anyone who has been a regular visitor to these environments for the past two decades can attest." (Company report 1 )

Similarly, the quote below shows a government official discussing companies as being able to act to address trafficking and exploitation and how this is a potential solution to these problems.

"One kind of glimmer of hope I guess would be there's companies increasingly, these big international chains are starting to look to their supply chains and they are starting to put into place mechanisms where they can audit and not just on the environmental side fisheries, but also on the labour position side you know, those are, those are areas where there is improvement," (NZ Government Official 11)

The following example shows an explicit mention of "consumer power" as being a solution to preventing exploitation.

"so in the [agency name] we were looking at it [ethical sourcing] because we were very interested in exploitation within supply chains and New Zealanders buying products that may have been made by slave labour, even if it's in Bangladesh and very distant from New Zealand and Australia. Are our communities aware of that and do we want to you know be part of the solution to prevent that through consumer power" (NZ Government Official 9) 


\subsubsection{Outcomes of the commercial businesses and systems as saviours narrative}

Using ethical souring and supply chain transparency as a way of addressing trafficking situates trafficking as taking place in commercial supply chains and as a factor of international labour markets and neoliberal profit-making schemes. The inclusion of ethical sourcing in anti-trafficking work draws attention to the wider systems in which exploitation occurs and has potential to direct a stream of anti-trafficking work towards interventions which focus on systematic and structural factors, rather than a sole focus on individual offenders and victims. However, the way in which ethical sourcing has been narrated in documents analysed and interviews conducted for this research with the character of the heroic commercial business or system as good and moral is problematic.

This narrative creates a certain character which is positioned in a way that enables certain actions and restricts others. Companies and commercial systems are positioned as moral and as doing good, and as separate from the problem of trafficking. Consumerism and capitalist systems are presented as the answer to the trafficking problem and as opposed to being presented as having a part in creating the context in which exploitation can occur. The result of this positioning is that these systems are encouraged to continue and grow and are given new credibility as being seen as a force for good. Companies are encouraged to keep outsourcing their labour to lower cost countries which allow them to make bigger profit margins, these systems of sourcing goods and labour are encouraged to continue, and consumers are empowered to keep consuming by thinking they are solving the problem by consuming ethically sourced goods. By promoting consumerism and capitalism as the answer to trafficking, the aspects of these systems that create exploitative situations - such as demand for cheap goods and services, and the idea of making a financial profit off the labour of others - are not challenged.

Another problematic feature of the commercial businesses and systems as saviours narrative is that it can leave companies in a conflicted role. The role enterprises are given in this narrative conflicts with their ultimate aim of making profit and doing so through established systems of capitalism and consumerism. This conflicting role was shown in discussions of the difficulties of ethical sourcing work in company reports and interviews with company representatives. An example of this, which was raised in a few of the data sources, was the issue of long working hours for employees in supplier factories.

In this example, companies want to source goods which have been produced by workers working hours which are legal under local law or international labour standards. However, the practice in the countries they source from is to work for hours which are over the legal limit. To fulfil their 
commercial goal of profiting by purchasing goods at a low cost or purchasing goods that there is a consumer demand for, companies must continue to source from these factories. This maintains a system of long working hours and leaves unquestioned why the long hours exist. Presumably it is because workers do not receive sufficient pay from working lesser hours and higher wages cannot be provided because the employer, factory owner, companies that purchase the products, and all the other parties up the commercial chain, are motivated to make greater profit margins. This conflict is shown in the following excerpts from an interview with a company representative. The interviewee discusses the difficult position that the company is in as they are trying to adhere to legal standards for working hours but the company still needs to source production from these countries.

"So we've got to be pragmatic right because if you say the standard is so high that it's at the legal like country law, you actually won't create any work for anybody. Yeah. So then you go well what's the local practice and the good example is working hours and you know we've a tolerance of working hours up to I think its 70 hours per week. Now if we said no you can only work say 50 hours per week when you're working on our stuff, we wouldn't be able to get the production. Because the local standard is higher than the local law and the workers want the work and whether we like that or not that's a thing um. So there's we've got to be pragmatic but we report on that and say look, our tolerance for working hours is this, we achieve it in this percent of our factory base. Where it's not being achieved we would be trying to work on corrective action with that country but we're conscious that if we pull out then these people have no work." (Company representative 2)

The character created through this narrative of the commercial systems and companies as saviours has further implications which are worth considering in terms of who governs and defines trafficking as a social problem. In this narrative, businesses are ascribed an increased responsibility for governing the problem of trafficking both in determining what they will count as trafficking and exploitation and in how to respond. One company included in this research was involved in carrying out a wide range of development activities in a country they were sourcing their product from. These activities included building schools and education infrastructure, agriculture infrastructure, and programmes aimed at increasing gender equality. These are types of activities which would traditionally be the responsibility of the state government or other local governance groups. By taking on these functions, commercial enterprises are taking on governance roles which may normally sit with local governance bodies and structures. It is worth considering what the implications may be for both commercial companies and the country. 
Positioning commercial companies and systems in the saviour role puts them in a new and sometimes conflicting role of having to prevent and, in some cases, govern social harm issues. It also promotes consumerism and capitalism as the answer to trafficking and embeds the trafficking problem in neoliberal discourses. This means that neoliberalism and the systems that go along with is such as global labour markets, consumerism, demand for cheap goods and services, and the idea of profiting off the labour of others are not challenged. While companies and commercial systems are a crucial character to include in trafficking narratives, their role in being part of such systems and as making profits should be at the fore rather than positioning them solely as saviours.

It is not surprising to find the commercial companies as saviours narrative being voiced by businesses. We can assume that it is in part taken up as a strategic narrative which as it creates benefits for companies as their 'brand' is shown to be ethical. While this narrative cannot be generalised as indicative of anti-trafficking discussions from other NZ businesses, this narrative can be seen being taken up more widely in the data, featuring both in the US DoS reports and some of the interviews with New Zealand government officials. It has the potential to become a powerful narrative in the anti-trafficking field through its persuasiveness and its likely repetition in the public domain. Mayer (2014) describes stories which have well known characters such as a hero and which are have a moral component, as being likely to be persuasive as they capture the public's interest and resonate with their audience. He also notes that stories that are repeated in society are more powerful as repeated exposure to narratives makes them more likely to be taken up by individuals (Mayer, 2014). As this strategic narrative of companies as saviours is promoted to consumers, it is likely to be influential as it is repeated in the public domain. Given the strength of this narrative and the increasing incorporation of commercial enterprises into anti-trafficking efforts, it is important to be aware of how the role of companies and commercial systems is narrated.

\subsection{Narrative 3. Trafficking as dodgy business}

\subsubsection{Overview of narrative}

This narrative takes the form of a common proposition about the problem of trafficking - that it is business carried out on the borders of legality. In this narrative trafficking is something that takes place in small scale, often family run businesses. Exploitation takes place in everyday business practice and is not considered unusual. These practices may border on legal but have a 'dodgy' edge. Work and employment arrangements such as hours worked and amounts paid are important and take precedence over other discussions. The characters who do the exploitation are described as restaurant owners, travel agents, small scale labour contractors and other small business 
practitioners. Those being exploited are described as workers. Both those doing the exploitation and those being exploited are driven by profit. The exploited workers have agency and act to make rational decisions and take opportunities to secure a better income or residency. Exploitation is seen as widespread, unsurprising and taking place in New Zealand industries.

\subsubsection{Evidence of narrative}

This narrative came through strongly in the interviews with the New Zealand officials and was the dominant narrative present in these sources. It was present in discussions of cases of trafficking or exploitation that people had worked on and discussions about what trafficking looked like in New Zealand. This narrative did not occur in the international reports (UN and US DoS reports) or the interviews with company representatives and company reports.

The interviewees came from a range of organisations and so it is difficult to attribute the uptake of this narrative to a set of discourses available within a specific agency, for example, discourses available within NZ Police or NZ Immigration agencies. Rather, the presence of this narrative across agencies suggests that it has grown out of a group of agencies and individuals trying to make sense of situations they have experienced. These situations have involved people who are recent migrants being exploited in work settings. Following narrative criminology theory that all experience is storied (Presser, 2009), narratives become unavoidable and so there will no doubt be a range of existing positions and discourses drawn on in creating this particular narrative. As this narrative is not tied to one organisation it is difficult to say what these may be. However the absence of this narrative in the international guidance documents suggests that it has developed alongside the New Zealand experience.

In this section I present evidence of this narrative from the data using quotes as illustrative examples. The evidence is grouped into five areas. The first of these is positioning of characters in business terms where those carrying out the exploitation and those who are exploited being positioned in relation to the business they work in and the role. The second is work and employment arrangements which border on legal where work arrangements are central to the narrative and are presented as 'dodgy'. The third is a focus on profit which includes both profits as motivations for exploiters and exploited people as well as a focus on the loss of income through exploitation. The fourth section shows evidence for the role of victims as autonomous and rational actors who make decisions in order to earn money or gain residency. The last section shows the inclusion of industries as the setting for where trafficking takes place. 


\subsubsection{Positioning of characters in business terms}

The evidence discussed in this subsection shows how, through character positioning, those who are carrying out trafficking or exploitation and those who are trafficked or exploited are positioned in relation to their business and employment roles. This sets trafficking as something that happens within working arrangements. The types of business roles discussed also shows trafficking as taking place in small scale, often family run businesses.

In the interviews with officials, those carrying out the trafficking or exploitation are described in terms of their work position. This included "restaurant owners", "travel agents", "immigration agents", "employers", "business owners", or "contractors". They are also described as "entrepreneurial people" and business people. For example, in the quote below from NZ Government Official 7 those who carry out trafficking are described as restaurant owners or contractors. In the following quote from NZ Government Official 4, those who carry out trafficking are described as entrepreneurial and opportunistically business minded people.

“(Speaking about a person who has been trafficked)... at the same time you're mindful that he's been victimised by this particular member of the community who might be the restaurant owner or the contractor ..." (NZ Government Official 7)

"They have been entrepreneurial people who have seen potential in immigration policy settings and taken great advantage of them..." (NZ Government Official 4)

As well as positioning those carrying out the exploitation in their business role, their business was often named and the business was often described as a family business. These details added to the representation of trafficking as taking place within a business context, and specifically, businesses which were small scale and sometimes family run operations. For example, Government Official 5 describes a trafficking operation as being carried out through a family run restaurant chain.

"It was a family run, so a restaurant chain, and obviously bringing people here and paying them bugger all" (NZ Government Official 5)

Those who are exploited or trafficked, although frequently referred to as victims, are also often called "workers" and sometimes their specific work position is named such as "kiwi fruit worker" or "construction workers". For example, the following quote shows victims being described as "Filipino workers that were brought here as chefs", emphasising their position as operating within a workplace situation. 
“..we've had a recent case in fact, one we just went through trial and got guilty pleas in result of the trial in an exploitation case that involves five victims, Filipino workers that were brought here as chefs and exploited." (NZ Government Official 2)

\subsubsection{Work and employment arrangements which border on legal}

Evidence for the trafficking as dodgy business narrative also came through in the focus on work arrangements and employment practices given in the interviews, and their presentation as being "dodgy" and bordering on illegality. This focus situates trafficking as happening within work arrangements and shows exploitation as occurring within these dishonest, fraudulent, illegitimate, or unethical business practices.

In the interviews with New Zealand officials there was much discussion of the work arrangements and employment practices in cases of trafficking or examples of potential trafficking situations. This included the hours employees worked, how much they were paid, and the type of work they were carrying out. These topics were the focus of much of the interviews as opposed to other topics such as abuse of victims, their suffering, and the use of force and violence - topics which are typically associated with human trafficking in international media and advocacy campaigns (Andrijasevic and Mai, 2016). For example, discussions of hours worked and the amount paid were common, as is shown in the following excerpt where a situation is described where workers were made to work for more hours than originally agreed, were not given holidays, and were paid less than they expected for the hours worked.

"They were in effect going over and offering jobs on three year work visas to be paid at a certain rate and conditions and when people got here they were exploited in the sense that they worked many more hours that what they were told, weren't given any holidays and bits a pieces, and their rate of pay comparable to the hours worked wasn't what it was supposed to be." (NZ Government Official 2)

The business practices are described as being "dodgy", legally ambiguous, or unethical in that work schemes "rip people off", and "fleece them", "bleed them". Business arrangements are also described as being a "caper" or a "circus" implying they are illicit escapades which are in some ways ridiculous or false. For example, the following quote shows employment practices, illegitimate profits and tax practices being described as "dodgy".

"There has been some dodgy employment practices in the past and there's a case probably from seven or eight years ago where there was three or four guys convicted... there was 
guys on the books receiving lots of money and not a lot of tax being paid and some dodgy stuff going on." (NZ Government Official 1)

As well as being "dodgy" such business practices are described as being legally ambiguous. For example, Government Official 17 describes a business's recruitment practices as "less than transparent" and describes how the operators have exploited a "legal loophole".

“...that particular method of bringing people in in less than transparent circumstance... it's a legal loophole." (NZ Government Official 17)

Although often described as legally ambiguous, these exploitative situations are presented as unethical work and business arrangements. Business practices are described as being designed to "bleed as much off the people who are desperate for jobs" (NZ Government Official 4), to "fleece them" (Government Official 19), and victims are described as being "ripped off in a thousand ways" (NZ Government official 8). The focus on work arrangements and employment practices which are dodgy, unethical and bordering on illegality, situates trafficking as happening within fraudulent, illegitimate business practice. This is a focus that is very different compared to the long-standing international narratives about trafficking as being carried out by largescale sinister organised groups.

\subsubsection{Focus on profit}

Evidence for the trafficking as dodgy business narrative also came through in the emphasis given to financial profits in the interviews with New Zealand officials. This included profit as a motivator for both those carrying out the trafficking and those being exploited. It also includes discussions of how and how much profit was made by employers, and the loss of money for the workers through the exploitation. The focus on profit emphasises the nature of trafficking as being something that happens within commercial enterprises and money making schemes.

Narrations of trafficking situations given by interviewees often included the business owners or employers who carry out the exploitation as being motivated by financial profit. This is demonstrated in the following quote where the interviewee discusses the importance of profit for the person carrying out the exploitation.

"Basically it just comes down to the money from the offender's side of it. It's just an easy bit of cash for them to fill their pockets with um yeah." (NZ Government Official 18)

Narrations also often included the financial motivation on the part of the exploited person as well as the exploiter. The people who are exploited are considered to be motivated by profit and as having sought work in order to make a financial gain for themselves, their family, or their community. In the 
following example, Government Official 7 describes exploited workers as being driven by the aim of earning a higher wage in New Zealand than they would be able to in their home country, and how their motivation is to earn money for their extended family in their home country.

"They [exploited workers] know that the opportunities are better here in terms of the money, the rates...from an economic point of view, a financial point of view, they know that they're better off working here and being able to send remittance home and it's not just the immediate family or wife or children. You're talking about a whole heap or big range of extended family members that they would be supporting. So that's why ideally they'd love to go [home] but as they say no, what they're able to earn here is a lot lot better than what they could be earning back home." (NZ Government Official 7)

As well as discussing profit as a driving factor, there were also frequent discussions about how money is made by employers and how money is lost for the workers through the exploitative business practices. For example, Government Official 10 includes as description of how an employer makes a profit off the work of others and how the workers are left with a financial loss. This recurrent focus on profit emphasises trafficking as being something that happens within commercial profit-making schemes.

"In this particular scenario it's a case of um, in a typical community bringing younger people back into New Zealand and getting them to work and taking a huge percentage of that money and leaving them with almost nothing, and that sort work exploitation is what the um, is what we're looking at." (NZ Government Official 10)

\subsubsection{Victims as autonomous and rational actors}

Under this narrative, the victims of trafficking are largely described as being active and as having agency. They have goals of making money or of gaining residency and they are discussed as making rational choices and being active in taking opportunities available to them to achieve their goals. This positioning contributes to the trafficking as dodgy business narrative as it emphasises victims' position as workers seeking to make money through employment arrangements. This positioning of victims as autonomous and rational actors is very different from more traditional presentations of victims of trafficking in international campaigns, reports, and political rhetoric as innocent, nonconsenting, deceived, tricked, or subject to force or violence (Andrijasevic and Mai, 2016; Mai, 2016; Andrijasevic, 2007). 
As an example, the following excerpt from an interview shows how victims in a trafficking case are positioned as rational and active. In this example, the victims see an opportunity to earn a greater wage in New Zealand than they would be able to in Fiji and take action to secure this opportunity.

"They just saw the opportunity to come to New Zealand as just unbelievable. \$17 NZ is about \$25 Fijian an hour. So that money for them when they were earning \$1 or 2 an hour Fijian is it's just an unbelievable opportunity for their families." (NZ Government Official 3) In another example, the interviewee describes victims as taking action to achieve their goal of attaining residency through a work scheme. It is implied that the victims are aware that the work scheme is undesirable but that they are making a rational choice in taking up the best opportunity available to them within a limited situation.

"There's a lot of schemes in terms of purchasing residence and again whether that meets the threshold of trafficking, but you know the employer will say 'I'll create a work position for you but you have to pay $\$ 50,000$ and your own salary and that will get you on a path to residency', and people are in situations of desperation and they will do absolutely anything to try and give themselves and their families a better life." (NZ Government Official 15)

\subsubsection{Inclusion of industries}

Trafficking is further situated within business practices through the inclusion of industries in many of the discussions with officials. In these discussions, trafficking is shown as taking place within certain New Zealand industries. Within industries, employment types such as low to medium skilled employment, seasonal work and short term work, and labour hire contracting arrangement are also discussed as being situations where trafficking occurs. There is also an emphasis given to industries which employ migrants in short term labour arrangements.

For example, in the first quote below from NZ Government Official 13, the horticulture industry is named as having a long history of exploitative practices occurring within it. The second quote from NZ Government Official 22 shows trafficking situations as being placed within a certain type of employment - seasonal and transient - which occurs within the fruit growing industry.

"I think in terms of the horticulture industry, there's probably a lot more historically that's gone on that's just been accepted, but under the covers of, there was not a lot of talk about it, it wasn't in everybody's best interests to disclose it." (NZ Government Official 13) 
Interviewer: "do you think more of these types of cases [involving trafficking] will come up for your area?" Interviewee: "Oh potentially, yeah, for sure. Purely for the fact that we've got a lot of transient workers here especially in the summer time with the fruit industry what have you." (NZ Government Official 22)

Where exploitation takes place within certain New Zealand industries it is also discussed as being widespread and as something that is not uncommon within working arrangements. For example in the following excerpt exploitation is discussed as being "rife" within certain industries.

"...exploitation in New Zealand is rife. So the underpayment of people is just everywhere. So you've got lots of industries like the education industry where someone can work for 20 hours on a student visa... that's part of it or the hospitality industry where a restaurant will say 'yep you can work for me', they get exploited...' (NZ Government Official 3)

Viewing exploitation as common place within industries positions it as a function of commercial enterprises as opposed to an abnormal and morally abhorrent crime as is seen in the first narrative discussed in this chapter of trafficking as a profitable organised criminal enterprise. The inclusion of certain industries and the types of employment practices which occur within certain industries also places trafficking with the local receiving country context rather than presenting it as a problem which has foreign origins and is brought into the country from outside. The pervasive narrative, where trafficking is presented as a foreign problem, is shown in the following chapter.

\subsubsection{Outcomes of the trafficking as dodgy business narrative}

When trafficking is narrated as dodgy business the problem of trafficking takes on a distinct form which leads to certain outcomes, which in turn work to further define the parameters of the issue. By narrating trafficking as dodgy business, trafficking is situated in normal everyday business practices, which border on legality. The focus is on the work arrangements themselves and the industries in which they occur. This narrative draws attention to businesses, employment practices, and industries where exploitation occurs with the desired action being that exploitative employment practices are addressed. The course of action this narrative privileges is monitoring and regulating employment practices and certain industries. By prioritising these types of anti-trafficking work over others, work arrangements, business practices, and certain industries become central to both antitrafficking efforts and the definition of what trafficking looks like.

The narrative also draws attention to profits made, how they are made, and how they are distributed in terms of how much those doing the exploitation gain and how much those who are 
exploited lose. The implications of focusing on the profits made by those doing the exploitation and the workers is that profits should be more fairly, and legally, distributed. The course of action that follows from this focus on profits would be actions to ensure workers receive minimum wage, are paid for the hours they work, or receive they wage they thought they would be paid in taking on the work. Actions may also focus on the redistribution of profits that the business has made so that those who were exploited receive a greater share.

The trafficking as dodgy business narrative constitutes a different form of victimhood which allows victims to have agency, take action in seeking work, and consent to take part in the schemes they become involved in. This positioning of victims as agential is different from the more traditional presentations of trafficking which position victims as innocent, passive, acted on by traffickers, and as non-consenting (Andrijasevic and Mai, 2016; Mai, 2016; Andrijasevic, 2007). When the exploited parties are positioned as autonomous actors, in a description of trafficking, it makes it possible for them to claim victim status and the supports and assistance that come along with that status without having to fit the mould of innocent victims who had been forced into a labour scheme unwillingly. This form of victimhood is discussed alongside other forms which were present in the data, in Chapter Seven.

The trafficking as dodgy business narrative focuses very much on exploitation in the local context that it occurs in. Attention is paid to the industries and employment practices where exploitative conditions arise. In this way, this narrative lends itself to anti-trafficking work which attends to structural factors within certain industries which create vulnerable situations for workers. For example, this may be factors raised by some interviewees such as contracting and labour hire arrangements or a tolerance for poor working conditions in some industries.

While the first two narratives presented in this chapter are problematic, this third narrative presents a counter narrative which avoids the problems created by the first two. It provides a broader version of trafficking which does not focus on organised criminal groups as offenders. In this way it avoids the mismatch between the traditional narrative of trafficking as a problem of serious organised transnational enterprise and the breadth of situations trafficking is applied to. It also avoids the narrow focus on individual offenders created through the narrative of trafficking as a profitable organised criminal enterprise as it pays attention to structural and situational factors creating the problem. This narrative also avoids the problem posed by the second narrative-commercial companies and systems as saviours - where trafficking is separated from the commercial systems in which it occurs. In the second narrative commercial companies and systems are positioned as good and moral, and as the solution rather than a part of the problem. Whereas, the third narrative 
situates trafficking as happening within commercial enterprise, linked inherently to profit-making practices, and as common within certain industries.

The philosophical approach of this research meant that it did not seek out a reality or narratives which are most closely aligned with reality. This means that narratives cannot be ranked in accuracy. However, this research did seek to understand the material effects of different narratives, and in doing so, to understand which narratives are more useful and less harmful than others in terms of the realities they constitute. In avoiding the problematic effects of the first two narratives, the trafficking as dodgy business narrative provides an alternative way of understanding trafficking and one which may be useful in addressing harmful situations.

\subsection{Conclusion}

This chapter has presented three separate narratives which were identified in the data. These three narratives link trafficking to business, situate trafficking as happening within commercial enterprise and have a shared focus on profit. They are however, discrete with little overlap among them, and each have different implications for how trafficking is conceptualised and responded to. In this way, through the three narratives, three different forms of trafficking are structured, produced, enacted, and reinforced.

Each narrative is tied strongly to certain bodies, institutions, or groups. The first narrative about trafficking as profitable organised criminal enterprise came through predominantly in the UN and US DoS reporting and is a well-known narrative which has been a part of trafficking discourse during its modern development on an international stage. The second narrative where commercial systems and companies are positioned as saviours was most evident in the data from commercial companies, but was also present in US DoS reporting and some of the New Zealand based interviews. While its importance as a narrative for commercial companies is not surprising, its uptake by the US DoS as an internationally influential institution and in some of the interviews with New Zealand officials suggests that it is a narrative which has become widespread in supply chain transparency antitrafficking work. The third narrative where trafficking is presented as dodgy business appears exclusively in the interviews with New Zealand Government officials, but those from across a range of agencies. This suggests that this is a narrative which has arisen out of a group of people trying to make sense of situations of exploitation at work rather than as being tied to established discourses of a particular institution. 
The positioning of trafficking within a 'business' frame that occurs with the three narratives described in this section is useful as it highlights the neoliberal and capitalist systems in which trafficking takes place. The anti-trafficking interventions empowered by a 'business' type narrative would focuses on redistribution of profits and targeting systems which drive exploitative labour. However, the first two narratives explained in this chapter are problematic. While the epistemological underpinning of this research does not allow for conclusions about some narratives being more accurate than others, the third narrative does offer a way forward as it avoids problematic aspects of the first two. In the first narrative discussed, trafficking is presented as sinister, organised criminal enterprise. This narrative focuses on immoral individuals carrying out trafficking and lends itself to individualised criminal responses that do not account for systemic or structural problems that could be addressed to improve working conditions. It also provides a narrow characterisation of traffickers and a script for victimhood which does not include agency. The featuring of this narrative in international guiding texts has perhaps contributed to the low prosecution rate worldwide and the intensive nature of trafficking investigations and prosecutions, as a range of exploitative labour situations are shoehorned into a certain mould.

In the second narrative discussed in this chapter, commercial businesses and systems are presented as saviours. This narrative is problematic as it creates an impression of the character of companies and the supply chains themselves as moral actors out to do good which positions them as exempt from the problem of trafficking. The effect is that the neoliberal and capitalist systems become the solution rather than being included as a part of the cause of the problem. Furthermore, in this second narrative, while trafficking is situated as happening within businesses there is no discussion of profit, including questions of who profits and how profits could be better distributed.

The third narrative discussed in this chapter, the trafficking as dodgy business narrative, provides a very different framework for conceptualising trafficking. It situates exploitation and trafficking within the receiving country where it takes place, including employment structures, industry practices, and work arrangements. It is seen to occur locally rather than presenting trafficking as a problem brought in from outside with outside causes. The outcomes this narrative lends itself to are those which can be achieved by governments as they are largely within a state's control and are likely to be more practicable than targeting organised criminal businesses internationally. They also give some agency to the victims who may actively take a part in the work schemes in order to earn money.

While there can be no conclusions drawn about which narrative is more accurate, through studying the versions of trafficking which each narrative constitutes we can understand which narratives are 
harmful and which are more useful to the groups they affect. By avoiding the key problematic features of the first two narratives, the trafficking as dodgy business narrative provides an alternative way of understanding trafficking and one which may be useful in addressing harmful situations. 


\section{Chapter Six: Western exceptionalism and individualising trafficking}

In this chapter, I discuss three narratives which underlie the dominant approach taken in much antitrafficking work worldwide. These narratives are widespread and pervasive. They are present across the data sources and are a central part of wider trafficking discourse, seen throughout antitrafficking work, political rhetoric and campaigns around the world. These narratives are firstly, trafficking as a foreign other problem, secondly, trafficking as an abhorrent aberration, and thirdly, trafficking as a big unknown problem. When taken together they are constitutive of a form of trafficking where migrant groups are placed at the heart of the problem and become the target of interventions, policing and detection activities. When trafficking is constructed in this form, the way the problem is defined and acted on neglects the role of western countries and systems in creating the problem. Consequently a certain picture of trafficking, what the causes are, who is at the centre of the problem and who sits outside, is formed. The three narratives overlap, feed into each other, and point actions in a similar direction. The outcomes linked to these narratives are criminal, individual interventions which do not focus on receiving country factors, in particular western-anglo country factors, or wider systemic factors that allow trafficking to occur. The result is western exceptionalism from the causes of the trafficking problem.

This chapter pulls out these three narrative strands for analysis so that we can see them and assess their material impacts for the groups involved more clearly. Pulling them out for analysis shows how they work in creating a picture of trafficking which has been pervasive and widespread in the antitrafficking field despite being problematic. Considering how these narratives work is important in attempting to shift to an alternative narrative. In terms of how the narratives work and what they do, the first, which shows trafficking as a foreign other problem, is a common proposition which has a long history in migration and organised crime policy. The second narrative about trafficking as an abhorrent aberration is a moral story and the third, trafficking as a big unknown problem, is a crisis narrative. Moral tales and crisis stories contribute towards this dominant framing of trafficking through their persuasiveness and public appeal. While pulled out for analysis in this chapter, these three narratives also enforce the narratives discussed in Chapter Six about trafficking as serious organised criminal enterprise and about commercial systems as saviours through the othering of the trafficking problem.

As the three narratives described in this chapter have been an integral part of trafficking discourse and central in much trafficking policy and interventions, it is difficult to imagine an alternative approach. As a way of addressing this, after presenting each of the three narratives, I outline an alternative narrative to demonstrate a different way of narrating the problem of trafficking. This 
alternative narrative focuses on the local or receiving country where the exploitation takes place and lends itself to interventions that focus on local structural factors.

The alternative narrative is taken from literature on human trafficking for domestic services. An article by Thanos Maroukis (2017) is used as a specific example. In this example trafficking is narrated as having causes which are tied to the country or situation in which the exploitation occurs. These causes are compared to the causes of trafficking given in the three narratives presented in this chapter, to highlight a different way of thinking about trafficking. The causes in the alternative narrative include the extent to which the domestic service industry sector is regulated by labour authorities, the extent to which publicly funded care services are available as opposed to private and informal arrangements, local trends about providing home care within families versus privately, the immigration controls and visa conditions that create precarious work situations for migrants, and migrants' access to legal aid. Whereas the causes in the three narratives found in this research are about migrant groups and factors tied to less developed, non-western countries. This includes the culture and norms of migrants, their acceptance of poor working conditions and lack of education, the cruelty and greed of foreign traffickers, poverty and inequality in less developed countries, and corruption and weak law enforcement in less developed countries.

These two sets of underlying propositions about the problem of trafficking lend themselves to two very different types of anti-trafficking work and shape the problem of trafficking in different ways. The focus on local country factors leads to responses which address power imbalances in employment relationships, local norms about labour, the role of regulatory bodies, and local social and economic issues. In this alternative narrative migrant groups are no longer presented as being at the heart of the problem, and symbolic boundaries between the local country and the problem are removed.

\subsection{Narrative 1: Trafficking as a foreign other problem}

\subsubsection{Overview of narrative}

In this narrative trafficking is seen as a problem brought into western countries from other less developed countries. The problem is seen as foreign in two ways. Firstly, those being trafficked and the traffickers are narrated as being from 'other' countries. Secondly, the causes of the problem are external to the receiving country such as culture, norms, expectations, poverty, gender inequality, corruption, and poor policing in other less developed countries. International bodies such as the UN and western country governments are positioned as being responsible for fighting trafficking and are the experts in responding to the issue. 


\subsubsection{Evidence for narrative}

This is a widespread, dominant narrative and could usually be seen in some form throughout the interviews, observations and reports. It is particularly evident in the UN and US DoS reports. This narrative has been a part of trafficking discourse since its conception as a crime type through the UN Trafficking Protocol. The Trafficking Protocol positions trafficking as a transnational criminal and irregular migration issue by situating the Protocol within the UN Convention Against Transnational Organised Crime, and as sitting alongside protocols on smuggling migrants. It is not surprising therefore that the trafficking as a foreign other problem narrative comes through in the UN reporting or US DoS TIP reporting as they are international guiding documents, both drawing on and reproducing an internationally prevalent presentation of trafficking. Nor is it surprising that it comes through in interviews with New Zealand officials as this dominant picture of trafficking is embedded in practice as New Zealand, like many states, to date has used trafficking law exclusively in situations involving border crossing.

Externalising the causes of social problems, in particular crime, is not a new phenomenon and often features in populist campaigns which relate social problems to immigration. The process of othering that takes place when crime problems are blamed on foreign incoming groups is explained by alien conspiracy theory. This theory is discussed in detail in Chapter Eight and shows how organised crime in the US has been conceptualised as being brought into the country by foreign groups who conspire to corrupt western society (Smith, 1976). In this construction, organised crime is seen as something that comes from other countries, imported by ethnic minority groups who have immigrated to the US (Potter, 1994). These problematic groups are positioned as being outside of 'normal' society and are shown as acting on state governments, legitimate markets, and fiscal structures in a sinister, threatening, and conspiratorial way, to attempt to corrupt, infiltrate, and monopolise them (Potter, 1994). This construction of organised crime is embodied through US institutions, immigration policy, and foreign policy through their focus on external causes of organised crime and neglect of the interlinking role organised crime has with legitimate society (Hobbs and Antonopoulos, 2013). It creates the form organised crime takes since the focus on migrant groups as problematic increases policing and detection among these groups and increases their exclusion from society. The focus on migrants also obscures any structural and situational local factors that contribute to crime.

Alien conspiracy theory offers an explanation for why evidence of this narrative is present in both the US DoS and the UNODC reporting. As discussed in Chapter Five, discourses about trafficking as something carried out by immoral organised criminal groups were propagated through the US government's role in creating trafficking as a crime type during the design of the Trafficking Protocol, and is likely to have played a part in the ongoing othering of the trafficking problem (Hobbs and 
Antonopoulos, 2013; Woodiwiss and Hobbs, 2009). As well as focusing on immoral, sophisticated criminal enterprises, trafficking was also presented as a foreign threat to 'civilised' states which are described as being separate from the problem.

Woodiwiss and Hobbs (2009) trace alien conspiracy theory as a narrative theme through speeches given first at a conference in Washington DC for high-level US law enforcement and intelligence officials in September 1994, and then a few months later at the UN World Ministerial Conference on Organised Transnational Crime in Naples. The language used in the Washington conference showed the dominance of the alien conspiracy model and foreign othering in understanding organised crime:

"The keynote speaker at the conference, FBI Director Louis Freeh, stressed that 'the ravages of transnational crime' were the greatest long-term threat to the security of the United States and warned that the very fabric of democratic society was at risk everywhere. CIA Director, R. James Woolsey, followed up by noting that 'the threats from organized crime transcend traditional law enforcement concerns. They affect critical national security interests ... some governments find their authority besieged at home and their foreign policy interests imperilled abroad' (Woodiwiss and Hobbs, 2009, p. 116)

At the UN conference this language was repeated by UN Secretary-General Boutros Boutros-Ghali, in his opening address, as shown by Woodiwiss and Hobbs:

"In Europe, in Asia, in Africa and in America, the forces of darkness are at work and no society is spared ....' It 'scoffs at frontiers,' he continued, 'and becomes a universal force.' (Woodiwiss and Hobbs, 2009, p. 117)

Woodiwiss and Hobbs also highlight how the UN Secretary General positions transnational crime as separate from functioning legitimate states and commercial systems:

"It 'undermines the very foundations of the international democratic order. Transnational crime poisons the business climate, corrupts political leaders and undermines human rights. It weakens the effectiveness and credibility of institutions and thus undermines democratic life' (Woodiwiss and Hobbs, 2009, p. 117)

As discussed in Chapter Five, the result of the UN conference was a call to action for UN member states to act on transnational organised crime and led to the creation of the United Nations Convention against Transnational Organized Crime (UNTOC), which includes the Trafficking Protocol. 
Although the narrative of foreign othering is long-established and has been taken up in much antitrafficking work, this dominant picture of trafficking is currently being challenged internationally in various ways. International data collected by the UNODC shows much of trafficking as occurring within countries or within regions as opposed to being brought into western countries from distant developing non-western nations (UNODC, 2018a, p. 9). It is also problematized by the US DoS to focus on domestic trafficking, a large part of which is sex trafficking, where underage prostitution, regardless of immigration, is criminalised under trafficking law (United States Department of State, 2018a). Furthermore, signatory states to the Trafficking Protocol are required to take up a definition of human trafficking in national law which defines trafficking as occurring within a country as well as across borders (UNODC, 2019a). In New Zealand, the legal definition of human trafficking was changed in 2014 to include domestic movement rather than solely cross border movement (as outlined in the introduction).

In this section I present evidence of the trafficking as a foreign other problem narrative from the data using quotes as illustrative examples. The evidence is grouped into two areas. The first is character positioning of victims and offenders as foreign as these characters are shown as "coming over" from less developed countries, or existing domestically within "other" subcultures, and the positioning of victims as "overstayers" or "illegal immigrants". The second area is symbolic boundaries between the problem of trafficking and western countries which is shown through locating the causes of trafficking with other cultures, norms, and structural and governmental problems of developing nations. This area also examines the character positioning of international bodies and western governments as those who are striving to solve the problem of trafficking.

\subsubsection{Character positioning of victims and offenders as foreign}

The findings discussed in this section show how, through character positioning, victims and traffickers are constructed as foreign. They are shown as coming from 'other' countries, from 'other' nationalities and ethnicities. When they have not crossed a border, they are from an ethnic subculture or recent settler group within the state. The foreign problem narrative is also created through the positioning of trafficking victims as overstayers and illegal immigrants, drawing on a double metonym to equate trafficking with migration and crime.

Throughout the data, movement of trafficked people (especially across borders) is emphasised. Throughout all the data sources, trafficked people are shown as 'being brought in' and crossing international borders. For example, one interviewee describes trafficking victims as being "brought over" to New Zealand in order to earn money to send to their families in their home county: 
“They've been brought over here and they've been told, they're here to make money for their families back home." (NZ Government Official 10)

Another interviewee emphasises cross border movement by describing trafficking victims as coming into the country on an aeroplane:

"The opportunity to make money over here is overwhelming [so they are told] so 'you believe my lies', jump on a plane and then they were exploited." (NZ Government Official 3) The descriptions of trafficking shown in the New Zealand Plan of Action, outlined here, describe trafficking being a problem that 'crosses international borders' and involves 'people from overseas', thus emphasising the foreign nature of the problem and as being brought in to New Zealand from other countries. For example it is noted that:

"People trafficking is a crime against humanity that crosses international borders and damages an untold number of lives....In its simplest form, it involves the deceptive recruitment of people from overseas for forced exploitation, sometimes slavery like conditions." (DoL, 2010, p 3-4)

Movement across borders is also emphasised in the US DoS reports through short stories about victims' experiences. These are titled with the country of origin and the destination country (for example "Dominican Republic - United States" or "Bangladesh - Scotland", p7 and 37, US DoS, 2018) and some feature images which show movement, such as a family traveling from Burma to Bangladesh by boat (US DoS, 2018, p5) or an overcrowded boat presumably crossing the Mediterranean (US DoS, 2018, p33). In UN reporting, maps of the world with arrows showing international trafficking flows are used to show movement across borders (for example see diagram 1. in Chapter Four). The UNODC reports also include sections on 'trafficking flows' which present data on trafficking victims' source and destination countries and the geographical distances they have travelled.

Trafficked people and those carrying out the trafficking are also positioned as foreign throughout the data sources. This is done through the consistent inclusion of the trafficked people or traffickers' ethnicities or nationalities. For example, an interviewee lists the nationalities of people who may have been trafficked along with their work situation as "Indian students, Chinese labourers, Filipino construction workers, Sri Lankans on a dairy farm".

“...they [other government officials] might say 'we heard about such and such', but just a media report of whether it might be [about a potential trafficking situation], Indian students, 
Chinese labourers, Filipino construction workers, Sri Lankans on a dairy farm, whatever it may be..." (NZ Government Official 11)

Naming nationalities and ethnicities also was often used to describe those carrying out the trafficking or exploitation. For example, here an interviewee describes those carrying out the exploitation as "Indian bosses":

"A lot of them are on student visas and they're allowed to work 20 hours a week but that 20 hours is often stretched, the uh the Indian bosses threaten to send them back to India." (NZ Government Official 18)

Trafficking is also discussed as taking place within countries, but where this happens, trafficking and exploitation are shown as taking place within recent settler communities or within foreign subcultures. These groups are presented as being separate from a cohesive national culture. For example, one interviewee discusses potential trafficking cases which do not involve border crossing. In these cases, the exploitation is described as happening within certain ethnic communities, committed by members of the community to other members:

"Increasingly the problem is here in New Zealand with a uh say a franchise turns up for a dairy or a 7/11 kind of franchise, whatever it may be, where someone in that particular uh ethnic community is sold a job from within the existing community here in New Zealand and they have to pay back money to the person who secured them that job and they're all in the country so it's not transnational, they're here already." (NZ Government Official 22)

Another interviewee describes the problem of trafficking as existing within New Zealand but as happening within certain migrant groups. This constructs the problem as still being a foreign one which has been "brought in" to New Zealand through the migrants "bringing in" exploitative "cultural and commercial practices" and applying them to others in the migrant community.

"See what's happening there is that it's actually being brought in by agents who are themselves a migrant and they're bringing in some of these cultural and commercial practices from their source countries and they're not doing well by their citizens or countrymen. Often it's a migrant recruitment agent exploiting migrants." (Company representative, 3)

In several of the interviews, trafficked or exploited people are described as "overstayers" and "illegal migrants". This positioning creates a double metonym where trafficking is equated with migration, and immigration is equated with illegality. For example, here an interviewee describes potential trafficking victims as both "illegal immigrants" and "overstayers": 
"Another thing, I don't know if it would be relevant, is that they were all [victims and offenders] um in illegal immigrants in New Zealand so they'd come over on a visa which expired and they're all overstayers..." (NZ Government Official 20)

This is a phenomenon identified by Charteris-Black (2006) in his analysis of political dialogue on immigration policy in the UK. The use of such terms as substitutes for trafficked people creates an "illogical link" (Charteris-Black, 2006, p. 574) where, in this case, trafficking is linked with migration, and the migration is shown as illegal. This link cements the idea that trafficking is a problem that is brought into the country, sits with migrant groups, and that these groups are tied to illegal practices.

\subsubsection{Symbolic boundaries between the problem of trafficking and western countries}

The trafficking as a foreign other problem narrative is enforced through the symbolic boundary constructed between the problem of trafficking and western countries and western institutions. This boundary is constructed in two main ways. Firstly, the cause of the problem is located with external factors, such as other countries' cultures, norms, work expectations, corruption, inequality, or conflict. The role of the receiving country in creating demand for trafficked labour and in creating situations where exploitation occurs is excluded. Secondly, western governments and global north based international bodies are positioned exclusively as either experts in dealing with trafficking or those responsible for stopping trafficking as opposed to having a more complex position of being involved in creating situations where exploitation can occur. This position is seen through the conclusions or morals of the story and through conceptual metaphoric language which works to position these bodies as experts.

Throughout most of the interviews and reports, trafficking was described as having causes which were related to the migrants who had been trafficked or the countries they had come from. These could be individual factors linked to the migrants, factors linked to the sending country government, or structural or contextual factors about the sending country. In terms of individual factors, migrants' culture, norms, beliefs, work expectations, being a part of a closed tight knight community, having a lack of education, or a general naivety were named as causal factors creating conditions for the exploitation to occur. A lack of English and trust in authorities allowed the exploitation to continue. Also the cruelty, greed, and a willingness to make a profit by any means on the part of those carrying out the exploitation was also named in some sources. For example, one interviewee lists a "lack of knowledge", a tolerance of poor work conditions, and coming from a "closed community" as causal factors and a lack of English and "fear of authorities" is shown as allowing the exploitation to occur: 
“...but that is the most obvious um kind of vulnerability point where people who are coming from a different country with lack of knowledge, lack of access to information, their levels of expectations are lower about what they're willing to put up with in order to secure what they see as a better life than where they've come from, and they're a very closed community where perhaps they don't speak English and there's a fear of authorities whether they're here legally or not." (NZ Government Official 8)

The quote below is an example of how practices from other countries around tolerance for exploitation and a "lack of moral responsibility" are causes of trafficking. As with the quote above, this shows the causes of trafficking as external and related to other country factors.

"I put it in the context of you come from countries where the population size is huge, and then there's, although on paper, policy might say yes no violation of human rights and so forth but you know in practice it doesn't happen. And so [if] you make money off the back of misery of people that's alright. You know, that moral responsibility that we would come in with just doesn't factor in with some of the communities we come in, come from." (NZ Government Official 7)

Factors to do with governments in the sending countries were also often included in the causes of trafficking in some of the interviews and reports. These included corrupt officials, weak law enforcement and little monitoring of labour standards, and limited immigration policies. For example, the following interviewee describes corruption in other countries as creating a "breeding ground" for trafficking to occur.

"...the smaller the community and the more cultural or racial the groups are, the tight knit communities base type stuff we find, not only in Pacific islands but other small countries that's what you run in to. African countries are probably very similar in terms of um you know you don't use the word 'corrupt' quickly but it's like that, it's the start of that where they've got influence and that sort of creates a breeding ground for some of that offending." (NZ Government Official 12)

Other wider structural or contextual factors to do with sending countries were also named as causes of trafficking in some of the reports and interviews. These included poverty, gender and wealth inequality, acceptance of violence against women, unemployment, demographic factors, armed conflict, and environmental disasters. For example, in one company report, the existence of child labour is related to local demographic factors of having a young population " $53 \%$ of the population is under the age of 19. These demographic trends create a fertile environment for child labour to exist." 
(Company report 1). In another example an interviewee names India's caste system and gender inequality as a cause of trafficking "Then you've got the caste systems, this hierarchy, then the male and the female." (NZ Government Official 7).

These external, source country causes dominated discussions about trafficking. However, in a few of the interviews participants also named receiving country factors as causing or facilitating trafficking. These findings are shown in Chapter Five, in the trafficking as dodgy business narrative. In this chapter interviewees discuss trafficking as taking place within certain New Zealand industries. Employment types such as low to medium skilled employment, seasonal work, and short term work, and labour hire contracting arrangements are also discussed as contributing to or allowing exploitative situations to occur.

The second way in which the symbolic boundary between western countries and the problem of trafficking was enforced was by presenting state governments of receiving countries as those acting to solve the problem of trafficking. This was shown through studying the conclusions and recommendations as the morals of the story, which shows which groups are positioned to act to address the problem (Presser and Sandberg, 2015b). Throughout the interviews, reports and observations the New Zealand government, the US, the UN, or a collaboration of UN signatory states were shown as being able to act to solve the trafficking problem. This positions these state governments as the solution to the problem as opposed to positioning them as linked to the problem in more complex ways such as creating conditions for exploitation to occur through a range of state policies. While difficult to demonstrate this positioning in a short excerpt of text, the following excerpt from the 2018 US DoS report shows the United States Government being positioned as having the ability to address the trafficking problem as a "committed leader" with the ability to combat or fight the crime of trafficking through allocating "resources" to the issue:

"The United States remains a committed leader in combatting this global threat. President Trump has made ending human trafficking a top priority for the Administration and has dedicated the government's full resources to fighting this crime." (US DoS, 2018, introductory message from the Secretary of State)

Conceptual metaphoric language used throughout the US DoS and UN reporting also creates a distance between these bodies and the problem of trafficking, by positioning them as experts. This contributes to the symbolic boundary between western states and the problem of trafficking as the US government, as a western country, and the UN as a historically a Global North based institution, are positioned solving the problem. In this conceptual metaphor, as was shown in Chapter Five in relation to the commercial systems as saviours narrative, the language used is borrowed from the 
field of computer science. The language is around systems, processes and mechanisms. Its repeated use creates an image of the anti-trafficking work carried out by these bodies as scientific, precise, authoritative, and leading to accurate solutions. The focus is on the systems, processes, and tools themselves rather than on the author of the report, which works to obscure the bodies carrying out this work and any aims and agendas they may have.

The following text from the US DoS and UN reports show examples of how this conceptual metaphor is built. They use borrowed terminology which includes language about "systems", "generation of estimates", "programmatic action", "schemes", "mechanisms", "instruments", and "diagnostic tools, spectrums, and measurement frameworks". For example the excerpts from the 2018 UNODC report describe a technical tool called the "Multiple Systems Estimation" which will work, seemingly of its own accord, to create "the generation of estimates" about how many trafficking victims exist and in this way produce knowledge about them in order to address the problem.

"The 2016 edition presented Multiple Systems Estimation (MSE), a methodology that permits the generation of estimates of hidden populations such as trafficking victims on the basis of sound national-level data." (UNODC, 2018, p36)

Similarly, the text below from the 2018 report describes a set of schemes, programmes, and mechanisms which work, seemingly objectively and independently to address the trafficking problem.
"Where the number of detected victims has increased after legislative or programmatic action, however, these actions - including amendments to legislation, enforcement of well- designed action plans, victim protection schemes and national referral mechanisms - have clearly contributed to improving the identification of victims and the effectiveness of criminal justice responses." (UNODC, 2018, p13).

Further to this, in a narrative analysis of US DoS trafficking in persons reports by Taylor and Isgro (2018) they showed how aspects of the report setting worked to position the US DoS and Anglowestern countries as separate from the problem of trafficking. In studying the setting I included the intended audience of the documents. In Taylor and Isgro's study of US DoS TIP reporting over the years, they found that the reports were published on the US DoS website and were available largely and for some issues, exclusively, in English. This brings into question the nominal purpose of these reports - being to inform state governments around the world, and implies that the US and other Anglo countries are those who take a stance against trafficking. 


\subsubsection{Outcomes of the trafficking as a foreign other problem narrative}

This narrative creates the problem of trafficking as one where migrant communities are central and where local receiving country factors are neglected. This narrative shows the causes of trafficking as foreign and as coming from less developed countries into western or global north countries. The result is that western countries are seen as separate from the causes of the problem. Interventions that are enabled by this narrative are those which focus on external factors or migration itself, as opposed to more local factors that relate to the situation where the exploitation has occurred. In such interventions, the problem of trafficking is largely individualised as the migrants, both victims and offenders are the focus. Responses that target migration include increasing border security, creating immigration policies that limit migration, and repatriating victims. Individualised interventions focus on criminal prosecutions of individual offenders or those that focus on migrants themselves as a vulnerable group which can result in monitoring and policing of migrant communities in an attempt to prevent trafficking. The focus on these individuals and groups places them at the heart of the problem, whereas the wider range of factors that allow exploitation to occur are omitted.

The trafficking as a foreign other problem narrative separates the problem of trafficking from the situations in which the exploitation takes place. In this narrative local factors that may cause or facilitate exploitation are excluded. This means that the structural or situational factors which allow exploitation to take place are not acted on as causes of the problem. These could be a range of factors, for example as named in the alternative narrative presented at the end of this chapter, they could include policy settings such as immigration policy or employment law which creates precarious situations for workers, or practices or employment structures within certain industries. This distance created between the problem of trafficking and the situations in which exploitation takes place contributes to a sense of western exceptionalism from the problem of trafficking.

I use the term 'western exceptionalism' to describe a set of findings where western countries, including New Zealand and in particular the US shown through the US DoS reporting, western institutions including the UNODC, and western favoured neoliberal systems of consumerism, commercialism and international trade, are presented as being separate from the problem of trafficking. As well as being separate, they are also positioned as being the bodies who can 'fight' the problem of trafficking and are shown as being superior to the places where the problem comes from in their ability to address it. The term 'exceptionalism' has been used to describe the presentation of countries, groups, systems or institutions as being exceptional in some way. Exceptional is used to present the group as unique and also superior (Roberts and Dicuirci, 2013; Lipset, 1997). The idea of exceptionalism also shows the exceptional group as being exempt from certain issues and as 
separate from certain groups. Any differences are overstated, and similarities and commonalities are downplayed. The term exceptionalism is often tied to nationalism and white supremacy (Thobani, 2018). The term's most popular use has been as 'American exceptionalism', where the American nation and its identity, culture, and values are held as superior to other nations and their superiority carries the notion that American norms should be spread around the world (Nolte and Aust, 2013). The idea of western exceptionalism carries the notion that western states, institutions, systems, and values are superior and the ideals of western civilisation should be taken up in less 'developed' countries (Thobani, 2018; Rahman, 2014). Along with this, western civilisation is seen as being exempt from problems which are brought in from less civilised, non-western states (Thobani, 2018; Rahman, 2014).

As discussed above, the trafficking as a foreign other problem narrative has been a major part of trafficking discourse since its conception as a crime type through the UN trafficking protocol. The form of trafficking constituted in this narrative can be seen in the types of trafficking interventions which are promoted as good practice and which have been carried out around the world to date. Policies to tighten border security and limit migration have been a frequently used response to trafficking in many states (GAATW, 2007; Ahmed, 2005; Anderson and O'Connell Davidson, 2003). These policies have been well documented and critiqued (this body of literature is discussed in the Literature review Chapter Two). The major criticism of limiting migration is that by making legal migration less available, migrants must undertake illegal forms of migration, as the factors driving migration remain the same (Meyer and Boll, 2018; Anderson and O'Connell Davidson, 2002, 2003). These illegal or 'irregular' forms are more open to exploitation as migrants do not have legal rights to travel or to be employed (Ahmed, 2005; Sanghera, 2005, p. 8). These types of interventions both define and create trafficking as a being a problem about migrant groups as these groups are monitored and have their channels of safe and legal migration and employment limited, placing them in vulnerable situations.

Alongside responses that limit or control migration, criminal prosecutions of individual traffickers have been prioritised as a main response to trafficking internationally. This approach is pushed through the UN protocol requirements which include the requirement for signatory states to include trafficking in criminal legislation. This response is also promoted through the use of criminal prosecutions as a success measure for responding to trafficking in international forums. For example this is a part of rating state governments' success in anti-trafficking work in the US DoS reporting and the UNODC reports. The use of criminal prosecutions which focus on trafficking as a crime carried out by foreign traffickers or international criminal groups as the main response to trafficking, has been criticised in much academic literature (this is discussed in Chapter Two in more detail). The 
main critique is that by focusing on individual prosecutions, local and global factors that drive trafficking are neglected, such as addressing weaknesses in local labour frameworks or addressing driving factors of neoliberal systems of trade and production (George et al., 2017; Szörényi, 2016; Kempadoo, 2015; Dottridge, 2007).

The other type of intervention legitimised by the trafficking as a foreign other narrative is the targeting of migrant groups. This is a response to trafficking which has been seen in a number of forms around the world. For example, one interviewee discussed a project in the UK where police collected information about women of different ethnic groups in the sex industry as a way of responding to trafficking through monitoring these groups. Other examples include in some countries, women's ability to migrate is restricted as a protective measure against future exploitation (GAATW, 2007) and in some countries migrant women are forcibly detained in prisonlike shelters in the name of victim protection (Abdul-Hamid, 2019; Lee, 2014; Gallagher and Pearson, 2010). These types of interventions result in monitoring, policing and in some cases punishing of certain migrant groups through restricting ability to migrate and work legally (Anderson and O'Connell Davidson, 2003; Ahmed, 2005). Again, this type of intervention constitutes migration at the centre of the trafficking problem through focusing on migrant communities with increased policing and monitoring as well as interventions that can create vulnerable situations for these groups.

As well as constructing a problematic form of trafficking and contributing to a sense of western exceptionalism, the trafficking as a foreign other problem narrative also creates an issue for antitrafficking work going forwards as this dominant narrative is currently being challenged. As discussed earlier, the trafficking as a foreign other problem does not fit with trafficking law or reflect the international statistics collected by the UNODC (2018a), yet it is embodied through government responses in many states. The challenge for state governments then is to decide how to define what counts as a trafficking situation when the foreign other narrative no longer applies.

\subsection{Narrative 2: Trafficking as an abhorrent aberration}

\subsubsection{Overview of narrative}

In this narrative trafficking is shown as something that is abnormal, immoral, horrific, and unusual. It is shown as an abhorrent aberration that takes place in otherwise good systems of labour markets and supply chains. It causes a stain on these otherwise good systems and involves individuals acting in immoral ways. In terms of the form this narrative takes, it is a moral story which is linked to the earlier narrative of trafficking as a foreign other problem and the narrative discussed in the next 
section which shows trafficking as a big unknown problem. This moral narrative strand sits alongside the other two strands and emphasises the moral divide between civilised states and the immoral individual 'others' who bring the problem in from less civilised societies.

\subsubsection{Evidence for narrative}

This is a dominant narrative that is frequently attached to trafficking in reporting and media coverage of trafficking internationally, as trafficking tends to be presented as a horrific and abnormal crime (Kempadoo, 2015; Tomkinson, 2012; Vance, 2011a). In the data I analysed, I found this narrative featured in international documents on trafficking and in discussions and reports about commercial businesses carrying out ethical sourcing and supply chain transparency work. It was largely absent from the interviews with New Zealand officials and came through only in instances where trafficking was being discussed in very general terms as opposed to specific cases.

Moralistic language and caricatures of evil traffickers and innocent victims have been identified through analyses of anti-trafficking campaigns which treat trafficking as sex trafficking (Snajdr, 2013; Tomkinson, 2012; Andrijasevic, 2007). These have been tied to an underlying moral opposition to prostitution (Andrijasevic and Mai, 2016; Kempadoo, 2015; Doezema, 2010). These moralistic campaigns about sex trafficking have been widespread in the past 30 years of anti-trafficking work and it is likely this has meant that discourses of morality are readily available in international antitrafficking work. This may explain the presence of the trafficking as an abhorrent aberration narrative in some of the data used in this study. This may also explain the absence of this narrative in the interviews with New Zealand officials given that in New Zealand sex-work is decriminalised and moral and religious debates about abolishing prostitution are less prominent. New Zealand's position in this regard may mean that moralistic discourses about trafficking have less relevance and less uptake among officials working on anti-trafficking projects.

In this section I present evidence of this narrative from the data using quotes as illustrative examples. The evidence is grouped into two areas. The first is a symbolic boundary between trafficking and normality where trafficking is presented as something horrific that sits outside of a joint humanity. The second is the use of melodrama where melodrama is used as a narrative form which focuses on individual victims and traffickers. 


\subsubsection{Symbolic boundary between trafficking and normality}

The trafficking as an abhorrent aberration narrative is enforced through a symbolic boundary drawn between instances of trafficking and normality. Trafficking is shown as something that is horrific and unusual and separate from 'normal life' or a joint humanity. It is also shown as something that sits outside of normal and healthy functioning systems of production, international trade, and labour markets as opposed to something that may happen within them.

Presenting trafficking as something horrific and abnormal is not unique to this research and is a common theme in international anti-trafficking work (Kempadoo, 2015; Tomkinson, 2012; Vance, 2011b, 2011a). It is therefore not surprising that trafficking is presented this way in the US and UN reporting, as international guiding documents, as well as the New Zealand Plan of Action which at its time of development, drew heavily on information from international bodies.

In these sources, language is used to describe trafficking as "abhorrent", "horrific", "heinous", and "horrendous". For example, in the 2016 UNODC report trafficking is described as a "horrendous crime" (UNODC, 2016, introduction from the Executive Director United Nations Office on Drugs and Crime), and in the 2018 report is described as horrific: "Trafficking in armed conflict has taken on horrific dimensions" (UNODC, 2018 introduction from the Executive Director United Nations Office on Drugs and Crime). In the US DoS 2017 report it is described heinous in nature and thus requiring harsh punishment: "...the government of the country should prescribe punishment that is sufficiently stringent to deter and that adequately reflects the heinous nature of the offense." (US DoS, 2017, p38).

The idea that trafficking is something abhorrent that sits outside of a joint humanity is conveyed through the UN Plan of Action as trafficking is positioned as a "serious threat to human dignity" and as a "serious challenge to humanity".

"Reiterating its strong condemnation of trafficking in persons, especially women and children, which constitutes a serious threat to human dignity, human rights and development, ... Recalling also the 2005 World Summit Outcome adopted by the General Assembly on 16 September 2005, noting that trafficking in persons continues to pose a serious challenge to humanity and requires a concerted international response ..." (UN Plan of Action, 2010, p1)

Similar language is shown in the NZ Plan of Action where trafficking is positioned as an "assault on human dignity". These examples show language which enforces the boundary between trafficking and humanity. 
"Human trafficking is an assault on human dignity and should be penalized accordingly." (US DoS, 2017, p12)

The symbolic boundary between trafficking and normality is further enforced through presentations of trafficking as something that happens outside of good and functioning systems of international trade and production of goods, global industries, global labour markets and financial systems. In Chapter Five the narrative of commercial companies and systems as saviours was presented. Under this narrative, systems of commerce and consumerism were presented as good and as being the solution to the trafficking problem as opposed to being a part of it. This data came from interviews with company officials, company reports and the US and UN reporting. In Chapter Five data is presented which shows discussions of people being "lifted out of poverty through trading relationships with developing countries" (Company representative 3), and where "Global supply chains have transformed many lives for the better..." (US DoS, 2018, 52). These systems are presented as good and trafficking and exploitation are shown as abnormal instances and as a "taint" on "global industries" and "supply chains" (US DoS, 2018, 29) and as "extreme and isolated examples" (Company representative 3 ) within supply chains.

\subsubsection{The use of melodrama}

The narrative of trafficking as an abhorrent aberration is contributed to by the use of melodrama in the US DoS and UN reporting and to a much lesser extent in the New Zealand Plan of Action and a few of the interviews. In this narrative analysis I did not intend to include narrative genre as a strategy for analysis. However, melodrama stood out as a central part of the trafficking as an abhorrent aberration narrative.

Melodrama is a narrative genre which focuses on sensational and romantic plots that feature struggles and danger and appeal to audiences' emotions. Sensational plots tend to take precedence over detailed character development and characters are oversimplified and stereotyped with little depth or development. They are commonly victims, heroes, and villains (Redmond, 1992; Brooks, 1985). Carol Vance identifies melodrama as 'the favourite narrative form for telling trafficking stories' in anti-trafficking campaigns (2011b, p. 136). In her analysis she shows how melodramatic stories about women in the sex industry are used in anti-trafficking campaigns to the extent that these sorts of scenarios have become normalised in the public's understanding of trafficking (Vance, 2011b). Melodrama is used to focus on individual actors characterised as victims and villains and shows how this focus works to divert attention from wider structural factors contributing to trafficking (Vance, 2011b, 2011a). 
The use of melodrama identified in this analysis contributes to the trafficking as an abhorrent aberration narrative as it shows trafficking as something that is individualised, affecting individual victims, carried out by individual traffickers, and as something sensational and unusual which stands apart from the normal or mundane.

The focus on individual, simplified, stereotypical characters is shown through depictions of victims and traffickers. In Chapter Five the character positioning of traffickers as immoral actors is shown through their alignment with criminal, military, armed, extremist, and terrorist groups in US and UN reporting. While they are presented as immoral there is little detail given about the traffickers - who they are, how they operate, what they do, and where they are in the world. Victims are shown as being in desperate situations and as being passive, acted on by the immoral characters. This is often expressed using animalistic metaphoric language about offenders who "prey" on or "entrap" their victims showing victims as helpless, desperate, lacking any agency and acted on by the traffickers who are powerful and predatory.

The following excerpt from the 2016 UNODC report gives an example of how people who are trafficked are often shown as being in desperate situations, facing challenges such as, in this example, 'physical and economic insecurity', 'poverty', and 'difficult living conditions'. In such situations of desperations victims are often described as being preyed on or in this example, 'fall prey' to the traffickers.

"Faced with physical and economic insecurity, families may see early forced marriage as a way of alleviating poverty and protecting girls from difficult living conditions. Similarly, they may fall prey to traffickers who claim to offer their children a safer place and job opportunities." (UNODC, 2016, p64)

The focus on sensational, dramatic, and unusual situations can be seen in the depiction of victims in dangerous or desperate situations. For example one image used in the US DoS 2018 report show a man on a boat crying and pleading as he travels away from a conflict zone with his family (US DoS, 2018 5), and another shows a woman standing in front of a dilapidated greenhouse holding a baby (US DoS, 2018, p6). The 2017 US DoS report starts with a dramatic story given by the Ambassador-atLarge to Monitor and Combat Trafficking in Persons. The story focuses on the desperate situation of the victim, and the danger and abuse that she faced.

"I am particularly and acutely aware of the lives destroyed by human trafficking. I will never forget a young woman in a case I prosecuted, a survivor who I'll call Teresa. She was raised in Central America by her grandmother, and as a young woman, was deceived by a man she 
thought cared for her with promises of love and a better life. That man brought Teresa to the United States and, instead of building a new life with her, forced her into commercial sex, took all the money she was paid, and intimidated her with threats of deportation and humiliation before her family. His threats not only instilled fear in Teresa and coerced her into exploitation; they also convinced her she was a criminal for violating federal immigration and local anti-prostitution laws."(US Dos, 2017, introduction from the Ambassador-at-Large to Monitor and Combat Trafficking in Persons)

In another example of a melodramatic plot, an interviewee describes an example of trafficking he was given at an international training course. In this example there is extreme and horrific violence and danger and suffering faced by the victims. As the interviewee says, this is a "sad and tragic case" and notes that these emotive examples were used in the training course.

"Or they talked about, there was an example, I'm not sure who gave it, it was just a general example that was given where they trafficked say like 18 Russian girls into Thailand um for to be prostitutes and they took them up to like a sort of, the $18^{\text {th }}$ floor of this building and they talked about what they're going to do and they just got one of the girls and they pushed her out the window. So what they had they had immediate compliance from all of the others... So there were quite a lot of sad and tragic cases used." (NZ Government Official 16)

It is worth noting that the melodrama as a narrative form largely did not feature in the interviews. In the few instances where it did, it was in relation to stories of trafficking which participants had heard discussed in international forums such as training courses (such as the above quote), or when trafficking was discussed in a very broad sense. Rather than focusing on stereotypical characters and desperation, violence and suffering, the focus was on employment arrangements such as hours worked and pay received and the 'victims' were discussed as having agency and being active in seeking work and better incomes (this is discussed under the trafficking as dodgy business narrative in Chapter Five). This is perhaps reflective of the lack of uptake of discourses of morality in antitrafficking work in New Zealand, as discussed at the start of this section.

\subsubsection{Outcomes of trafficking as an abhorrent aberration narrative}

The trafficking as an abhorrent aberration narrative shows trafficking as something that is abnormal and horrific. It is unusual and isolated cases carried out by individual offenders and is separate from wider systems of trade, labour markets, and employment, and sits apart from work and business 
practices within states and internationally. The actions attached to this narrative are those that focus on isolated cases of trafficking as carried out by individuals. This aligns with criminal prosecutions and sanctions for individual offenders as the appropriate response.

As well as individualising and criminalising trafficking responses, in constructing the problem as horrific and exceptional, it justifies the use of strategies to 'fight' trafficking which might in other contexts be seen as overly harsh or oppressive. For example, this could include severe criminal sentences for human trafficking or policies where migrants are held for extended periods of time in detention centres as a strategy to deter trafficking. The constitutive narrative of trafficking as being horrifying in nature diverts criticism from trafficking responses and legitimises them in the name of protection.

The trafficking as an abhorrent aberration narrative feeds into the idea that trafficking is a foreign incoming problem from which the receiving countries are separate. Alongside this, the wider systems in which trafficking can take place are not included as causes or facilitators of exploitation, as trafficking is presented as abnormal instances that are unrelated to wider systems of employment, supply chains, and labour markets. The implications of this are that anti-trafficking interventions would not attempt to look for and challenge structural factors in receiving countries or systemic factors within commercial systems which can create exploitative situations. This includes both global systems of capitalism, such as supply chains and international labour markets, the idea of migrating for work, as well as local receiving country factors such as industry norms, accepted work arrangements, and local immigration and employment legislation.

This narrative is closely linked with the other two discussed in this chapter and it is likely that its moralistic focus works to sustain the overall picture of western exceptionalism present in much antitrafficking work internationally. In Mayer's (2014) analysis of how narratives work, he identifies moral tales and melodramatic plots as having particular persuasive value as they are collectively known stories which draw people in. The melodramatic and moralistic nature of this narrative may be contributing to the longevity of the widespread idea of trafficking as a foreign and threatening issue and creating a barrier to change.

\subsection{Narrative 3: Trafficking as a big unknown problem}

\subsubsection{Overview of narrative}

In this narrative, trafficking is described as a big unknown problem which is hidden in everyday life. It sits alongside normality but is separate from it. It is sometimes sinister and insidious. Trafficking is 
seen as a large problem which can be overwhelming and seem out of control. Although it is hidden, it can be uncovered by officials, businesses, and society as people become more aware of what instances of trafficking look like. This narrative is closely linked with the earlier two narratives outlined in this chapter. It takes the form of a crisis narrative and, in this way, it fits together with the other two narratives to emphasis the severity of the issue and serves as a call to action.

\subsubsection{Evidence for narrative}

Presenting trafficking as a large, threatening and growing problem is a widely used and well documented theme in anti-trafficking campaigns, political rhetoric, and official reports internationally (Wylie, 2016; Weitzer, 2014; Doezema, 2010). It is therefore not surprising that the trafficking as a big unknown problem narrative was present in the reports from the UN and the US DoS as international guidance documents on trafficking. It was also present in many of the interviews with New Zealand officials. However, the form it took in the interviews was as a large, unknown problem to be discovered. This differed from the international reports where it was presented as both a large and unknown problem as well as one which is sinister and insidious in nature, creating a sense of trafficking as an unknown threat.

In this section I present evidence of this narrative from the data using quotes as illustrative examples. The findings are grouped into three areas. The first is common sayings, metaphors, and anecdotes to show trafficking as large and hidden. The second is characters positioned to 'spot' trafficking implying that the trafficking problem is extensive and waiting to be uncovered throughout society. The third is the use of language about trafficking as dark and sinister to evoke threat where such language is used to present the problem as both hidden and sinister.

\subsubsection{Common sayings, metaphors, and anecdotes to show trafficking as large and hidden}

Common sayings and metaphors, and personal anecdotes which came through in the interview data and the international guidance reports, contributed to the trafficking as a big unknown problem narrative. Common sayings, some of which were metaphorical, which were circulating amongst antitrafficking practitioners, and which were reflected in some of the international reporting, created an image of trafficking as a large, sometimes overwhelming, and hidden problem. There was also a small number of personal anecdotes in the interviews and reports which worked to present trafficking as hidden and sitting alongside normality. 
Common sayings, some of which include linguistic metaphors, which show trafficking as a large and hidden problem, were present in data from some of the interviews with anti-trafficking practitioners and in the observations. Some of these sayings were reflected in the international guidance reports and repeated through media reporting and anti-trafficking campaigns both in New Zealand and internationally. The repetition of these common sayings shows the trafficking as a large unknown problem narrative is dominant both in New Zealand and internationally, and shows how it is taken up and circulated.

The most frequently used saying and metaphor is that an instance of detected trafficking or a number of instances are the "tip of the iceberg". This is a frequently used saying and metaphor in anti-trafficking discourse internationally. A quick google search for 'tip of the iceberg human trafficking' results in numerous reports, articles, and academic publications from around the world which use this saying. In the New Zealand context this phrase was repeated in some of the interviews and in observations. For example, the $2017 \mathrm{New}$ Zealand conference for anti-trafficking practitioners was called 'Tip of the Iceberg: Addressing Exploitation and Trafficking in Persons throughout Aotearoa New Zealand' (Frazer, 2017). The following quote gives an example of how this metaphor is used by practitioners to represent the unknown scale of the problem:

"You know, as the name of the conference suggests, it is the tip of the iceberg and in the coming months and years we'll become more aware of the actual problem that is here and I hope that we'll be in a better position to deal with it in terms of training and better cooperation with our agency partners and NGOs." (NZ Government Official 17)

This saying probably started as a play on words with TIP being used as an abbreviation for trafficking in persons. The key message in this saying is that the problem is a large one of unknown size, which is estimated to be much greater than what is known. The iceberg metaphor also conveys a threat through the image of a hidden mass of ice which poses a danger to ships.

Another common saying repeated in the New Zealand context through interviews and observations is "we can't prosecute our way out of this". This saying presents the problem as being overwhelming in scope when faced by those attempting to address it. The following quote from an interviewee gives an example of how this phrase is used to show the inability of governments to address such a large scale problem.

"It's part of a comprehensive approach and you know, as we said at the conference, we're never going to be able to prosecute our way out of this so engaging with the private sector is 
a really excellent form of looking at prevention, so governments can't do this alone." (NZ Government Official 15)

Another set of sayings, which convey the hidden nature of trafficking and position it as sitting alongside everyday life, were repeated in some of the interviews and in some of the international reporting. The wording of these sayings tends to differ but together they convey an image of trafficking occurring in 'everyday life' in a way which is hidden, for example 'hidden in plain sight', 'imperceptible to the general observer', and 'in our own backyard'. Sometime these saying include the idea of 'normal people', such as 'people on the street', being surprised if they knew trafficking happened in their everyday spheres. For example, the 2018 US DoS report describes victims as being "hidden in plain sight", as "hidden by the appearance of regularity" and as "imperceptible to the general observer" (US DoS, 2018, p3 and 10). Although the trafficking as a big and unknown problem narrative is often used alongside the narrative about trafficking as an abhorrent and irregular occurrence, these types of saying are somewhat contradictory as they portray trafficking as something common to 'everyday life'. This narrative avoids this obvious contradiction by portraying the everyday aspect of trafficking alongside the hidden, with the implication that it is something sinister or threatening occurring under the surface of society.

This language is repeated in one of the interviews where the interviewee talks about potential trafficking scenarios as happening in plain sight and as sitting alongside normal everyday life and happening in the house next door "...things are happening here in plain sight possibly like with the painters of the house next door..." (NZ Government Official 11). The idea of trafficking as occurring in everyday spheres, unknown to people is shown in the following interview where the interviewee talks about "people out in the street" as being unaware of the large scale of the problem which is happening around them.

"A lot of people, if you survey 100 people out in the street, very few would think that it would happen to be happening here but a lot more of it would happen than you'd think." (NZ Government Official 13)

These sayings are also repeated more widely in New Zealand through media and anti-trafficking campaigns. For example, the New Zealand advocacy group Stand Against Slavery runs a campaign named \#Not in our backyard (Stand Against Slavery, 2017), a phrase which has been frequently repeated in media reporting on trafficking in New Zealand. Such phrasing is also common on an international scale, with anti-trafficking campaigns repeating similar phrases. For example the Walk Free Global Slavery Index present their 2018 findings under a campaign titled "Modern Slavery: A Hidden, Everyday Problem" (Walk Free Foundation, 2018). 
There were also a small number of personal anecdotes presented in the interviews and reports which worked to present trafficking as hidden and sitting alongside normality. For example, the following excerpt is taken from an interview where the interviewee talks about how a trafficking scenario could have been taking place in their own back yard. The interviewee sees a house being painted as a normal practice and then begins to question whether there is a hidden situation where exploitation is occurring.

“I'll give you, this is purely anecdotal and I don't know if this is relevant to you or not, but in my own case, the house on the back of where I live, they took away the house and put a new house and about a year ago they were painting this house. I noticed there was an elderly, sounded Chinese guy, and there were three young women painting the house. And I thought, that's great that's like Mr Lee and Daughters decorators and he's got his three daughters who are helping him out and it's going to be a family business and good on them. And it wasn't until I started here I thought maybe it wasn't. I thought maybe it was three young women who were here in a private training establishment, a beauty therapy PTE, who couldn't make ends meet, and maybe they weren't. But it only occurred to me, it's right there, it could be right there." (NZ Government Official 11)

Another interviewee uses a personal anecdote of going to a restaurant and questioning whether workers are being exploited to discuss how everyday people, in this case "consumers", may be carrying out their everyday practices alongside hidden situations of exploitation.

"Yeah so something, I think restaurants, ethnic restaurants should have that certification because then for those who are consumers like ourselves walking into a business, I'm more aware of it and you think are they doing the ethical thing? This particular business, and then at least I can enjoy the meal I'm having, unless I'm constantly thinking, is this young person being exploited?" (NZ Government Official 7)

The following quote is made by an $\mathrm{FBI}$ agent and used in the 2017 US DoS report to infer that trafficking situations can be happening in everyday life, unknown to the general public. The quote is about cases of online sexual exploitation and positions trafficking as an unknown threat where anyone, including your own family, could be victimised.

"That could be anybody's daughter...That could be your neighbour. That could be your daughter's or your son's friend at school." (US DoS, 2017, p32 quote from FBI Agent Bob Parker) 
Inferences about trafficking being hidden are often paired with the positioning of a range of groups in society as being able to 'uncover' trafficking. Attached to this idea is the proposition that a range of groups should be educated so that they are aware of trafficking 'indicators' and are able to 'spot' trafficking and report it. This is discussed in the following section.

\subsubsection{Characters positioned to 'spot' trafficking}

The evidence discussed in this subsection shows how through character positioning a wide range of groups are positioned as being able to identify instances of trafficking. The span of groups is broad and includes governments, enforcement agencies and policing bodies, the judiciary, jurors, international agencies, consumers, businesses, supply chains, global labour markets, industries, community leaders, civil society leaders, and communities. This positioning supports the trafficking as a big unknown problem narrative as it embeds the idea that trafficking is widespread in society and is hidden, but will be uncovered with the right tools. This theme also enforces the narrative of trafficking as an abhorrent aberration as it positions a wide section of society as being separate from the problem of trafficking, implying that trafficking is an aberration. Rather than seeing trafficking as something that takes place within say businesses or communities, it is shown as something separate and abnormal.

These groups are shown as needing to be educated on how to identify trafficking and, once they have been educated, be able to 'spot' these abnormal instances of trafficking where they occur and help victims by reporting them. The idea of educating a range of groups to 'spot' trafficking has been popular in anti-trafficking work internationally for the past few years and in the UK and US, the government has carried out awareness campaigns where the public are shown 'signs' of trafficking so that they will be able to spot such situations (United States Department of State, 2018a). Along with this numerous NGOs and commercial entities have taken up victim 'spotting' work in order to identify victims of trafficking (for example see Hope for Justice, 2020; Stop the Traffik, 2020; Department of Health and Human Services USA, 2019). The idea of training the public or other groups to identify trafficking came through in the international reports and in some of the interviews.

The following text taken from the US DoS 2018 report is an example of how a range of groups are positioned to address trafficking, indicating the wide extent of the problem in society. These groups include "local communities", "law enforcement", "religious leaders", "teachers", "tribal elders", and "business executives". This text also shows how this narrative is linked to the trafficking as an abhorrent aberration narrative as trafficking is called an "abhorrent crime" and these groups are 
positioned as being in opposition to trafficking and as able to prevent it through being "vigilant" and identifying "vulnerabilities"”.

“This year's report focuses on effective ways local communities can address human trafficking proactively and on how national governments can support and empower them. Local communities are the most affected by this abhorrent crime and are also the first line of defence against human trafficking. By engaging and training law enforcement, religious leaders, teachers, tribal elders, business executives, and communities, we become more vigilant and learn to identify and address vulnerabilities swiftly. Proactive community-driven measures strengthen our ability to protect our most vulnerable and weaken a criminal's ability to infiltrate, recruit, and exploit." (US DoS, 2018, Introduction from the US Secretary of State)

The inclusion of "communities" in the range of groups who can identify trafficking shows trafficking as something that is both widespread in everyday life and something that sits apart from communities as opposed to happening within them. For example, the 2018 US DoS report quotes the then UK Prime Minister Theresa May as she describes "local communities" as being able to "spot the signs of modern slavery" and in this way address the problem through helping victims.

"I welcome the focus on engaging with local communities to help them to spot the signs of modern slavery. We need to shine a light on this hidden crime and to encourage more victims to come forward so that we can provide them with the support they need." (US DoS, 2018, p3; quote from the then incumbent UK Prime Minister Theresa May)

This positioning was reflected in some of the interviews. As shown in the following quote, an interviewee positions "communities" as having the ability to identify and report trafficking cases once they have been educated about what to look for.

“...even with human slavery or people trafficking, whatever term you use I think it's still a lack of understanding in our communities about what either of those terms mean and even forced labour, most people wouldn't think that that kind of thing exists in New Zealand and it's our job to make sure that we educate and increase the awareness and make sure that that sort of thing is reported." (NZ Government Official 17)

This positioning implies that trafficking is taking place across a broad section of society and is currently hidden and unknown. It also means that this broad range of groups sits outside of the problem of trafficking which brings into question who is doing the trafficking and where is it occurring if they are not a part of any of the above groups or systems. The nature of many trafficking 
cases discussed within the reports and interviews suggests that trafficking often takes place within communities, between people who have some kind of family or community tie, or within employment and business arrangements. This singling out of 'trafficked people' through victim spotting is also problematic as research from Volodko, Cockbain and Kleinberg suggests that it is difficult to find reliable indicators that can be used to 'spot' victims (Volodko et al., 2020). In particular, indicators that have been used by commercial companies or law enforcement do not differentiate between sex work and trafficking and there is a risk that their use will result in the indiscriminate targeting of sex workers who have not been trafficked (Shand-Baptiste, 2020).

\subsubsection{Language about trafficking as dark and sinister to evoke threat}

In forming the trafficking as a big unknown problem narrative, the findings from the interviews with New Zealand officials narrate trafficking as something that is large, unknown, and sometimes overwhelming, as shown above, but generally not as something that is sinister or threatening. However, in the international guidance reports from the UN and US DoS, and in parts of the New Zealand Plan of Action, language about trafficking being clandestine and hidden as well as metaphors about light and dark are used which portrays trafficking as something that is sinister and threatening as well as being a large and unknown issue.

The language used in the UNODC reports, the US DoS reports, and the NZ Plan of action show trafficking being presented as "clandestine by nature", insidious, "disturbing", and trying to "gain a foothold in New Zealand" (UNODC, 2016, Preface; US DoS, 2018, p3, DoL, 2010, p5).

Metaphoric language about light and dark is also used in the reports by UN and US DoS and contributes to the presentation of trafficking hidden and sinister. Trafficking is discussed as "operating in the shadows", the "darkness" is where "modern day slavery thrives" (US DoS, 2018, Introduction by the Secretary of State), and information is used to "shed light" on the unknown areas of trafficking such as "trafficking flows" (UNODC, 2016, p81). The following example from the UNODC 2018 report shows how metaphoric language about light and dark is used to show trafficking as "operating in the shadows", conveying the idea of something dark, hidden and threatening.

"The international community needs to accelerate progress to build capacities and cooperation, to stop human trafficking in conflict situations and in all our societies where this terrible crime continues to operate in the shadows" (UNODC, 2018, preface)

This metaphoric language is not unusual and features often in anti-trafficking reporting and campaigns internationally. For example, the 'dark figure' of trafficking is widely used to refer to the 
unknown number of people who are victims of trafficking worldwide (Romer, 2019; Lyneham et al., 2019; UNODC, 2018a). As it is a common metaphor used internationally, it is not surprising to see it taken up and reproduced through the international guiding reports.

\subsubsection{Outcomes of the trafficking as a big unknown problem narrative}

When trafficking is narrated as a big unknown problem, the implications that follow are that trafficking is an issue which needs attention and about which something must be done. When the trafficking is narrated as being both unknown and threatening, it conveys a sense of fear and anxiety and implies that urgent action is required. This narrative works to construct a crisis and the material effects of a crisis are that action is required, certain bodies are legitimised as those crucial in providing the action, and certain responses are positioned as unquestionably appropriate.

Presenting a problem as a crisis is a common part of contemporary political discourse. Peter Skilling (2014) carries out an analysis of 'crisis narratives' used in contemporary politics, and in doing so, identifies a set of common components which make up these narratives. The same components that Skilling identifies can be seen in the data, particularly in relation to the trafficking as a big unknown problem narrative.

These components are:

1. There is a departure from normal. This is seen in the positioning of trafficking alongside but separate from normality through sayings such as 'in plain sight' and 'in our own back yard', and through the personal anecdotes of where interviewees have come across potential trafficking situations in 'everyday life'.

2. The problem is presented through official agencies which are shown to be authorities on the problem. This is shown in relation to the first narrative where the UN and the US DoS are positioned as authorities on the trafficking problem and who have the tools and expertise to address it.

3. A threat is indicated in the narrative. Language about trafficking being dark and sinister is used in the international reporting and New Zealand Plan of Action to evoke the idea of a threat.

4. Metaphors about war can be used. The trafficking as warfare narrative is present in the UN and US DoS reports and the NZ Plan of Action. This narrative was discussed in the Methodology chapter as an example of how the analysis was carried out. In the trafficking as warfare narrative, there is a common proposition that trafficking is a battle to be fought. 
Traffickers or trafficking itself is presented as something that poses a threat to national security and international groups or a collaboration of state governments must come together to 'fight' it. In the UN, US DoS and NZ Plan of action, trafficking is presented as a battle to be fought through the use of conceptual metaphoric language borrowed from the military field such as "combat human trafficking", "the fight against trafficking", "personnel" being "deployed in field missions" (for example see UNODC, 2018, p13), New Zealand being "targeted", and "people trafficking infiltrating our border controls" (NZ DoL, 2010 p10).

5. Problems are externalised and are shown as being out of governments' control. This is seen in the trafficking as a foreign other narrative where the trafficking problem and its causes are externalised and situated with 'other' countries.

Skilling (2014) shows how these components come together to form a crisis narrative. Creating a sense of crisis through such narratives presents the problem as being one that needs urgent attention and actions. It works to normalise and affirm a certain set of responses and legitimises the bodies that carry out the responses (Skilling, 2014). Where trafficking is presented as a crisis, the groups providing international guidance - the UN and the US DoS are legitimised as the bodies who can address the problem, and criminal prosecutions and sanctions are affirmed as the appropriate response. This feeds into western exceptionalism from the problem of trafficking as the UN and the US government, as global north institutions, are positioned as responding to the crisis.

As discussed earlier, presenting trafficking as a large, unknown, and threatening problem is a widely used and well documented theme in anti-trafficking campaigns, political rhetoric, and official reports internationally (Wylie, 2016; Weitzer, 2014; Doezema, 2010). The sense of crisis that this presentation elicits has worked to legitimise many anti-trafficking endeavours around the world. As described by Carol Leigh (2015) the presentation of trafficking as a big, threatening and urgent issue has led to the creation of an 'anti-trafficking industrial complex' where anti-trafficking efforts produce a profitable industry which must then be sustained. This includes profits for businesses promoting ethical supply chains, and funding for NGOs and criminal justice enforcement bodies. The sense of crisis legitimises certain responses and neglects others. Presenting trafficking as a large unknown and threatening problem sustains individualised criminal responses whereas wider systemic or local receiving country factors which may be contributing to the exploitation are neglected.

A problem with this narrative is that the presentation of trafficking as a large, unknown, and sometimes threatening entity, which is used in international discourse, has been shown to be based on unreliable or non-existent statistics. Statistics used to show the scale of trafficking worldwide 
have been criticised for having little evidentiary basis, methodological failings, and in some cases bias (Weitzer, 2005, 2007, 2014, 2014; Kelly, 2005; Laczko and Gozdziak, 2005; Tyldum and Brunovskis, 2005). As described in Chapter Three where positivist approaches to researching trafficking are discussed, the types of trafficking situations recorded in statistics are those which come to the attention of official agencies, making their recording dependant on detection and definitions of trafficking which can vary across countries and over time and or be applied in different ways (Dempsey, 2017; Weitzer, 2014; Kangaspunta, 2007). In terms of bias, studies which seek to raise awareness of the harms of trafficking have been argued to have a self-fulfilling aspect as research methods involve seeking out certain situations or forms of harm such as women in forced prostitution (Weitzer, 2014). These critiques have brought into question the veracity of claims about the size of the trafficking problem (Wylie, 2016; Weitzer, 2014; Doezema, 2010). Despite such critiques, statistics showing trafficking to be a largescale problem are frequently used by state governments, official institutions addressing trafficking, NGOs and political actors (Russell, 2018; Wylie, 2016; Weitzer, 2014; Doezema, 2010). The narrative about trafficking as a big, unknown, sometimes threatening problem still is widespread in international trafficking discourse and appears in the current study.

\subsection{Alternative narratives}

The three narratives presented in this chapter: trafficking as a foreign other problem, trafficking as an abhorrent aberration, and trafficking as a big unknown problem, tie together in that they separate exploitation from the context and the systems in which it occurs. Trafficking is constructed as a problem which comes into the receiving country from elsewhere and as having external causes. It is constructed as abhorrent abnormal instances that occur separately from the systems which may create conditions for exploitative practices to arise. The problem is shown as a large one of unknown scope which can pose a threat to nation states.

This group of narratives depicts trafficking as a problem that comes into western or global north countries from less developed countries, and occurs within good and functioning systems of commerce and trade. These depictions of trafficking have been much reproduced and taken up in international anti-trafficking work since trafficking's conception as a crime type in international law. The material effects of this construction of the trafficking problem are interventions that focus on securing borders, targeting individuals with criminal justice responses, and policing and monitoring groups of migrants who are associated with the problem. What is neglected is the situations in which 
exploitation occurs and structural or systemic factors within the country where the exploitation takes place.

This section presents an alternative narrative to the three shown in this chapter. An alternative is presented here because the three narratives have been such a central part of anti-trafficking work internationally, making it difficult to imagine an alternative. An alternative narrative to these three would be one that focuses on the local country where the exploitation occurs and the factors which cause or contribute to the problem, and one which presents trafficking as happening within these local contexts rather than showing it as something incoming and abhorrent.

The trafficking as dodgy business narrative shown in Chapter Five provides one alternative narrative. In this narrative trafficking is situated as taking place within business and employment practices, and to some extent, within certain industries. Situating trafficking within these context draws attention to situational and structural factors which can create situations in which people are exploited. There is potential for these factors to be targeted by anti-trafficking initiatives whereas narratives that focus on problematic individuals coming in from other countries would detract attention from such local factors.

An alternative narrative can also be seen through literature on human trafficking for domestic services. This body of literature takes an approach which is different from other forms of trafficking and focuses on receiving country factors which create conditions prone to exploitation as opposed to external and individual factors linked with incoming migrants (for example Angeli, 2017; de Volder, 2017; Maroukis, 2017; Palumbo, 2017). Trafficking in domestic work situations has not received much attention as a form of trafficking until recently. Although it has not been a key focus of anti-trafficking literature, there is a well-established evidence base of research about domestic work which highlights how social, labour and immigration policies, along with social norms and values, together with the placement of domestic work in the private sphere, create conditions favourable to exploitation (Ricard-Guay and Maroukis, 2017). It is possible that the late arrival of domestic work to the trafficking field, and its attached evidence base showing the importance of local structural and situational factors, has meant that trafficking for domestic work is considered differently than other forms of trafficking traditionally have been.

In this alternative narrative, the causal factors of trafficking are presented as local or receiving country factors. In this way the migrant groups are no longer presented as being at the heart of the problem and symbolic boundaries between the local country and the problem are removed. 
The table below uses an article on domestic trafficking in the UK by Thanos Maroukis (2017) as an example of the alternative narrative and outlines the causes of trafficking listed in this article. The first column shows the causes of trafficking which were identified in the data used in this thesis which form a picture of trafficking as a foreign, incoming problem. In the second column I place the causal factors for trafficking which are identified in Maroukis's article about trafficking for domestic services, which form an alternative narrative where trafficking is presented as taking place within the country in which the exploitation occurs.

\section{Table 3}

Causal Factors of Trafficking from Thesis Data Compared with Causal Factors of Domestic Services Trafficking Given by Maroukis (2017)

\begin{tabular}{|c|c|}
\hline $\begin{array}{l}\text { Causal factors of trafficking given in } \\
\text { narratives presented in this chapter }\end{array}$ & $\begin{array}{l}\text { Causal factors of domestic services tra } \\
\text { presented in an alternative narrative }\end{array}$ \\
\hline 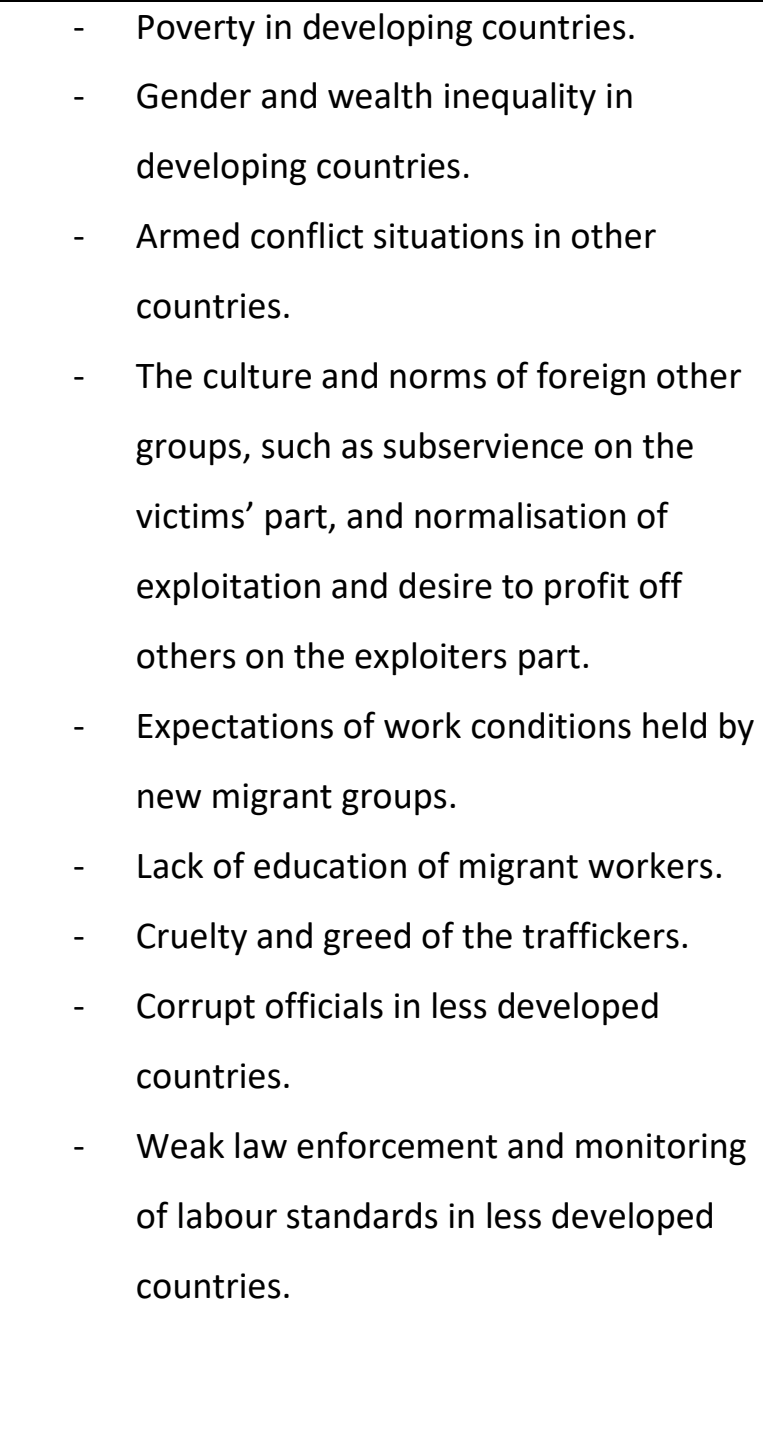 & $\begin{array}{l}\text { - Less publicly funded care services and } \\
\text { more private and informal care } \\
\text { arrangements in the country where the } \\
\text { exploitation occurs. } \\
\text { - } \quad \text { Trends over time to outsourcing care } \\
\text { rather than providing it within the } \\
\text { family (linked to a range of economic } \\
\text { and social factors). } \\
\text { Funding cuts to policing and regulatory } \\
\text { bodies. } \\
\text { Weak regulation of domestic labour by } \\
\text { labour authorities. } \\
\text { Restricted access to legal aid for } \\
\text { migrant workers. } \\
\text { Strict immigration controls making it } \\
\text { more difficult for migrants to work } \\
\text { legally. } \\
\text { Visa conditions for migrant domestic } \\
\text { workers such as tying workers to one } \\
\text { employer and setting a six month visa } \\
\text { limit. }\end{array}$ \\
\hline
\end{tabular}


Note: This list presents the key causal factors given in the article by Thanos Maroukis (2017) but is not exhaustive. Maroukis discusses many causal and facilitating factors relating to the receiving country and the factors listed in this table are also further unpacked.

These two sets of underlying propositions about the problem of trafficking lend themselves to two very different types of anti-trafficking work. The domestic trafficking focus on local country factors leads to responses of addressing power imbalances in employment relationships, local norms about labour, the role of regulatory bodies, and local social and economic issues. This narrative leads antitrafficking work in a very different direction to the three narratives discussed in this chapter which lend themselves to a focus on individual traffickers, the exploited groups themselves, including their culture and norms, as well as cross-border migration. The domestic services trafficking narrative is constitutive of a different form of problem - one where systemic and structural factors create conditions where exploitative practices are likely to occur. Those who are exploited can be anyone who finds themselves in these positions of structured vulnerability. The causes of the problem are broader than individual offenders and poor conditions in developing countries, and the changes that can be made to try and address the problem are those that the receiving country can largely control.

\subsection{Conclusion}

This chapter has presented three overlapping narratives which are constitutive of a form of trafficking where migrant groups from developing countries are central and western states and western favoured systems are exempt from the causes and facilitators of the problem. The trafficking as a foreign other problem, trafficking as an abhorrent aberration, and trafficking as a big unknown problem narratives work to separate exploitation from the context in which it occurs. The first narrative where trafficking is shown as a foreign other problem constructs trafficking as a foreign problem with foreign causes to do with less developed countries from which the receiving country is separate. Appropriate interventions attached to this narrative are those that restrict migration, target individual traffickers, and position migrant groups as the source of the problem. The second narrative depicts trafficking as abnormal, horrific, and as isolated, unusual instances, carried out by individual offenders. The implied action is to target individual instances of trafficking using criminal legislation and enforcement. The third narrative, where trafficking is shown as a big, unknown and sometimes threatening entity, creates a state of crisis and implies that something must be done. It legitimises both criminal justice sanctions as the appropriate response and state governments and global north institutions as those who are crucial in the fights against trafficking. 
When taken together, these three narratives create a sense of western exceptionalism from the problem of trafficking, as the role of the local receiving country in creating the conditions for exploitation is excluded and western-anglo countries and global north institutions are positioned as outside of the problem. Similarly, trafficking is seen as an aberration to the essentially good systems of international labour markets, supply chains, and capitalism. It acts on these systems rather than being a consequence or part of them and in this way there is no room to challenge the part of such systems in creating situations of exploitation.

These three narratives are not unique to the data used in this study and have been widespread and pervasive in anti-trafficking work around the world. They have been a central part of anti-trafficking dialogue internationally for some years. They are embodied in local practice in many countries through a tendency to use trafficking legislation for cases which include cross-border movement and through the use of interventions that restrict migration, and target individual offenders and migrant groups. These narratives are so embedded in anti-trafficking discourse and practice as to make it difficult to imagine an alternative. For this reason, this chapter has included an alternative narrative which focuses on the local or receiving country where the exploitation takes place.

The alternative narrative demonstrates that it is possible to conceptualise the trafficking problem in a different way, and that by doing so, a very different set of responses become relevant and appropriate in responding to the issue. In the counter narrative shown, the problem is constituted as one where systemic and structural factors create conditions where exploitative practices are likely to occur. Rather than focusing on migrant groups as the cause and centre of the problem, those who are exploited can be anyone who finds themselves in these positions of structured vulnerability. The causes of the problem are broader than individual offenders and poor conditions in developing countries, and the changes that can be made to try and address the problem are those that the receiving country can largely control. This alternative narrative also has the potential to highlight systemic factors which are broader than the local state, such as the wider systems of international trade, capitalism, and consumerism which can create situations favourable to exploitation.

Pulling out these three narrative strands for analysis gives some indication of how they work and how they have enforced the prevalent and inert discourses about western exceptionalism in antitrafficking work. The trafficking as a foreign other problem narrative is linked to the long-standing proposition about organised crime as a foreign threat, the trafficking as an abhorrent aberration narrative appeals to collective action through drawing on a moral and melodramatic scripts, while the trafficking as a big unknown problem narrative works to provide a sense of crisis. The persuasive 
components of these narratives creates a barrier to the uptake of this alternative narrative. This is discussed further in Chapter Eight. 


\section{Chapter Seven: Victimhood, vulnerability, agency, and consent}

This chapter discusses the two main narratives about the 'victims' of trafficking which were identified in the data. Identifying these narratives of victimhood and analysing their material effects is important as the way these groups are narrated leads to different outcomes. The two narratives are constitutive of two different forms of trafficking and have determining effects for who can attain victim status and the benefits that go along with it and who is subject to criminal sanctions, deportation or imprisonment. The first of these narratives is the more established narrative of the innocent victim of sex trafficking which has been prominent in anti-trafficking work for the last 20 years. The second is the emerging narrative of the vulnerable migrant worker.

The first narrative gives little agency to victims and positions them as innocent and non-consenting. It provides a problematic and difficult to attain version of victimhood with those who fall short of its characterisation being likely to be subject to criminal sanctions or deportation. The vulnerable migrant worker narrative is a newer construction and a way of understanding victimhood in labour trafficking situations. It allows more agency to victims as they consent to travel for work opportunities. This narrative draws heavily on the concept of vulnerability and the way vulnerability is narrated, as being either individual or situational, and has different implications for how the affected groups are treated and how trafficking is dealt with.

This chapter concludes that the emerging vulnerable migrant worker narrative allows trafficked people more agency in comparison with the more long standing innocent victim of sex trafficking narrative. However, the way that vulnerability is constructed is important to consider as by conceptualising migrant workers as individually or inherently vulnerable, interventions where migrants are monitored, policed, or held responsible for pulling themselves out of vulnerability are supported. Conceptualising vulnerability as situational supports responses that pay attention to receiving country structural factors which may be causing vulnerability, and altering them as a way of preventing exploitation for occurring.

The analysis of these two narrations of victimhood also highlights the distinction made between trafficking into the sex industry and trafficking into other industry sectors as a trend in antitrafficking work. This chapter also concludes that narratives which treat vulnerability as situational and structured provide a means of overcoming the persistent distinction made between trafficking into prostitution and trafficking into other industry sectors. In this construction of vulnerability, attention is directed to how positions of vulnerability are structured for any form of exploitation and do not rely on positioning of victims as innocent and non-consenting or on older stereotypical narratives about prostitution. 


\subsection{Narrative 1 . The innocent victim of sex trafficking}

\subsubsection{Overview of narrative}

In this narrative trafficking is seen as happening in the sex industry with people being forced into prostitution. The typical victims are portrayed as female and young. The narrative infers that victims do not consent to being trafficked and are deceived about the nature of work they will carry out. The traffickers are seen as active in exploiting people and preying on victims, they are controlling, use force, and are sometimes violent. In this narrative, work in the sex industry is presented as being an unquestionable harm as opposed to a form of labour.

\subsubsection{Evidence of narrative}

This is a well-established narrative which has been present in human trafficking media, advocacy, and political discussions internationally for the last 30 years. Positions that conflate human trafficking with prostitution have been a central part of conceptualising trafficking in its modern form (Kempadoo, 2005). As discussed in the literature review, this position has previously been taken up by the UN and the US Government. The 1949 UN Convention for the Suppression of the Traffic in Persons and the Exploitation of Prostitution of Others focused on prostitution, and the US Government has previously held a strong anti-prostitution political agenda which has been manifested in US anti-trafficking law and policy (Ditmore and Allman, 2013).

Another main driver of this approach has been the ideological view held by some feminists that prostitution must be abolished because it is understood to be a form of violence against women, caused by women's subordination in a patriarchal society (Barry, 1984). This movement has presented trafficking as a key example of the harms of prostitution. Concerns about trafficking cannot be separated from concerns for women working in the sex industry, and as such, trafficking and prostitution are conflated. This perspective is prominent in anti-trafficking campaigns and ranges on a continuum from focusing on trafficking for prostitution as the main form of trafficking, to the more extreme view of equating all prostitution with sexual slavery (Raymond and Hughes, 2001). Abolitionist perspectives are still prominent around the world in anti-trafficking work (Mai, 2016; Haynes, 2014; Kapoor, 2013). 'Neo-abolitionism' is an increasingly dominant perspective on prostitution which has spread from Sweden throughout many European countries in recent years (Scoular and Carline, 2014). In this approach, those who sell sex are treated as victims and purchasers are criminalised. As with older prostitution abolitionist approaches, this approach conflates trafficking with prostitution is applied in anti-trafficking work (for a detailed description of neo-abolitionism see Vanwesenbeeck, 2017; Scoular and Carline, 2014; Chuang, 2010). 
As discussed in the literature review, this approach to trafficking has been heavily critiqued for its exclusion of other forms of trafficking, in particular labour trafficking and its narrow definition of victims as female, non-consenting, and innocent, and the harmful outcomes it has had for sex workers who have been targeted by anti-trafficking interventions (Cojocaru, 2016; Hoefinger, 2016; Tomkinson, 2012; Mahdavi and Sargent, 2011; Lebov, 2010; Segrave et al., 2009; Andrijasevic, 2007; GAATW, 2007; Doezema, 2001). In response to criticisms of the narrow focus of this approach, there has been a conscious effort on the part of the UN and some state governments to broaden definitions of trafficking to be more inclusive of exploitation that happens in industries other than the sex industry. However, while official governance bodies attempt to move away from a focus on prostitution, abolitionist discourses have an ongoing presence in much anti-trafficking work carried out by governments and anti-trafficking campaigns (O'Brien, 2018a; Wylie, 2016; Doezema, 2010). Both the ongoing presence of trafficking as prostitution approach and the attempted shift to broaden trafficking discourse can be seen in the sources used in this research. The narrative of the innocent victim of sex trafficking was identified in the international guidance documents from the UN and the US DoS. However, although this narrative features throughout the reports, it is not the only way victims are represented, and sits alongside the narrative of the vulnerable migrant worker (presented later in this chapter), with both narratives shown strongly throughout the documents. It is not surprising to find this narrative produced through reports from the UN or the US DoS, given its historical basis in international law created by the UN and through its propagation as a popular political position from the US Government in previous years. Its equal footing with the emerging narrative about the vulnerable migrant workers suggests that either the narrative of victimhood is changing or diverging along two distinct paths.

In the data gathered within New Zealand, this narrative was present in the NZ Plan of Action, which is not surprising as the plan at its time of writing drew on definitions of trafficking and its appropriate responses as given in UNODC guidance documents and US DoS TIP reporting. In the interviews, this narrative came up rarely, and when it did, it was in relation to cases of trafficking which they had heard of discussed in international reports, news, campaigns, or training courses. This suggests that the narrative is a part of trafficking discourse in a broader international sense and is taken up when talking about trafficking broadly as a concept rather than as what is happening locally.

In this section I present evidence of this narrative from the data using quotes as illustrative examples. I have grouped the evidence into three areas. The first is the presentation of sexual exploitation as a prominent and discrete form of trafficking where sex trafficking, trafficking for 
sexual exploitation, and trafficking for forced prostitution are presented as the dominant form of trafficking separate from other forms. The second area shows the character positioning of victims as non-consenting and deceived and traffickers as active and predatory in which victims are presented as innocent, largely women and girls, who are passive, non-consenting and not aware that they will be working in the sex industry and the traffickers are presented as active in preying on their victims. The third area is the importance of violence, force, and abuse which is shown as being used by the traffickers.

\subsubsection{Sexual exploitation as a prominent and discrete form of trafficking}

The innocent victim of sex trafficking narrative is enforced through a focus on trafficking for sexual exploitation, inferring that trafficking for forced prostitution is the main form human trafficking takes. As well as being the main form of trafficking, trafficking for sexual exploitation is also presented as a separate form of trafficking and something that is inherently distinct from other forms of trafficking, as opposed to something that can occur in conjunction with other forms of exploitation. Showing sexual exploitation as a main form of trafficking embeds the narrative of the innocent victims of sex trafficking as it infers that trafficking is something that happens largely in the sex industry. By constructing trafficking for sexual exploitation as a discrete category which is separate from other forms of trafficking, sexual exploitation is emphasised above other forms of exploitation. The prominence of sexual exploitation as a discrete category and the main form of trafficking can be seen in the definitions of trafficking used, the organisation and presentation of statistics in the UN reporting, and the frequent use of stories about victims of sex trafficking or forced prostitution shown in the US DoS reports. The prominence of sex trafficking is also taken up in the NZ Plan of Action where statistics from these guidance organisations are repeated.

The foregrounding of sexual exploitation as a main form of trafficking is outlined in the UN Trafficking Protocol definition of exploitation. The UN definition focus on trafficking for prostitution and sexual exploitation is repeated through the UN Plan of Action where exploitation is categorised into exploitation for prostitution or other forms of sexual exploitation, forced labour, slavery, servitude, or the removal of organs. Trafficking for prostitution or sexual exploitation is presented as the first main type of exploitation and as a discrete category separate from other forms of exploitation.

"...for the purpose of exploitation, which includes, at a minimum, the exploitation of the prostitution of others or other forms of sexual exploitation, forced labour or services, slavery or practices similar to slavery, servitude or the removal of organs, as set forth in the Protocol 
to Prevent, Suppress and Punish Trafficking in Persons, Especially Women and Children, supplementing the United Nations Convention against Transnational Organized Crime (hereinafter referred to as "the Trafficking Protocol")..." (UN Plan of Action, 2010, p5-6)

The UN Trafficking Protocol treatment of trafficking for sexual exploitation as a main and discrete type of trafficking is also reproduced through the UNODC Trafficking in Persons reports where data on trafficking cases detected around the world is condensed into four discrete categories trafficking for sexual exploitation, trafficking for forced labour, trafficking for the removal of organs, and trafficking for 'other forms of exploitation'. This is explained below in text from the 2017 UNODC report. This excerpt shows the way exploitation is defined in the Protocol and how this definition is taken up in the UNODC reporting in the collation and presentation of international data into different categories.

"The Global Report employs four broad categories of trafficking in persons. This classification is based on the United Nations Trafficking in Persons Protocol, where the following list of purposes is included: "Exploitation shall include, at a minimum, the exploitation of the prostitution of others or other forms of sexual exploitation, forced labour or services, slavery or practices similar to slavery, servitude or the removal of organs." (Article 3, paragraph (a)). The first category is trafficking for sexual exploitation, which includes the exploitation of the prostitution of others and similar situations. The second category includes trafficking for forced labour or services, slavery and similar practices and servitude. The third category includes trafficking for the removal of organs, and the fourth and final category is trafficking for "other forms of exploitation". (UNODC 2017, p26)

These four categories are used to show global statistics on forms of trafficking. Trafficking for sexual exploitation is represented as the most prominent form as it is the most detected. These categories also show trafficking for the purposes of sexual exploitation as being separate from other forms of exploitation. For example the 2018 UNODC report presents global data suggesting that trafficking for sexual exploitation is the most common form of trafficking. The report also presents this as a discrete category as it goes on to note that there were only $2 \%$ of victims globally who could be counted as having experienced 'mixed forms of exploitation'.

"Forms of exploitation [section heading]

Trafficking for the purpose of sexual exploitation is the most detected form of trafficking globally. Victims trafficked for sexual exploitation comprised 59 per cent of the detected victims in 2016....Data for 2016 indicate that some 2 per cent of the victims detected globally were trafficked for 'mixed forms of exploitation', such as victims exploited both sexually and 
in forced labour, or exploited in begging as well as in criminal activity (often carrying out petty crimes)." (UNODC 2018, p29)

The categorisation of trafficking for prostitution and sexual exploitation as a main and discrete form of trafficking can also be seen in the US DoS reporting. For example in the 2017 US DoS report, in a section titled "The face of modern slavery", forms of trafficking are split into firstly "sex trafficking" followed by "child sex trafficking" and then "bonded labour or debt bondage", "domestic servitude", "forced child labour" and "unlawful recruitment and use of child soldiers"(US DoS 2017, p17). The presentation of forms of exploitation in both the UN and US DoS reporting shows sexual exploitation is considered a main form of trafficking which stands on its own. The categories do not allow for overlap or for capturing situations where people may be exploited in a range of ways including sexually and in labour situations. These divisions also communicate the underlying assumption that work in the sex industry is considered as abusive rather than labour, and labour exploitation cannot occur in the sex industry.

By showing sexual exploitation as a main form of trafficking, trafficking is depicted as something that happens for the most part in the sex industry. Alongside this, by showing trafficking for sexual exploitation as a discrete form of trafficking, without acknowledging the multiple forms of exploitation people may experience, sexual exploitation is placed at the forefront in the image of trafficking that is created. This emphasis of sexual exploitation feeds into the innocent victim of sex trafficking narrative as trafficking is shown as something that largely happens in the sex industry. This is one way in which the constitutive nature of this narrative is visible, as narrative forms which emphasise trafficking for sexual exploitation as a discrete and major form of trafficking create statistics to reinforce this representation through the way statistical categories are designed and evidence is collected and reported. The division between sex trafficking and labour trafficking also works to sustain the abolitionist construction of trafficking where sex work is considered to be harmful as opposed to being considered as labour. The implications of this are that any more 'mundane' exploitation that happens within the sex industry, such as underpayment or breaches of contracts, are neglected.

The prominence of trafficking for prostitution and sexual exploitation is taken up in the NZ Plan of Action. The plan refers to 'international experience' and a 'world-wide' picture of trafficking where trafficking for commercial sexual services is emphasised as a main form of trafficking: "International experience has shown that the most prominent form of people trafficking is of women for commercial sex services." (DoL, 2010, p9) and where "World-wide, the most prominent form of trafficking is of women for commercial sexual services." (DoL, 2010, p15). The plan also draws on 
statistics from the US DoS as a source of guidance, where commercial sexual exploitation is dominant: "As estimated by the US Department of State, approximately 800,000 people are trafficked annually across international borders, with 80 percent of victims believed to be female, and up to 50 percent minors. It is believed that the majority of this trafficking is for commercial sexual exploitation" (DoL, 2010, p4).

The prominence of trafficking for prostitution is also emphasised through the US DoS reports in the frequent use of examples of trafficking which involve sexual exploitation. These reports present many examples of trafficking. These are in the form of short vignettes called 'victim stories', large photographs with a very short descriptive caption attached, reports of the experience of people who have been victimised by trafficking and have become 'survivors', and examples given by antitrafficking professionals about cases they have worked on. Many of these examples are about trafficking for forced prostitution. For example the following text is a 'victim story' taken from the 2017 US DoS report. In this story, the case of trafficking involves a woman who is unknowingly forced into prostitution.

"Working with a recruiter in Venezuela, Sarah accepted a job in a nursing home in Trinidad and Tobago. She was thrilled by the chance to earn more money, yet nervous that she had to leave her home and did not have enough experience in elder care. When Maria arrived in Trinidad and Tobago, she realized she had been deceived. The recruiter informed her she owed a large debt, and instead of working at a nursing home, she was forced into prostitution at a local hotel bar. Her recruiter confiscated most of her earnings each night." (US DoS, 2017, p13).

The positioning of people trafficked into the sex industry as transitioning from 'victims' to 'survivors' is reflective of the abolitionist role in developing the innocent victims of sex trafficking narrative. The survivor narrative is presented in abolitionist campaigns and works to depict the sex industry as inherently dangerous and problematic. By focusing on survivors, escaping or being rescued from the sex industry is presented as the appropriate action. The use of the term 'survivor' also draws on imagery of victims of abuse and implies that sex work is inherently abusive (Armstrong, 2020; Mac and Smith, 2018, p. 13). 

predatory

In the innocent victims of sex trafficking narrative, the victims are positioned as being nonconsenting and deceived about the nature of the work they would be carrying out or as forced into prostitution through either physical force or other forms of abusive coercion. The victims are also shown to be largely women and girls who are passive and acted on by the traffickers. In contrast to the victims, the traffickers are positioned as active and predatory. They are depicted as actively seeking out victims and exploiting them and are often described as predatory. This positioning is evident in the UN and US DoS reporting, the NZ Plan of Action, and in one interview with a New Zealand official who discussed forms of trafficking presented at an international course.

In this positioning, victims are portrayed as not knowing that they will work in the sex industry and as working in the sex industry unwillingly. They do not consent and are deceived, tricked or forced into these situations by the traffickers. This is inferred in many of the examples and cases of trafficking discussed in the US DoS and UN reporting. For example, the following "victim story" is taken from the 2017 US DoS report. In it, a woman is deceived by a trafficker and coerced into working in prostitution.

"Paula was walking home from the market in her hometown in Nigeria when a man approached her and offered her a job in Italy that included good pay and housing. The man told Paula she would have to pay a substantial recruitment fee for the job, but she did not have enough money. Paula reasoned that a job in Europe was a once-in-a-lifetime opportunity, and the proposed salary would be enough to pay back the debt easily, so she borrowed the money and eagerly accepted. Paula and a group of other Nigerian women travelled with the recruiters to Italy. Upon arrival, the women realized they had been deceived; the recruiters forced them into prostitution to repay their travel debts. Paula and the other women were discovered during a police raid." (US DoS 2017, p26)

This type of story where victims are positioned as forced into working in the sex industry through violence and deception was also those reported by a New Zealand official who is discussing forms of trafficking presented at an international course. The quote below from this interviewee shows a similar depiction of victimhood:

"[The person presenting at the course] used an example of, I think it was a Romanian or Albanian girl, I can't remember, who had met this boy, become boyfriend and girlfriend, and he said he's playing ice hockey in London. Took her to London, says he has to go to the toilet as soon as he gets to the airport. She just gets grabbed by a couple of males who walk her 
out, and then for two years she's kept as a sex slave in prostitution you know. And um her mother made a complaint and couldn't find her and that's how it started and they [the UK police] got her and they just worked their way through all their intel database, went through all the brothels and had to target, and eventually they found her." (NZ Government Official 16)

The positioning of victims as innocent, non-consenting, and deceived is enhanced by the use of passive voice to describe the victim's part in the situation. Using positioning as one of the six strategies for analysis in this thesis included identifying common patterns of language such as active and passive voice to study how subjects are positioned within a narrative (Juntrasook et al., 2013; Moghaddam and Harré, 2010). A common pattern of language that accompanies with this narrative is where victims are acted on by traffickers or groups helping them such as government officials. This language pattern can be seen above in the story of Paula. Paula is "approached" by a recruiter, together with the other women she is "deceived", and "forced" into prostitution. The women are then "discovered" by the police. Similarly in the story described by Government Official 16, the victim is taken to London, she gets "grabbed" and "walked out", "kept" as a sex slave and then "got" by the police.

In contrast to the victims' positioning, the traffickers are positioned as being active in seeking out opportunities to entrap and exploit victims, and described through active voice as acting on victims. They are often positioned as predatory, and preying on the vulnerabilities of their victims. For example in this text from the 2018 US DoS report, traffickers are active in preying on their victims "... the majority of trafficking cases involve Lithuanian trafficking networks that prey on Lithuanian victims." (US DoS, 2018, p277), and in the following text from the 2018 UNODC report, vulnerable groups are acted on and exploited by traffickers "...are vulnerable children, women and men who can be easily exploited by smugglers and traffickers." (UNODC 2018, p1). This pattern of language is common throughout reports and reinforces the idea of victims' passivity and of not consenting to be involved in any part of the trafficking. In this simplistic characterisation, victims are devoid of any agency and any more complex information, such as the part they took in seeking to move for work, is omitted.

While this is a common pattern of language, victims are also given more agency in some discussions of sex trafficking. For example, in the US DoS 2018 report there is a section on trafficking "Heroes" (p46) who carry out anti-trafficking work. Some of the heroes have been victims of sex trafficking and are shown as being active in overcoming these situations to become survivors and then as being active in advocating for other victims. This perhaps reflects the conscious shift the UN and some 
state governments are making away from the more traditional version of trafficking as involving passive and inactive victims.

In the character positioning of victims in the innocent victim of sex trafficking narrative, the victims are shown as being mostly women or girls. The UNODC and US DoS reporting as well as the NZ Plan of Action presents summary information which shows woman and girls as being the main type of victim. For example the NZ Plan of Action shows trafficking as effecting women most commonly, although other groups can also be effected "While the most well-known form of trafficking involves women who are used for sexual purposes, people trafficking of men, women and children for forced labour is also emerging as an international trend." (DoL 2010, p3). In the UNODC 2017 and 2018 victims are shown as largely being women and girls, for example "Most of the victims detected across the world are females; mainly adult women, but also increasingly girls." (UNODC 2017, p10), and "In most areas of the world, the information on detected victims shows that trafficking in persons mainly affects women and girls." (UNODC 2018, p26).

These statements are based on international aggregated statistics about trafficking victims. While statistics indicate that victims of trafficking in the sex industry are largely women and girls, this narrative presents victims of all forms of trafficking as being primarily women, which contributes to the stereotypical image of the female victim of sex trafficking conveyed in this narrative. The implications for showing victims as being women and girls is discussed in the outcomes section below. Furthermore, these aggregate statistics will likely be tangled in with the traditional image of trafficking as something that happens to women in the sex industry. These statistics are presumably based on prosecution data which means cases recorded will be those that come to the attention of law enforcement, which in turn depends on what types of trafficking enforcement bodies are looking for and how they define trafficking. If law enforcement bodies are reliant on a more traditional picture of trafficking, then they will be more aware of cases involving women in the sex industry.

Through the positioning shown in this section, people who are trafficked and those carrying out the trafficking are aligned with stereotypical images of victims as acted on, tricked, deceived, and subject to violence and abuse. Those doing the trafficking are aligned with villains who are active in exploiting victims. Earlier discussed narratives about profitable organised criminal enterprise and commercial businesses and systems as saviours also feature these stereotypical characters of villains and heroes. As discussed earlier, these well-known characters have the power to engage and persuade audiences as they are compelling and draw on well-known cultural scripts (Mayer, 2014; Vance, 2011b). The character positioning discussed in this section also employs an element of 
melodrama. In the narrative genre of melodrama, as discussed in Chapter Six, stereotyped roles of victims and villains are used (Redmond, 1992; Brooks, 1985). In melodrama there is a lack of depth given to the characters. Rather, the focus is on emotive story lines featuring desperation, conflict, violence, and struggle (Vance, 2011b, 2011a). The use of melodrama in the positioning of victims and traffickers further enforces the innocent victim of sex trafficking narrative by drawing on tropes about innocent victims and bad traffickers. The persuasiveness of such narrative forms may account for the longevity of this narrative and its continual presence despite attempts to shift anti-trafficking work in a different direction.

\subsubsection{Importance of violence, force, and abuse}

Evidence for the innocent victim of sex trafficking narrative also came through in the emphasis given to the use of force, violence, and abuse by traffickers against victims. The importance of violence, force, and abuse emphasises the victims' position as powerless, non-agential, non-consenting, and acted on by the traffickers. This emphasis featured in some of the examples or short stories about trafficking in the US DoS reporting and in one of the interviews where an interviewee discusses examples which were reported on at an international training course. It also comes through in the UN reporting in the icons used in diagrams and the emphasis given to conflict and armed militia groups in describing the trafficking problem.

The US DoS reports present many examples of trafficking throughout. Many of these examples emphasise violence, force, and abuse carried out on victims by traffickers. For example the following text is a "victim story" taken from the 2017 US DoS report. In this story, the victims are shown as being forced into commercial sex, and as enduring severe abuse and violence. This accentuates their position as powerless and non-consenting.

"Maya was 22 when she fled her home country of Syria due to conflict in the region. She was promised a job working in a factory in Lebanon, but when she arrived she was forced into commercial sex along with more than 70 other Syrian women. They endured severe physical and psychological violence. Eventually, police raided the apartment units the women lived in and arrested 10 men and eight women who had been part of the sex trafficking scheme."

(US DoS, 2017, P4)

In one of the interviews, an interviewee discusses the examples of trafficking which were given on an international training course. The interviewee presents an example from the course which features deception, a lack of consent from the victim, force, and sexual violence. As with the 
example from the US DoS report given above, this story emphasises the victim's position as powerless, non-consented, and acted on by the traffickers.

Interviewer: "What kind of examples do they use [on an international training course]?"

Interviewee: "For instance um trafficking in persons means coercion and the time one of the examples used was Rwanda to the UK. [Reading training notes] 'When she was 14 Anita's boss, a trader for whom she worked at the market told her to go with two men, he said they would take her to live abroad where she would be safe and could go to school. When she reached Great Britain a man picked her up and took her to a house. Another man came to the house and raped her. For two years the teenager was forced to live in a locked room, access only to the toilet basin and kept her as a sex slave until she escaped and found a driver who took her to the police.' So that sort of thing." (NZ Government Official 16)

In the UNODC 2016 and 2018 report, icons are used to represent different forms of trafficking in diagrams throughout the reports. These icons convey the idea of violence, force, and abuse being present in trafficking situations. For example, in the UNODC 2016 report, trafficking for labour is called "forced labour" and uses an icon of a figure standing in a pool of water sifting something in a dish while a figure holding a machine gun and wearing a military looking cap and vest stands over them. Other icons that represent trafficking happening in relation to conflict include an image where bombs are shown hitting houses and where men with machine guns are shown running towards something. Other icons are used to depict "victims of slavery" where figures are shown with a ball and chain attached to their leg.

In the UNODC reports, special emphasis is also given to trafficking in conflict situations, in particular where armed groups have been involved in trafficking. This is shown through the inclusion of conflict situations in dedicated sections of the reports. In the UNODC 2016 report there is a chapter "Chapter II Human Trafficking, Migration and Conflict" which focuses on how trafficking occurs within migration driven by conflict situations. The UNODC also published an additional report that sits alongside the 2018 UNODC Trafficking in Persons report which focuses exclusively on trafficking which occurs where there has been armed conflict (called Booklet 2 of the Global report: Trafficking in Persons in the Context of Armed Conflict) (UNODC, 2018a).

Given the author of the report is a UN institution and the ultimate aim of the UN is to maintain international peace and security (United Nations, 1945), it is perhaps not surprising that the report would include a particular focus on armed conflict. However, the focus on armed conflict and accompanying force, violence, and abuse, in a guiding document that presents the trafficking 
problem internationally in its entirety, feeds into a narrative where victims of trafficking are nonconsenting and acted on, subject to force and violence. As discussed in the following section, the implications of this are that those who have consented to work in a certain country and industry do not fit in with this picture of victimhood.

\subsubsection{Outcomes of the innocent victim of sex trafficking narrative}

Narrations of victimhood where victims are female, non-consenting, and forced to work in prostitution by a predatory trafficker legitimise a certain set of enforcement responses and policy implications. This narrative of victimhood has been present in much anti-trafficking work around the world, as trafficking has been conflated with prostitution in much of its development as crime type. The outcomes of this narrative can be seen in anti-trafficking responses and have been critiqued by academics, advocacy groups and anti-trafficking practitioners (see for example Doezema, 2010; Segrave et al., 2009; GAATW, 2007; Kempadoo, 2005). The outcomes that this narrative enable are a focus on trafficking for prostitution and sexual exploitation and the exclusion of other forms of trafficking, the promotion of the idea that sex work is not labour and so must be considered separately from other forms of trafficking, the creation of a narrow and inaccessible definition of victimhood, a focus on individual criminal prosecutions with a neglect of wider structural factors, and 'rescue' type interventions which can result in deportation or criminalisation of those working in the sex industry.

The innocent victim of sex trafficking narrative is constitutive of a form of trafficking where sexual exploitation is important and where the sex industry is the place trafficking takes place. The focus on prostitution in trafficking has been criticised for excluding other forms of trafficking, in particular trafficking into other forms of labour (Shamir, 2012; Chuang, 2010; Chang and Kim, 2007). While there has been a conscious effort on the part of the UN and some state governments to broaden the focus of anti-trafficking work, the ongoing propagation of the innocent victim of sex trafficking narrative inhibits this by redirecting attention to exploitation in the sex industry. In this narrative, there is a clear distinction between trafficking into the sex industry and trafficking into other industries. This distinction highlights the underlying stance that sex work is not work and therefore must be considered its own type of trafficking. This both reflects and reproduces the abolitionist position on prostitution which has been influential in anti-trafficking work, and many states' legal position on the sex industry. As with wider arguments for decriminalising the sex industry, the problem this creates is that the type of exploitation constructed in this narrative is very specific and discrete, and does not include more mundane types of exploitation that may occur in the sex 
industry. Consequently, other types of exploitation experienced by those who have chosen to work in the sex industry cannot be safely addressed. In New Zealand the treatment of sex work as labour through the Prostitution Reform Act creates a different stand point from which to consider exploitation in the sex industry, and indeed the innocent victim of sex trafficking narrative is largely absent in the New Zealand based data. The implications of this are discussed in relation to the vulnerable migrant worker narrative.

The innocent victim of sex trafficking narrative shows victims as female, innocent, non-consenting and as not knowing about the situation they would be working in. This version of victimhood has received much criticism for being narrow and creating an inaccessible version of victimhood which excludes male victims and those who knowingly chose to work in the sex industry, increasing the criminalisation of sex workers (Tomkinson, 2012; Mahdavi and Sargent, 2011; Lebov, 2010; Doezema, 2001). Research studies have indicated that many people who are trafficked for the purposes of prostitution are aware that they will be working in the sex industry (Lebov, 2010; GAATW, 2007). The image of trafficking promoted by the innocent victims of sex trafficking narrative does not fit male victims or many victims of trafficking for sexual exploitation who have chosen to work in the sex industry, making it difficult for these groups to gain victim status and the supports and benefits that go along with it (Cojocaru, 2016; Hoefinger, 2016; Andrijasevic, 2007). When such affected people cannot gain victim status, they are at risk of being considered illegal immigrants and of being deported from the country (O'Brien, 2018b, p. 34).

This image of victimhood constitutes who victims are and creates dangerous positions for those who cannot attain it. Those who can fit this version of victimhood gain victim status and are recorded as victims of trafficking in statistics. Through receiving this status and through such situations being recorded as trafficking, the narrative where trafficking is about sexual exploitation which largely affects women and occurs within the sex industry, is reinforced. The danger that is created through this narrative is that those who cannot be portrayed as fitting this version of victimhood may be classed as illegal immigrants to be criminalised or deported. Ironically, the responses that result from the innocent victim narrative are very much at odds with the depictions of abused victims in need of rescue as they tend to involve punishment rather than support (Fouladvand and Ward, 2019; Carline, 2012; Scoular and O'Neill, 2008).

As well as excluding forms of exploitation and limiting the accessibility of victim status, the innocent victim of sex trafficking narrative's casting of innocent victims and predatory offenders enables responses which are focused on individual criminal prosecutions and the rescue of victims. Prioritising criminal prosecutions as the response to trafficking, as discussed in the previous chapter, 
individualises the problem of trafficking. The main criticism of this approach has been that by focusing on individual traffickers, the local and global factors that drive trafficking are neglected, such as addressing weaknesses in local labour frameworks or addressing driving factors of neoliberal systems of trade and production (George et al., 2017; Szörényi, 2016; Kempadoo, 2015; Dottridge, 2007).

The positioning of victims as innocent, non-consenting, and passive encourages 'rescue' type responses where victims are seen as being in need of rescue and are then repatriated or institutionalised in a shelter. These 'rescue' type approaches have been criticised for taking away victims' agency (Agustin, 2007, 2012), repatriating victims although it may not be safe to do so or they may not be willing to return to their home country (GAATW, 2007), or placing people in trafficking shelters or labour schemes against their will (Abdul-Hamid, 2019; Hoefinger, 2016; Gallagher and Pearson, 2010).

\subsection{Narrative 2. The vulnerable migrant worker narrative}

\subsubsection{Overview of narrative}

In this narrative, the vulnerable migrant worker is a key character. They are people who have agency and who seek work opportunities, usually in other countries, in order to earn money for themselves, their family, or community. These migrants are not portrayed as seeking work in the sex industry. Sometimes the amount of agency ascribed to this character becomes problematic as they may actively take part in illegal work schemes. This makes criminal prosecutions and assigning the workers with victim status difficult.

Although victims have agency, it is limited due to their vulnerability. Vulnerability is ascribed in two distinct ways - as either as something inherent to the individual or to the migrant group, or as something created by the situation they find themselves in. When vulnerability is an individual characteristic, it is seen as something that is intrinsic to the vulnerable group, tied to their culture, norms, and other factors like their lack of education and naivety. When vulnerability is situational the groups are vulnerable due to the circumstance they find themselves in, and attention is given to the setting in which they are exploited.

\subsubsection{Evidence of narrative}

The vulnerable migrant worker narrative was present throughout most of the data sources. This narrative came through in the interviews with New Zealand officials and company representatives 
and was the dominant way of characterising victims of trafficking in these discussions. This narrative also came through in the US DoS, the UN reporting, and the NZ Plan of Action. While the vulnerable migrant worker narrative was dominant in the interviews, in the US DoS, the UN reporting, and the NZ Plan of Action, it was used alongside the innocent victim of sex trafficking narrative.

Trafficking for the purposes of labour (not including exploitation in the sex industry) has received a growing amount of attention in many countries and by international bodies, with more anti-

trafficking efforts focusing on labour trafficking and more cases of labour trafficking being detected (UNODC, 2018b). The presence of a different narrative of victimhood is likely due to this conscious shift to broaden the trafficking definition, and in particular, to create a definition of trafficking that allows international bodies and state governments to address other forms of exploitation as well as sexual exploitation. The presence of this emerging narrative of the vulnerable migrant worker in the international guidance reports, reflects the efforts to broaden anti-trafficking work to better fit with situations of labour trafficking. The presence of this narrative in the company reports and interviews with company representatives is likely to be due to companies' focus on the production of products through labour.

The dominance of this narrative and the comparative absence of the more established sex trafficking narrative in the interviews with New Zealand officials can also be attributed to the changing way sex work is seen in New Zealand. New Zealand is in the unique position of having a decriminalised sex industry. Under the Prostitution Reform Act, sex work is positioned as labour as opposed to inherently harmful criminal activity. By treating sex work as labour, prostitution is not positioned as a problem to be addressed through human trafficking criminal legislation, criminal investigations, and prosecutions. This position has also created grounds for resistance against the dominant longstanding international narrative and, in previous years, the New Zealand Government has declined calls from the US DoS to recriminalize parts of the sex industry using trafficking legislation (United States Department of State, 2007, 2018a; Showden, 2017). The unique start point the New Zealand legislation provides has potential to lead in two different directions, either for trafficking into the sex industry to be considered as labour trafficking, or for exploitation in the sex industry to be ignored and trafficking into other industries to become the focus of anti-trafficking work. At the time of this research, the four cases prosecuted using trafficking law involved exploitation in the horticulture and hospitality industries, with no cases involving the sex industry. However, it is difficult to determine how this relates to the dominant narration of victimhood and the direction that is following from such a narrative. The impacts of the dominant narrative taken among New Zealand officials is discussed in the outcomes section. 
Within the vulnerable migrant worker narrative, there are two distinct ways of presenting vulnerability. One form vulnerability takes is as something that is inherent to certain groups and tied to individuals. The other form is as something that is created by certain situations, policy settings, and governance structures. The two versions of vulnerability were present in both the interviews and the international guidance reports, sometimes with the same speaker or document presenting both forms interchangeably. However, the second form of vulnerability, as situational or structural, tended to be presented more strongly in the interviews with New Zealand officials than in the international guidance reports. The greater use of situational vulnerability in the interviews and the tendency towards individual vulnerability in the international reports aligns with the previous narratives discussed. The trafficking as dodgy business narrative shown in Chapter Five shows New Zealand officials focusing on business and employment arrangements as playing a role in allowing exploitation to occur. The trafficking as a foreign other narrative shown in Chapter Six and the innocent victim of sex trafficking narrative shown above demonstrate a tendency for the international guidance reports to focus on individual traffickers and victims as opposed to situational factors. The reasons for this difference are explored in Chapter Eight.

In this section I present evidence of this narrative from the data using quotes as illustrative examples. The evidence is grouped into three areas. The first is character positioning of victims as having agency which shows how victims are shown as active in making decisions and seeking work opportunities. The second and third areas are about how the term 'vulnerability' is used and the two different presentations of the term. The second area is vulnerability as individual and inherent where vulnerability is used as a label for certain groups or is attributed to individual factors about migrants. The third area is vulnerability as situational or structural where vulnerability is shown as created through situational factors including visa status, employment structures, and industry practices in the receiving country.

\subsubsection{Character positioning of victims as having agency}

The evidence discussed in this subsection shows how through character positioning, victims of trafficking are presented as people who have agency, make rational decisions about their future, and are motivated by financial gain or residency in countries where they can access better working and living conditions for themselves and their families. Sometimes they have so much agency that they become complicit with the traffickers in running their illegal businesses and this makes criminal prosecutions and assigning the workers with victim status difficult. 
This positioning of victims came through in the interviews with officials as the main way of discussing people who have been trafficked. For example, in the following interview victims are positioned as rational actors who see an opportunity to make a greater wage and decide to take up the opportunity.

"They want to come to New Zealand to better their lives, have opportunities, support their families and it's not until they arrive in New Zealand that they realise that they've been deceived... the Fiji case is a perfect example. So these individuals, they applied for jobs that they saw advertised with an agent in Suva, 'come to New Zealand you know, you'll get paid $900 \$$ a week' and when you're looking at what the minimum wage is in Fiji that's an attractive offer. 'Pay this money up front and we'll pay for your flights, work permits, accommodation'. So basically it's a fantastic offer, who wouldn't?" (NZ Government Official 15)

In the following example the interviewee discusses situations where students are exploited in work settings. In this discussion the victims are active in seeking work within a limited set of circumstances. These actors seek the work opportunities available to them in order to pay debt they have incurred in coming into the country and onto study schemes, and in order to seek residency.

"Where people are taken advantage of, in particular students, the settings that we've had um a lot of people who came in were in debt and even if they weren't in debt they had to work to be able to just pay for themselves, keep themselves going, generally didn't speak English amazingly well, generally, and this is not only in New Zealand, um found it easiest to get work or possibly only could get work from people in their own ethnic community, were often horribly exploited on the way, particularly if the work they were doing, if they needed to get a skilled job in order to progress to residence which was a big aim for a lot of them..." (NZ Government Official 4)

This presentation emphasises the trafficked people's agency in making decisions to suit their circumstances and needs. This positioning is very different from the innocent victims of sex trafficking narrative and the more traditional presentations of victims of trafficking in international campaigns, reports, and political rhetoric as innocent, non-consenting, deceived, tricked, or subject to force or violence (Andrijasevic and Mai, 2016; Mai, 2016; Andrijasevic, 2007).

This characterisation of victims as active was present, but to a lesser extent, in the international guidance reports where it sat alongside the innocent victim of sex trafficking narrative. In the US DoS and UN reporting, victims are often ascribed agency at the beginning of their stories, for example 
the text below from the 2018 UNODC report shows victims as taking action to improve their lives, before they then become exploited an acted on by traffickers.

"The stories of victims of trafficking, however, often start as brave attempts to improve their life, as is also the case with many migration stories. Those who end up in the hands of traffickers often envisioned a better life in another place; across the border, across the sea, in the big city or in the richer parts of the country." (UNODC 2018, p13)

This example is illustrative of the amount of agency ascribed to victims in the international guidance reports. They are shown to make decisions and take available opportunities in order to better their circumstances. However, they are then acted on by traffickers and are often positioned as not consenting to the type of work they find themselves in. In the interviews with officials, the victims are more aware of the type of work situations they will be employed in but not the exploitative conditions they then find themselves working under. In a few of the interviews, the trafficked people are shown as having so much agency that the boundary between victims and offenders becomes blurred as the victims become complicit in their exploitation. These situations are discussed as posing a challenge to trafficking prosecutions and it becomes difficult for the people involved to attain official victim status. The following excerpt from an interview with a government official shows an example of how, when trafficked people show too much agency in seeking work, their role as victims is questioned during a criminal prosecution. This is similar to the difficulties created through the way agency is narrated in the innocent victim of sex trafficking narrative. The narrowness of the innocent victim character means that those who have shown agency in working in the sex industry cannot attain victim status and are likely to be criminalised.

"A lot of them came here um to um work uh for a guy and then um but their main goal was to get residency yeah so defence council would stand up and say 'sure you were underpaid and you were even exploited, our defendant here admits to not paying you what you should have been paid and we'll pay you some reparation but the fact is that your main goal was to come here and get residency and you were well prepared to sacrifice, you know, everything to get that so in essence you're complicit to some degree'. So then we work off like a seesaw balance thing because a lot of our victims are often complicit in some of the offending. They start to slide off that balance of complicity and if they slide too far then we'll not consider prosecuting because they've got to stand up in court and then it becomes quite clear that you were complicit in this so called offending. You were well aware, you knew and you knew what the end goal was here so you were prepared to sacrifice." (NZ Government Official 3) 


\subsubsection{Vulnerability as individual and inherent}

Within the vulnerable migrant worker narrative there were two distinct ways of presenting vulnerability. This section shows the presentation of vulnerability as something that is inherent to certain groups and due to individual characteristics of the victims. This presentation of vulnerability came through in some of the interviews and in the international guidance documents. This version of vulnerability is shown through the use of 'vulnerable' as a label for certain groups and populations, implying that it is a characteristic of these groups. In this presentation of vulnerability, sometimes the drivers of vulnerability are discussed, but they are exclusively individual factors tied to the vulnerable groups such as a lack of education and awareness.

There are many examples throughout the UN documents, the US DoS reporting, the NZ Plan of Action, and some of the interviews, where vulnerability is presented as label for certain groups. For example, "vulnerable groups", "vulnerable populations", and "vulnerable communities" are used as terms to describe potential victims of trafficking. This example from the 2018 US DoS report shows how vulnerability is used as a label firstly for groups and secondly for populations to show how they have the potential to be trafficked.

"The government also remained without measures to screen for trafficking victimization among vulnerable groups, including migrants and persons in prostitution... Law enforcement and social services officials lacked a standardized mechanism for screening vulnerable populations." (US DoS 2018, p70-71)

When 'vulnerable' is used as a label like this, vulnerability becomes a characteristic inherently tied to these groups. There is little or no discussion given to contextualise what may be causing the vulnerability such as a lack of other opportunities for the victims or a lack of protection for those working illegally in a country. As well as being used as a label, vulnerability can also be attributed to certain groups, such as in the example below where an interviewee describes migrant groups as vulnerable. As with labelling, presenting groups in this way without contextualising the vulnerability implies that the vulnerability sits with the affected group and is an inherent characteristic they hold.

"There is certainly a public perception, and in fact I think it was said expressly by one of the government agencies at the working group, that over $90 \%$ of the cases that they deal with and the investigations they deal with are within migrant communities. Those people are the most vulnerable." (NZ Government Official 11)

In some cases when vulnerability is presented in this way, the interviewee or text will include a discussion of the drivers of vulnerability, but they are shown as being individual factors which 
characterise the members of the vulnerable group. Individual factors include aspects of a migrant's culture such as subservience to those in more powerful positions, a lack of education, a lack of awareness, a general naivety, and a lack of English. For example, the text below is taken from the 2018 UNODC report and describes victims as being vulnerable to organ trafficking because of their low levels of education and lack of knowledge about how the body works. While this may be a factor that allows organ trafficking to happen, its inclusion in the place of other factors contributes to the presentation of vulnerability as an individual condition.

"The vulnerability of victims also appears in terms of poor education. One study based on interviews with 103 confirmed victims revealed how none had any education beyond high school level, and only half had primary education or below. As a result, traffickers take advantage of those factors by peddling lies claiming that kidneys grow back after being removed or that it is abnormal to have two kidneys in the first place." (UNODC, 2018, p31)

In a similar example taken from an interview, naivety on the part of the trafficked people is discussed in relation to their vulnerability. As with the example above, while a lack of awareness on the victims' part may be a contributing factor, the emphasis given to victims' naivety in this way contributes to the image of vulnerability being inherently tied to victims.

“People don't know, they see the ad and they don't even have a warning bell in their head, 'this just sounds really dodgy. Sounds too good to be true, cool' they just go 'oh cool'.

There's a nativity about being trafficked. Maybe some education New Zealand could do to help its vulnerable neighbours?" (NZ Government Official 14)

In the example above, the Government is also positioned as being able to "help" its "vulnerable neighbours" though focusing on their education. This positioning enforces the vulnerability as lying with the affected group and neglects situational or structural factors which can contribute to vulnerability and which the government has a role in creating through policy and law. The following section presents the alternative version of vulnerability which was also taken up in the vulnerable migrant worker narrative. In this alternative version of vulnerability, the positioning of government bodies takes a very different form.

\subsubsection{Vulnerability as situational or structural}

This section shows the presentation of vulnerability as something that is created by certain situations, policy settings, governance structures, and industry practices. The narrative was present across the data sources, and in some sources used in conjunction with the other form of 
vulnerability as inherent to certain populations. However, situational vulnerability was discussed more explicitly in the interviews with New Zealand officials, and came through less strongly in the international guidance reports.

When vulnerability was discussed in this way, it was presented as being created by state controlled factors such as legislation, policy settings, and government policing and monitoring of potentially exploitative situations. Factors named as creating vulnerability included visa policies in the receiving country such as policies that tied workers to one employer which created a dependence and vulnerability for the worker. Also visa limitations, such as limiting the hours international students can legally work to 20 hours per week, meaning that any work carried out outside of this period would be illegal creating a precarious work situation for the student. Long drawn out processes to grant asylum or inaccessible asylum seeking processes were also included in international reports as creating vulnerability through making it difficult for refugees to work legally. The legal acceptance of high recruitment fees in both the sending and receiving countries was named as a factor creating vulnerability through allowing debt bondage to occur. A lack of government enforcement bodies in monitoring labour conditions in certain industries was also included as a contributing factor to vulnerability. Areas of New Zealand's legislation which make it illegal for people who hold temporary visas to work in the sex industry were also discussed in a couple of interviews as creating vulnerability by setting up a precarious situation for new migrants working in this industry.

An example of vulnerability being presented as structural is shown in the following excerpt from an interview. Here the interviewee is talking about how, although working in the New Zealand sex industry is decriminalised for permanent residents, Section 19 of the Prostitution Reform Act makes it illegal for people on temporary visas. They note that this can create vulnerability as it does not allow in this case international students to work in the sex industry. This then creates a vulnerable situation as if these students work in the sex industry they will be violating their visa conditions. They would not be likely to seek protection through official channels if they were exploited, as this may result in their visas being cancelled.

"Um what that means is that the one kind of downside [of New Zealand's legislation] is that people that aren't on a permanent visa without conditions who do end up providing commercial sexual services um are therefore in breach of their visa conditions and liable to have their visas cancelled and thrown out [of the country] which then makes them vulnerable... There's certainly anecdotes that that is happening with students, with foreign students" (NZ Government Official 4) 
This example taken from the 2016 UNODC report also shows vulnerability being discussed as being created by state controlled factors. In this example, receiving country state-run asylum-seeking procedures are shown as creating vulnerability through either being inaccessible or being longwinded. In both cases, refugees do not have access to legal channels to seek work through, and so may have to seek an income through illegal and unregulated channels, meaning that they do not have access to protection from exploitation. Even when migrants gain refugee status, they may not have access to employment, and while there is little description as to why they do not have access, it is implied that there are further structural barriers in the receiving country which create vulnerability.

"However, in the country where protection is sought, an individual may not have access to asylum procedures or may face a long wait before their application for international protection is assessed. Moreover, even if they are granted protection, refugees may still experience limited access to labour markets or to education opportunities. Such circumstances, and the lack of an appropriate durable solution, put the person asking for asylum in a limbo, which makes them vulnerable to trafficking." (UNODC, 2016, p63)

In a few of the interviews, industry practices in New Zealand were also discussed as creating vulnerability to trafficking and exploitation. These industry practices included structural factors about how an industry functioned such as a reliance on seasonal workers or the use of short term labour or labour for hire arrangements. Industry practices also included the norms within certain industry sectors about the type of working conditions which were considered acceptable, and the extent to which an industry sector self-regulates its employment practices. For example, the excerpt below is taken from a group interview and shows two interviewees discussing a case of trafficking where migrant labours were exploited in the horticulture industry. In this example, the role of a lack of regulation and monitoring in the horticulture industry is discussed as creating a vulnerable situation where exploitation of workers goes unchecked. In this example, the lack of regulation in the horticulture industry is due to both a lack of monitoring through government enforcement agencies and a lack of monitoring on the part of the industry.

NZ Government Official 12: "Obviously if it had been shut down from the horticulture perspective where they had tighter checks and balances around who they employ and how they pay them then there would be no reason for this man to bring them in [the victims in a trafficking case]. Because he's not bringing them in from a charitable perspective or to give them a holiday, he's bringing them in to earn money off them and if you take that away from 
him or the ability to earn that money, then there's no reason for him to bring them in anymore."

NZ Government Official 13: "And the example for that is the fishing industry. I know there's cameras on the boats and you almost have to take an observer along when a vessel went out fishing to counter all the problems of illegal fishing and yet we've got these large land based industries that have no inspections...There's no sort of day to day or week to week examinations of who's working that land, are they employed properly, are they IRDed [Inland Revenue Department]? All those things, whereas you've got people who are actually observers who are standing on the back of the fishing vessels and doing this sort of stuff out there, so you protect, and were catching up but we're protecting some industries but other industries are sort of in that phase of how do we protect the workers? And generally they're vulnerable because they're at the bottom of, they need the work, whether it be through being coerced or threatened but a lot of them are reliant on that work so that's something too that the industry should be taking more responsibility for."

In the above examples, by discussing vulnerability as being caused by state controlled factors such as legislation, policy settings, government policing and monitoring of potentially exploitative situations, and factors to do with the industry sector in which the exploitation takes place, vulnerability is shown as something that is tied to situations and wider structures in the receiving country as opposed to the individual or certain groups.

\subsubsection{Outcomes of the vulnerable migrant worker narrative}

The vulnerable migrant worker narrative is constitutive of a different form of trafficking when compared to the internationally long-established innocent victim of sex trafficking narrative. The innocent victims of sex trafficking narrative is linked to responses which focus on the 'rescue' of victims and criminal responses targeting individual offenders. It also draws tighter limitations around who can claim victim status, meaning that the benefits of official victim status are only available to those who fit the character of the innocent victim. In this narrative there is little room for agency on the part of migrants as they seek work opportunities. In the vulnerable migrant worker narrative, vulnerability is used to replace ideas of consent and allows people who have chosen to move for work to be considered as victims and receive support. This narrative enables a broader version of victimhood including both men and women as well as those who knowingly and actively take part in work schemes. 
While this narrative allows victims some agency, agency becomes problematic as the amount of agency which is acceptable is unclear. This creates a tension between who is deserving of victim status and who is not, and indicates that this newer narrative is conflicting with older narratives of victimhood and innocence. In some cases where the migrant workers have known about the work they would be carrying out and the working conditions they would be working under, they become complicit in the scheme and although they are exploited they are no longer seen as victims. Those who try but cannot attain victim status are then in a precarious situation, as the state is able to deport them or bring criminal sanctions against those deemed complicit. This is a challenge law enforcement bodies will face as more agency becomes acceptable in definitions of victimhood.

The simultaneous use of the two narratives in the international guidance documents can be seen as constitutive of the divide between trafficking into the sex industry and trafficking into other industry sectors. The presence of the two narratives both embodies this divide and upholds and reproduces it. The implications are that the sex industry is different from other industries and so sex trafficking must be considered in a different way. This is built on the premise that sex work is not labour but inherently exploitative, whereas other forms of labour where trafficking occurs are counted as legitimate work forms. In this way, this narrative both reflects and reproduces the abolitionist position on prostitution which has been influential in anti-trafficking work.

The dominance of the vulnerable migrant worker narrative and the absence of the innocent victim of sex trafficking narrative in the interviews with New Zealand officials can be attributed to the legal approach of sex work being defined as labour in New Zealand. However, it is yet to be seen what the impact of such a narrative trend will be for how trafficking is considered in relation to the sex industry. This characterisation of victims as vulnerable migrant workers has potential to lead in two different directions, either for trafficking into the sex industry to be considered as labour trafficking or for exploitation in the sex industry to be ignored and trafficking into other industries to become the focus of anti-trafficking work.

At the time of this research, the four cases prosecuted using trafficking law involved exploitation in the horticulture and hospitality industries, with no cases involving the sex industry. After the fieldwork for this thesis was carried out, Immigration NZ carried out a review of 57 brothels across New Zealand. The brief online media release about this review describes it as being both a compliance activity to assess whether there were people working on temporary visas in the sex industry and a proactive information gathering activity to assess whether migrant workers in the sex industry are experiencing exploitation (Immigration NZ, 2019a). This review suggests that the sex industry is not being ignored in work to address migrant exploitation. 
The briefing notes that this project was a part of preventing exploitation in the sex industry "It [the review] also included educating the sex industry to ensure employers, facilitators of service and workers understand their rights and legal obligations." And later "While temporary migrants are unable to work in the sex industry, migrant workers have the same employment rights as all other workers in New Zealand,", and that "The sex industry is one element of broader Ministry of Business, Innovation and Employment work to combat migrant exploitation." The focus on employment rights implies that the sex industry is being considered as an industry where labour exploitation can take place, alongside other industries. However, this review also appears to be a compliance exercise targeting migrant workers. The briefing states "The information gathered helps us to investigate pathways of the migrant sex workers found to be in breach of their visas. It enables the INZ [Immigration NZ] Border Operations to improve the identification and management of migrant sex workers attempting to cross the border."

This type of approach appears to be treating the sex industry as a site where labour exploitation can take place yet is also targeting migrant groups in the name of helping to prevent exploitation with potentially negative consequences for migrant workers (the briefing states that 38 sex workers were found to be on temporary migrant visas but there is no information about whether they were served deportation orders or faced other criminal sanctions). The targeting of migrant groups in this approach takes precedence over any consideration of the structural factors contributing to migrant workers' vulnerability, namely the illegal working status for temporary migrants working in the sex industry.

In discussing the outcomes of the vulnerable migrant worker narrative, it is important to pay attention to how vulnerability is constructed. The two distinct versions of vulnerability identified in the data - individual and situational - legitimise different definitions and responses to the trafficking problem. The latter offers a means of overcoming the tension created through allowing victims agency and the divide between narratives for trafficking into the sex industry and other industries. These two versions are discussed in the two following subsections.

\subsubsection{Outcomes of vulnerability as Individual}

When vulnerability is presented as being tied to individuals and inherent to some groups, these groups are placed at the heart of the problem and are associated with the causes of the problem. In Fouladvand and Ward's analysis of human trafficking literature they conclude that by focusing on vulnerability of individuals rather than structural factors the result is the "pathologising 'vulnerable adults' as a category of defective beings" (Fouladvand and Ward, 2019, p. 54). The types of 
interventions that are supported by this narrative are those which target the 'vulnerable' group, both through increased policing and monitoring and through interventions which target individual factors of 'vulnerable' groups and hold individuals responsible for pulling themselves out of vulnerability.

Responses which target the 'vulnerable' group were discussed in the previous chapter as being enabled by the trafficking as a foreign other problem narrative. These types of interventions can mean these groups are policed, monitored or regulated. The examples used in Chapter Six were a project discussed in an interview where the UK police collected information about women of different ethnic groups in the sex industry as a way of responding to trafficking through monitoring these groups. Another example used was that in some countries, women's ability to migrate is restricted as a protective measure against future exploitation (GAATW, 2007).

As well as being regulated or policed, the migrant groups may become the target of intervention programmes to reduce vulnerability where they are held responsible for pulling themselves out of vulnerability. When vulnerability is treated as inherent, it individualises the problem and the responses to the problem also become individualised. For example, Maher and Segrave (2018) carried out research with migrant and refugee women in Australia who had experienced domestic violence and analysed how the term 'vulnerability' was constructed and attached to these women through official service provision channels. They found that when language of vulnerability was used in a way that attached vulnerability to individuals and their culture, it led to responses that focus on individuals and a neglect of the structurally created risks to these groups, which were set up through government policy and service provision.

The 2018 US DoS report gives examples of interventions which target individuals in 'vulnerable' groups. In the two following examples, the report promotes programmes which educate and raise awareness about the dangers of migration among vulnerable groups so that they can be avoid being trafficked.

“...Ms. Salas pioneered the establishment of the Village of Migrant Workers, a community that provides skills training and support to individuals and their families who migrate for economic opportunity and that works to increase awareness about human trafficking among this vulnerable population." (US DoS 2018, p49)

"Ms. Okoedion also partners with the Catholic Church, particularly women religious, and travels throughout her home country of Nigeria to educate vulnerable women and girls in poor and remote areas to help them detect traffickers' fraudulent recruitment and 
employment tactics, including false promises of work and a better life in large cities and other countries" (US DoS 2018, p50)

In these examples, the affected groups are held responsible for making sure they do not enter into trafficking situations. While these individualised approaches may reduce some aspects of vulnerability, they cannot wholly address it as they do not consider the structural factors that create vulnerable positions.

As well as enabling responses which target and responsibilise migrant groups, the use of vulnerability as inherent in the vulnerable migrant worker narrative, reinforces the trafficking as a foreign other problem narrative, described in the last chapter. In this version of vulnerability the problem is seen as being brought into the country by incoming migrant groups and is something that is inherently tied to their culture, norms, and beliefs. The result of both narratives is that the causes of the problem are seen as external and structural factors of the receiving country which may be creating the conditions for exploitation to occur are neglected.

\subsubsection{Outcomes of situational or structured vulnerability}

Where vulnerability is described as situational or structured, attention is paid to the situational and structural factors creating the vulnerability as opposed to the individuals themselves. This focus enables anti-trafficking work that considers factors that cause or contribute to vulnerability which are under a governments control such as altering immigration law, visa conditions, monitoring and regulation of certain industries, or using employment law to address employment structures that create power imbalances between employers and employees. This construction of vulnerability focuses on the local country where the exploitation occurs, and so avoids treating trafficking as a foreign problem with external causes which is brought into the country by problematic groups.

This form of vulnerability avoids the issue of agency and how much agency victims can be allowed to have, which has been a challenge in anti-trafficking debates. The innocent victim of sex trafficking narrative allows very little agency and excludes many from claiming victim status. The vulnerable migrant worker narrative, where vulnerability is an individual characteristic, allows victims to have agency but when they have too much they become complicit in the trafficking and this is problematic for prosecutions and those trying to gain victim status. Situational vulnerability focuses on the structural factors creating vulnerability as opposed to the individuals themselves and so the amount of agency individuals show becomes less important. 
Using structured vulnerability in narratives of victimhood also offers a means of overcoming the divide between narratives for trafficking into the sex industry and other industries. This narrative would focus on how positions of vulnerability are structured as opposed to the individuals experiencing vulnerability, their characteristics, the type of exploitation, and the extent to which they have consented to the situation they are in. If applied to trafficking within the sex industry, framing migrants as situationally vulnerable would pay attention to why people are vulnerable to exploitation in certain settings. For exploitation in the sex industry this may mean drawing attention to legislation and looking at whether it protects or creates vulnerabilities. The criminalising of prostitution in many countries could be considered as a structural factor creating vulnerable situations by making protection unavailable to those who chose to work in the sex industry. Although the vulnerable migrant worker narrative could be applied using situational vulnerability, if vulnerability is constructed as inherent, this could be harmful and lead to similar outcomes of the innocent victim of sex trafficking narrative, where inherently vulnerable groups would be seen as in need of rescue and lead to interventions where 'vulnerable groups' are regulated or deported.

The presentation of vulnerability as situational and structural also has potential to draw attention to the wider systems in which exploitation occur such as international supply chains, international labour markets, and systems built on capitalist and neoliberal principles. By situating vulnerability within these systems their role in creating situations favourable to exploitation is included. Also, the systems themselves are not positioned as exempt from the problem or as the solution to the problem, as is seen in the companies as saviours narrative discussed in Chapter Five.

\subsection{Conclusion}

This chapter has presented the two main ways in which victimhood is narrated in the data. The innocent victim of sex trafficking narrative is a well-established position that has been used in much anti-trafficking discourse internationally over the past 20 years. The vulnerable migrant worker narrative appears to be a more recent emerging narrative which is tied to the conscious effort of international agencies to focus more on labour trafficking. The two narratives have different implications for anti-trafficking work, and in particular how agency, consent, and vulnerability are conceptualised.

The two narratives are constitutive of two different forms of victimhood. These narratives are enacted through the process of attributing victim status, as those who can fit the prescribed narrative form can be classed as legitimate victims. These individuals and their situations are then recorded as being trafficking victims, contributing to an image of victimhood which is then 
reproduced through trafficking statistics. Those who cannot fit the prescribed image of victimhood are redefined as illegal immigrants or are criminalised for working illegally or being complicit with trafficking schemes. In this way, these narratives define and distribute definitions about trafficking victims, and determine how different groups are conceptualised and treated.

The emerging narrative of the vulnerable migrant worker provides an alternative to the more embedded innocent victim of sex trafficking narrative. The innocent victims of sex trafficking narrative enables criminal justice responses which target individual offenders as well as the rescue and repatriation of victims. This long-standing narrative creates a narrow and difficult to attain version of victimhood and those who cannot fit this image are at risk for deportation or criminal sanctions. In this narrative, there is also a clear distinction between trafficking into the sex industry and trafficking into other industries. The inference is that sex work is not work and therefore must be considered its own type of trafficking. In this way the narrative both reflects and reproduces the abolitionist position on prostitution which has been influential in anti-trafficking work and which has supported the targeting and surveillance of sex workers.

While the innocent victim of sex trafficking narrative offers little room for agency, in the vulnerable migrant worker narrative, vulnerability is used to replace ideas of consent and allows people who have chosen to move for work and actively do so to be considered as victims and receive support. This narrative enables a broader version of victimhood including both men and women as well as those who knowingly and actively take part in work schemes.

The data showed vulnerability as being presented in two distinct ways, which affects the type of responses that are legitimised. When vulnerability is presented as being tied to individuals and inherent to some groups, these groups are placed at the heart of the problem and are associated with the causes of the problem. This supports interventions which target the 'vulnerable' group, both through increased policing and monitoring and through interventions which target individual factors of 'vulnerable' groups and hold individuals responsible for pulling themselves out of vulnerability. This narrative also creates a tension in terms of the amount of agency allowed for victims. While victims can show some agency, showing too much can result in them being seen as complicit with the trafficking. This then negates their rights to claim victim status and they are criminalised as a result.

Where vulnerability is described as situational or structured, attention is paid to the situational and structural factors creating the vulnerability as opposed to the individuals themselves. This focus enables anti-trafficking work that considers factors that cause or contribute to vulnerability which are under a government's control, such as altering immigration law, visa conditions, monitoring and 
regulation of certain industries, or using employment law to address employment structures that create power imbalances between employers and employees. This construction of vulnerability focuses on the local country where the exploitation occurs, and so avoids treating trafficking as a foreign problem with external causes which is brought into the country by problematic groups. The presentation of vulnerability as situational and structural also has potential to draw attention to the wider systems in which exploitation occurs, such as international supply chains, international labour markets, and systems built on capitalist and neoliberal principals.

This form of vulnerability avoids the issue of agency and how much agency victims can be allowed to have, which has been a challenge in anti-trafficking debates. Situational vulnerability focuses on the structural factors creating vulnerability as opposed to the individuals themselves, and so the amount of agency individuals show becomes less important. Using structured vulnerability in narratives of victimhood would also help to avoid the problematic distinction made between trafficking into the sex industry and trafficking into other industries. This form of vulnerability would focus on how positions of vulnerability are structured, as opposed to the type of exploitation experienced, characteristics of the victims, and the extent to which they have consented to the situation they are in. 


\section{Chapter Eight: Towards an alternative narrative}

This research set out to identify and unpack narratives of human trafficking in New Zealand. It sought to understand how human trafficking is defined, what discourses are drawn on, and how international narratives may be influencing local responses, with the overall aim of identifying new and more productive ways of conceptualising human trafficking and responding to migrant exploitation. The findings of this thesis illustrate the multiple narratives of trafficking which are active in the field and demonstrates how different narratives are constitutive of different forms of trafficking as a social problem. In this chapter, I propose an alternative narrative about structured vulnerability and hidden capital. This narrative is presented as a way of shifting trafficking approaches away from those which target migrant groups, have a problematic focus on sex work, and neglect local contexts.

The first section of this chapter outlines how this research has shown that narratives are constitutive of trafficking realities. They determine the shape the problem takes, who is involved, and what the causes and solutions are. This study concludes that attention to narrative is crucial - as narratives structure reality and action, to change how we deal with certain problems, the way the problem is narrated must also change. Given the problematic long-established international responses to trafficking, there is a pressing need for alternative narratives to enable different responses.

This chapter continues with a deeper discussion of two key findings: western exceptionalism and the difference between narratives expressed at an international and at a New Zealand level. In this discussion I show the contexts in which the dominant and problematic narratives about trafficking are produced. These contexts are important to understand, as they essentially limit the uptake of more nuanced narratives though powerful long-standing political discourses and institutions.

In the first of these subsections I show how the pervasiveness of western exceptionalism from the problem of trafficking is evident across the findings of this thesis. Alien conspiracy theory is then discussed as a method through which crime problems are externalised, which is particularly relevant to human trafficking representations, and as a model which offers an explanation for the prominence of western exceptionalism in trafficking discourse.

In the second of these subsections, I consider the differences in international and New Zealand based narratives. These differences found in this thesis reflect two major challenges debated in the international body of literature on anti-trafficking work. This includes questions of how to broaden trafficking definitions and concepts of victimhood, in particular to include labour trafficking, and to shift away from an overt focus on prostitution. It also includes questions of how to address the tension between internationally led approaches to trafficking versus locally led approaches, with the 
argument that international definitions do not reflect local realities. The differences found between the international and New Zealand based data show the importance of having locally based narratives rather than relying on those presented by international bodies. These differences also highlight aspects of the New Zealand context which provide unique insights to the challenge of shifting away from narrow narratives which focus on the sex industry.

At the end of this chapter, I present a counter narrative, drawn from the findings of this study, which offers a way forward avoiding the problems of western exceptionalism and the narrow definitions of victimhood. In this final section, the alternative modes of conceptualising trafficking identified in this research are described, and the counter narrative is presented. This alternative narrative is one where trafficking is constituted as something that takes place within the local settings in which the exploitation occurs and within wider systems of capitalism and neoliberalism. It shows profit-making as important and looks at how positions of vulnerability are structured by systemic and local country policy and legislative settings. The likelihood of such a narrative becoming mainstream is also discussed. In this discussion, the substantial barriers to uptake due to the long-standing persuasive and pervasive narratives are weighed against the changing political and economic landscape which has resulted from the 2020 Covid pandemic.

\subsection{Narratives and the 'real' world}

This section provides a discussion of the constitutive nature of narratives. It recalls the starting premises of this research, namely that narratives are an important and relevant subject in attempts to move forwards in the anti-trafficking field, and that narratives structure realities and lead to action. This section shows how both these premises were reinforced throughout this study as the findings show how different constructions of the trafficking problem shape what the problem is, how it is responded to, who responds, and who are classed as victims and perpetrators.

This research sought narratives as an important avenue of study in attempting to improve the way issues involving migration and harm are addressed. As described in Chapter Three, in setting out to research human trafficking, a focus on narratives appeared pertinent and appropriate. The range of different ways trafficking has been approached and the ongoing debates about definitions and responses show that trafficking is a contested concept, yet one which has rapidly gained popularity and been applied across the world to a range of complex issues (Lloyd and Simmons, 2015; Anderson and O'Connell Davidson, 2002). 
Academic critics have pointed out how the popular and politicised nature of trafficking has meant that trafficking campaigns have been charged with different discourses about immigration, gender, western supremacy, and current anxieties around 'global threats' and 'international security challenges' (Meyer and Boll, 2018; Kempadoo, 2005, 2015; Kapur, 2005). Critics have shown how different approaches to the trafficking problem, including treating trafficking as prostitution, a border security threat, and modern day slavery, have led to certain responses (As discussed in Chapter Three for example: Chuang, 2014; GAATW, 2007; Chew, 2006; Kempadoo, 2005). These responses have been criticised as harming the groups who are affected by trafficking and as setting up a circular problem where exploitation is not addressed (Andrijasevic and Mai, 2016; Dottridge, 2007; Kempadoo, 2005; Sanghera, 2005). The problem becomes cyclical as the factors driving the problem are excluded from the response, and those harmed by the exploitation become the target of interventions which, rather than reducing the problem, tend to perpetuate the harm for those affected. Based on these previous analyses, narratives appeared to be playing a central role in the definition and treatment of trafficking and studying them would enable an unpacking of the discourses that are drawn on, the positions available to groups involved, and the resulting responses.

The second premise this research was based on was that narratives are constitutive. In this view, all experience is storied, it makes up how we see the world and leads to future action. In this way narrative cannot be divided from reality or experience, as narratives make up our reality and determine action (Presser and Sandberg, 2014; Presser, 2009). When applied to the way a policy problem is told, narratives shape 'the truth' (Breuil et al., 2011, p. 31), invoke 'knowledge claims' (Boswell et al., 2011), or make problems 'thinkable and thus governable' (Edwards and Gill, 2002a). This is done through determining how a problem is understood, what evidence is relevant in understanding the problem, and what solutions are available. The way the problem is understood shapes responses as claims about the problem take effect in policy, practice, and institutions (Weitzer, 2007; Spector and Kitsuse, 1973). These responses affect which groups are positioned as being central to the problem, as the way that the groups who are the subject of the policy are constructed effects the opportunities available to them, how they are perceived and treated, their identity, how institutions are formed to regulate them, and the development of further policies (Ingram et al., 2007; Ingram and Schneider, 1991). In this way, narratives are constitutive of the social problem, as the way the problem is narrated determines what becomes understood as the problem. The process in cyclical as the 'problem' then shapes further narratives.

Both these premises were reinforced throughout this study, as the findings show different ways of narrating the problem of trafficking that are present in anti-trafficking work, illustrating how 
different constructions shape what the problem is understood to be, how it is responded to, who responds, who are positioned as victims and perpetrators, and how the causes of the problem are defined. These narratives constitute different forms of trafficking. Those who are targeted as the cause of the problem become labelled as problematic groups and are positioned as being at the heart of the problem. The institutions and actors which are positioned as being able to fight trafficking have their roles legitimised. The scope of the problem and what can be done about it is confined through the exclusion of certain causal factors and characters from trafficking narratives.

This is demonstrated in various ways through the data. For example, when victims are narrated as being non-consenting or forced into exploitative situations, and the appropriate response legitimised through the narrative is a criminal prosecution, then in order to attain victim status, the affected person must show themselves as non-consenting and as not actively taking part in the exploitative work scheme. The criminal justice process where the character of the non-consenting victim is enacted further embeds this version of victimhood. Another pertinent example of the determining and circular effects of narratives is the construction of trafficking as a foreign and incoming problem. The responses enabled by this narrative are those which target migrant groups, both in criminalising the traffickers and positioning the victims as vulnerable and in need of protection and intervention. The focus on these groups sets them up as being at the heart of the trafficking problem, emphasising their position as causing the problem and embedding the foreign other narrative and the external, incoming nature of trafficking.

Narratives provide the stories we live by, shaping physical realities, creating positions for people to take up, and helping us to interpret experience. While they structure our realities, they are not fixed and inflexible. This research showed that there are multiple narratives about trafficking. Some share similarities and some are conflicting. They can be taken up at different times and used in conjunction or opposition and they are open to change. For example, as shown in Chapter Seven, the more established narrative of victimhood, which is about sex trafficking, was present in some of the data sources and was used interchangeably with a newer narrative about victims as vulnerable migrant workers. The use of the two narratives interchangeably was most likely part of the current effort to broaden trafficking definitions to encompass different forms of trafficking outside of sexual exploitation. In another example, the data shown in Chapter Six demonstrates how the pervasive international narrative of trafficking as a foreign problem has been taken up in the New Zealand context in an altered form. This altered form differs from the more traditional versions as it shows trafficking as a foreign problem tied to developing nations, but not one which is sinister and threatening in nature. This altered narrative suggests some aspects of the long-standing international narrative about foreign problems and alien threats are taken up but in an altered form. 
This research has shown that given the power of narratives to structure reality and action, in order to change how we deal with certain problems, the way the problem is narrated must also change. In seeking to improve the way issues involving migration and harm are addressed, it is important to identify, understand, and challenge social narratives which are legitimising or facilitating harm, and identify new less problematic narratives.

As discussed in the outset of this thesis, the field of anti-trafficking work has been subject to much debate and contestation. Although there has been much literature and research critiquing antitrafficking approaches, the dominant anti-trafficking discourses appear difficult to significantly shift. This study found long-standing traditional narratives to be present and pervasive in anti-trafficking discussions and policy, and that the ongoing presence of these narratives is likely to be constraining attempts to shift trafficking work in a different direction. At the time of this research, the main debates in the anti-trafficking field and questions that academics, practitioners, and advocates were trying to address were: how to broaden trafficking definitions and concepts of victimhood, in particular to include labour trafficking, and to shift away from a focus on prostitution ${ }^{2}$; how to avoid the problem of anti-trafficking work and campaigns in conceptualising trafficking as something that western states, and western-favoured systems of neoliberalism are exempt from ${ }^{3}$; and how to address the tension between internationally led approaches to trafficking versus locally led approaches, with the argument that international definitions do not reflect local realities ${ }^{4}$.

These challenges were observable in the data used in this research. The issue of needing to broaden concepts of victimhood could be seen through the two forms of victimhood created through narratives. The vulnerable migrant worker narrative offered a way of broadening constructions of victimhood, yet the more traditional narrative of the innocent victim of sex trafficking still had a strong presence in the international guidance sources. The exclusion of western countries and systems from the problem of trafficking was present throughout the data sources and was particularly evident in the narrative of trafficking as a foreign problem. Identifying this narrative shows how trafficking is constituted as a problem of migrant groups from which western systems are exempt. The question of whether approaches should be locally or internationally led was also reflected in the data as the narratives examined show two different ways the trafficking problem is

\footnotetext{
2 (For example see: Cojocaru, 2016; Hoefinger, 2016; Wylie, 2016; Chuang, 2010, 2014; Shamir, 2012; Tomkinson, 2012; Mahdavi and Sargent, 2011; Lebov, 2010; Andrijasevic, 2007; Chang and Kim, 2007; GAATW, 2007; Doezema, 2001)

${ }^{3}$ (For example see George et al., 2017; Kempadoo, 2015, 2017; Okyere, 2017; Szörényi, 2016; Chuang, 2014; Kapur, 2005, 2010; Sharp, 2009, p. 106; Dottridge, 2007).

${ }^{4}$ (For example see Anderson and Li, 2018; Blouin and Button, 2018; Juliawan, 2018; Sanchez, 2018; Soltis and Walters, 2018; Snajdr, 2013; Mahdavi and Sargent, 2011)
} 
constituted: at an international level, and at a New Zealand level. The international level constructions have problematic implications for how those involved are treated and how the problem is addressed, suggesting that international influence in determining trafficking definitions and responses should be limited.

In the following section, two key findings - the pervasiveness of western exceptionalism and the reoccurring differences between New Zealand and international level narratives, are discussed further in relation to the current challenges faced in the anti-trafficking field. These findings are important to consider in relation to bringing about change in the anti-trafficking field as they demonstrate powerful processes which act to maintain the more entrenched and problematic narratives. To build on the conclusion of this research: that in order to change how we deal with certain problems the way the problem is narrated must also change; this chapter ends with the presentation of an alternative narrative created through drawing together components of narratives identified in this research. This alternative is proposed as a way of avoiding the problematic aspects of existing and long-established narratives in the anti-trafficking field, and as a way forward in responding to current challenges in the anti-trafficking field.

\subsection{Entrenched narratives and the New Zealand perspective}

There were two central findings which stood out as recurring across the findings chapters. These are: western exceptionalism from the problem of trafficking and the differences between narratives shown in international level data and at a New Zealand national level. These findings came through strongly in this study and are relevant to the current directions of anti-trafficking scholarship and practice. This section discusses each of the key findings in more detail, contextualises them by drawing on the international body of literature, and shows what can be learnt from each theme in moving forwards in attempts to better respond to exploitative situations. Examining these findings also illustrates how long-standing and problematic narratives have achieved such a pervasive presence and how local and international political and economic contexts can limit or encourage the uptake of more productive narratives. Acknowledging the processes which inhibit the uptake of alternative narratives is important to consider in attempting to move towards less harmful constructions of the trafficking problem. 


\subsubsection{Western exceptionalism from the problem of trafficking}

The idea of western exceptionalism from the problem of trafficking is seen throughout the research findings. It is discussed explicitly in Chapter Six but is also a key theme throughout Chapters Five and Seven. In this section I discuss this theme in relation to anti-trafficking literature and demonstrate how the concerns raised by critics are visible in the data examined in this study. The findings from this research reflect this line of critique, and provide a way forward by drawing together narrative strands identified in the data which provide an alternative narrative and a more progressive approach to anti-trafficking work. The findings are then discussed in relation to alien conspiracy theory as a method through which crime problems are externalised. This theory is particularly relevant to human trafficking representations. It provides an explanation for the widespread narrative of trafficking as a foreign problem and has implications for the likelihood of bringing about change in anti-trafficking responses.

The presentation of western states, institutions and systems as being exempt from the problem of trafficking, and a lack of attention given to western state controlled factors and aspects of neoliberal systems of commerce, trade, and consumerism in creating exploitation has been highlighted as a problematic aspect of anti-trafficking discourse and practice in international scholarship and advocacy. Critics of anti-trafficking work have described how the neoliberal and capitalist systems, favoured by western states, create conditions favourable to trafficking and exploitative labour. In this argument, the rise of neoliberal policies in state governments around the world as well as increasingly globalised labour markets are drivers of both exploitative work practices and migration. Demand for cheap goods and services drives migration, as it displaces people through limiting opportunities in some countries and increasing them in others (Chang and Kim, 2007). Where this increased movement takes place, so do illegal and unprotected forms of migration such as trafficking (Mahdavi and Sargent, 2011). Increased migration for work tends to be misaligned with states' immigration policies, and the gap between demand for cheap goods and services and the legal channels for providing them creates non-legal and unsafe migration (Sanghera, 2005). Neoliberal policies in receiving countries, such as limiting labour regulations, then make it possible for exploitive work situations to occur (Hoefinger, 2016; Kempadoo, 2015; Sanders, 2008; Anderson and O'Connell Davidson, 2003; Kelly and Regan, 2000).

Anti-trafficking work has been criticised for not including neoliberal and capitalist systems in the causes of trafficking, and for largely not seeking to address aspects of these systems in attempts to prevent trafficking. This area is neglected as most anti-trafficking work takes an individualised approach which focuses on prosecuting individual offenders using criminal law, rescuing individual victims, or targeting migrant groups through interventions such as raising their awareness of 
trafficking or restricting their ability to migrate as a protective measure (Kempadoo, 2015, 2017; Okyere, 2017; GAATW, 2007). Anti-trafficking campaigns have also been criticised for focusing on stereotypical characters of victims and villains and through this individual focus, neglecting the wider systemic causes of the problem (Andrijasevic and Mai, 2016; Hoefinger, 2016; Kempadoo, 2015; Tomkinson, 2012; Chuang, 2010). Individualist approaches have been further criticised for their presentation of trafficking as abnormal rather than as an expected part of neoliberal work environments. When trafficking is presented as discrete cases carried out by criminal individuals, trafficking is presented as something unusual that happens within otherwise ethical systems. Trafficking and exploitation is portrayed as an aberration to migrant working conditions rather than a consequence of free-market and neoliberal policies (Andrijasevic and Mai, 2016). Others have been critical of the positioning of neoliberal systems of international trade and consumerism as being the solution to problems of trafficking and exploitation as opposed to being a part of the problem. For example, positioning corporations as having the potential to do good through eliminating slavery in their corporate supply chains (O'Brien, 2018a) or through a commercial company linking itself to anti-trafficking campaigns in order to be seen as ethical and presumably to increase sales (Andrijasevic and Mai, 2016; Leigh, 2015).

As well as critiquing western favoured systems of neoliberalism and capitalism being exempt from the problem of trafficking, international literature also criticises the lack of attention given to western states and their governments in contributing the trafficking problem. Critics of antitrafficking work have described how western states play a role in creating situations which are favourable to exploitation through policies, legislation, and practices which create a demand for goods or services, a lack of legal avenues for the labour to be provided, and a lack of other protections for workers and migrants (George et al., 2017; Hill, 2016; Dottridge, 2007; O'Connell Davidson, 2006). The methods for excluding western states have been identified in international literature as occurring when trafficking is presented as a foreign problem and a national security threat, and where governments are presented as those who fight trafficking and protect and rescue victims (Hill, 2016; Anderson et al., 2009; O’Connell Davidson, 2006).

While the term 'western exceptionalism' is not widely used in anti-trafficking literature, it is relevant to the above critiques as literature has described the ideology behind these phenomena as being tied to white supremacy (Kempadoo, 2015), imperialism (Agustin, 2012), colonialism, and the idea of 'western heroes' (O'Brien, 2018b, p. 131), as upholding distinctions between civilised and uncivilised (Chuang, 2014), and as a method of "keeping the 'Rest' away from the 'West'" (Kapur, 2005, p. 25). These ideologies align with western exceptionalism as western civilisation is upheld as separate from the problem of trafficking and as superior in its ability to fight trafficking and rescue victims. 
This research has identified western exceptionalism as a key theme and shown how it is problematic, contributing to the existing knowledge and debate in this field. As well as enforcing concerns raised in international literature, this research draws together a group of fringe narratives which provide an more nuanced narrative of trafficking and one which can be used to steer anti-trafficking work away from the embedded narratives of othering and problematizing migrant groups. The text below summarises how the theme of western exceptionalism can be seen across the findings chapters, supporting the calls for change voiced in the field.

In Chapter Five, which showed how trafficking was narrated in relation to commercial enterprise, western exceptionalism is demonstrated through the narrative of trafficking as profitable organised criminal enterprise, as trafficking is attributed to sinister and threatening organised criminal and militia groups. In this narrative, western governments are positioned as being outside of the problem and as being responsible for 'fighting' these trafficking groups. In this chapter, westernfavoured commercial systems are also positioned as being outside of the trafficking problem. This is shown in the narrative of commercial systems and businesses as saviours where global neoliberal systems are positioned as good and as working to pull people out of poverty. Commercial businesses are also positioned as doing good through ensuring their supply chains are free from exploitation. In this way, consuming goods from companies who monitor their supply chains is promoted as a solution to the trafficking problem. The role of companies and the model of international trade which works to create profit from cheap labour, are not included in this narrative.

In Chapter Six, the idea of western exceptionalism is conveyed through the presentation of trafficking as a foreign problem which is incoming from other developing and non-western countries. In this narrative, people who commit trafficking offences and people who are trafficked are presented as foreign and the causes of the trafficking problem are shown as external to the receiving country and tied to other country factors such as culture, norms, and poverty. Sitting alongside the trafficking as a foreign problem narrative are the narratives of trafficking as an abhorrent aberration, and trafficking as a big unknown problem. These two narratives add to the idea of trafficking as a foreign problem by showing it as something that is abnormal, abhorrent, and sometimes threatening, which sits outside of everyday life. These narratives neglect local factors which create situations of exploitation in the countries, industries, and work environments where trafficking occurs and detract attention from policy and legislative settings which contribute to exploitative situations.

In Chapter Seven the new emerging narrative of the vulnerable migrant worker can result in western exceptionalism when vulnerability is used in an inherent and individualised sense. When 
vulnerability is used in this way, migrant groups are presented as being inherently vulnerable and thus the problem of trafficking is situated with these groups as something they bring into the country. Interventions tied to this version of vulnerability can result in migrants being monitored and policed, or can focus on educating migrants and holding them responsible for pulling themselves out of vulnerability. In this narrative form structural and situational factors that create vulnerability such as those created by state governments through policy and legislative settings, and those created through systems of commercialism which seek to produce low cost goods and services, are neglected.

\subsubsection{Alien conspiracy theory and othering of the trafficking problem}

This section explores alien conspiracy theory as a process of othering, which can be seen as working to divide trafficking and exploitation from legitimate systems and the formal and accepted economy. The alien conspiracy model has been a part of academic debates which critique the way organised crime has been represented in political rhetoric, policing, and popular presentation in the United States (Kleemans, 2014). The model is particularly relevant to human trafficking. Alien conspiracy theory offers a possible explanation for the ongoing presence of the foreign other narrative and the strong sense of western exceptionalism created through trafficking discourse. Discourses about trafficking as organised crime - and organised crime as a foreign problem - were propagated through the US government's role in creating trafficking as a crime type during the design of the Trafficking Protocol, and is likely to have played a part in the ongoing othering of the trafficking problem (Hobbs and Antonopoulos, 2013; Woodiwiss and Hobbs, 2009).

As discussed in Chapter Six, the alien conspiracy model is a way of understanding organised crime which has been an integral part of politics, policy, policing, and popular representations in the US as the idea of organised crime has developed (Kleemans, 2014). The underlying proposition of this model is that organised crime is a foreign problem which is brought into the US by immigrant groups. The problem is incoming and alien but also threating to US society in that it poses a risk to law abiding citizens, and is sinister in that organised criminal groups conspire to corrupt US systems through infiltrating official structures (Potter, 1994). Alien conspiracy theory creates a process of othering as it emphasises differences between problematic groups and 'normal' law abiding citizens. The key defining feature of these problematic groups is ethnicity, as organised crime is seen as something that comes from other countries imported by ethnic minority groups who have immigrated to the US (Potter, 1994). These problematic groups are positioned as being outside of 'normal' society, and are shown as acting on state governments, legitimate markets, and fiscal 
structures in a sinister, threatening, and conspiratorial way, to attempt to corrupt, infiltrate, and monopolise them (Potter, 1994). Stereotyped characters of villains and heroes are drawn on to discriminate between the problematic groups and the good and functioning systems of government (Hobbs and Antonopoulos, 2013; Weitzer, 2007).

This portrayal of organised crime results in policies and practices where ethnic groups are targeted through criminal justice responses. A long-standing response has been the targeting of individual offenders thought to head ethnically distinct criminal groups with arrest and seizure of assets, a response which has been criticised for its failure to reduce organised criminal activity (Mastrofski and Potter, 1987). Individualising the problem and attributing it to certain ethnic groups creates process of othering through discrimination and exclusion based on ethnicity and leads to further criminalisation of migrant groups (for example see Antonopoulos, 2006). It also feeds into moral panics where migrant groups are linked to crime and become seen as a threat to society, which when popularised through political rhetoric, results in policies to further target and marginalise migrant groups (Woodiwiss and Hobbs, 2009).

This process of othering also serves to distract from the embeddedness of organised crime in legitimate and legal economic systems (Mastrofski and Potter, 1987). By positioning organised crime as something sinister that is opposed to, and acts on, legitimate systems, the symbiotic relationship between legitimate and illegal aspects of the economy is disregarded. For example, legal institutions and systems can support organised crime through creating conditions where criminal activity is profitable and practicable, and illegal activities can provide goods and services that are in demand in a society where there are no legal channels through which to provide them. The alien conspiracy theory process of othering further neglects the blurred boundary that exists between legitimate and illegitimate aspects of business ventures and the economy. When illegal practices are defined as being something that is separate from normal good systems and that are brought in by a foreign criminal 'other', then the illegal practices are positioned in being in opposition to legitimate systems rather than being interlinked (Edwards and Gill, 2002b).

The same processes of othering which see organised crime divided from legitimate systems and the formal economy can also be seen in human trafficking discourse, where cases of trafficking and exploitation are divided from socially accepted and legal parts of the economy. As discussed in Chapter Six, the presence of the alien conspiracy model can be directly traced to the US government influence in the design of the Trafficking Protocol. Research by Woodiwiss and Hobbs (2009) and Hobbs and Antonopoulos (2013) demonstrates how alien conspiracy discourse used by US crime 
control authorities was taken up at a UN conference which led to the development of the trafficking protocol.

This process of othering creates legal and illegal sections of the economy and, in the case of human trafficking, some forms of migrant labour are divided from socially accepted and legal parts of the economy. This is explicated by Sanghera (2005) where she characterises human trafficking as happening in countries where there is a demand for labour or goods but not the legal means for these to be provided. This leaves a gap in the market which is then filled through illegal means, creating precarious situations for those working to fill the gap as legal rights are not available to them, and so conditions favourable to exploitation occur. She positions human trafficking as the outcome of an international legal system that has not caught up with globalised labour flows as immigration laws are not adapted to protect the flow of people migrating for work in response to demand and economic opportunity (Sanghera, 2005). In this view, human trafficking and exploitation are integrated into a state's economic systems as opposed to being an external alien force acting on them.

As well as human trafficking being integrated into commercial structures, some critics of antitrafficking work have shown how states and formal economies benefit from cheap and controllable labour, and show how trafficked labour fills a gap in global and local economies. Anderson and colleagues (2009) have criticised the current global model of sovereignty which allows sovereign states to control migration across borders and to determine how migrants are treated within their borders, through criminalising them, and granting certain rights and restricting others. They argue that states' ability to control migration, criminalise, and set limitations on migrants' rights serves both global capitalism and the system of sovereign states as it is a means of providing cheap labour through creating a controllable workforce. This is done through criminalising migrant workers by creating situations where the work is carried out illegally, or granting them subordinate working status such as temporary visas or visas that tie the employee to one employer. The combination of sovereign states' ability to control migrant workers, along with international neoliberal markets, and the globalisation of the labour force together create cheap labour which benefits certain states and the wider system of capitalism where cheap goods and services are readily available (Mahdavi and Sargent, 2011). However, the role of cheap and controllable labour as being beneficial to the receiving country is excluded when the causes of the trafficking problem are externalised and processes of othering where the problem is presented as an alien threat are employed.

Sharma (2017) shows how the benefits of exploitative labour to the formal economy can be seen throughout labour schemes of the $19^{\text {th }}$ century. She draws on $19^{\text {th }}$ century colonial migration law to 
show how regulating migration was used as a way of creating a cheap and controllable labour force. This was done through indenture systems where workers were taken to the British Colonies under extremely restrictive labour schemes with few rights. These labour schemes filed a gap in the labour market which was left by the abolition of the transatlantic slave trade. This historical perspective shows both how formal economies benefit from cheap labour and how, where there is a gap in the labour market, it tends to be filled. Whether this is done legally or illegally depends on a sovereign state's policy. In the case of the British colonies, it was done legally through legally accepted labour schemes, and in the case of trafficking, it is done illegally through unlawful migration schemes.

Although there was a strong recurrent theme of western exceptionalism from the problem of trafficking created through the narratives identified in this study, this research also identified some alternative narratives. These alternatives provide a way of reframing trafficking and creating a narrative which enables a different set of responses to those which have been widely used in antitrafficking efforts. These alternative narratives are drawn together and presented as a single counter narrative in the last section of this chapter. This counter narrative draws attention to the structural and systemic factors shaping exploitative situations and supports anti-trafficking efforts that aim to address legislative and policy settings and industry practices. In this way it aims to avoid treating trafficking as an alien or foreign problem. However, the endurance of these processes of othering creates barriers to the uptake of a more progressive narrative. Later in this chapter, these popular methods of othering are weighted against recent political and economic changes resulting from the Covid pandemic in considering the likelihood of an alternative narrative becoming mainstream.

\subsubsection{Differing narratives at international and New Zealand level}

The second central finding shown across the chapters is the differences in narratives employed in the international level data and in the New Zealand level data. The differences between the international and New Zealand level data stood out consistently and there was little difference in narratives within each level. The narratives seen in UN reports were similar to those in the US DoS reporting and the narratives communicated in the interviews with New Zealand government officials and government documents were similar both across government agencies and across interviewees' roles such as those in policy roles, management, and front-line enforcement positions. The exception to this was the 2009 New Zealand Plan of Action which aligned more closely with the international narratives than those from the interviewees. This is explained throughout the findings chapters as being due to the Plan being created at a time where there had been little to no antitrafficking work in New Zealand, and its development was heavily reliant on the definitions of 
trafficking and its appropriate responses as given in the UNODC guidance documents and the US DoS TIP reporting.

Company interviews and reports produced more of a mixed picture. They aligned in some ways with the international level data and in some ways with the New Zealand level findings. While narratives from company based data is included in this comparison, the focus is on the recurring and notable differences between the international and New Zealand levels.

This section discusses the differences between the international and New Zealand level narratives in relation to two major questions debated in the international body of literature on anti-trafficking work. These are how to broaden trafficking definitions and concepts of victimhood, in particular to include labour trafficking, and to shift away from those which single out sex work as the only context in which trafficking takes place ${ }^{5}$, and how to address the tension between internationally led approaches to trafficking versus locally led, with the argument that international definitions do not reflect local realities ${ }^{6}$. These differences show how two different forms of trafficking are constituted at an international and New Zealand level. They are important to consider in moving towards an alternative narrative as they demonstrate the pervasiveness of certain narratives and their link to certain institutions and their attached discourses. Furthermore, aspects of the New Zealand level narratives contribute to current debates by demonstrating a more inclusive form of victimhood. These findings call into question the role of international bodies in defining social problems and appropriate responses, and show the importance of local narratives. The following text shows how the difference in narratives was present across the three findings chapters.

The differences between international and New Zealand level narratives were evident in Chapter Five, where trafficking was presented as happening within commercial enterprise. The international level documents represented trafficking largely as a profitable organised criminal enterprise whereas in the New Zealand based narratives, it was presented most frequently as dodgy business. In the international level narrative trafficking is shown as being carried out by sophisticated criminal organisations who make significant profits. These characters are sinister and threatening, and are shown as criminals, terrorists, extremists, and militia groups. In the New Zealand based narrative, trafficking is something that takes place in small scale, often family run businesses and is not considered threatening or uncommon.

\footnotetext{
${ }^{5}$ For example see Cojocaru, 2016; Hoefinger, 2016; Wylie, 2016; Chuang, 2010, 2014; Shamir, 2012; Tomkinson, 2012; Mahdavi and Sargent, 2011; Lebov, 2010; Andrijasevic, 2007; Chang and Kim, 2007; GAATW, 2007; Doezema, 2001.

${ }^{6}$ For example see Anderson and Li, 2018; Blouin and Button, 2018; Juliawan, 2018; Sanchez, 2018; Soltis and Walters, 2018; Snajdr, 2013; Mahdavi and Sargent, 2011.
} 
These differing narratives are likely to be a reflection of the different types of work carried out by the UNODC and the New Zealand Government officials. The UN's original agenda was to address conflict situations (United Nations, 1945) and so it is not surprising that trafficking as carried out by military groups is a major focus. The positioning of the anti-trafficking portfolio within the UNODC also explains the dominance of this narrative, as the organisation has a focus on international drug crime and internationally organised criminal groups. The New Zealand based narratives are likely to be in part constituted by the type of trafficking cases dealt with by officials which, to date, have involved labour exploitation carried out in small family run businesses. This differing focus raises the question of whether these bodies are dealing with two separate phenomenon and whether it is useful to characterise both as trafficking.

This international level narrative of trafficking as sinister transnational organised crime can also be traced through the long-standing use of the alien conspiracy model in American politics and its influence in the development of the Trafficking Protocol (Hobbs and Antonopoulos, 2013; Woodiwiss and Hobbs, 2009). The presence of the idea that trafficking constitutes transnational organised crime which is carried out by threatening foreign 'others', in the UN and US reports, suggests that the alien conspiracy model remains central to understandings of intersecting problems of migration and crime.

In Chapter Six, the trafficking as a foreign other narrative was present in both the New Zealand based and international data. However, the international level narrative showed the problem as having a sinister and threatening aspect whereas the New Zealand based narrative showed it as a widespread problem but not one that was frightening or uncommon. An explanation for this difference could be that the alien conspiracy model is present internationally through its repetition through UNODC and US DoS documents but has been taken up nationally to a limited extent. The consistent adoption of the trafficking as a foreign problem narrative in New Zealand data is likely due to the close integration of this narrative into anti-trafficking practice internationally. For example, New Zealand, as with many state governments, has focused exclusively on cases which involve victims being brought in from other countries. Trafficking was also defined in New Zealand legislation until 2014 as requiring border crossing.

The data from commercial companies did not follow either the international narrative about trafficking as serious organised criminal enterprise or the New Zealand based trafficking as dodgy business narrative. The focus of the company narratives was rather on commercial systems positioning as being saviours and as the solution to trafficking and exploitation. This reflects their current situation, given the recent trend in anti-trafficking work where companies are encouraged to 
carry out ethical sourcing, as having to position themselves in relation to exploitation in supply chains. While the company data produced a different picture in relation to these narratives, it did take up the pervasive trafficking as a foreign problem narrative which was seen across the data sources. While the company data is not representative of other New Zealand businesses, the repetition of the foreign problem narrative in the sources analysed, is indicative of the powerful process of externalising trafficking as an alien issue. It shows that this narrative is carried through in the work of these companies in their approach to ethical sourcing.

In Chapter Seven, the international level data conveyed the traditional narrative of the innocent victim of sex trafficking whereas this narrative was largely absent from the New Zealand level data. The emergent narrative of the vulnerable migrant worker was present across the data sources but the way vulnerability was articulated differed with a greater emphasis given to inherent vulnerability in the international sources as compared to the New Zealand data.

As discussed in Chapter Seven, the portrayal of trafficking as largely involving the sex industry, and specifically female victims who are forced into prostitution and are unaware they will be working in the sex industry, has a long history in trafficking discourse. These representations have been subject to much criticism by anti-trafficking practitioners, advocates, and academics owing to the harms such characterisations create for those who do not fit this narrow version of victimhood. The work of these critics has shown how this narrative has been a central part of trafficking definitions through the development of the Trafficking Protocol, influenced by a feminist abolitionist approach to prostitution and by the US Government's anti-prostitution agenda (for example see Kempadoo, 2005, 2015; Ditmore and Allman, 2013; Doezema, 2010).

It is not surprising that this narrative did not feature in the New Zealand based data as the decriminalisation of sex work means that the international narrative where sex work is synonymous with violence against women does not align with the current New Zealand context. Sex work is defined as a form of labour under New Zealand legislation, and moral and religious debates about abolishing prostitution are much less apparent (Showden, 2017). From this legal start point, there is an acknowledgement that exploitation can and does occur in sex work but sex work is defined as work which means that the sex industry is not exceptionalised and targeted as the main site of human trafficking.

The second narrative of victimhood, the vulnerable migrant worker, was present across the data sources, yet in the international level sources vulnerability was conceptualised more as an individual trait, which was central to some migrant groups. This focus on vulnerable migrant groups signifies the embeddedness of the foreign other narrative and alien conspiracy model in representations of 
the trafficking problem. There is still a sense that the problem is incoming, tied to certain groups, and linked with poverty, corruption, and conflicts elsewhere, and in particular as being tied to individual factors of these populations such as culture, norms, education, and expectations.

While both types of vulnerability were present in New Zealand based data, structural vulnerability was more apparent when compared with the international sources. This is reflective of a narrative lean towards situational, local and structural factors in the New Zealand based data. While it is difficult to explain this trend, given that the point of difference between New Zealand and other states is that New Zealand has to date focused exclusively on labour trafficking cases, it is possible that this experience has contributed towards constituting a narrative where situational and structural factors are more prominent. For example, in the New Zealand based data there was a focus on work arrangements such as the amount of money paid to trafficking victims and the hours they worked. This focus situates exploitation as happening within employment conditions, drawing attention to how employment relations are structured within certain industries and what conditions are considered acceptable in certain New Zealand industry sectors.

These differences found across this research contribute to two areas of debate in anti-trafficking literature. These areas are firstly, how to broaden concepts of victimhood, and secondly, questions of whether international bodies should play such a prominent role in defining approaches to trafficking.

In terms of broadening ideas of victimhood, the newer vulnerable migrant worker narrative seen across sources provides a version of victimhood that encompasses those who have experienced labour exploitation rather than singling out sexual exploitation, encompasses victims of all genders instead of solely focusing on women and girls, and acknowledges the agency of victims, enabling more nuanced insights into how exploitation occurs. The construction of vulnerability as situational or structural, which is present in a greater extent in the New Zealand data, provides a means of both broadening conceptions of victimhood and moving away from conceptualisations of trafficking as a foreign problem that focuses on migrant populations. Narratives which treat vulnerability as situational and structured also provide a means of overcoming the persistent distinction made between trafficking into sex work and trafficking into other industry sectors. In this construction of vulnerability, attention is directed to how positions of vulnerability are structured for any form of exploitation, and do not rely on positioning of victims as innocent and non-consenting or on stereotyped narratives about prostitution.

The findings from this research support literature which questions the mismatch between international-level and local-level understandings of trafficking in other countries around the world. 
This research raises the question of whether it is useful to apply an internationally determined definition and response to a form of exploitation, in local settings around the world. In the international body of trafficking literature, this tension has been observed where international definitions have been criticised for not reflecting victims' realities. Much of this criticism has been focused on definitions and responses to trafficking which are based on the idea that victims are women who are forced into prostitution. These definitions have been critiqued as misrepresentations and as not capturing the reality for women who chose to travel and work in the sex industry and who express agency and consent in doing so (for example: Cojocaru, 2016; Hoefinger, 2016; Tomkinson, 2012; Mahdavi and Sargent, 2011; Lebov, 2010; Andrijasevic, 2007; GAATW, 2007; Doezema, 2001). Other literature has criticised top-down definitions and responses to trafficking as presenting oversimplified characterisations of migrants, victims and offenders which do not capture the complex realities of people moving for work (for example: Anderson and Li, 2018; Blouin and Button, 2018; Juliawan, 2018; Sanchez, 2018; Soltis and Walters, 2018; Mahdavi and Sargent, 2011).

This research, under the post-structural theoretical framework, did not seek migrant realities and did not treat reality as existing to be discovered. Rather, through identifying the differences between the International and New Zealand based data, it shows two differing versions of trafficking being constituted. In the international level data, a form of trafficking is constituted where the problem is located with migrant groups. The sources of the problem are seen as coming from outside and the legitimised responses are those which target individuals, both vulnerable migrants and traffickers. In this construction of trafficking there is much which is excluded. These omissions are the context in which the exploitation occurs, including the systems of employment and industries where the exploitation occurs, the national legal and policy frameworks which create situations favourable to exploitation, and the wider systems of neoliberalism and capitalism where both the supply of cheap labour and migrating for work are encouraged. The limited set of responses enabled by this construction of trafficking make it questionable as to its use in reducing harms which occur around migration and work.

As well as limiting actions to those that target migrant groups, these representations appear to clash with other aspects of anti-trafficking work. As discussed in Chapter Five, the narration of trafficking as serious organised crime may be contributing to the difficulty found in many states with prosecuting trafficking cases (Gallagher, 2011), as the types of situations prosecuted under trafficking law often do not involve organised criminal groups. As discussed in Chapter Six, the foreign alien threat description of trafficking clashes with both legal definitions of trafficking as being something that also happens domestically and international data about trafficking showing it as 
something that occurs largely within regions. Furthermore, as discussed in Chapter Seven, the narratives of victimhood which focus on prostitution and a lack of consent, appear at odds with the breadth of situations which are treated as trafficking around the world.

The findings raise the question of whether international bodies should define and guide responses to these forms of harm and exploitation. Through focusing on narratives, this study has demonstrated how this model of working is problematic, as the international level narrative is limiting in terms of the responses it enables, while restricting many others. These international level narratives have proved to be pervasive and have endured despite calls for change in the anti-trafficking field. Their pervasiveness can be linked to the institutions through which they are propagated and the discourses associated with these institutions. As discussed earlier, the UNODC is an agency which has historically had as its primary focus addressing organised crime, corruption and terrorism on a transnational level (UNODC, 2019b). Given the leading role of the UNODC in defining trafficking and legitimising responses, it is not surprising that discourses about sinister transnational groups and international security threats are enacted. Similarly, the US DoS has a long history of adopting an alien conspiracy model to conceptualise crime and migration issues. There is also a commitment to the abolition of prostitution in US politics which is pursued via the criminalisation of sex work which frames the mainstream international approaches to anti-trafficking interventions. Given the influential role of the US DoS in monitoring and enforcing trafficking definitions and legitimising responses through TIP reporting, it is not surprising that the discourses which are associated with the US DoS around foreign threats and prostitution and morality are recreated through the international level narratives.

The findings from this study recommend that anti-trafficking work employ more locally developed and determined policies and practices. This goes against the current trends in the field, where the UNODC and US DoS hold an influential role in defining what trafficking is and what responses are appropriate. The narratives upheld by these institutions are powerful as they are propagated and dispersed by institutions positioned as international leaders and experts. These bodies also play a direct role in enforcing these constituted versions of trafficking through monitoring and reporting activities, including bringing sanctions against states which do not comply (for example, the ability to bring about sanctions is outlined in the US TVPA; United States Department of State, 2018a). Furthermore, state governments are encouraged to increase the numbers of trafficking prosecutions that are carried out and, as the international guidance bodies advocate for increased use of trafficking legislation, a wider breadth of exploitative situations are being considered as trafficking (United States Department of State, 2018a; UNODC, 2018a). This means that the international 
construction of trafficking, which this research has shown to be problematic, is being applied to a wider range of situations.

\subsection{Alternative narrative: a way forward}

This research has shown that given the power of narratives to structure reality and action, to change how we deal with certain problems, the way the problem is narrated must also change. Given the problems highlighted with the current dominant trafficking narratives, there is a pressing need for alternative narratives where migration and exploitation are concerned. This section presents an alternative narrative created through drawing together components of narratives identified in this research. This alternative is proposed as a way of avoiding the problematic aspects of existing and long-established narratives, and as a way forward in relation to current challenges in the antitrafficking field. In particular, this alternative narrative contributes to the current debates from academics, practitioners, and advocates around how to broaden trafficking definitions and concepts of victimhood to include labour trafficking and to shift away from singling out prostitution ${ }^{7}$. It also contributes to efforts to avoid conceptualising trafficking as something that western states, and western-favoured systems of neoliberalism are exempt from ${ }^{8}$.

This narrative is presented in the text box below in the same format that the narratives identified in this research have been presented; with a short name and description of cause of the problem, groups involved, groups affected and appropriate responses. The likelihood of such a narrative being taken up as a mainstream is limited by the persuasiveness of current dominant narratives and their embeddedness in certain institutions. The barriers to taking up this proposed narrative are discussed in relation to the potential for change which has been created through the current political landscape, as altered by the 2020 Covid pandemic.

\footnotetext{
${ }^{7}$ For example see Cojocaru, 2016; Hoefinger, 2016; Wylie, 2016; Chuang, 2010, 2014; Shamir, 2012; Tomkinson, 2012; Mahdavi and Sargent, 2011; Lebov, 2010; Andrijasevic, 2007; Chang and Kim, 2007; GAATW, 2007; Doezema, 2001.

${ }^{8}$ For example see George et al., 2017; Kempadoo, 2015, 2017; Okyere, 2017; Szörényi, 2016; Chuang, 2014; Kapur, 2005, 2010; Sharp, 2009, p. 106; Dottridge, 2007.
} 
Alternative narrative: Structured vulnerability and hidden capital

Overview of narrative:

In this narrative trafficking is seen as something that happens in situations where profit is made. How profit is made, by whom and how it is distributed are important. Rather than being something sinister and threatening, trafficking is seen as an unfortunate but unsurprising phenomenon that can happen in these settings.

The causes of the problem are broader than individual offenders and poor conditions in developing countries. In this narrative, trafficking is narrated as having causes which are tied to the country or situation in which the exploitation occurs. These can be local country factors such as legislation, policy settings, government policing and monitoring of potentially exploitative situations, and factors to do with the industry sector and employment types in which the exploitation takes place. Causes can also be systemic factors which are broader than the local state, such as the wider systems of international trade, capitalism, and consumerism which can create situations favourable to exploitation.

Rather than migrant groups being seen as the cause of the problem, those who are exploited can be anyone who finds themselves in these positions of structured vulnerability. Vulnerability can be due to these local causes or wider systemic problems and is supported by lack of transparency as to who really benefits in the whole chain of supply and demand.

Rather than presenting trafficking as something large, threatening, and out of control, it is narrated as something that can be controlled in part through creating good working conditions. The relevant solutions can be altering legislation and policy to address situations of vulnerability in certain industries and employment situations, and addressing vulnerable situations created through commercial enterprise and supply chains.

This narrative is created through drawing together narrative threads identified in this research. It comes in part from the trafficking as dodgy business narrative shown in Chapter Five. In this narrative, trafficking is situated as taking place within business and employment practices, and within certain industries. The businesses and their work arrangements are a central focus. Profit is also important and seen as the driver of exploitation. Exploitation is seen as widespread and it is not surprising that it takes place in settings where profit is being sought. In this way trafficking and exploitation are an unsurprising if unfortunate part of systems of commerce and capitalism, as opposed to something unusual which acts on them in a sometimes threatening way. Situating trafficking within these contexts draws attention to situational and structural factors which can 
create situations in which people are exploited. For example, this may highlight certain employment practices such as subcontracting arrangements which make employer responsibility unclear or industry norms such as an acceptance of poor working conditions. Such practices would then be targeted by anti-trafficking initiatives.

Another narrative, which highlights an alternative way forwards in trafficking discourse, is the commercial businesses and systems as saviours narrative which is discussed in Chapter Five. The positioning of commercial systems and businesses in this narrative aligns with dominant narratives about trafficking as an external problem from which western-favoured systems of neoliberalism are separate. However, as with the other narratives which link trafficking to business, it is based on the proposition that trafficking is something that can happen where profit-making is involved and that commercial businesses and systems are an important character. This narrative problematically excludes the role of commercial companies and global supply chains in creating profit off the labour of others. A narrative which includes commercial systems and companies as a central character and which includes questions of who profits and how the profits are distributed would help to enable responses which focus on the redistribution of profit with material benefits to people who have suffered financial losses through exploitation. The focus on money and profit-making would also highlight neoliberal and capitalist systems as the setting in which trafficking can occur. This has implications for anti-trafficking work in creating a focus on structural features of systems of international trade and consumerism, where cheap goods are made readily available for consumption.

This alternative narrative is also drawn from the counter narrative presented in Chapter Six. Chapter Six showed how the trafficking as a foreign incoming problem narrative is an integral part of antitrafficking policy and practice in many states, making it difficult to consider different ways of narrating the problem. To help overcome this I presented an alternative narrative which is taken from an article on trafficking for domestic service (Maroukis, 2017). In this article, the causes of trafficking and exploitation are shown to be factors that relate to the country and situation in which the exploitation occurs. These include the availability and accessibility of publicly funded care services, immigration controls making legal migrant labour difficult, certain visa conditions that restrict workers, weak regulation of domestic services, and limited access to legal aid for migrant workers, and local norms about outsourcing care which are linked to a range of economic and social factors. When compared to the causes of trafficking presented in dominant narrations, these offer a different line of action where local country factors become important in addressing trafficking. The type of responses that are legitimised by this narrative would be those that address power 
imbalances in employment relationships, local norms about labour, the role of regulatory bodies, and local social and economic issues.

In Chapter Seven an emergent narrative of victimhood is identified which provides an alternative to the limited long-standing narrative about the innocent victim of sex trafficking. This newer narrative is about vulnerable migrant workers, and allows for a broadened version of victimhood to be constituted which encompasses a wider range of people and situations and allows victims more agency. However, within this narrative, when 'vulnerability' is used in an individual or inherent sense, it enforces the trafficking as a foreign problem narrative by placing migrant groups at the heart of the problem. Under this narrative, agency also becomes a problem as some is allowed, yet when too much is expressed, the victims become complicit in the trafficking.

The use of 'vulnerability' in a situational sense provides a solution to these issues. It focuses on how situations of vulnerability are created through structural and systemic factors. This includes a focus on local country factors where the exploitation occurs, supporting anti-trafficking work that considers factors that cause or contribute to vulnerability which are under a governments control such as altering immigration law, visa conditions, the monitoring and regulation of certain industries, or using employment law to address employment structures that create power imbalances between employers and employees. The presentation of vulnerability as situational and structural also has potential to draw attention to the wider systems in which exploitation occur such as international supply chains, international labour markets, and systems built on capitalist and neoliberal principles. By situating vulnerability within these systems, their role in creating situations favourable to exploitation is included and the systems themselves are not positioned as exempt from the problem or as the solution to the problem.

Using structured vulnerability in narratives of victimhood would also help to avoid the problematic distinction made between trafficking into the sex industry and other industries, which is upheld through the innocent victims of sex trafficking narrative alongside the newer vulnerable migrant worker narrative. The inference is that sex work is not work and therefore must be considered its own type of trafficking. In this way these two forms of victimhood both reflect and reproduce the abolitionist position on prostitution which has been influential in anti-trafficking work. The use of structured vulnerability in an alternative narrative would focus on how positions of vulnerability are structured as opposed to the individuals experiencing vulnerability, their characteristics, the type of exploitation, and the extent to which they are deemed to have consented to the situation they are in. If applied to trafficking within the sex industry, framing migrants as situationally vulnerable would pay attention to why people are vulnerable to exploitation in certain settings. For example, 
situational vulnerability as a lens to understand exploitation in the sex industry would enable a focus on legislation and examining whether existing laws protect against or exacerbate the potential for exploitation.

Drawing together these narrative components identified in the research provides a different way of conceptualising trafficking that avoids treating trafficking as an alien or foreign problem, targeting migrant groups, and creating narrow definitions of victimhood and agency. This alternative narrative draws attention to the structural and systemic factors shaping exploitative situations, and lends itself to anti-trafficking efforts that aim to address legislative and policy settings and industry practices.

While there are already individuals and groups who take up this type of narrative, it is not mainstream in the same way that the more widespread narratives about migrant groups, western exceptionalism, and sex work are in the anti-trafficking field. The rationale for presenting this narrative as an alternative is not to suggest that one sole narrative can or should exist. This research has shown that in relation to a particular social problem there are multiple narratives in existence and these are not fixed or inflexible. Various narratives can be taken up at different times and used in conjunction or opposition to other narratives. They are open to change and existing narratives can alter or take up components of others. This research has also shown certain narratives to be more widespread in their uptake and more pervasive over time than others. In presenting this alternative narrative, I am suggesting that there is space for it to be used more widely in anti-trafficking work. Its uptake would allow for a different set of responses to be enabled, compared to current dominant narratives about trafficking as a migrant other problem and as an external threat.

There are a number of barriers to this alternative narrative being taken up as mainstream. The longstanding narrative themes of seeing social problems as foreign threats and conflations of trafficking with sex work are persuasive and persistent. As discussed in the findings chapters, in Mayer's (2014) analysis of how narratives work, he identifies certain components of narratives as being persuasive, which results in some narrative being taken up by society. These persuasive components include moral stories, melodrama, and well-known plots and characters. As demonstrated in the findings chapters, dominant representations of trafficking often involve melodramatic plots and stereotyped characters of villains and victims, and employ moral language about good and evil, light and dark. These narrative components appeal to audiences as they are collectively known stories which draw people in. The caricatures of villains and victims, and the melodramatic and moralistic nature of these widespread narratives may be contributing to their longevity and creating a barrier to change. The embeddedness of these popular narratives in certain institutions also creates a barrier to change. Repetition is another key component of narrative success which Mayer (2014) identifies. 
Stories that are repeated in society are more powerful, as repeated exposure to narratives makes them more likely to be taken up by individuals (Mayer, 2014). As discussed in the findings chapters, the UN Trafficking Protocol was born out of discussions about crime as a foreign, non-western threat and so it is not surprising that such discourses continue to be repeated by the agencies who provide international guidance - the UNODC and the US DoS. The narrative of commercial businesses as moral and heroic also holds persuasive power through its repetition by commercial bodies as they promote themselves to the public. The political and economic context, where these international bodies and commercial groups have influential roles in defining and responding to trafficking, creates a barrier against the alternative narrative being taken up.

A more nuanced narrative about state responsibility and one which questions wider neoliberal systems may seem less likely to be adopted in comparison to more simplistic moral stories. However, the political landscape in New Zealand and globally has been altered by the 2020 Covid pandemic. In New Zealand, narratives employed during the Covid response emphasised kindness, working together as a country, and being responsible for the well-being of others. It can be assumed that these narratives used by the New Zealand Government had widespread public buy-in given the high level of compliance with government instructions (Jamieson, 2020) and the high level of public support for the Government response (public opinion polls showed more than $80 \%$ of people supported the Government's response: Cooke, 2020; Cooke and Malpass, 2020; Coughlan, 2020). Furthermore, the working and living conditions experienced by temporary migrant workers have received media attention as a result of the pandemic. Labour shortages in the agricultural and horticultural sectors have been created as seasonal workers have largely not been able to enter the country. These labour shortages have not been filled by those already in New Zealand, despite a rise in national unemployment and campaigns to attract those already in New Zealand into these jobs (Bedford, 2020; Statistics New Zealand, 2020). These labour shortages have raised discussions about the low wages, working conditions, and accommodation offered to seasonal workers, and the implication that most New Zealand citizens and residents would not tolerate such conditions (Andrew, 2020; Hall, 2020; Mckenzie-Mclean and Angeloni, 2020). This has highlighted both the country's reliance on cheap imported labour and the often substandard working and living conditions in these sectors. Given this altered political, economic, and social context, there may be more potential for narratives about improving working conditions in New Zealand and taking responsibility for the welfare of others to be taken up.

In considering the uptake of narratives, it is also worth questioning the extent to which public collective action should influence anti-trafficking work. Human trafficking has received much public 
attention through media, political debate, and other campaigns compared with many other social issues (Segrave et al., 2018; Lloyd and Simmons, 2015; Anderson and O'Connell Davidson, 2002). Narratives that gain public support have been shown to be crisis narratives and those which elicit emotions and draw on peoples' morals (Mayer, 2014; Skilling, 2014; Vance, 2011a). As demonstrated in this research, each of these narrative components is linked to problematic material outcomes in terms of the type of response they enable and the effects of these responses for people experiencing exploitation. These finding indicates that a more productive narrative, as is proposed here, is one which avoids dramatizing and moralising policy narratives.

\subsection{Conclusion}

This research set out to identify and unpack narratives of human trafficking in New Zealand. It sought to understand how human trafficking is defined, what discourses are drawn on, and how international narratives may be influencing local responses, with the overall aim of identifying new and less problematic ways of conceptualising human trafficking and responding to migrant exploitation. Through identifying and analysing narratives, this thesis has demonstrated both problematic narratives and those which offer a way forward. This study confirms the importance of narratives and the material consequences they have for the groups they describe. It has shown the pervasiveness of certain narrative trends and highlighted the pressing need for new and more productive stories. This thesis contributes to anti-trafficking knowledge by providing an alternative narrative which enables a shift towards responses which address structured vulnerability. It also highlights the need for further work to be carried out to understand how some narratives persist and what can be done to achieve widespread uptake of more nuanced stories.

This section presents the conclusions from the research and discusses their significance in relation to ongoing attempts in the field of anti-trafficking work to improve the way situations involving migration and harm are defined, addressed, and prevented. This research identified a range of narratives which were present in the New Zealand setting and in international guidance documents. These narratives at times aligned, merged, contrasted, and conflicted with one another. They are both reflective of the current challenges in the anti-trafficking field as well as offering some less harmful forms in which the problem of trafficking can be constituted. The narratives found in this study are summarised in the paragraphs below. They are followed by a summary of the two key recurrent themes which were present across the findings chapters.

In Chapter Five, the three narratives identified in the data demonstrate the different ways in which trafficking is situated as happening within commercial enterprise. These three narratives are: 
trafficking as a profitable organised criminal enterprise; commercial systems and companies as saviours; and trafficking as dodgy business. This chapter explains how trafficking can be presented either as being on the spectrum of acceptable commercial enterprise or as something that is set apart from acceptable business practice. Trafficking is shown as being on a spectrum of commercial enterprise through the trafficking as dodgy business narrative where exploitation is shown as taking place in everyday business and employment practices. The problem of trafficking is set apart from acceptable business practices in the narrative of trafficking as profitable organised criminal enterprise where trafficking is narrated as large scale profitable business carried out by criminal groups. It is also set apart in the narrative of commercial systems and companies as saviours which describes commercial companies as separate from the problem of trafficking by positioning them as moral, and positioning international supply chains and consumerism as the answer to the trafficking problem. In these two narrations of trafficking, the problem is set apart from the context in which the exploitation occurs and the response they enable focus on individual criminals while excluding commercial and neoliberal systems.

Chapter Six analyses three narratives which reflect the problems with trafficking discourse identified in much international literature where trafficking is presented as a problem which is separate from western states and wider systems of international trade and neoliberalism, and where antitrafficking interventions target individual offenders and migrant populations. The three narratives are: trafficking as a foreign other problem; trafficking as an abhorrent aberration; and trafficking as a big unknown problem. These narratives feed into the idea of western exceptionalism, as the role of the receiving country in creating the conditions for exploitation is excluded and western countries and global north institutions are positioned as outside of the problem. Similarly, trafficking is seen as an aberration to the essentially good systems of international labour markets, supply chains, and capitalism. The responses legitimised by these narratives are criminal, individual interventions where migrant groups are positioned as being central to the problem.

Chapter Seven contrasts the two main ways in which victimhood is narrated in the data, showing the ongoing presence of the well-established narrative of the innocent victim of sex trafficking and the newer emergent narrative of the vulnerable migrant worker. The findings from this chapter are relevant to the attempts to broaden trafficking definitions and concepts of victimhood to include labour trafficking, men and women, and to allow victims more agency. The vulnerable migrant worker narrative, in comparison to the innocent victim of sex trafficking narrative allows a wider version of victimhood where victims can be men or women, and are able to express agency in deciding to travel and be a part of certain work schemes while still being able to access victim status and the benefits that are attached to it. However, the way 'vulnerability' is narrated is important to 
consider as when used in an inherent sense it maintains the idea that trafficking is an individualised problem to do with migrant groups. When used in a situational or structural sense, 'vulnerability' is shown as a structured position where attention should be paid to policy and legislative settings, industry practice and wider systems which are designed around making profit from cheap labour.

The two central findings which were recurrent across the chapters were western exceptionalism from the problem of trafficking and the difference between narratives expressed at an international and at a New Zealand level. The recurring and pervasive theme of western exceptionalism from the problem of trafficking has been shown in this study and is the subject of some criticism amongst anti-trafficking scholars and practitioners. The alien conspiracy model of understanding organised crime provides some explanation for the ongoing presence of narratives about trafficking as a foreign problem and outlines the process of othering that occurs through positioning trafficking as a foreign problem from which western contexts, legitimate systems, and the formal economy are exempt. The recurrence of this theme across the findings chapters reflects a current challenge which has been identified in the wider international anti-trafficking field. Its presence across the data sources in this study shows the pervasiveness of this narrative trend and its link to alien conspiracy theories shows the long history this type of construction has. Although this narrative trend was present throughout the data, there were also alternative narratives identified which were constitutive of a form of trafficking where local, situation, and receiving country factors were presented as being the causes and solutions to the problem. These findings contribute to the antitrafficking field by highlighting both an alternative more productive narrative and the barriers to taking up such a narrative which are created by the embedded nature of long-standing processes of othering of crime problems.

The second central finding present across the chapters is the recurring differences between the international and New Zealand level narratives. These findings contribute to the discussions in antitrafficking work of how to broaden trafficking definitions and concepts of victimhood, in particular to include labour trafficking, and to shift away from a focus on prostitution. The differences highlight a form of victimhood which allows victims agency in choosing to take part in certain work schemes as well as focusing on wider societal factors which structure positions of vulnerability.

These findings support the body of literature which outlines the tensions between internationally led and locally led initiatives designed to prevent harm in migration. The differences between the international and New Zealand level data, when taken together, show international level narratives as being problematic as they position migrant groups as being at the heart of the trafficking problem and exclude the contexts in which exploitation occurs. The international narratives are also 
problematic in that they clash with other aspects of anti-trafficking work, including the focus on serious organised crime, prostitution, and non-agential, non-consenting victims. The findings raise the question of whether international bodies should define and guide responses to these forms of harm and exploitation. Through focusing on narratives, this study has demonstrated how this model of working is problematic, as the dominant international level narratives are limiting in terms of the responses they enable, while restricting many others. The findings from this study recommend that anti-trafficking work employ more locally developed and determined policies and practices.

This research shows the importance of narratives in structuring reality and action. Given the current problematic mainstream narratives, there is a critical need for alternative narratives which allow for different types of responses. The narratives summarised above are constitutive of trafficking realities as they determine the shape the problem takes, who is involved and what the causes and solutions are, who responds, and who are classed as victims and perpetrators. The cyclical nature of these narratives can be seen in the findings of this study, as the way the problem is narrated determines what becomes the problem and when defined in this way, shapes further narratives. Those who are targeted as the cause of the problem become problematic groups and are positioned as being at the heart of the problem. The institutions and actors who are positioned as being able to fight trafficking have their roles legitimised. The scope of the problem and what can be done about it is confined through the exclusion of certain causal factors and characters from trafficking narratives.

This research has also demonstrated the flexible and shifting nature of narratives, which indicates that they are open to change. This is shown in this thesis as multiple narratives about trafficking were found with some sharing similarities and some conflicting with one another. The findings showed instances where narratives were taken up at different times and used in conjunction or opposition, demonstrating their openness to change. In calling for a narrative shift, this thesis has compiled a counter narrative by drawing together narrative strands identified in this research. This counter narrative allows responses which address structured vulnerability and avoids the problematic aspects of existing and long-established narratives in the anti-trafficking field. This alternative narrative is one where trafficking is constituted as something that takes place within the local settings in which the exploitation occurs and within wider systems of capitalism and neoliberalism. It shows profit-making as important and looks at how positions of vulnerability are structured by systemic and local country policy and legislative settings.

This type of narrative is already taken up by some individuals and groups. However, it is not mainstream in the way that the more widespread discourses about migrant groups, western exceptionalism, and sex work are in the anti-trafficking field. This research has identified certain 
barriers to such a narrative being taken up. The narrative analysis techniques used in this study make visible the persuasive narrative components at play in these dominant mainstream stories. The caricatures of villains and victims, and the melodramatic and moralistic nature of these widespread narratives are likely to be contributing to their longevity and creating a barrier to change. The embeddedness of these popular narratives in certain institutions also makes change difficult. The political and economic context, where these international bodies and commercial groups have influential roles in defining and responding to trafficking, creates a barrier to the alternative narrative being taken up.

The findings from this study highlight the need for further research to examine why these narratives continue to dominate and what the barriers are to other narratives being taken up. Research into what makes narratives pervasive, popular, or convincing would enable a better understanding of how narratives operate, how counter narratives can be formed, and how harmful, long-standing narratives which prove difficult to shift can be better addressed. In addition to this, research into where narratives come from would provide insights into what discourses are being enacted through narratives, and create an awareness of whether these are discourses that we want to perpetuate. Further investigation into how narratives change over time and what influences them would provide knowledge about how to both shift long-established harmful narratives and encourage the uptake of alternatives.

The timing is apt for considering narrative shifts and the mainstreaming of a more nuanced narrative about state responsibility which questions wider neoliberal systems. The 2020 Covid pandemic has created an appetite for change in many societies around the world where the long-standing neoliberal and capitalist systems, alongside states' reliance on migrant workers, is being questioned. Given this altered political, economic, and social context, there may be more potential for narratives about improving working conditions and taking responsibility for the welfare of others, to be taken up. 


\section{References}

Abdul-Hamid, H. (2019) 'Sex trafficking in Malaysia: Repositioning the trafficked victim and victim protection mechanism', Southeast Asian Social Science Review, vol. 4, no. 1, pp. 135-151.

Abel, G. and Roguski, M. (2018) Migrant Sex Workers in New Zealand, Wellington, MBIE [Online]. Available at nzpc.org.nz/pdfs (Accessed 12 November 2020).

Agustin, L. (2007) Sex at the Margins: Migration, Labour Markets and the Rescue Industry, Chicago, The University of Chicago Press.

Agustin, L. (2012) 'The soft side of imperialism', Counterpunch [Online]. Available at http://www.counterpunch. org/2012/01/25/the-soft-side-of-imperialism (Accessed 25 November 2016).

Ahmed, A. (2005) 'Using a dynamic, interactive, and participatory process to develop and redefine the human trafficking paradigm in Bangladesh', in Kempadoo, K., Sanghera, J., and Pattanaik, B. (eds), Trafficking and Prostitution Reconsidered: New Perspectives on Migration, Sex Work, and Human Rights, Boulder, Paradigm Publishers, p. Chapter 11 ebook.

Albright, E. and D'Adamo, K. (2017) 'The media and human trafficking: A discussion and critique of the dominant narrative', in Chisolm-Straker, M. and Stoklosa, H. (eds), Human Trafficking is a Public Health Issue: A paradigm expansion in the United States, Cham, Springer International Publishing, pp. 363-379 [Online]. DOI: 10.1007/978-3-319-47824-1 (Accessed 18 October 2021).

Alvarez, R. R. (1995) 'The Mexican-US border: The making of an anthropology of borderlands', Annual Review of Anthropology, vol. 24, pp. 447-470.

Anderson, B. and O'Connell Davidson, J. (2002) Trafficking - A Demand Led Problem? A multi-country pilot study, Stockholm, Save the Children Sweden.

Anderson, B. and O'Connell Davidson, J. (2003) Is Trafficking in Human Beings Demand Driven? A multi-country pilot study, IOM Migration Research Series, Geneva, International Organisation for Migration [Online]. (Accessed 5 May 2015).

Anderson, B., Sharma, N. and Wright, C. (2009) 'Editorial: Why no borders?', Refuge, vol. 26, pp. 518.

Anderson, D., Jamieson, S. and Naidu, K. (2012a) 'Managed migration? The health and safety and human rights implications for student migrant labourers in the horticulture sector', Sixteenth ILERA World Congress, Philadelphia, USA, pp. 2-5 [Online]. Available at http://ilera2012.wharton.upenn.edu/NonRefereedPapers/Anderson,\%20Jamieson,\%20Naidu.pdf (Accessed 14 August 2017).

Anderson, D., Jamieson, S. and Naidu, K. (2012b) 'Managed migration? The health and safety and human rights implications for student migrant labourers in the horticulture sector', Sixteenth ILERA World Congress, Philadelphia, USA, pp. 2-5 [Online]. Available at http://ilera2012.wharton.upenn.edu/NonRefereedPapers/Anderson,\%20Jamieson,\%20Naidu.pdf (Accessed 14 August 2017).

Anderson, D. and Naidu, K. (2010) 'The land of milk and honey? The contemporary working lives of contingent youth labour', New Zealand Journal of Employment Relations, vol. 35, no. 3, p. 61. 
Anderson, D. and Tipples, R. (2014) 'Are vulnerable workers really protected in New Zealand?', New Zealand Journal of Employment Relations, vol. 39, no. 1, p. 52.

Anderson, J. and Li, A. (2018) 'Refugees or victims of human trafficking? The case of migrant domestic workers in Hong Kong', Anti-Trafficking Review, no. 11, pp. 52-68.

Andrew, M. (2020) 'Can you really make $\$ 400$ a day picking cherries?', The Spinoff, 27th November [Online]. Available at https://thespinoff.co.nz/business/10-01-2021/can-you-really-make-400-a-daypicking-cherries-2/ (Accessed 14 January 2021).

Andrijasevic, R. (2007) 'Beautiful dead bodies: Gender, migration and representation in antitrafficking campaigns', Feminist Review, vol. 86, no. 1, pp. 24-44.

Andrijasevic, R. and Mai, N. (2016) 'Trafficking (in) representations: Understanding the recurring appeal of victimhood and slavery in neoliberal times', Anti-Trafficking Review, no. 7 [Online]. Available at http://antitraffickingreview.org/index.php/atrjournal/article/view/197 (Accessed 12 November 2016).

Angeli, D. (2017) 'Migrant domestic workers and human trafficking in Greece: Expanding the narrative', Journal of Immigrant and Refugee Studies, vol. 15, no. 2, pp. 187-203.

van den Anker, C. and van Liempt, I. (2012) Human Rights and Migration: Trafficking for Forced Labour, Basingstoke, Palgrave.

Antonopoulos, G. A. (2006) 'Greece: Policing racist violence in the "fenceless vineyard"', Race \& Class, vol. 48, no. 2, pp. 92-100 [Online]. DOI: 10.1177/0306396806069526.

Armstrong, L. (2017) 'Decriminalisation and the rights of migrant sex workers in Aotearoa/New Zealand: Making a case for change', Women's Studies Journal, vol. 31, no. 2, pp. 69-76.

Armstrong, L. (2018) 'New Zealand', in Sex Workers Organising for Change: Self-representation, community mobilisation, and working conditions, GAATW [Online]. Available at https://www.gaatw.org/resources/publications/941-sex-workers-organising-for-change (Accessed 10 April 2019).

Armstrong, L. (2020) 'Decriminalisation of sex work in the post-truth era? Strategic storytelling in neo-abolitionist accounts of the New Zealand model', Criminology \& Criminal Justice, pp. 1-18 [Online]. DOI: 10.1177/1748895820918898.

Armstrong, S. (2009) 'Managing Meaning: Metaphor in Criminal Justice Policy', SCCJR Working Paper. [Online]. Available at https://www.sccjr.ac.uk/publications/managing-meaning-metaphor-incriminal-justice-policy/ (Accessed 23 January 2017).

Aspden, K. and Hayward, K. (2015) 'Narrative criminology and cultural criminology: Shared biographies, different lives?', in Narrative Criminology: Understanding Stories of Crime, New York, New York University Press, pp. 235-259.

Assemblee Nationale (2017) Assemblee Nationale Session Ordinaire de 2016-2017 [Online]. Available at http://www.assemblee-nationale.fr/14/ta/ta0924.asp (Accessed 14 November 2020).

Australian Government Department of Home Affairs (2018) Modern Slavery [Online]. Available at https://www.homeaffairs.gov.au/criminal-justice/Pages/modern-slavery.aspx (Accessed 14 November 2020). 
Bales, K. (1999) Disposable People: New slavery in the global economy, Berkely, University of California Press.

Bales, K. and Soodalter, R. (2009) The Slave Next Door: Human trafficking and slavery in America today, California, University of California Press.

Balgamwalla, S. (2016) 'Trafficking in narratives: Conceptualizing and recasting victims, offenders, and rescuers in the war on human trafficking', Denver Law Review, vol. 94, no. 1, pp. 1-42.

Barry, K. (1984) Female Sexual Slavery, New York, NY, New York University Press.

Barry, K. (1995) The Prostitution of Sexuality:The global exploitation of women, New York, New York University Press.

Bateman, S. (2018) 'Fijian woman charged with human trafficking to New Zealand', Newshub, 20th August [Online]. Available at https://www.newshub.co.nz/home/new-zealand/2018/08/fijianwoman-charged-with-human-trafficking-to-new-zealand.html (Accessed 16 August 2019).

Bedford, C. (2020) New Zealand's seasonal labour shortage: why local workers aren't enough [Online]. Available at https://devpolicy.org/new-zealands-seasonal-labour-shortage-why-localworkers-arent-enough-20201124/ (Accessed 10 January 2021).

Beer, C. and Lewis, N. (2006) 'Labouring in the vineyards of Marlborough: Experiences, meanings and policy', Journal of Wine Research, vol. 17, no. 2, pp. 95-106 [Online]. DOI:

10.1080/09571260601004187.

Beutin, L. (2017) 'Black suffering for/from anti-trafficking advocacy', Anti-Trafficking Review, vol. 9, pp. 14-30.

Block, G. (2019) 'Seven migrant sex workers deported Dunedin', Otago Daily Times, 10th June [Online]. Available at https://www.odt.co.nz/news/dunedin/seven-migrant-sex-workers-deporteddunedin (Accessed 5 November 2020).

Blouin, C. and Button, E. (2018) 'Addressing overlapping migratory categories within new patterns of mobility in Peru', Anti-Trafficking Review, no. 11, pp. 69-84.

Bohle, P., Quinlan, M., Kennedy, D. and Williamson, A. (2004) 'Working hours, work-life conflict and health in precarious and "permanent" employment', Revista de Saúde Pública, vol. 38, no. suppl, pp. 19-25 [Online]. DOI: 10.1590/S0034-89102004000700004.

Bonnett, G. (2019) 'Long wait for immigration decision on human trafficking victims', Radio New Zealand, 13th August [Online]. Available at https://www.rnz.co.nz/news/national/396554/long-waitfor-immigration-decision-on-human-trafficking-victims (Accessed 21 August 2019).

Boswell, C. (2011) 'Migration control and narratives of steering', The British Journal of Politics and International Relations, vol. 13, no. 1, pp. 12-25 [Online]. DOI: 10.1111/j.1467-856X.2010.00436.x.

Boswell, C., Geddes, A. and Scholten, P. (2011) 'The role of narratives in migration policy-making: A research framework', The British Journal of Politics and International Relations, vol. 13, no. 1, pp. 111 [Online]. DOI: 10.1111/j.1467-856X.2010.00435.x.

Bosworth, M. and Guild, M. (2008) 'Governing through migration control: Security and citizenship in Britain', British Journal of Criminology, vol. 48, no. 6, pp. 703-719 [Online]. DOI: 10.1093/bjc/azn059. 
Brace, L. and O'Connell Davidson, J. (2018) 'Slavery and the revival of anti-slavery activism', in Brace, L. and O'Connell Davidson, J. (eds), Revisiting Slavery and Antislavery, Cham, Springer International Publishing, pp. 3-34 [Online]. DOI: 10.1007/978-3-319-90623-2_1 (Accessed 15 November 2020).

Breuil, B. C. O., Siegel, D., van Reenen, P., Beijer, A. and Roos, L. (2011) 'Human trafficking revisited: Legal, enforcement and ethnographic narratives on sex trafficking to Western Europe', Trends in Organized Crime, vol. 14, no. 1, pp. 30-46 [Online]. DOI: 10.1007/s12117-011-9118-0.

Bridgman, T. and Barry, D. (2002) 'Regulation is evil: An application of narrative policy analysis to regulatory debate in New Zealand', Policy Sciences, vol. 35, no. 2, pp. 141-161.

Brookman, F. (2015) 'The shifting narratives of violent offenders', in Narrative Criminology: Understanding Stories of Crime, New York, New York University Press, pp. 207-234.

Brooks, P. (1985) The Melodramatic Imagination: Balzac, Henry James, melodrama and the mode of excess, New York, Columbia University Press.

Brouwer, J., van der Woude, M. and van der Leun, J. (2017) '(Cr)immigrant framing in border areas: Decision making process of Dutch border police officers', Policing and Society, pp. 1-16.

Browne, K. (2005) 'Snowball sampling: Using social networks to research non-heterosexual women', International Journal of Social Research Methodology, vol. 8, no. 1, pp. 47-60 [Online]. DOI: 10.1080/1364557032000081663.

Cain, C. (1991) 'Personal stories: Identity acquisition and self-understanding in Alcoholics Anonymous', Ethos, vol. 19, pp. 210-253.

Caritas (2016) Standing Up for What's Right: Supporting migrant workers, Caritas New Zealand.

Carline, A. (2012) 'Of frames, cons and affects: Constructing and responding to prostitution and trafficking for sexual exploitation', Feminist Legal Studies, vol. 20, pp. 207-11.

Carson, J. (2015) 'Brothers found not guilty of New Zealand's first human trafficking charges', Stuff, 20th December [Online]. Available at https://www.stuff.co.nz/national/crime/75274861/ (Accessed 21 August 2019).

Chang, G. and Kim, K. (2007) 'Reconceptualizing approaches to human trafficking: New directions and perspectives from the field(s)', Stanford Journal of Civil Rights and Civil Liberties, vol. 3, no. 2, pp. 317-344.

Charmaz, K. (2006) Constructing Grounded Theory: A practical guide through qualitative analysis, Thousand Oaks CA, Sage Publications.

Charteris-Black, J. (2006) 'Britain as a container: Immigration metaphors in the 2005 election campaign', Discourse \& Society, vol. 15, no. 5, pp. 563-581.

Chew, D. (2006) 'Gender, migration and trafficking - an introduction', Labour, Capital and Society, vol. 39, no. 2, pp. 1-18.

Chew, L. (2005) 'Reflections by an anti-trafficking activist', in Kempadoo, K., Sanghera, J., and Pattanaik, B. (eds), Trafficking and Prostitution Reconsidered: New perspectives on migration, sex work, and human rights, Boulder, Paradigm Publishers, p. Chapter 4 ebook. 
Chuang, J. (2010) 'Rescuing trafficking from ideological capture: Prostitution reform and antitrafficking law and policy', University of Pennsylvania Law Review, vol. 158, no. 6.

Chuang, J. (2014) 'Exploitation creep and the unmaking of human trafficking law', The American Journal of International Law, vol. 108, no. 4, pp. 609-649.

Coghlan, D. and Wylie, G. (2011) 'Defining trafficking/denying justice? Forced labour in Ireland and the consequences of trafficking discourse', Journal of Ethnic and Migration Studies, vol. 37, no. 9, pp. 1513-1526.

Cohen, L., Manion, L. and Morrison, K. (2011) 'Organising and presenting qualitative data', in Research Methods in Education, 7th edn, Oxton, Routledge, pp. 547-558.

Cojocaru, C. (2016) 'My experience is mine to tell: Challenging the abolitionist victimhood framework', Anti-Trafficking Review, no. 7 [Online]. Available at http://antitraffickingreview.org/index.php/atrjournal/article/view/198 (Accessed 12 November 2016).

Cooke, H. (2020) 'Coronavirus: Public surge in trust of Government during Covid-19 crisis', Stuff, 8th April [Online]. Available at https://www.stuff.

co.nz/national/health/coronavirus/120911320/coronaviruspublic-surge-in-trust-of-government-andnational-pride (Accessed 10 January 2021).

Cooke, H. and Malpass, L. (2020) 'Coronavirus: Poll shows Kiwis back harsh measures but are extremely worried about virus', Stuff, 25th March [Online]. Available at https://www.stuff.co.nz/national/health/ coronavirus/120534052/coronavirus-poll-shows-kiwisbackharsh-measures-but-are-extremely-worried-about-virus (Accessed 10 January 2021).

Copes, H. (2016) 'A narrative approach to studying symbolic boundaries among drug users: A qualitative meta-synthesis', Crime, Media, Culture, vol. 12, no. 2, pp. 193-213.

Coughlan, S. (2019) 'Hotels train staff to spot human trafficking', $B B C$ [Online]. Available at https://www. bbc.co.uk/news/business-47201210 (Accessed 4 December 2020).

Coughlan, S. (2020) 'Coronavirus: The government's Covid-19 lockdown measures have overwhelming public support, according to a poll', Stuff, 23rd April [Online]. Available at https://www.stuff.co.nz/ national/121231591/coronavirus-the-governments-covid19- lockdownmeasures-have-overwhelming-public-supportaccording-to-a-poll (Accessed 10 January 2021).

Czarniawska, B. (1998) A Narrative Approach to Organization studies: Qualitative research methods, Thousand Oaks CA, Sage Publications, vol. 43.

Czarniawska, B. (2006) Narratives in Social Science Research, London, Sage Publications.

Dale, K. (2005) 'Building a social materiality: Spatial and embodied politics in organizational control', Organization, vol. 12, no. 5, pp. 649-678.

Davies, B. and Harré, R. (1990) 'Positioning: The discursive production of selves', Journal for the Theory of Social Behaviour, vol. 20, no. 1, pp. 43-63 [Online]. DOI: 10.1111/j.14685914.1990.tb00174.x.

Deignan, A. (2005) Metaphor and Corpus Linguistics, Philidelphia, PA, John Benjamins Publishing Company. 
Deignan, A. (2016) 'From linguistic to conceptual metaphors', in Semino, E. and Demjen, Z. (eds), The Routledge Handbook of Metaphor and Language, Routledge Handbooks in Linguistics, London, Routledge, p. 18.

Dempsey, M. M. (2017) 'What counts as trafficking for sexual exploitation? How legal methods can improve empirical research', Journal of Human Trafficking, vol. 3, no. 1, pp. 61-80 [Online]. DOI: 10.1080/23322705.2017.1280325.

Department of Health and Human Services USA (2019) 'Identifying Victims of Human Trafficking Fact Sheet', Department of Health and Human Services [Online]. Available at

https://www.google.com/url?sa=t\&rct=j\&q=\&esrc=s\&source=web\&cd=1\&cad=rja\&uact=8\&ved=2ah UKEwiltcn_m4nnAhXDH7cAHVxyBj8QFjAAegQIAhAB\&url=https\%3A\%2F\%2Fwww.acf.hhs.gov\%2Fsit es\%2Fdefault\%2Ffiles\%2Forr\%2Ffact_sheet_identifying_victims_of_human_trafficking.pdf\&usg=AOv Vaw2P51rDfabxodY-12Rhmj4E (Accessed 17 January 2020).

Department of Labour (2009) 'Plan of Action to Prevent People Trafficking', Department of Labour [Online]. Available at https://www.immigration.govt.nz/about-us/policy-and-law/integrity-of-theimmigration-system/people-trafficking (Accessed 14 April 2019).

Desyllas, M. (2007) 'A critique of the global trafficking discourse and U.S. policy', Journal of Sociology \& Social Welfare, vol. XXXIV, no. 4, pp. 57-79.

Ditmore, M. H. and Allman, D. (2013) 'An analysis of the implementation of PEPFAR's antiprostitution pledge and its implications for successful HIV prevention among organizations working with sex workers', Journal of the International AIDS Society, vol. 16, no. 1 [Online]. DOI: 10.7448/IAS.16.1.17354 (Accessed 25 November 2016).

Doezema, J. (2001) 'Ouch!: Western Feminists' "wounded attachment" to the "Third World Prostitute"', Feminist Review, no. 67, pp. 16-38.

Doezema, J. (2010) Sex Slaves and Discourse Masters: The Construction of Trafficking, London, Zed Books.

Dottridge, M. (2007) 'Introduction', in Collateral Damage: The impact of anti-trafficking measures on human rights around the world, Bangkok, GAATW, pp. 1-27.

Edwards, A. and Gill, P. (2002a) 'The politics of "transnational organised crime": Discourse, reflexivity and the narration of "threat", British Journal of Politics and International Relations, vol. 4, no. 2, pp. $245-270$.

Edwards, A. and Gill, P. (2002b) 'Crime as enterprise? The case of "transnational organised crime"', Crime, Law and Social Change, vol. 37, pp. 203-223.

Edwards, A. and Gill, P. (2003) Transnational Organised Crime: Perspectives on Global Security, London, Routledge.

Elliott, S. (2018) 'Call me by my name', Anti-Trafficking Review, no. 11, pp. 133-136.

Erdal, M. B. and Oeppen, C. (2018) 'Forced to leave? The discursive and analytical significance of describing migration as forced and voluntary', Journal of Ethnic and Migration Studies, vol. 44, no. 6, pp. 981-998 [Online]. DOI: 10.1080/1369183X.2017.1384149. 
Espiritu, Y. L. (2000) "'We don't sleep around like the white girls do": Family, culture and gender i Filipina American lives', Signs, vol. 26, no. 2, pp. 415-40.

Fischer, F. (2003) Reframing Public Policy: Discursive Politics and Deliberative Practices, Oxford, Oxford University Press.

Fleetwood, J. (2016) 'Narrative habitus: Thinking through structure/agency in the narratives of offenders', Crime, Media, Culture, vol. 12, no. 2, pp. 173-192.

Foucault, M. (1970a) The Order of Things, London; New York, Tavistock.

Foucault, M. (1970b) L'Ordre du Discours, Paris, Inaugural lecture at the College de France.

Foucault, M. (1980) Power/knowledge: Selected interviews and other writings 1972-77, London, Harvester Wheatsheaf.

Fouladvand, S. and Ward, T. (2019) 'Human trafficking, vulnerability and the state', The Journal of Criminal Law, vol. 83, no. 1, pp. 39-54.

Fox, J. E., Moroşanu, L. and Szilassy, E. (2012) 'The racialization of the new European migration to the UK', Sociology, vol. 46, no. 4, pp. 1-16.

Frazer, C. (2014) Summary Report of the 2014 Prevent People Trafficking Conference, June 5-6 2014, Wellington, N.Z., The Salvation Army [Online]. Available at https://www.salvationarmy.org.nz/2014PPTCONFERENCE\%20REPORT.

Frazer, C. (2017) Prevent People Trafficking Conference Report August 2017, Wellington, NZ.

GAATW (ed.) (2007) Collateral Damage: The impact of anti-trafficking measures on human rights around the world, Bangkok, GAATW.

GAATW (2014) Global Alliance Against Traffic in Women: Human rights at home, abroad and on the way [Online]. Available at

https://www.gaatw.org/index.php?option=com_content\&view=article\&id=451\&ltemid=83

(Accessed 15 November 2020).

GAATW (2016) Critical Assessment of the Implementation of Anti-Trafficking Policy in Bolivia, Colombia and Guatemala, Global Alliance Against Traffic in Women [Online]. Available at http://www.gaatw.org/resources/publications.

GAATW (2018) Anti Trafficking Review Special Issue: Irregular migrants, refugees or trafficked persons?, Global Alliance Against Traffic in Women [Online]. Available at http://www.antitraffickingreview.org/index.php/atrjournal/issue/view/19 (Accessed 18 April 2019).

Gabriel, Y. (2000) Storytelling in Organizations, Oxford, Oxford University Press.

Gallagher, A. (2016) Regional Review on Laws, Policies and Practices within ASEAN relating to the Identification, Management and Treatment of Victims of Trafficking, especially Women and Children, Jakarta, ASEAN Secretariat.

Gallagher, A. and Pearson, E. (2010) 'The high cost of freedom: A legal and policy analysis of shelter detention for victims of trafficking', Human Rights Quarterly, vol. 32, no. 1, pp. 73-114. 
Gallagher, A. T. (2011) 'Improving the effectiveness of the international law of human trafficking: A vision for the future of the US Trafficking in Persons Reports', Human Rights Review, vol. 12, no. 3, pp. 381-400 [Online]. DOI: 10.1007/s12142-010-0183-6.

Gallagher, A. T. and Karlebach, N. (2011) Prosecution of Trafficking in Persons Cases: Integrating a human-rights based approach in the administration of criminal justice, United Nations Human Rights Office of the High Commissioner [Online]. Available at https://www.ohchr.org/EN/pages/home.aspx.

Gee, S. (2019) 'Migrant sex workers in top of south deported', Stuff, 11th November [Online]. Available at https://www.stuff.co.nz/national/crime/117188869/migrant-sex-workers-in-top-of-thesouth-deported (Accessed 5 November 2020).

George, E., McNaughton, D. and Tsourtos, G. (2017) 'An interpretive analysis of Australia's approach to human trafficking and its focus on criminal justice over public health', Journal of Human Trafficking, vol. 3, no. 2, pp. 81-92 [Online]. DOI: 10.1080/23322705.2016.1153367.

Glazebrook, J. S. (2010) 'Human Trafficking and New Zealand', Speech at 2010 International Association of Women Judges Conference, Seoul Korea, vol. 14 [Online]. Available at https://courtsofnz.govt.nz/speechpapers/NZ\%20trafficking\%20Paper\%20-\%20final\%20\%203\%20Feb.pdf (Accessed 12 November 2016).

Guha, M. (2018) 'Disrupting the "life-cycle" of violence in social relations: Recommendations for anti-trafficking interventions from an analysis of pathways out of sex work for women in Eastern India', Gender \& Development, vol. 26, no. 1, pp. 53-69.

Guha, M. (2019) 'Dynamic lives, dynamic identities: Representing agency and victimhood within the lives of women in sex work', The Sociological Review, Politics of Representation collection.

Haddadin, Y. and Klímová-Alexander, I. (2013) 'Human rights based approach to trafficking: The work of the United Nations Office of the High Commissioner for Human Rights', Judges' Journal, vol. 52, no. 1 , pp. 22-27.

Hajer, M. (1995) The Politics of Environmental Discourse: Ecological Modernization and the Policy Process, New York, Oxford University Press.

Hall, K. (2020) 'Kiwi fruit pickers have simple message as growers cry out for labour - "pay us more"', $T V N Z$, 7th November [Online]. Available at https://www.tvnz.co.nz/one-news/new-zealand/kiwifruit-pickers-have-simple-message-growers-cry-labour-pay-us-more (Accessed 10 January 2021).

Ham, J. (2017) Sex work, Immigration, and Social Difference, Abingdon, Routledge.

Hao, L. (2008) 'Workplace nonfatal injuries among immigrants to the US', John Hopkins University [Online]. Available at http://paa2008.princeton.edu/download.aspx?submissionID=80386 (Accessed 21 August 2017).

Hardy, C. and Philips, N. (1999) 'No joking matter: Discursive struggle in the Canadian refugee system', Organization Studies, vol. 20, pp. 1-24.

Harley, J. B. (1988) 'Maps, knowledge and power', in The Iconography of Landscape, Cambridge, Cambridge University Press, pp. 277-312.

Haynes, D. (2014) 'The celebratization of human trafficking', The ANNALS of the American Academy of Political and Social Science, vol. 653, pp. 25-45. 
Hill, A. (2016) 'How to stage a raid: Police, media and the master narrative of trafficking', AntiTrafficking Review, no. 7 [Online]. Available at http://antitraffickingreview.org/index.php/atrjournal/article/view/199 (Accessed 12 November 2016).

Hobbs, D. and Antonopoulos, G. A. (2013) "Endemic to the species": Ordering the "other" via organised crime', Global Crime, vol. 14, no. 1, pp. 27-51 [Online]. DOI:

10.1080/17440572.2012.753324.

Hoefinger, H. (2016) 'Neoliberal sexual humanitarianism and story-telling: The case of Somaly Mam', Anti-Trafficking Review, no. 7 [Online]. Available at http://antitraffickingreview.org/index.php/atrjournal/article/view/200 (Accessed 12 November 2016).

Hope for Justice (2020) Spot the Signs of Human Trafficking [Online]. Available at https://hopeforjustice.org/spot-the-signs/.

Immigration NZ (2016) Defendants pay a high price for immigration fraud [Online]. Available at https://www.immigration.govt.nz/about-us/media-centre/media-releases/defendants-pay-a-highprice-for-immigration-fraud (Accessed 21 August 2019).

Immigration NZ (2018a) Barrister linked to New Zealand's first human trafficking convictions found guilty of fraud [Online]. Available at https://www.immigration.govt.nz/about-us/mediacentre/media-releases/barrister-first-human-trafficking-convictions-guilty (Accessed 21 August 2019).

Immigration NZ (2018b) Fijian arrest linked to NZ's human trafficking convictions [Online]. Available at https://www.immigration.govt.nz/about-us/media-centre/media-releases/fijian-arrest-linked-tonz-human-trafficking-convictions (Accessed 16 August 2019).

Immigration NZ (2018c) Man arrested for human trafficking and slavery following joint INZ/Police investigation [Online]. Available at https://www.immigration.govt.nz/about-us/media-centre/mediareleases/man-arrested-for-human-trafficking-slavery-following-joint-inz-police-investigation (Accessed 21 August 2019).

Immigration NZ (2019a) Migrants working unlawfully in sex industry by choice [Online]. Available at https://www.immigration.govt.nz/about-us/media-centre/media-releases/migrants-workingunlawfully-in-sex-industry-by-choice.

Immigration NZ (2019b) Bangladeshi couple found guilty of migrant exploitation [Online]. Available at https://www.immigration.govt.nz/about-us/media-centre/media-releases/bangladeshi-couplefound-guilty-of-migrant-exploitation (Accessed 21 August 2019).

Immigration NZ (2019c) Defendants jailed for exploiting migrants [Online]. Available at https://www.immigration.govt.nz/about-us/media-centre/media-releases/defendants-jailed-forexploiting-migrants (Accessed 21 August 2019).

Immigration NZ (2019d) People Trafficking [Online]. Available at https://www.immigration.govt.nz/about-us/policy-and-law/integrity-of-the-immigrationsystem/people-trafficking (Accessed 14 April 2019). 
Immigration NZ (2020) Guilty verdicts in slavery and trafficking trial [Online]. Available at https://www.immigration.govt.nz/about-us/media-centre/media-releases/guilty-verdicts-in-slaveryand-trafficking-trial (Accessed 12 November 2020).

Independent Anti-Slavery Commissioner (2015) Independent Anti-Slavery Commissioner Strategic Plan 2015-2017, London, UK Independent Anti-Slavery Commissioner.

Ingram, H. and Schneider, A. L. (1991) 'The choice of target populations', Administration and Society, vol. 23, no. 3, pp. 333-356.

Ingram, H., Schneider, A. L. and DeLeon, P. (2007) 'Social construction and policy design', in Sabatier, P. A. (ed), Theories of the Policy Process, Boulder, CA, Westview Press, pp. 169-89.

IOM (2018) 'The Global Compact for Migration 2018', IOM UN Migration [Online]. Available at www.iom.int/global-compact-migration (Accessed 21 May 2019).

Jackson, S. (1998) 'Telling stories: Memory, narrative and experience in feminist research and theory', in Henwood, K., Griffin, C., and Phoenix, A. (eds), Standpoints and Differences, Essays in the Practice of Feminist Psychology, London, Sage Publications, pp. 45-64.

Jamieson, T. (2020) “'Go hard, go early": Preliminary lessons from New Zealand's response to COVID19', The American Review of Public Administration, vol. 50, no. 6-7, pp. 598-605 [Online]. DOI: 10.1177/0275074020941721.

Jones, M. D. and McBeth, M. K. (2010) 'A Narrative Policy Framework: Clear enough to be wrong?', Policy Studies Journal, vol. 38, no. 2, pp. 329-353 [Online]. DOI: 10.1111/j.1541-0072.2010.00364.x.

Juliawan, B. H. (2018) 'Seeing migration like a state: The case of irregular Indonesian migrant workers deported from Malaysia', Anti-Trafficking Review, no. 11, pp. 36-51.

Juntrasook, A., Nairn, K., Bond, C. and Spronken-Smith, R. (2013) 'Unpacking the narrative of nonpositional leadership in academia: Hero and/or victim?', Higher Education Research \& Development, vol. 32, no. 2, pp. 201-213 [Online]. DOI: 10.1080/07294360.2011.643858.

Kangaspunta, K. (2007) 'Collecting data on human trafficking: Availability, reliability and comparability of trafficking data', in Savona, E. U. (ed), Measuring Human Trafficking: Complexities and pitfalls, New York, Springer New York, pp. 27-36.

Kapoor, I. (2013) Celebrity Humanitarianism: The ideology of global charity, New York, Routledge.

Kapur, R. (2005) 'Cross-border movements and the law: Renegotiating the boundaries of difference', in Kempadoo, K., Sanghera, J., and Pattanaik, B. (eds), Trafficking and Prostitution Reconsidered: New perspectives on migration, sex work, and human rights, Boulder, Paradigm Publishers, $\mathrm{p}$. Chapter 2 ebook.

Kapur, R. (2010) Makeshift Migrant and Law: Gender, belonging, and postcolonial anxieties, New Delhi, India, Routledge, Taylor \& Francis Group.

Kara, S. (2009) Sex Trafficking: Inside the business of modern slavery, New York, Columbia University Press.

Kaye, J., Millar, H. and O'Doherty, T. (2019) 'Exploring human rights in the context of enforcementbased anti-trafficking in persons responses', in Winterdyk, J. and Jones, J. (eds), The Palgrave 
International Handbook of Human Trafficking, Cham, Palgrave Macmillan [Online]. Available at doi.org/10.1007/978-3-319-63192-9_36-1 (Accessed 3 November 2020).

Kelley, J. G. and Simmons, B. A. (2015) 'Politics by Number: Indicators as social pressure in international relations', American Journal of Political Science, vol. 59, no. 1, pp. 55-70 [Online]. DOI: 10.1111/ajps.12119.

Kelly, L. (2005) "You can find anything you want": A critical reflection on research on trafficking in persons within and into Europe', International Migration, vol. 43, no. 1-2, pp. 235-265.

Kelly, L. and Regan, L. (2000) Stopping Traffic: Exploring the Extent of, and Responses to Trafficking in Women for Sexual Exploitation in the UK, Police Research Series, London, Home Office, Policing and Reducing Crime Unit.

Kempadoo, K. (2005) 'From moral panic to global justice: Changing perspectives on trafficking', in Kempadoo, K., Sanghera, J., and Pattanaik, B. (eds), Trafficking and Prostitution Reconsidered: New perspectives on migration, sex work, and human rights, Boulder, Paradigm Publishers, pp. vii-xxxiv.

Kempadoo, K. (2015) 'The modern-day white (wo)man's burden: Trends in anti-trafficking and antislavery campaigns', Journal of Human Trafficking, vol. 1, no. 1, pp. 8-20 [Online]. DOI: 10.1080/23322705.2015.1006120.

Kempadoo, K. (2017) "'Bound Coolies" and other indentured workers in the Caribbean: Implications for debates about human trafficking and modern slavery', Anti-Trafficking Review, vol. 9, pp. 48-63.

Khan, U. (2015) 'Antiprostitution feminism and the surveillance of sex industry clients', in Dubrofsky, R. E. and Amielle Magnet, S. (eds), Feminist Surveillance Studies, Durham, Duke University Press, pp. 189-207.

Kim, J.-H. (2015) Understanding Narrative Inquiry: The crafting and analysis of stories as research, Texas, US, Sage Publications.

King, N. (2016) No Borders: The politics of immigration control and resistance, London, Zed Books.

Kinney, E. (2015) 'Victims, villains, and valiant rescuers: Unpacking sociolegal constructions of human trafficking and crimmigration in popular culture', in Guia, M. J. (ed), The Illegal Business of Human Trafficking, Cham, Springer International Publishing, pp. 87-109.

Kleemans, E. (2014) 'Theoretical perspectives on organised crime', in Paoli, L. (ed), The Oxford Handbook of Organised Crime, Oxford, Oxford University Press, pp. 32-52.

Kohler Riessman, C. (2008) Narrative Methods for the Human Sciences, Thousand Oaks CA, Sage Publications.

Labov, W. (1972) Language in the Inner City: Studies in the Black English vernacular, Philidelphia, University of Pennsylvania Press.

Labov, W. and Waletzky, J. (1967) 'Narrative analysis: Oral versions of personal experience', in Elms, J. (ed), Essays on Verbal and Visual Arts, Seattle, WA, University of Washington Press, pp. 12-44.

Laczko, F. and Gozdziak, E. M. (2005) Data and Research on Human Trafficking: A global survey, Geneva, International Organization for Migration. 
Lakoff, G. and Johnson, M. (1980) Metaphors We Live By, Chicago, University of Chicago Press.

Lamm, F., Lamare, R., Laurenson, T. M., McDonnell, M., Schweder, P., Shulruf, B. and Walters, D. (2010) 'Issues around researching OHS of Samoan migrant workers', Labour, Employment and Work in New Zealand [Online]. Available at https://ojs.victoria.ac.nz/LEW/article/view/1680 (Accessed 14 August 2017).

Lamont, M. and Molnár, V. (2002) 'The study of boundaries in the social sciences', Annual Review of Sociology, vol. 28, no. 1, pp. 167-195.

Lamont, M., Pendergrass, S. and Pachucki, M. (2015) 'Symbolic Boundaries', in Smelser, N. and Baltes, P. (eds), International Encyclopedia of the Social \& Behavioral Sciences, Elsevier, pp. 850-855 [Online]. DOI: 10.1016/B978-0-08-097086-8.10416-7 (Accessed 14 April 2019).

Lebov, K. (2010) 'Human trafficking in Scotland', European Journal of Criminology, vol. 7, no. 1, pp. 77-93 [Online]. DOI: 10.1177/1477370809347944.

Lee, M. (2014) 'Gendered discipline and protective custody of trafficking victims in Asia', Punishment and Society, vol. 16, no. 2, pp. 206-222.

Legislation UK (2015) Modern Slavery Act 2015 [Online]. Available at https://www.legislation.gov.uk/ukpga/2015/30/contents/enacted (Accessed 14 November 2020).

Leigh, C. (2015) 'Anti-Trafficking Industrial Complex Awareness Day-1st edition 2015', Trafficking Policy Research Project: Examining the effects of U.S. trafficking laws and policies, Blog [Online]. Available at https://storify.com/carolleigh/anti-trafficking-industrial-complex-awareness-day (Accessed 5 September 2017).

Lippert, R. and Stenson, K. (2007) 'Introduction: Special issue on urban governance and legality from below', Canadian Journal of Law and Society, vol. 22, no. 2, pp. 1-4.

Lippert, R. and Stenson, K. (2010) 'Advancing governmentality studies: Lessons from social constructionism', Theoretical Criminology, vol. 14, no. 4, pp. 473-494 [Online]. DOI: $10.1177 / 1362480610369328$.

Lipset, S. M. (1997) American Exceptionalism: A Double Edged Sword, New York, W. W. Norton \& Company.

Lloyd, P. and Simmons, B. A. (2015) 'Framing for a new transnational legal order: The case of human trafficking', in Halliday, T. and Shaffer, G. (eds), Transnational Legal Orders, Cambridge, Cambridge University Press, pp. 400-438 [Online]. Available at http://papers.ssrn.com/sol3/papers.cfm?abstract_id=2299624 (Accessed 29 January 2016).

Loh, K. and Richardson, S. (2004) 'Foreign-born workers: Trends in fatal occupational injuries, 19962001', Monthly Lab. Rev., vol. 127, p. 42.

Lovelock, K. and Martin, G. (2016) 'Eldercare work, migrant care workers, affective care and subjective proximity', Ethnicity \& Health, vol. 21, no. 4, pp. 379-396 [Online]. DOI: 10.1080/13557858.2015.1045407.

Lyneham, S., Dowling, C. and Bricknell, S. (2019) 'Estimating the dark figure of human trafficking and slavery victimisation in Australia', Australian Institute of Criminology, Statistical bulletin, no. 16, p. 8. 
Mac, J. and Smith, M. (2018) Revolting Prostitutes: The fight for sex workers' rights, New York, Verso Books.

Macfarlane, D. (2017) 'The slave trade and the right of visit under the law of the sea convention: Exploitation in the fishing industry in New Zealand and Thailand', Asian Journal of International Law, vol. 7, no. 1, pp. 94-123 [Online]. DOI: 10.1017/S2044251315000235.

Mahdavi, P. and Sargent, C. (2011) 'Questioning the discursive constructions of trafficking and forced labour in the United Arab Emirates', Journal of Middle East Women's Studies, vol. 7, no. 3, pp. 6-35.

Maher, J. and Segrave, M. (2018) 'Family violence risk, migration status and "vulnerability": Hearing the voices of immigrant women', Journal of Gender-Based Violence, vol. 2, no. 3, pp. 503-518 [Online]. DOI: 10.1332/239868018X15375304047178.

Maher, S. (2017) 'Historicising "irregular" migration from Senegal to Europe', Anti-Trafficking Review, vol. 9, pp. 77-91.

Mai, N. (2016) 'Assembling Samira: Understanding sexual humanitarianism through experimental filmmaking', AntiAtlas Journal, vol. 1 [Online]. Available at http://www.antiatlas-journal.net/01assembling-samira-understanding-sexual-humanitarianism-throughexperimental-filmmaking.

Majic, S. (2021) 'Publicizing the (in)visible? Celebrities, anti-human trafficking activism, and feminist ideologies', Social Politics: International Studies in Gender, State \& Society, vol. 28, no. 1, pp. 94-118 [Online]. DOI: 10.1093/sp/jxz040.

Manchester, A. (2005) 'Filipino nurses suffer abuse and exploitation', Kai Tiaki: Nursing New Zealand, vol. 11, no. 4.

Maroukis, T. (2017) 'Keeping up appearances: The British public policy response to the trafficking of domestic workers in a changing regime of social protection', Journal of Immigrant \& Refugee Studies, vol. 15, no. 2, pp. 155-170 [Online]. DOI: 10.1080/15562948.2017.1304602.

Marshall, P. and Thantun, S. (2005) 'Miles away: The trouble with prevention in the Greater Mekong Sub-region', in Kempadoo, K., Sanghera, J., and Pattanaik, B. (eds), Trafficking and Prostitution Reconsidered: New perspectives on migration, sex work, and human rights, Boulder, Paradigm Publishers, p. Chapter 3 ebook.

Martin, C., De Borde, M. P., Guarnieri, F. and Lamm, F. (2010) 'OH\&S in small and medium-size enterprises and the issue of cultural diversity: Ongoing research in the construction industry', 14th Labour Employment and Law conference, pp. 7-pages [Online]. Available at https://hal-minesparistech.archives-ouvertes.fr/docs/00/73/70/82/PDF/Martin_LEW2010.pdf (Accessed 14 August 2017).

Martin, M. (2016) Legal status of foreign sex workers in New Zealand [Online]. Available at https:// blog.laurentlaw.co.nz/2016/01/20/legal-status-of-foreign-sex-workers-in-new-zealand/ (Accessed 5 November 2020).

Maruna, S. (2015) 'Forward: Narrative criminology as the new mainstream', in Narrative Criminology: Understanding stories of crime, New York, New York University Press, pp. vii-x.

Mastrofski, S. and Potter, G. (1987) 'Controlling organized crime: A critique of law enforcement policy', Criminal Justice Policy Review, vol. 2, no. 3, pp. 269-301 [Online]. DOI:

10.1177/088740348700200305. 
Mayer, F. (2014) Narrative Politics: Stories and collective action, Oxford, Oxford University Press.

McAdams, D. (1999) 'Personal narratives and the life story', in Pervin, L. and John, O. (eds), Handbook of Personality: Theory and research, 2nd edition., New York, Guilford, pp. 478-500.

McBeth, M. K., Shanahan, E. A., Arnell, R. J. and Hathaway, P. L. (2007) 'The intersection of Narrative Policy Analysis and Policy Change Theory', Policy Studies Journal, vol. 35, no. 1, pp. 87-108 [Online]. DOI: 10.1111/j.1541-0072.2007.00208.x.

McBeth, M. K., Shanahan, E. A. and Jones, M. D. (2005) 'The science of storytelling: Measuring policy beliefs in Greater Yellowstone', Society \& Natural Resources, vol. 18, no. 5, pp. 413-429 [Online]. DOI: 10.1080/08941920590924765.

McKay, S., Craw, M. and Chopra, D. (2006) Migrant Workers in England and Wales: An assessment of migrant worker health and safety risks, London, Health and Safety Executive.

Mckenzie-Mclean, J. and Angeloni, A. (2020) 'Visa changes will help ease labour shortage crisis for Kiwi growers', Stuff, 22nd September [Online]. Available at https://www.stuff.co.nz/business/farming/122848586/visa-changes-will-help-ease-labour-shortagecrisis-for-kiwi-growers (Accessed 10 January 2021).

Meyer, C. and Boll, S. (2018) 'Categorising migrants: Standards, complexity, and politics', AntiTrafficking Review, no. 11, pp. 1-15.

Milivojevic, S., Segrave, M. and Pickering, S. (2017) 'The limits of migration-related human rights: Connecting exploitation to immobility', in Weber, L., Fishwick, E., and Marmo, M. (eds), The Routledge International Handbook of Criminology and Human Rights, 1st Ed., Routledge, pp. 291300.

Miller, R., Mason, G. and Moore, C. (2017) 'Trafficking and Exploitation in New Zealand', Tip of the Iceberge: Addressing Exploitation and Trafficking, Wellington.

Moghaddam, F. and Harré, R. (2010) 'Words, conflicts and political processes', in Words of Conflict, Words of War: How the language we use in political processes sparks fighting, Santa Barbara, CA, Praeger.

Morrah, M. (2018) 'Labour Inspectorate's refusal to investigate workplace complaints slammed', Newshub, 19th November [Online]. Available at https://www.newshub.co.nz/home/politics/2018/11/labour-inspectorate-s-refusal-to-investigateworkplace-complaints-slammed.html (Accessed 14 April 2019).

Mumby, D. (2011) 'What's cooking in organizational discourse studies? A response to Alvesson and Kärreman', Human Relations, vol. 64, no. 9, pp. 1147-1161.

Naderifar, M., Goli, H. and Ghaljaie, F. (2017) 'Snowball sampling: A purposeful method of sampling in qualitative research', Strides in Development of Medical Education, vol. 14, no. 3 [Online]. DOI: 10.5812/sdme.67670 (Accessed 14 April 2019).

Nolte, G. and Aust, H. (2013) 'European exceptionalism?', Global Constitutionalism, vol. 2, no. 3, pp. 407-436 [Online]. DOI: 10.1017/S2045381713000038. 
NZ Police (2016) 'New Zealand Police Research Application Requirements', [Online]. Available at www.police.govt.nz/resources/NZ_Police_application_requirements.pdf (Accessed 1 December 2016).

O'Brien, E. (2016) 'Human trafficking heroes and villains: Representing the problem in anti-trafficking awareness campaigns', Social \& Legal Studies, vol. 25, no. 2, pp. 205-224 [Online]. DOI: $10.1177 / 0964663915593410$.

O'Brien, E. (2018a) 'Human trafficking and heroic consumerism', International Journal for Crime, Justice and Social Democracy, vol. 7, no. 2 [Online]. DOI: 10.5204/ijcjsd.v7i4.430 (Accessed 20 May 2019).

O'Brien, E. (2018b) Challenging the Human Trafficking Narrative: Victims, Villains, and Heroes, ProQuest Ebook Central, Routledge.

O'Connell Davidson, J. (2006) 'Will the real sex slave please stand up?', Feminist Review, vol. 83, p. 10.

O'Connell Davidson, J. (2010) 'New slavery, old binaries: Human trafficking and the borders of "freedom"', Global Networks, vol. 10, no. 2, pp. 244-261 [Online]. DOI: 10.1111/j.14710374.2010.00284.x.

O'Connell Davidson, J. (2016) "Things" are not what they seem: On persons, things, slaves, and the new abolitionist movement', Current Legal Problems, vol. 69, no. 1, pp. 227-257 [Online]. DOI: 10.1093/clp/cuw008.

O'Connell Davidson, J. (2017) 'The presence of the past: Lessons of history for anti-trafficking work', Anti-Trafficking Review, vol. 9, pp. 1-13.

O'Connor, T. (2005) “"Embarrassed and ashamed to be a New Zealander": A New Zealand nurse shares her shame about the treatment of Filipino nurses in this country', Kai Tiaki: Nursing New Zealand, vol. 11, no. 4.

OHCHR (2002) Recommended Principles and Guidelines on Human Rights and Human Trafficking, Office of the High Commissioner for Human Rights [Online]. Available at https://www.google.com/search?client=firefox-b$d \& q=h u m a n+t r a f f i c k i n g+U N+$ human+rights+approach (Accessed 18 November 2020).

Okyere, S. (2017) “"Shock and awe": A critique of the Ghana-centric child trafficking discourse', AntiTrafficking Review, vol. 9, pp. 92-105.

Palumbo, L. (2017) 'Exploiting for care: Trafficking and abuse in domestic work in Italy', Journal of Immigrant \& Refugee Studies, vol. 15, no. 2, pp. 171-186 [Online]. DOI: 10.1080/15562948.2017.1305473.

Pearson, E. (2007) 'Australia', in Collateral Damage: The impact of anti-trafficking measures on human rights around the world, Bangkok, GAATW, pp. 28-60.

Peligman-Toclo, J. (2011) 'A study investigating common experiences amongst Chinese, Indian and Filipino migrant health workers in Aotearoa/New Zealand', [Online]. Available at http://unitec.researchbank.ac.nz/handle/10652/1683 (Accessed 14 August 2017). 
Pickering, S. and Weber, L. (2006) 'Borders, mobility and technologies of control', in Pickering, S. and Weber, L. (eds), Borders, Mobility and Technologies of Control, The Netherlands, Springer, p. 117.

Plummer, K. (1995) Telling Sexual Stories: Power, change and social worlds, London, Routledge.

Pointon, N. (2020) 'Australia slavery act could expose NZ companies' risk', RNZ, 2nd July [Online]. Available at https://www.rnz.co.nz/news/business/421574/australia-slavery-act-could-expose-nzcompanies-risks (Accessed 18 November 2020).

Potter, G. W. (1994) Criminal Organizations, Prospect Heights IL, Waveland Press.

Presser, L. (2009) 'The narratives of offenders', Theoretical Criminology, vol. 13, no. 2, pp. 177-200 [Online]. DOI: 10.1177/1362480609102878.

Presser, L. and Sandberg, S. (2014) 'Narrative criminology for these times', British Society of Criminology Newsletter, vol. 75, pp. 7-10.

Presser, L. and Sandberg, S. (2015a) Narrative Criminology: Understanding stories of crime, New York, New York University Press.

Presser, L. and Sandberg, S. (2015b) 'Research strategies for narrative criminology', in Miller, J. and Palacios, W. R. (eds), Qualitative Research in Criminology: Advances in criminological theory, New Brunswick, Transaction Publishers.

Prochazkova, J. (2013) 'Foreign seasonal workers in New Zealand horticulture: An ethnographic account of the nexus of labour and immigration policies and employment practices', University of Otago [Online]. Available at https://ourarchive.otago.ac.nz/handle/10523/3648 (Accessed 15 August 2017).

Promsaka Na Sakolnakorn, T., Naipinit, A., Tepsing, P. and Kroeksakul, P. (2013) 'Thai migrant workers in agriculture farms in New Zealand: A short case study', Asian Social Science, vol. 9, no. 17 [Online]. DOI: 10.5539/ass.v9n17p163 (Accessed 14 August 2017).

Pullar, J. (2016) 'Man jailed for false refugee claims in landmark human trafficking trial', Stuff, 29th January [Online]. Available at https://www.stuff.co.nz/nelson-mail/news/76386522/ (Accessed 21 August 2019).

Radio New Zealand (2017) 'Witnesses in human trafficking case feel betrayed', Radio New Zealand, 22nd June [Online]. Available at https://www.rnz.co.nz/news/national/333573/witnesses-in-humantrafficking-case-feel-betrayed (Accessed 21 August 2019).

Radio New Zealand (2018) 'Man arrested for human trafficking and slavery named', Radio New Zealand, 17th December [Online]. Available at https://www.rnz.co.nz/news/national/378469/manarrested-for-human-trafficking-and-slavery-named (Accessed 21 August 2019).

Rahman, M. (2014) 'Queer rights and the triangulation of western exceptionalism', Journal of Human Rights, vol. 13, no. 3, pp. 274-289 [Online]. DOI: 10.1080/14754835.2014.919214.

Raymond, J. G. and Hughes, D. M. (2001) Sex Trafficking of Women in the United States: International and domestic trends, New York, Coalition Against Trafficking in Women.

Redmond, J. (1992) Melodrama, Cambridge, Cambridge University Press. 
Ricard-Guay, A. and Maroukis, T. (2017) 'Human trafficking in domestic work in the EU: A special case or a learning ground for the anti-trafficking field?', Journal of Immigrant \& Refugee Studies, vol. 15, no. 2, pp. 109-121 [Online]. DOI: 10.1080/15562948.2017.1310340.

Roberts, T. and Dicuirci, L. (2013) American Exceptionalism, London, Pickering \& Chatto Limited.

Roe, E. (1994) Narrative Policy Analysis: Theory and practice, New Haven, CT, Yale University Press.

Roguski, M. (2013) Occupational health and safety of migrant sex workers in New Zealand: Prepared for the New Zealand Prostitutes Collective, [Online]. Available at http://old.nswp.org/sites/nswp.org/files/Roguski-2013-OSH-of-migrant-sex-workers-in-NZ-1.pdf (Accessed 14 August 2017).

Romer, A. (2019) The Dark Figure, UK, Fedrigoni Papers [Online]. Available at https://anotherplacepress.bigcartel.com/product/amy-romer-the-dark-figure.

Russell, A. (2018) 'Human Trafficking: A research synthesis on human-trafficking literature in academic journals from 2000-2014', Journal of Human Trafficking, vol. 4, no. 2, pp. 114-136 [Online]. DOI: 10.1080/23322705.2017.1292377.

Salminen, S. (2011) 'Are immigrants at increased risk of occupational injury? A literature review', The Ergonomics Open Journal, vol. 4, pp. 125-130.

Sanchez, G. (2018) "Circuit Children": The experiences and perspectives of children engaged in migrant smuggling facilitation on the US-Mexico border', Anti-Trafficking Review, no. 11, pp. 103120.

Sandberg, S. (2009) 'Gangster, victim or both? The interdiscursive construction of sameness and difference in self-presentations', The British Journal of Sociology, vol. 60, no. 3, pp. 523-542 [Online]. DOI: 10.1111/j.1468-4446.2009.01254.x.

Sandberg, S. (2010) 'What can "lies" tell us about life? Notes towards a framework of Narrative Criminology', Journal of Criminal Justice Education, vol. 21, no. 4, pp. 447-465 [Online]. DOI: 10.1080/10511253.2010.516564.

Sandberg, S. (2013) 'Are self-narratives strategic or determined, unified or fragmented? Reading Breivik's manifesto in light of narrative criminology', Acta Sociologica, vol. 56, no. 1, pp. 69-83 [Online]. DOI: 10.1177/0001699312466179.

Sandberg, S. and Ugelvik, T. (2016) 'The past, present, and future of narrative criminology: A review and an invitation', Crime Media Culture, vol. 12, no. 2, pp. 129-136.

Sanders, T. (2008) 'Selling sex in the shadow economy', International Journal of Social Economics, vol. 35, no. 10, pp. 704-716 [Online]. DOI: 10.1108/03068290810898927.

Sanghera, J. (2005) 'Unpacking trafficking discourse', in Kempadoo, K., Sanghera, J., and Pattanaik, B. (eds), Trafficking and Prostitution Reconsidered: New perspectives on migration, sex work, and human rights, Boulder, Paradigm Publishers, p. Chapter 1 ebook.

Scoular, J. and Carline, A. (2014) 'A critical account of a "creeping neo-abolitionism": Regulating prostitution in England and Wales', Criminology \& Criminal Justice, vol. 14, pp. 608-626. 
Scoular, J. and O'Neill, M. (2008) 'Legal incursions into supply/demand: Criminalising and responsibilising the buyers and sellers of sex in the UK', in Munro, V. E. and Della Guista, M. (eds), Demanding Sex: Critical reflections on the regulation of prostitution, Aldershot, England, Ashgate Publishing, pp. 13-29.

Scuzzarello, S. (2015) 'Policy actors' narrative constructions of migrants' integration in Malmö and Bologna', Ethnic and Racial Studies, vol. 38, no. 1, pp. 57-74 [Online]. DOI:

10.1080/01419870.2013.848287.

Searle, W., McLeod, K. and Ellen-Eliza, N. (2015) Vulnerable Temporary Migrant Workers: Canterbury construction industry, Wellington, MBIE.

Searle, W., McLeod, K. and Stichbury, C. (2015) Vulnerable Temporary Migrant Workers: Hospitality industry, Wellington, MBIE.

Segrave, M. (2009) 'Human trafficking and human rights', Australian Journal of Human Rights, vol. 14, no. 2, pp. 71-94.

Segrave, M., Milivojevic, S. and Pickering, S. (2009) Sex Trafficking: International context and response, Devon, Willan Publishing.

Segrave, M., Milivojevic, S. and Pickering, S. (2018) Sex Trafficking and Modern Slavery: The absence of evidence, London; New York, Routledge, vol. The second volume of Sex Trafficking: International context and response.

Segrave, M., Piper, N. and Napier-Moore, R. (2015) 'What's in a name? Distinguishing forced labour, trafficking and slavery', The Anti-Trafficking Review, vol. 5, pp. 1-9.

Shah, S. (2009) 'Sex work \& women's movement', Ain't I A Woman? CREA Conference March 2009, Bangkok.

Shah, S. (2014) Street Corner Secrets: Sex, Work and migration in the city of Mumbai, Durham, Duke University Press.

Shamir, H. (2012) 'A labor paradigm for human trafficking', UCLA Law Review, vol. 76, pp. 78-135.

Shand-Baptiste, K. (2020) 'Don't be fooled by the idea that identifying sex trafficking victims is easy', The Independent [Online]. Available at https://www.independent.co.uk/voices/uber-rivers-sextraffickinghow-spot-hotel-workers-marriott-modern-slavery-victims-signs-a8765981.html.

Sharapov, K., Hoff, S. and Gerasimov, B. (2019) 'Editorial: Knowledge is power, ignorance is bliss: Public perceptions and responses to human trafficking', The Anti-Trafficking Review, vol. 13, pp. 111.

Sharapov, K. and Mendel, J. (2018) 'Trafficking in human beings: Made and cut to measure? Antitrafficking docufictions and the production of anti-trafficking truths', Cultural Sociology, vol. 12, no. 4, pp. 540-560 [Online]. DOI: 10.1177/1749975518788657.

Sharma, N. (2017) "The new order of things": Immobility as protection in the regime of immigration controls', Anti-Trafficking Review, vol. 9, pp. 31-47.

Sharp, J. (2009) Geographies of Postcolonialism, London, SAGE Publications. 
Shaw, A. (2019) 'Human trafficking trial: Chefs "sold a dream" by Auckland couple', NZ Herald, 12th February [Online]. Available at

https://www.nzherald.co.nz/business/news/article.cfm?c_id=3\&objectid=12202668 (Accessed 21 August 2019).

Shore, C. and Wright, S. (1997) Anthropology of Policy: Critical perspectives on governance and power, London; New York, Routledge.

Showden, C. R. (2017) 'From human rights to law and order: The changing relationship between trafficking and prostitution in Aotearoa/New Zealand policy discourse', Women's Studies Journal, vol. 31, no. 1, pp. 5-21.

Silverman, D. and Torode, B. (1980) The Material World: Some theories about language and its limits, London, Routledge \& Kegan Paul.

Simmons, G. and Stringer, C. (2014) 'New Zealand's fisheries management system: Forced labour an ignored or overlooked dimension?', Marine Policy, vol. 50, pp. 74-80 [Online]. DOI:

10.1016/j.marpol.2014.05.013.

Skilling, P. (2012) 'Immigration policy in New Zealand: Divergent narratives, shared assumptions and national identity', Critical Policy Studies, vol. 6, no. 4, pp. 363-378 [Online]. DOI:

10.1080/19460171.2012.730765.

Skilling, P. (2014) 'Everyday emergency: Crisis, unease and strategy in contemporary political discourse', Critical Policy Studies, vol. 8, no. 1, pp. 61-77 [Online]. DOI:

10.1080/19460171.2013.862504.

Smith, B. and Sparkes, A. C. (2006) 'Narrative inquiry in psychology: Exploring the tensions within', Qualitative Research in Psychology, vol. 3, no. 3, pp. 169-192 [Online]. DOI:

10.1191/1478088706qrp068oa.

Smith, B. and Sparkes, A. C. (2009) 'Narrative analysis and sport and exercise psychology:

Understanding lives in diverse ways', Psychology of Sport and Exercise, vol. 10, no. 2, pp. 279-288

[Online]. DOI: 10.1016/j.psychsport.2008.07.012.

Smith, D. C. (1976) 'Mafia: The prototypical alien conspiracy', The ANNALS of the American Academy of Political and Social Science, vol. 423, no. 1, pp. 75-88 [Online]. DOI:

10.1177/000271627642300108.

Snajdr, E. (2013) 'Beneath the master narrative: Human trafficking, myths of sexual slavery and ethnographic realities', Dialect Anthropol, vol. 37, pp. 229-256.

Snider, L. (2003) 'Constituting the punishable woman: Atavistic man incarcerates postmodern woman', British Journal of Criminology, vol. 43, pp. 354-378.

Soltis, K. and Walters, R. (2018) “'What's in a name?": Mislabelling, misidentification, and the US Government's failure to protect human trafficking survivors in the Central American refugee crisis', Anti-Trafficking Review, no. 11, pp. 85-102.

Spector, M. and Kitsuse, J. (1973) 'Social Problems: A re-formulation', Social Problems, vol. 21, no. 2, pp. 145-159. 
Stand Against Slavery (2017) \#Not in Our Backyard 2017 Campaign [Online]. Available at http://www.standagainstslavery.com/notinourbackyard/ (Accessed 8 October 2019).

Statistics New Zealand (2020) Unemployment rate hits 5.3 percent due to COVID-19 [Online]. Available at https://www.stats.govt.nz/news/unemployment-rate-hits-5-3-percent-due-to-covid-19 (Accessed 10 January 2021).

Stenson, K. (2005) 'Sovereignty, biopolitics and community safety in Britain', Theoretical Criminology, vol. 9, no. 3, pp. 265-287.

Stiles, S. (2018) 'Good versus evil or "saying more": Strategies of telling in sex trafficking documentary films', Journal of Human Trafficking, vol. 4, no. 1, pp. 35-47 [Online]. DOI: $10.1080 / 23322705.2018 .1423445$.

Stone, D. (2002) Policy Paradox: The art of political decision making, 3rd Ed., New York, Norton.

Stop the Traffik (2020) Spot the Signs: Recognising the key indicators of human trafficking in your community [Online]. Available at https://www.stopthetraffik.org/spot-the-signs/ (Accessed 17 January 2020).

Stringer, C. (2016) Worker Exploitation in New Zealand: A troubling landscape, Wellington, The Human Trafficking Research Coalition.

Stringer, C., Hughes, S., Whittaker, D. H., Haworth, N. and Simmons, G. (2016) 'Labour standards and regulation in global value chains: The case of the New Zealand Fishing Industry', Environment and Planning A, vol. 48, no. 10, pp. 1910-1927 [Online]. DOI: 10.1177/0308518X16652397.

Sullivan, B. (2003) 'Trafficking in Women', International Feminist Journal of Politics, vol. 5, no. 1, pp. 67-91 [Online]. DOI: 10.1080/1461674021000056773.

Swan, N. and Wheeler, D. (2020) Organisations with consolidated revenues in Australia of over AU\$100m must now publish annual Modern Slavery Statements [Online]. Available at https://chapmantripp.com/trends-insights/modern-slavery-statements-new-disclosurerequirement-in-australia/ (Accessed 15 November 2020).

Szörényi, A. (2016) 'Expelling slavery from the nation: Representations of labour exploitation in Australia's supply chain', Anti-Trafficking Review, no. 7 [Online]. Available at http://antitraffickingreview.org/index.php/atrjournal/article/view/201 (Accessed 12 November 2016).

Tamboukou, M. (2003) 'Genealogy/Ethnography: Finding the rhythm', in Tamboukou, M., Ball, S., and Lang, P. (eds), Dangerous Encounters: Genealogy and ethnography, New York, pp. 195-216 [Online]. Available at

http://www.academia.edu/download/42642514/GenealogyEthnography_Finding_the_Rhythm2016 0213-19770-uca556.pdf (Accessed 6 September 2017).

Tamboukou, M. (2011) 'A Foucauldian approach to narratives', in Andrews, M., Squire, C., and Tamboukou, M. (eds), Doing Narrative Research, London, Sage Publications [Online]. DOI: 10.4135/9780857024992 (Accessed 6 September 2017).

Tan, L. (2018) 'Budget 2018: Labour Inspectorate gets $\$ 8.8 \mathrm{~m}$ boost for more inspectors', New Zealand Herald, 17th May [Online]. Available at 
https://www.nzherald.co.nz/nz/news/article.cfm?c_id=1\&objectid=12053421 (Accessed 14 March 2019).

Taylor, J. L. and Isgro, K. L. (2018) 'TIP Reports as policy and narrative: Exploring the communicative framework for policy enactment', Journal of Human Trafficking, vol. 4, no. 1, pp. 48-60 [Online]. DOI: $10.1080 / 23322705.2018 .1423446$.

The Bali Process (2016) Enhancing a Victim Centred Approach, The Bali Process on People Smuggling, Trafficking in Persons and Related Transnational Crime [Online]. Available at https://www.baliprocess.net/regional-support-office/resources/ (Accessed 10 October 2019).

The Global Slavery Index (2018) The Global Slavery Index: Global findings 2018 [Online]. Available at https://www.globalslaveryindex.org/2018/findings/global-findings/ (Accessed 12 June 2018).

Thobani, S. (2018) 'Neoliberal multiculturalism and western exceptionalism: The cultural politics of the West', Fudan Journal of the Humanities and Social Sciences, vol. 11, no. 2, pp. 161-174 [Online]. DOI: 10.1007/s40647-018-0227-x.

Thorburn, N. (2018) 'You can't see it if you're not looking: Sex trafficking in Aotearoa New Zealand', Auckland, NZ, University of Auckland.

Tipples, R., Rawlinson, P. and Greenhalgh, J. (2012) 'Vulnerability in New Zealand dairy farming: The case of Filipino migrants', New Zealand Journal of Employment Relations (Online), vol. 37, no. 3, pp. $13-33$.

Tognato, C. (2015) 'Narratives of tax evasion: The cultural legitimacy of harmful behaviour', in Narrative Criminology: Understanding stories of crime, New York, New York University Press, pp. 261-286.

Tomkinson, S. (2012) 'The multiplicity of truths about human trafficking: Beyond "the sex slave" discourse', CEU Political Science Journal, vol. 7, no. 1, pp. 50-67.

Tyldum, G. and Brunovskis, A. (2005) 'Describing the unobserved: Methodological challenges in empirical studies on human trafficking', International Migration, vol. 43, no. 1-2, pp. 17-34.

Ugelvik, T. (2012) 'Prisoners and their victims: Techniques of neutralization, techniques of the self', Ethnography, vol. 13, no. 3, pp. 259-277 [Online]. DOI: 10.1177/1466138111435447.

UK Home Office (2013) Human trafficking: Tough sentences to help end modern slavery [Online]. Available at https://www.gov.uk/government/news/human-trafficking-tough-sentences-to-helpend-modern-slavery (Accessed 9 August 2017).

United Nations (1945) 'Charter of the United Nations 24 October 19451 UNS XVI', [Online]. Available at http://www.unwebsite.com/charter (Accessed 6 November 2019).

United Nations (1994) 'Background Release, Propose Formulation of Global Convention Against Organised Crime: World Ministerial Conference November 1994', Naples.

United States Department of State (2007) 2007 Trafficking in Persons Report, Washington DC, United States Department of State [Online]. Available at https://www.state.gov/j/tip/rls/tiprpt/ (Accessed 17 May 2019). 
United States Department of State (2017) Trafficking in Persons Report June 2017, Washington DC, United States Department of State.

United States Department of State (2018a) Trafficking in Persons Report June 2018, Washington DC, United States Department of State.

United States Department of State (2018b) 2018 Trafficking in Persons Report [Online]. Available at https://www.state.gov/j/tip/rls/tiprpt/ (Accessed 14 April 2019).

UNODC (2000) 'United Nations Convention Against Transnational Organized Crime and the Protocols thereto', [Online]. Available at https://www.unodc.org/unodc/en/organized-

crime/intro/UNTOC.html\#Fulltext (Accessed 16 May 2019).

UNODC (2010) 'United Nations Global Plan of Action to Combat Trafficking in Persons', [Online]. Available at https://digitallibrary.un.org/record/687201 (Accessed 14 April 2019).

UNODC (2016) Global Report on Trafficking in Persons 2016, Vienna, United Nations Publications.

UNODC (2017) UNODC report on human trafficking exposes modern form of slavery [Online]. Available at https://www.unodc.org/unodc/en/human-trafficking/global-report-on-trafficking-inpersons.html (Accessed 14 April 2019).

UNODC (2018a) Global report on trafficking in persons: in the context of armed conflict, 2018, Vienna, United Nations Publications.

UNODC (2018b) Global report on trafficking in persons 2018, Vienna, United Nations Publications.

UNODC (2019a) Human Trafficking [Online]. Available at https://www.unodc.org/unodc/en/humantrafficking/what-is-human-trafficking.html (Accessed 16 May 2019).

UNODC (2019b) About the United Nations Office on Drugs and Crime [Online]. Available at https://www.unodc.org/unodc/en/about-unodc/index.html?ref=menutop (Accessed 9 January 2020).

Vance, C. (2011a) 'States of contradiction: Twelve ways to do nothing about trafficking while pretending to', Social Research, vol. 78, no. 3, pp. 933-948.

Vance, C. (2011b) 'Thinking trafficking, thinking sex', GLQ: A Journal of Lesbian and Gay Studies, vol. 17, no. 1, pp. 135-145.

Vanwesenbeeck, I. (2017) 'Sex work criminalization is barking up the wrong tree', Archives of Sexual Behavior, vol. 46, no. 6, pp. 1631-1640 [Online]. DOI: 10.1007/s10508-017-1008-3.

Vartia-Vaananen, M., Pahkin, K., Kuhn, K., Hauke, A., Mlodzka-Stybel, A., Tejedor, M., Laguarta, A., Nogareda, S., Debruyne, M., Roskams, N., Rial Gonzalez, E. and Irastorza, X. (2007) Literature Study on Migrant Workers, Eurpean Agency for Safety and Health at Work [Online]. Available at Available from <https://osha.europa.eu/en/publications/literature_reviews/migrant_workers/view> (Accessed 21 August 2017).

Vicol, D. and William, A. (2014) Bulgarians and Romanians in the British National Press: 1 Dec 2012 1 Dec 2013, Oxford, The Migration Observatory at the University of Oxford. 
de Volder, E. (2017) 'Trafficking in the domestic-work sector in the Netherlands: A hidden phenomenon', Journal of Immigrant \& Refugee Studies, vol. 15, no. 2, pp. 140-154 [Online]. DOI: 10.1080/15562948.2017.1307479.

Volodko, A., Cockbain, E. and Kleinberg, B. (2020) "'Spotting the signs" of trafficking recruitment online: Exploring the characteristics of advertisements targeted at migrant job-seekers', Trends in Organized Crime, vol. 23, no. 1, pp. 7-35 [Online]. DOI: 10.1007/s12117-019-09376-5.

Wagenaar, H. (1995) 'Urgent stories: Morality and narrative in public administration', Administrative Theory \& Praxis, vol. 17, no. 1, pp. 92-104.

Walk Free Foundation (2018) The Global Slavery Index 2018, Western Australia, The Walk Free Foundation [Online]. Available at https://www.globalslaveryindex.org/2018/findings/highlights/ (Accessed 23 August 2019).

Walker, L. (2008) 'A mixed picture: The experience of overseas trained nurses in New Zealand', Labour, Employment and Work in New Zealand conference series 2008, Wellington, Victoria University of Wellington [Online]. Available at https://ojs.victoria.ac.nz/LEW/article/view/1658 (Accessed 16 August 2017).

Warren (2012) 'Troubling the victim/trafficker dichotomy in efforts to combat human trafficking: The unintended consequences of moralizing labor migration', Indiana Journal of Global Legal Studies, vol. 19, no. 1, p. 105 [Online]. DOI: 10.2979/indjglolegstu.19.1.105.

Weitzer, R. (2005) 'New directions in research on prostitution', Crime, Law and Social Change, vol. 43, no. 4-5, pp. 211-235 [Online]. DOI: 10.1007/s10611-005-1735-6.

Weitzer, R. (2007) 'The social construction of sex trafficking: Ideology and institutionalization of a moral crusade', Politics \& Society, vol. 35, no. 3, pp. 447-475 [Online]. DOI:

$10.1177 / 0032329207304319$.

Weitzer, R. (2014) 'New directions in research on human trafficking', The ANNALS of the American Academy of Political and Social Science, vol. 653, pp. 6-23.

Williams, A. (2019) 'Sweet shop owners found guilty of exploiting migrants', Radio New Zealand, 6th March [Online]. Available at https://www.rnz.co.nz/news/national/384097/sweet-shop-ownersfound-guilty-of-exploiting-migrants (Accessed 21 August 2019).

Woodiwiss, M. and Hobbs, D. (2009) 'Organized evil and the Atlantic alliance: Moral panics and the rhetoric of organized crime policing in America and Britain', British Journal of Criminology, vol. 49, no. 1, pp. 106-128 [Online]. DOI: 10.1093/bjc/azn054.

Woolgar, S. and Pawluch, D. (1985) 'Ontological gerrymandering: The anatomy of social problems explanations', Social Problems, vol. 32, no. 3, pp. 214-227 [Online]. DOI: 10.2307/800680.

Wylie, G. (2016) The International Politics of Human Trafficking, London, Macmillan.

Yuan, S., Cain, T. and Spoonley, P. (2014) Temporary Migrants as Vulnerable Workers: A literature review, Wellington, MBIE. 


\section{Appendices}

Appendix A: Ontology of human trafficking research

Table 4

Map of Major Philosophical Approaches taken in Human Trafficking Research

\begin{tabular}{|c|c|c|c|}
\hline & \multicolumn{3}{|c|}{ PHILOSOPHICAL APPROACH: } \\
\hline & POSITIVIST & CRITICAL & SOCIAL CONSTRUCTIONIST \\
\hline $\begin{array}{l}\text { Ontology - } \\
\text { what is worth } \\
\text { studying }\end{array}$ & $\begin{array}{l}\text { Human trafficking } \\
\text { as a real, objective } \\
\text { phenomenon that } \\
\text { is occurring. }\end{array}$ & $\begin{array}{l}\text { Human trafficking is to } \\
\text { some extent a crime type } \\
\text { which is socially } \\
\text { constructed and based on } \\
\text { power relations. Although } \\
\text { it is socially constructed, } \\
\text { the way it is constructed } \\
\text { can be critiqued. } \\
\text { However victims' } \\
\text { experiences are treated } \\
\text { as the objective 'truth'. }\end{array}$ & $\begin{array}{l}\text { Human trafficking as a } \\
\text { problem or crime type is } \\
\text { constructed and based on } \\
\text { power. While reality is } \\
\text { unknowable, there are } \\
\text { multiple constructions of } \\
\text { trafficking, different } \\
\text { perspectives are held by } \\
\text { different groups, including } \\
\text { those vulnerable to } \\
\text { exploitation. }\end{array}$ \\
\hline $\begin{array}{l}\text { Axiology - why } \\
\text { is it important } \\
\text { to study this, } \\
\text { what do we } \\
\text { place value on? }\end{array}$ & $\begin{array}{l}\text { We need to scope } \\
\text { the size of the } \\
\text { problem and } \\
\text { understand how it } \\
\text { is occurring in } \\
\text { order to control it. } \\
\text { Quantifiable facts } \\
\text { are valuable. }\end{array}$ & $\begin{array}{l}\text { We need to reveal and } \\
\text { challenge the power } \\
\text { structures behind the } \\
\text { dominant definitions or } \\
\text { approaches to trafficking. } \\
\text { This will help to address } \\
\text { inequality and improve } \\
\text { the situation for migrant } \\
\text { workers. }\end{array}$ & $\begin{array}{l}\text { We need to reveal and } \\
\text { challenge the power } \\
\text { structures behind the } \\
\text { multiple approaches to } \\
\text { trafficking. While there is no } \\
\text { truth or correct response, } \\
\text { we need to challenge old } \\
\text { ways of thinking and offer a } \\
\text { new way of thinking about } \\
\text { trafficking or migrant } \\
\text { exploitation. It is valuable to } \\
\text { expose complexity and what } \\
\text { might be omitted. }\end{array}$ \\
\hline $\begin{array}{l}\text { Epistemology - } \\
\text { what proof is } \\
\text { recognised? }\end{array}$ & $\begin{array}{l}\text { Using available } \\
\text { data/official data } \\
\text { to show size of the } \\
\text { problem. } \\
\text { Surveys and other } \\
\text { research with } \\
\text { victims and official } \\
\text { groups who can } \\
\text { give an idea of the } \\
\text { size of the } \\
\text { problem. }\end{array}$ & $\begin{array}{l}\text { Critiques of constructions } \\
\text { of trafficking. } \\
\text { Research involving people } \\
\text { 'on the ground' and } \\
\text { affected groups - victims, } \\
\text { NGOs, traffickers. } \\
\text { This research treats } \\
\text { trafficking as a social } \\
\text { construction but gives } \\
\text { preference to NGO or } \\
\text { victim 'realities' as more } \\
\text { real. }\end{array}$ & $\begin{array}{l}\text { Use of multiple sources to } \\
\text { gain a picture of multiple } \\
\text { views or 'truths'. } \\
\text { Important to problematize } \\
\text { what has been presented as } \\
\text { orderly and disrupt taken- } \\
\text { for-granted truths. } \\
\text { Critiquing processes that } \\
\text { make a problem knowable- } \\
\text { claims, mentality, and } \\
\text { narratives. }\end{array}$ \\
\hline
\end{tabular}


Bryony Cornforth-Camden

PhD Candidate

Schoel of Secial and Cultural Studies

Victoria University of Wellington

23 June 2017

Dear Bryeny

Re: Muman Trafficking: Local Perspectives on an Internationally Framed Crime Problem (EV-12442)

Thank you for your interest in conducting research with New Zealand Police.

The New Zealand Police Research Review and Acoess Committee (RQAC) have considered this application to undertake research imvolving Police resource, data or privileged information and have provisionally approved subject to a number of conditions. These are:

a) That you and your supervisor adinowiedge that you will be undertaking the study under the conditions set out in the NZ Police Research Agreement - your University Research Office wil be required to sign the Agreement on your behalf

b) That you adhere to the new NZ Police RRAC policy

c) That you and your supervisor undergo and clear NZ Poliçe vetting

d) That you prowide regular updates (6 monthly) regarding progress

e] That you submit ary draft versions to NZ Police for review prior to publication

f) That you agree to conduct this research under the Royal Seciety of New Zealand Code of Professional Standards and Ethics http://www.royalsociety.org.nz/organisation/about/code/

Detective Insp. Craig Scott has agreed to be the NZ Police sponsor and will be your point of contact within the department.

I look forward to seeing the results from this work as I believe it to be important research that will offer new insights. I wish you well with progress and offer my support should you need amything further,

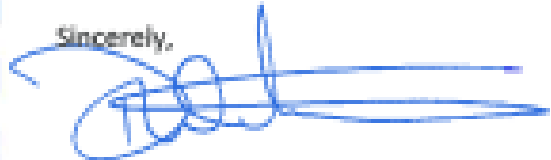

Darren Watton

Director of Research and Evaluation, New Zealand Police Adjunct Associate Professor, Psychology, University of Canterbury Police Notional HQ, 180 Molesworth Street, Wellington 
MEMORANDUM

\begin{tabular}{l|l}
\hline TO & Bryony Cornforth-Camden \\
\hline COPY TO & Prof Simon Mackenzie \\
\hline FROM & Dr Averil Coxhead, Acting Convener, Human Ethics Committee \\
\hline DATE & 24 May 2017 \\
\hline PAGES & 1 \\
\hline \multicolumn{2}{|l}{} \\
\hline SUBJECT & $\begin{array}{l}\text { Ethics Approval: 24442 } \\
\text { Human Trafficking: Local Perspectives on an Internationally } \\
\end{array}$
\end{tabular}

Thank you for your application for ethical approval, which has now been considered by the Standing Committee of the Human Ethics Committee.

Your application has been approved from the above date and this approval continues until 21 December 2019. If your data collection is not completed by this date you should apply to the Human Ethics Committee for an extension to this approval.

Best wishes with the research.

Averil Coxhead,

Acting Convener, Victoria University Human Ethics Committee 


\section{Human Trafficking: Local Perspectives on an Internationally Framed Crime Problem}

\section{INFORMATION SHEET FOR PARTICIPANTS}

Thank you for your interest in this project. Please read this information before deciding whether or not to take part.

My name is Bryony Cornforth-Camden and I am a Doctoral student in Criminology at Victoria University of Wellington. This research project will contribute towards my thesis.

\section{Purpose of the research}

This research is about how human trafficking as an internationally defined crime type is applied to local problems.

As a part of this project, I am conducting interviews with professionals who have carried out work on anti-trafficking initiatives or work in response to migrant exploitation. I am interested in hearing your views and experiences of anti-trafficking and migrant labour exploitation work you have been involved in.

By gathering the perspectives and experiences of professionals involved in responding to trafficking or migrant exploitation, and information on local circumstances, I hope to provide insights into the current dominant international framing of human trafficking and how it can be better used to suit local issues of migrant labour exploitation.

This research has been approved by the Victoria University of Wellington Human Ethics Committee (approval number: 24442).

\section{What you need to know:}

- Participation in this research is completely voluntary. If you decide you do not want to participate, you can contact me by email at any stage up to one month from the date of the interview (

- Interviews will take between 30 to 60 minutes.

- The interview will take place in a location convenient for you. If you prefer, the interview can be held at your place of work.

- This research is confidential. You will not be personally identified in any reporting of the research findings. Anything you say will be reported at a group-level e.g. Official 
from NZ Immigration, NZ Police etc. However, as there is a relatively small number of professionals working in this field, there is a chance that you may be identifiable. If a quote of piece of information would identify you, I will check with you and remove it if we agree this should be done.

- As this interview involves asking you about your work, any sensitive information about cases you have worked on will be kept confidential. Findings about exploitative migration in NZ will be aggregated. If there is a chance that a specific finding may make the case or any individuals involved identifiable, I will check with you and remove it if we agree this should be done.

- You do not have to answer any questions you don't want to. If you feel uncomfortable or have nothing to say, just let me know and we'll move on.

- I would like to audio record this session so that I can focus on talking to you (rather than taking notes). If you would prefer that I didn't, please let me know. Your recording will be kept in a secure location that only my supervisors and I will have access to. It will be destroyed after 7 years.

- If you would like to turn off the recorder at any time during the interview, please let me know.

- If you would like to see your transcript, please let me know and I will email you a copy.

- The results of this research will be presented in a PhD thesis, journal articles and conference presentations.

- On completion of my PhD thesis, I will compile a summary of the research findings. The summary and full thesis will be made available to those who participated in the study on request.

\section{Contact information}

If you have any questions, either now or in the future, please feel free to contact either myself (Bryony.Cornforth-Camden@vuw.ac.nz) or my Supervisor Professor Simon Mackenzie (email: Simon.Mackenzie@vuw.ac.nz; phone: +64-4-463-9452).

If you have any concerns about the ethical conduct of the research you may contact the Victoria University HEC Convener: Associate Professor Susan Corbett. Email susan.corbett@vuw.ac.nz or telephone +64-4-463 5480. 


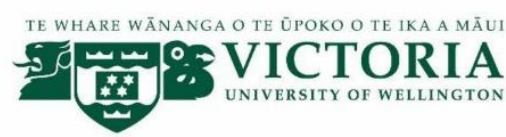

\section{Human Trafficking: Local Perspectives on an Internationally Framed Crime Problem}

\section{INTERVIEW CONSENT FORM}

Researcher: Bryony Cornforth-Camden, School of Social and Cultural Studies, Victoria University of Wellington.

- I have read the information sheet and the project has been explained to me. My questions have been answered to my satisfaction.

- I agree to take part in an interview for this research project.

- I give permission for the interview to be audio-recorded.

I understand that:

- Participation in this research is completely voluntary. If I decide that I do not want to participate, I can withdraw by emailing bryony.cornforth-camden@vuw.ac.nz at any stage up to one month from the date of my interview

- The information I have provided will be stored securely for up to 7 years. In this time, the information will be kept confidential and accessible only to research team (Bryony CornforthCamden and her supervisors). After 7 years, the information will be destroyed.

- The results will be used for a PhD report and a summary of the results may be used in academic reports and/or presented at conferences.

- Participation in this research is confidential. This means I will not be personally identified in any reporting. Anything I say will be reported at a group-level, e.g. Official from NZ Immigration, NZ Police etc. If a quote or piece of information looks like it could potentially identify me, the researcher team will check with me and remove it if we agree this is best.

- I would like a copy of the transcript of my interview Yes No

- I would like to receive a summary of the research results at the email address I have added below

Yes No

Signature of participant:

Name of participant:

Date:

Contact details: 


\section{Appendix F: Interview topic guides}

Interview guide: Decision makers, policy and programme managers/staff

\section{Role and nature of work}

To start with can you tell me a bit about what you do at $x$ ?

How long have you been working there?

What is your role in relation to anti-trafficking and migrant exploitation work?

What does your work on trafficking or migrant exploitation involve?

When did you start working in this area?

Has the nature of your work changed over time?

\section{Role of organisation and working with others}

What other groups do you work with on anti-trafficking and exploitation prevention work?

What parts do the different groups play?

What part does your organisation play?

\section{What does the problem of human trafficking look like in NZ?}

I'm interested in hearing, from your experience, what the problem of human trafficking looks like in NZ and the way cases are responded to.

Can you think of an example of a case that you thought could be classed as human trafficking?

It can be a case that you've worked on or heard of in your work, or a made up example that shows what trafficking looks like in NZ.

Can you please talk me through the example? e.g. the situation, how it came about, who was involved, how it came to officials' attention, what the official actors did in response?

Prompts if needed: Who are the affected groups? Where do they come from? What kinds of situations do they find themselves in? What leads them to be in that situation? Who is committing the offence/exploitation? What do official actors do in response? What happened in the end?

Is that example significant in any way? Is it typical of trafficking cases? Why did you chose it? Conclusion/recommendation: Were there any lessons that were learned from this case? 
In your experience have you come across cases, or heard of cases, where it's borderline as to whether it is trafficking or another form of exploitation?

Can you give me an example? It can be a case that you've come across in your work, or a made up example of what such cases might look like.

Prompts if needed: Who are the affected groups? Where do they come from? What kinds of situations do they find themselves in? What lead them to be in that situation? Who is committing the offence/exploitation? What do official actors do in response? What happened in the end?

How is it decided whether to treat the cases as human trafficking or as something else? What factors were important in determining this? (e.g. law, policy, a strong directive from above, legal precedence)

Conclusion/recommendations: What did you think about the way these instances of human trafficking or migrant exploitation are being responded to? Is there anything more or anything different that you think should be done?

\section{Training}

Did you receive any training on trafficking/migrant exploitation?

What did the training cover?

Did the training use any particular cases or examples of trafficking or migrant exploitation? What were they?

Did you find it useful?

Do you or anyone in your organisation deliver any training on trafficking or migrant exploitation?

Who is the training delivered to?

What does it cover?

Are there any particular cases or stories or trafficking or migrant exploitation used in the training? What are they? Why are those particular examples used?

Did you get a sense of how the training was received and how people reacted to the cases discussed?

\section{Challenges, what works well, what is needed?}

What are the main challenges you find in your anti-trafficking and migrant exploitation work? 
Can you think of a story or example from your work that sums up the challenges of doing this kind of work?

What do you think is working particularly well in your work on anti-trafficking and migrant exploitation prevention?

Can you think of a story or example from your work that sums up the progress or success you feel you're having in your work?

In your opinion, what is the most important aspect of anti-trafficking activities that needs to be worked on?

What do you need from political leaders to address human trafficking?

What would need to happen for trafficking to be prevented?

\section{Reflecting on work}

To finish, as a way of reflecting on your work in this area, can you think of a metaphor which sums up your work on anti-trafficking and exploitation prevention?

Prompt: Examples from my work history

Can you think of an instance or event that illustrates the metaphor you chose?

\section{Further interviews and materials}

Is there anyone else you think I should talk to in gathering professionals' experiences of antitrafficking work?

Are there any materials you think would help me to get a picture of what trafficking looks like in NZ and how it's responded to?

Thank and end 
Interview guide: Operational and front line professionals

\section{Role and nature of work}

To start with can you tell me a bit about what you do at $x$ ?

How long have you been working there?

What is your role in relation to anti-trafficking work and migrant exploitation?

What does your work on trafficking or migrant exploitation involve?

When did you start working in this area?

Has the nature of your work changed over time?

\section{Role of organisation and working with others}

What other groups do you work with on anti-trafficking and exploitation prevention work?

What parts do the different groups play?

What part does your organisation play?

\section{What does the problem of human trafficking look like in NZ?}

I'm interested in hearing about your experiences of working on cases that have been, or you think could have been classed as human trafficking, and cases that involved migrant exploitation but were not classed as human trafficking.

\section{Potential trafficking cases}

Have you worked on or heard of a case that was classed as human trafficking or you think could have been human trafficking?

Can you please talk me through the case, e.g. the situation, how it came about, who was involved, how it came to officials' attention, what the official actors did in response?

Prompts if needed: Who are the affected groups? Where do they come from? What kinds of situations do they find themselves in? What lead them to be in that situation? Who is committing the offence/exploitation? What do official actors do in response? What happened in the end?

Is there anything special about this example? Is it typical of trafficking cases? Why did you chose it?

Conclusion/recommendation: Were there any lessons that were learned from this case? 
Have you come across other cases you think could involve human trafficking? Can you please describe them?

\section{Borderline cases}

In your experience have you come across cases, or heard of cases, where it's borderline as to whether it is trafficking or another form of exploitation?

Can you talk me through an example? e.g. the situation, how it came about, who was involved, how it came to officials' attention, what the official actors did in response?

Prompts if needed: Who are the affected groups? Where do they come from? What kinds of situations do they find themselves in? What lead them to be in that situation? Who is committing the offence/exploitation? What do official actors do in response? What happened in the end?

\section{Other forms of migrant exploitation}

Have you worked on any cases that involve migrant exploitation but you do not think count as trafficking? Can you talk me through an example? e.g. the situation, how it came about, who was involved, how it came to officials' attention, what the official actors did in response?

When you were working on these cases, how was it decided how to treat the cases - as human trafficking or as something else?

What factors were important in determining this? (e.g. law, policy, a strong directive from above, legal precedence)

Conclusion/recommendations: What did you think about the way these instances of human trafficking or migrant exploitation are being responded to? Is there anything more or anything different that you think should be done?

\section{Training}

Did you receive any training on trafficking/migrant exploitation?

What did the training cover?

Did the training use any particular cases or examples of trafficking or migrant exploitation? What were they?

Did you find it useful?

Do you or anyone in your organisation deliver any training on trafficking or migrant exploitation?

Who is the training delivered to? 
What does it cover?

Are there any particular cases or stories or trafficking or migrant exploitation used in the training? What are they? Why are those particular examples used?

Did you get a sense of how the training was received and how people reacted to the cases discussed?

\section{Challenges, what works well, what is needed?}

What are the main challenges you find in your anti-trafficking and migrant exploitation work?

Can you think of a story or example from your work that sums up the challenges of doing this kind of work?

What do you think is working particularly well in your work on anti-trafficking and migrant exploitation prevention?

Can you think of a story of example from your work that sums up the progress or success you feel you're having in your work?

In your opinion, what is the most important aspect of anti-trafficking activities that needs to be worked on?

What do you need from political leaders to address human trafficking?

What would need to happen for trafficking to be prevented?

\section{Reflecting on work}

To finish, as a way of reflecting on your work in this area, can you think of a metaphor which sums up your work on anti-trafficking and exploitation prevention?

Prompt: Examples from my work history

Can you think of an instance or event that illustrates the metaphor you chose?

\section{Further interviews and materials}

Is there anyone else you think I should talk to in gathering professionals' experiences of antitrafficking work?

Are there any materials you think would be useful for me to look at to get a picture of what the trafficking problem looks like in NZ and how it's responded to?

Thank and end 